\title{
Limnologische Untersuchungen an einigen Seen im Amazonasgebiet
}

(Aus dem Institut für spezielle Botanik an der ETH., Zürich)

\author{
Von RUDOLF BRAUN
}

Eingegangen am ıo. November I95I

\section{INHALTSVER ZEICHNIS}

Einführung und Problemstellung . . . . . . . . . . . . . . . . . . 2

Untersuchungsmethoden . . . . . . . . . . . . . . . . . . . . 5

a) Physikalische Untersuchungen . . . . . . . . . . . . . . . . . . . 5

b) Chemische Untersuchungen . . . . . . . . . . . . . . . . 6

c) Biologische Untersuchungen . . . . . . . . . . . . . . . . . . . . 7

Erstcr Teil

Allgemeine Übersicht über das Untersucbungsgebiet

a) Geologisch-geographische Übersicht . . . . . . . . . . . . . . . 8

I. Varzea ................... . . . 13

2. Terrafirme . . . . . . . . . . . . . . . I4

3. Jgapó . . . . . . . . . . . . . . . . . . . . . . 15

b) Das Klima im Untersuchungsgebiet . . . . . . . . . . . . . . . I7

c) Die untersuchten Seen . . . . . . . . . . . . . . . . . 20

Zweiter Teil

Die physikalisch-cbemischen Eigenschaften der untersucbten Seen

a) Der Temperaturhaushalt . . . . . . . . . . . . . . . . . . . 29

b) Der Sauerstoffhaushalt . . . . . . . . . . . . . . . . 30

c) Das System Bikarbonat-freie Kohlensäure-pH-Wert . . . . . . . . . ${ }_{46}^{6}$

d) Die Stickstoffverbindungen . . . . . . . . . . . . . . . . . 54

e) Dic Phosphate . . . . . . . . . . . . . . . . . . . . . . . 57

f) Der $\mathrm{KMnO}_{4}$-Verbrauch und die Huminsäuren . . . . . . . . . . . ${ }_{58}^{8}$

g) Der Eisen- und Mangangehalt . . . . . . . . . . . . . . . . . . 6I

h) Chloride, Kieselsäure, Aluminium und Sulfate . . . . . . . . . . . . . 66

i) Die Gesamthärte . . . . . . . . . . . . . . . . . . . . . . . 70

k) Die Farbe und die Transparenz . . . . . . . . . . . . . . . . . . . 72

1) Vergleich des Chemismus der Seen mit den Flüssen . . . . . . . 77 
Die biologischen Verbältnisse

Dritter Teil

a) Die quantitative Entwicklung der Grundfauna . . . . . . . . . . . . 80

b) Die quantitative Entwicklung des Planktons . . . . . . . . . . . . . 92

Scblußfolgerungen

Vierter Teil

a) Der Einfluß der Regenzeit auf den Chemismus und auf die Biologie der Seen I09

I. Die chemischen Veränderungen . . . . . . . . . . . . 109

2. Die biologischen Veränderungen . . . . . . . . . . . . . II4

b) Versuch einer Einfügung der amazonischen Seen in das System der Sectypenlehre .................. . . I I 8

Zusammenfassung. . . . . . . . . . . . . . . . . . . 123

Literaturverzeichnis . . . . . . . . . . . . . . . . . . 126

EINFÜHRUNG

UND PROBLEMSTELLUNG

Als Hydrobiologe des brasilianischen «Instituto Agronomico do Norte» in Belém do Pará - im Mündungsgebiet des Amazonas - hatte ich Gelegenheit, ein Jahr lang (1947/48) an einigen Seen und Flüssen im Innern des Amazonasgebietes hydrobiologisch zu arbeiten. Ein Teil dieser Untersuchungen ist in der vorliegenden Arbeit niedergelegt. Mit Dr. Harald Sroli zusammen, dem Zoologen am Instituto Agronomico, bildeten wir eine Arbeitsgemeinschaft, indem sich SIOLI in erster Linie mit den Flüssen des Gebietes beschäftigte und ich die Seen einer eingehenderen Untersuchung unterzog.

Während die Biologie und der Chemismus der Gewässer in der gemäßigten Zone Gegenstand ausgedehnter Forschungen seit mehr als einem halben Jahrhundert sind und auch die tropischen Meere wiederholt untersucht wurden, wissen wir über die biologisch-chemischen Eigenschaften der rein tropischen Süßwässer wenig Bescheid. Abgesehen von einigen vereinzelten Messungen und Beobachtungen verschiedener Expeditionen, wie CunNington (I905) (zitiert nach RuTTNER, I93I), Downes (I9II) (zitiert nach JUDAY, I9I5) und MAR QUARDSEN (19I6) (zitiert nach RUTTNER, I93I), bearbeitete erst JUDAY (I9I5) nach den Prinzipien der moder- 
nen Limnologie vier zentralamerikanische Seen in Guatemala und Salvador. Obschon diese Seen nicht mehr rein tropischen Charakter besitzen - sie liegen auf zirka $I^{\circ}{ }^{\circ}$ nördlicher Breite -, zeigen sie doch schon verschiedene, mit rein tropischen Seen gemeinsame Merkmale auf. In der Arbeit GRAHAMS (1929) (zitiert nach RUTTNER, 193 I) über die Fischerei des Viktoriasees sind ebenfalls einige Messungen enthalten, die wir mit unsern Resultaten vergleichen werden, ebenso mit denjenigen WORTHINGTONs (1930) über den Victoria- und Albert-Nyanza.

Die eigentlichen fundamentalen Kenntnisse uiber Biologie und Chemismus tropischer Süßwässer verdanken wir THIENEMANN, RUTTNER und FEUERBORN durch ihre limnologischen Forschungen über die Gewässer des Sunda-Archipels. Die Früchte dieser Expedition sind in der Thienemannschen Serie Tropische Binnengewässer niedergelegt. In unserer Arbeit stützen wir uns insbesondere auf die Arbeit RUTTNERs (193I) über die hydrographischen und hydrochemischen Beobachtungen auf Java, Sumatra und Bali.

Von den nachher folgenden Untersuchungen tropischer Gewässer sind die Arbeiten BEADLES (1932) über einige große ostafrikanische Seen, vor allem aber die Untersuchungen Damas (1937) über die Seen Kivu, Edouard und Ndalaga in Belgisch-Kongo zu nennen.

Über die amazonischen Gewässer liegen bis heute nur einige chemische Wasseranalysen vor, die F. KATZER (1903, 1933) bei seinen geologischen Untersuchungen des untern Amazonasgebietes ausgeführt hat. Da uns KATZER über die chemischen Untersuchungsmethoden im ungewissen läßt und die Wasserproben damals längere Zeit aufbewahrt wurden, bevor sie analysiert werden konnten, können wir diesen Resultaten, die ohnehin nur als Ergänzung der geologischen Arbeit galten, keine allzu große Bedeutung beimessen.

Die ersten eigentlichen limnologischen Untersuchungen der amazonischen Fluisse stammen von Harald Sioli. Seine Resultate sind erst zum Teil veröffentlicht (SIOLI, I949, 1950).

So ist es denn zwangsläufig eine ganze Reihe von Problemen, die sich uns im Amazonasgebiet entgegenstellte, und da das eine Problem ins andere übergreift, ging es nicht an, sie isoliert zu behandeln. In der folgenden Arbeit soll deshalb versucht werden, einmal auf Grund physikalischchemischer und biologischer Untersuchungen den allgemeinen Charakter der amazonischen Seen zu beschreiben und sie in die heute gebräuchlichen Systeme der Seetypenlehre einzufügen. Außerdem schenkten wir unser besonderes Augenmerk dem Studium der Umweltseinflüsse auf Biologie 
und Chemie der Seen und wählten dazu folgendes Problem: Einfluß der Regenzeit auf den Chemismus und die Biologie der Seen.

Wir sind uns dabei vollkommen bewußt, daß während eines einjährigen Aufenthaltes in diesen Gebieten und durch ein Studium eines einzigen Zyklus Trockenzeit-Regenzeit alle diese Probleme nicht restlos gelöst werden können, und daher müssen wir uns auf die Beantwortung folgender Fragen beschränken :

I. Welche Arten von Seen (morphologisch-genetisch, chemisch, biologisch) sind im Untersuchungsgebiet vorhanden? Lassen sie sich einteilen in das System der Seetypenlehre oder weichen sie in ihrem Verhalten derart von den bis heute bekannten Typen ab, daß eine Ergänzung des Systems notwendig ist?

2. Durch welche Eigenschaften weichen die amazonischen Seen einerseits von den temperierten Seen der gemäßigten Zone, anderseits von den von RUTTNER untersuchten Tropenseen $a b$ ?

3. Übt die Regenperiode einen Einfluß aus auf die chemisch-biologischen Eigenschaften der amazonischen Seen, und von welcher Art ist er?

Die vorliegende Arbeit wurde nach meiner Rückkehr aus Brasilien im Institut für spezielle Botanik an der ETH., Zürich, fertiggestellt. Herrn Prof. Dr. ERNST GäUMANN gilt mein großer Dank, denn durch seine Vermittlung erhielt ich von der Universität São Paulo ein Stipendium, für dessen Zustandekommen ich auch Herrn Prof. Dr. FeLIX Rawitscher, Universidade de São Paulo, zu herzlichem Dank verpflichtet bin. Dadurch erst wurde mir meine. Brasilienreise ermöglicht, die außerdem durch den Schweizerischen Schulrat in großziigiger Weise unterstützt wurde, wofür ich dessen Präsidenten, Herrn Prof. Dr. Hans Pallmann, herzlich danke. Herr Prof. Dr. Otтo JaAg, unter dessen Leitung die Arbeit durchgeführt wurde, stand mir mit Rat und Hilfe beiseite, wofür ich ihm ebenfalls größten Dank schulde. Ebenso verpflichtet bin ich Herrn FeLISBERTO DE Camargo, Diretor do Instituto Agronomico do Norte, Belém do Pará, für seine Großzügigkeit bei der Durchführung unseres Untersuchungsprogramms. Herr Prof. Dr. WaLo KocH vom Institut für spezielle Botanik hat in verdankenswerter Weise die Bearbeitung der Makroflora übernommen.

Dr. Har ald Sioli, als langjähriger Kenner des Amazonasgebietes, war der eigentliche Spiritus rector unserer Reisen im Innern Amazoniens. Ohne seine Hilfe und seine Erfahrung hätte die ganze Untersuchung gar nicht durchgeführt werden können. lhm gilt mein herzlichster Dank. Und nicht zuletzt wollen wir unserer treuen eingeborenen Helfer am Amazo- 
nas gedenken, den Caboclos, die uns mit sicherer Hand durch Flüsse und Stromschnellen, durch Urwald und Sumpf führten, für uns auf die Jagd gingen, für unser leibliches Wohl aufs beste sorgten und dadurch erst die Grundlagen für unsere Arbeit schufen.

\section{UNTERSUCHUNGSMETHODEN}

Es ist in tropischen Gegenden besonders wichtig, die Wasserproben möglichst bald nach der Entnahme zu analysieren, wenn Fehlresultate vermieden werden sollen, denn die durch die hohe Temperatur gesteigerten Zersetzungsprozesse verändern ein Wasser in sehr kurzer Zeit.

Daher kamen für uns Reisen ins Innere mit jeweiliger Rückkehr nach Belém ins Laboratorium zur Verarbeitung der Proben gar nicht in Frage, denn, abgesehen von einem sehr großen Zeitverlust, wären die erhaltenen Resultate aus den genannten Gründen nicht einwandfrei gewesen. Es mußte daher ein Standquartier im Innern des Landes gewählt werden, wo wir die Möglichkeit hatten, chemische Untersuchungen durchführen $z u$ können. Ein solches stand uns in der Kautschukplantage «Belterra» am Rio Tapajoz, einem südlichen Zufluß des Amazonas, zur Verfügung, dic zu Beginn der dreißiger Jahre von HENRY FORD errichtet wurde und sich seit dem Jahre 1945 im Besitz der brasilianischen Regierung befindet. Dies war eine einzigartige Gelegenheit, mitten im Innern des Amazonasgebietes chemisch-biologisch zu arbeiten, an einem Ort mit verhältnismäßig großem Komfort, so daß wir ohne allzu große technische Schwierigkeiten unsere chemischen Arbeiten ausführen konnten.

Gravimetrische Untersuchungsmethoden kamen für uns aus technischen Gründen nicht in Frage. Wir mußten uns auf titrimetrische und kolorimetrische Methoden beschränken und führten folgende Bestimmungen durch:

\section{a) Physikalische Untersuchungen}

I. Transparenz: Mit einer weißen runden Secchi-Scheibe von $30 \mathrm{~cm}$ Durchmesser.

2. Temperatur: Mit dem in der Ruttnerschen Schöpfflasche eingebauten Thetmometer (Zehntelgradeinteilung).

3. Farbe: Zuerst wurde versucht, mit der Forel-Ule-Skala (Lösungen in Glasampullen) die Farbe zu bestimmen. Nach ein par Wochen zer- 
setzte sich jedoch der Ule-Teil der Farblösungen und flockte aus, so daß die Skala unbrauchbar wurde. Der Forel-Teil blieb einwandfrei.

4. Reaktion: Mit kleinem pH-Bestimmungsapparat, Marke «Lautenschläger», mit Chinhydronelektroden. Dabei wurde sicherheitshalber immer eine Parallelbestimmung mit dem Universalindikator "Merck» durchgeführt. Da die amazonischen Wässer allgemein sauer sind, war es angebracht, mit Chinhydron zu arbeiten. Bei pH-Werten uiber 7,5 ist diese Methode nicht mehr anwendbar.

\section{b) Chemische Untersuchungen}

5. Gelöster Sauerstoff: Titrimetrisch nach W. WINKLER (I9I4).

6. Freie Koblensäure: Nach J. Tillmanns und O. Heublein, in: Klut (I93 I).

7. Freies Ammoniak: Kolorimetrisch mit NeBler-Reagens und Seignettesalz. Vergleichslösung: Ammoniumchlorid. Nach OHLMüLLERSPITTA (193I, S. 8I).

8. Cbloride: Nach MOHR, in: BERL-LuNGE (1932, S. 278).

9. Nitrate: Nach Tullmanns und SuTTHOFF mit Diphenylamin-Schwefelsäure, in: BERL-LUNGE (1932, S. 263).

Io. Phosphate: Kombinierte Methode von Denigés, Florentin, Atkins mit Sulfomolybdän-Reagens und Zinnfolien, in: BERL-LuNGE (I932, S. 208-2II).

II. Sulfate: Jodometrisch mit Kaliumchromat, in: BERL-LUNGE (I932, S. 201-202).

I2. Eisen: Schnellmethode nach: Einheitsverfahren der physikalischen und chemischen Wasseruntersuchung (I940).

I3. Kaliumpermanganatverbrauch: Nach KuBEL-TIEMANN, in: OHLMÜLLERSpITTA (I93 I, S. 98).

I4. Kieselsäure: Kolorimetrisch mit Kaliumchromat als Vergleichslösung, in : OHLMÜller-SPITTA (I93 I, S. I26).

I5. Gesamthärte: Nach CLARK, in: BERL-LUNGE (I932, S. I65).

I6. Aluminium: Kolorimetrisch mit Alizarin, in: BerL-LUNGE (r932, S. I95).

I7. Mangan: Kolorimetrisch, in: OHLmülter-SpitTa (1931, S. I33).

I8. Bikarbonatkoblensäure: Titration mit $n /$ ro-Salzsäure auf Methylorange.

I9. Huminsäure: Nach OHLMüLLER-SPITTA (I93 I, S. 39).

Die Bestimmungen Nr. r-6 wurden gleich an Ort und Stelle durchgeführt. 


\section{c) Biologische Untersuchungen}

20. Grundfauna, qualitativ und quantitativ. Zur Gewinnung des Grundschlammes diente der Ekmannsche Bodengreifer. Der Schlamm wurde in einem Rahmennetz aus Seidengaze (Zooplanktonnetzstoff) ausgewaschen, die Zahl der im Bodengreifer festgestellten Tiere auf $I \mathrm{~m}^{2}$ Schlammoberfläche umgerechnet.

21. Pbyto- und Zooplankton, qualitativ mit Netzen aus Müller-Gaze Nr. 2s (77 Fäden pro Zentimeter) und Nr. 15 ( 55 Fäden pro Zentimeter), quantitativ mit dem Zürcher Filtertrichter (nach JAAG, MärKI und BraUN). Dabei wurde die gesamte, mit der Ruttnerschen Schöpfflasche gefaßte Wassermenge ( 1,8 l) filtriert, von jeder Probe zwei Kolkwitz-Kammern von $\mathrm{I} \mathrm{cm}^{3}$ Inhalt ausgezählt und die erhaltenen Durchschnittswerte auf I 1 Wasser umgerechnet. Da die detaillierte Artenanalyse des Planktons noch nicht erfolgt ist, beschränkt sich die quantitative Darstellung des Planktons auf Gruppen. Zahlreiche Untersuchungen mit dem Filtertrichter in der Schweiz haben ergeben, daß man damit gute Vergleichsresul tate bekommt. Es ist jedoch nicht möglich, mit dem Filtertrichter die vollständige Planktonmenge zu erfassen, denn durch die Maschen des Netzchens vermögen die kleineren Planktonformen, zum mindesten ein Teil von ihnen, durchzuschlüpfen. Ebenso werden die Resultate für die größeren Krustazeen zu niedrig, denn diese Tiere vermögen durch ihre aktive Beweglichkeit teilweise aus der geöffneten Schöpfflasche zu entfliehen. Doch für unseren Fall ergab sich keine andere Möglichkeit, das Plankton quantitativ zu erfassen. Es kam uns in erster Linie darauf an, Werte zu erhalten, die untereinander und mit solchen aus Schweizer Seen vergleichbar waren. Daß diese Werte etwas tiefer als die absolute Planktonmenge sind, fällt für unsere Fragestellung nicht sehr stark ins Gewicht.

22. Mikrofauna und-flora des Litorals und einiger spezieller Biotope, wie zum Beispiel Schwimmwurzeln der Wasserpflanzen, Oberflächenbelag von Pflanzen, Steinen, altem Holz usw.

23. Wasser-und Sumpfplanzen, zum Teil auch der an die Seen angrenzenden Jgapós (Ưberschwemmungswälder).

In der vorliegenden Arbeit werden im dritten Teil einige Ergebnisse der biologischen Untersuchung mitgeteilt, nämlich Grundfauna und Plankton quantitativ sowie in groben Zügen der Gang der Planktonentwicklung im Zyklus Trockenzeit-Regenzeit. Doch alles uibrige biologische Material konnte noch nicht berïcksichtigt werden, da es Jahre dauern wird, bis die 
Bearbeitung der einzelnen Tier- und Pflanzengruppen durch die Spezialisten erfolgt ist. Unsere Absicht ist, in dieser Arbeit hauptsächlich die physikalisch-chemischen Grundlagen für die Beurteilung bzw. Charakterisierung der amazonischen Seen darzulegen, um dann später, nach erfolgter Verarbeitung der Proben, einige ökologische und produktionsbiologische Betrachtungen über die amazonischen Seen und deren Verhalten während der Regenzeit anzustellen.

I.

\section{ALLGEMEINE ÜBERSICHT \\ UBER DAS UNTERSUCHUNGSGEBIET}

\section{a) Geologisch-geographische Übersicht}

Nach KATZER (1903 und 1933) erstreckte sich im Gebiet des heutigen Amazonastieflandes zur Zeit des Paläozoikums eine gegen Westen zum Pazifik offene Meeresbucht, die im Osten, Norden und Süden durch archaische Massive (Granit, Gneis) begrenzt war, deren Reste noch heute in den Hochländern von Guayana und Zentralbrasilien sichtbar sind. An der Stelle des heutigen Mündungsgebietes des Amazonas befand sich also die östliche Abgrenzung jener Bucht (bis zur Zeit des Tertiärs), gebildet von einer Gebirgskette, welche die archaischen Massive Guayanas und Zentralbrasiliens miteinander verband. Gegen Ende des Neokarbons zog sich das Meer langsam zurïck. Von nun an blieb das Gebiet des unteren Amazonas von weiteren Meeresbedeckungen frei, denn es sind bis heute weder aus der Trias- noch aus der Jurazeit marine Ablagerungen bekannt.

Die von den guayanisch-ostamazonischen Gebirgsketten entspringenden Flüsse flossen nach Westen ab, erodierten die paläozoischen Ablagerungen, wobei sie einige inselartige Reste stehen ließen. Diese starke Erosionstätigkeit wurde am Ende der Kreidezeit durch den beginnenden Aufstau der Kordilleren allmählich aufgehoben, was zu einer Verminderung der Fließgeschwindigkeit dieser Flüsse führte, und dadurch wuchs deren Aufschüttungstätigkeit. KATZER vermutet im heutigen Golf von Guayaquil die Mündung jener nach Westen gerichteten Hauptentwässerungsader des guayanisch-ostamazonischen Festlandes. Dieses Mündungsgebiet wurde dann durch den Stau der Kordilleren so weit verbarrikadiert, daß sich noch eine Zeitlang Springfluten landeinwärts schlagen konnten. Es bildeten sich Brackwasserlachen, die sich durch die zuströmenden Flüsse in Seen 
verwandelten, an deren Ränder sich Tone mit schwach brackischer Süßwasserfauna ablagerten. KATZER betont, daß der brackische Charakter dieser Ablagerungen also nicht auf den Einfluß des Atlantischen Ozeans, sondern auf die Verbindung mit dem Pazifik vor dem endgültigen Aufstau der Kordilleren zurückzuführen sei.

Erst im mittleren Miozän wurde jener westwärts gerichtete AbfluB der Flüsse durch die sich immer höher emporhebenden Kordilleren restlos gestoppt. Die Seen vergrößerten und vereinigten sich mit der Zeit, bis schließlich ein einziger gewaltiger Binnensee, besser gesagt ein Binnenmeer, die ganze Niederung zwischen guayanisch-ostamazonischem Festland im Osten und den sich aufstauenden Kordilleren im Westen bedeckte und während der ganzen Tertiärzeit bestehen blieb. Tonige und sandige Ablagerungen von großem Ausmaß bildeten sich am Grunde dieses Süßwasserbinnenmeeres. Seine Wasser suchten sich schließlich, als sich die Kordilleren immer höher hoben, einen Abfluß nach Osten. Einzelne Einschnitte erweiterten sich zu Rinnen, vereinigten sich und bildeten schließlich den heutigen Durchbruch zum Atlantischen Ozean, woraus sich auch die größte Nord-Süd-Ausdehnung des Amazonastieflandes im Westen, die geringe im Osten erklärt (siehe geologische Karte, Abb. I). Wahrscheinlich senkte sich auch das Land im Osten, wodurch dieser Durchbruch zum Atlantik erleichtert wurde. Das Binnenmeer entwässerte von nun an gegen Osten.

Beim Abfluß der Gewässer vom Fuß der Kordilleren nach Osten zum Atlantik bildeten sich große Seen, an deren Grunde sich die Neogenschichten des unteren Amazonasgebietes (Tertiärschichten) ablagerten, welche durch große Armut an Fossilien gekennzeichnet sind. Die grabhügelähnlichen Tafelberge bei der Ortschaft Almeirim sind Reste jener Tertiärablagerung.

Die alluvialen und diluvialen Ablagerungen im unteren Amazonasgebiet sind schwer zu unterscheiden, einesteils, weil ja die Entstehungsursachen dieselben gewesen sind, andernteils, weil durch die Erosionstätigkeit der strömenden Gewässer heute noch ständige Umlagerungen erfolgen.

Für unsere nachfolgenden Betrachtungen sind namentlich die Gebiete des Tertiärs und des Karbons von Wichtigkeit. Auch hier ist eine scharfe Abgrenzung zwischen Quartär- und Tertiärboden schwierig. Die letzteren sind Süßwasserablagerungen, die aus den Sedimenten des erwähnten tertiären Binnenmeeres bestehen und hauptsächlich aus tonigen und sandigen Schichten zusammengesetzt sind. Sie bedecken den Boden des amazonischen Tieflandes stellenweise in einer Mächtigkeit von mehreren hundert 
Metern. Diese Tertiärböden zeichnen sich durch große Armut an Nährstoffen aus, namentlich an Kalk, und sind sehr sauer.

Der Untergrund der Karbongebiete besteht aus marinen Ablagerungen, zum Teil aus Kalk, zum Teil aus Sandstein; an einigen Orten sind auch Gipslager festgestellt worden. Die Karbonböden sind im allgemeinen viel nährstoffreicher und alkalischer als die Tertiärböden, was auch in den betreffenden Gewässern zum Ausdruck kommt.

Der Amazonas entspringt in etwa $5000 \mathrm{~m}$ Höhe aus den Gletschern der Kordilleren (peruanisches Gebiet) in $\mathrm{IO}^{\circ} 3^{\prime}$ südlicher Breite und $76^{\circ} 4 \mathrm{O}^{\prime}$ westlicher Länge von Greenwich. Nach etwa $50 \mathrm{~km}$ nordwärts gerichteten Laufes durchbricht er die Felsschlucht von Pongo de Manseriché und wendet sich dann endgültig gegen Osten, führt von da an den Namen Maranon und ist bereits zeitweise mit kleineren Schiffen befahrbar. Beim Eintritt in brasilianisches Territorium wird der Strom Rio Solimões genannt bis zum ZusammenfluB mit dem Rio Negro bei Manaos, und von da an führt er den endgültigen Namen Rio Amazonas. Er durchfließt das weite, über $4000 \mathrm{~km}$ lange Tiefland in $\dddot{A}$ quatornähe in östlicher Richtung und mündet in der Nähe der Stadt Belém do Pará in den Atlantischen Ozean. Bei diesem Lauf quer durch den südamerikanischen Kontinent empfängt der Amazonas mehr als 200 Seitenflüsse, von denen ein großer Teil schiffbar ist. Etwa I7 von ihnen übertreffen den Rhein zum Teil um ein Mehrfaches an Länge. Die Gesamtlänge des Amazonas beträgt $5500 \mathrm{~km}$, wovon etwa $4300 \mathrm{~km}$ schiffbar sind.

Das mehr als 7 Millionen Quadratkilometer umfassende Einzugsgebiet mit einer Unzahl von Flüssen, Bächen und Seen bildet den wasserreichsten Strom der Erde, der pro Sekunde etwa $120000 \mathrm{~m}^{3}$ Wasser in den Atlantik führt (KATZER, 1903). Zur Regenzeit kann sich diese Menge vervielfachen. Das sehr geringe Gefälle im Unterlauf $(19 \mathrm{~mm} / \mathrm{km}$ ) und die enormen Wassermassen bewirken, daß sich der Hauptstrom stellenweise bis zu 30 und mehr Kilometer seenartig erweitert. An verschiedenen Stellen teilt sich der Hauptstrom in drei oder noch mehr Seitenarme auf, Paranás genannt, die manchmal mit größeren und kleineren Inseln durchsetzt sind. Diese Seitenarme können durch die intensiven Ablagerungsvorgänge mit der Zeit vom Hauptstrom abgeschnitten werden und sich in Altwässer und Seen verwandeln. Alle diese Ströme, Paranás, Bäche, Seen und Inseln bilden ein erstaunliches Netzwerk aus Wasser und Urwald, wie es in solcher Mannigfaltigkeit und Größe in keinem andern Stromgebiet der Erde zu finden ist.

Die schmalste Stelle des Hauptstromes befindet sich bei der Ortschaft 


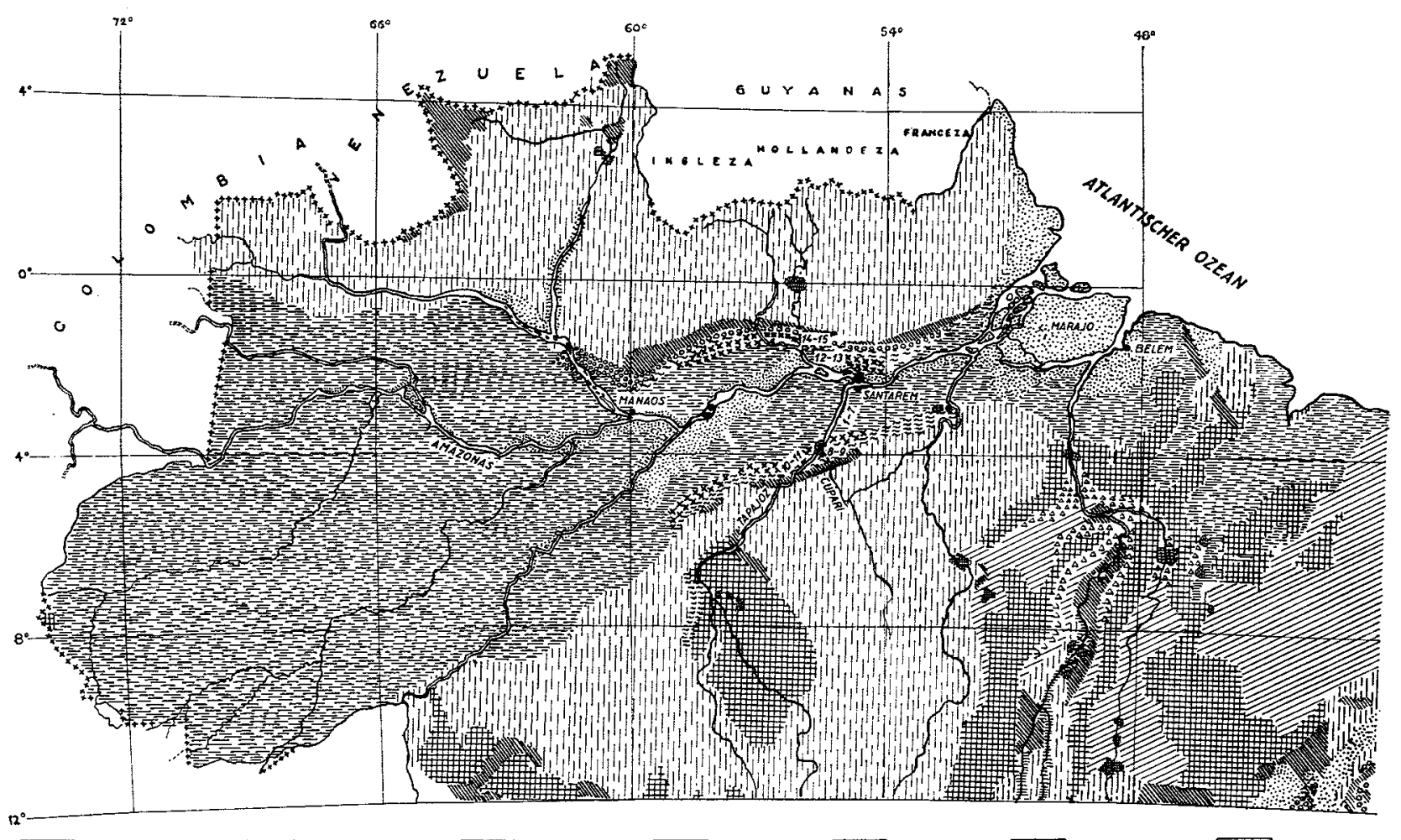

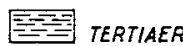

㡟需 KREIOE

PERM

泣清 OEVON

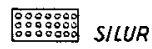

PRAEKAMBRIUM

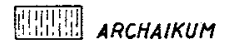

ERUPTIVA

\section{GEOLOGISCHE KARTE DES AMAZONASGEBIETES}

NACH OLIVEIRA (1938), MIT ABAENDERUNGEN NACH SIOLI (OLD)

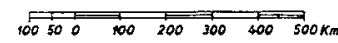


Obidos, etwa Iooo km von der Mündung in den Atlantik entfernt. Dort ist der Amazonas bloß I $890 \mathrm{~m}$ breit, mit einer Tiefe von zirka $85 \mathrm{~m}$. Dementsprechend ist auch die Strömungsgeschwindigkeit hoch $(7 \mathrm{~km} / \mathrm{h})$. Im übrigen Lauf beträgt sie durchschnittlich $2 \mathrm{~km} / \mathrm{h}$ (nach LE COINTE, I945).

Unsere limnologischen Untersuchungen erstreckten sich zur Hauptsache auf das Gebiet innerhalb des Staates Pará (Unterlauf des Amazonas), dessen Grenze mit dem Staat Amazonas durch die Flußenge von Obidos gebildet wird (siehe geologische Karte, S. II). Einzelne Reisen führten uns auch in den benachbarten Staat Amazonas. Die Abgrenzungen des unteren Amazonasgebietes (Staat Pará) sind: $46^{\circ}-59^{\circ}$ westlicher Länge und $9^{\circ}-4^{\circ} 20^{\prime}$ nördliche Breite von Greenwich, also insgesamt ein Gebiet von zirka I $50000 \mathrm{~km}^{2}$. Ein großer Teil des Gebietes gehört dem amazonischen Tiefland an, durch das der Strom von Westen nach Osten fließt und es in zwei ungleiche Teile teilt, nämlich in den nördlichen, kleineren Teil, der durch das Tumuc-Humac-Gebirge und das Hochland von Guayana begrenzt ist, und in den südlichen, größeren Teil, der durch das Hochland von Zentralbrasilien abgegrenzt wird. Rund drei Viertel des ganzen Gebietes sind mit Urwald bedeckt; die Flüsse bilden die einzigen Zufahrtsstraßen ins Innere.

Das heutige Amazonasgebiet ist also im allgemeinen ein flaches, zum größten Teil urwaldbedecktes Tiefland, das im Westen durch die Kordilleren, im Osten durch den Atlantischen Ozean, im Norden durch die Gebirgsketten von Guayana und im Süden durch das zentralbrasilianische Hochland begrenzt wird.

Dieses ganze System von Flüssen, Paranás, Bächen und Seen weist naturgemäß ein großes Wechselspiel von Abtragung und Aufschüttung auf. Durch Seitenerosion der Flüsse, durch steigendes und sinkendes Wasser mit seiner Brandungstätigkeit werden ganze Uferbezirke losgelöst (sogenannte "terras cahidas»), das Geschiebematerial wird wegtransportiert und an anderer Stelle wieder als alluviale Insel aufgeschüttet. Diese Kräfte werden außerdem noch unterstützt durch den Rückstau des Wassers während der Flut. Sie ist bis Obidos spürbar. Dort können wir noch einen Unterschied zwischen Ebbe und Flut von durchschnittlich $6 \mathrm{~cm}$ beobachten, in Santarém von $20 \mathrm{~cm}$. Sogar in den Zuflüssen - zum Beispiel im Rio Tapajoz - sind diese wechselnden Wasserstände noch feststellbar. Diese gezeitlich bedingte Stauwirkung des Wassers hemmt natürlich die Grunderosion, unterstützt jedoch die Seitenerosion der Flüsse. Diesem Umstand schreibt KaTZER (1903) die charakteristisch ausgeweitete Trompetenmündung der Flüsse zu. 
Einerseits führt der Hauptstrom von den Kordilleren her reichliche Mengen feiner Suspensionen mit, anderseits bringen die Zuflüsse grobe Sinkstoffe, die namentlich durch die erwähnte Seitenerosion der Flüsse entstehen. An Stellen geringerer Strömung werden diese Geschiebe und Suspensionen abgelagert und können nach und nach zu Inseln heranwachsen, manchmal mitten im Strom.

In ähnlichem Zusammenhang stehen auch die drei Begriffe Varzea, Terrafirme und Fgapó. Es sind überaus typische Landschaftsformen, die für das Amazonasgebiet von größter Bedeutung sind. Bei der Durchsicht der Literatur über das Amazonasgebiet fallen uns, was diese drei Begriffe anbelangt, einige sehr große Unklarheiten und Widersprüche auf (KATZER, I903; Ule, I9I5; BLUNTSCHLI, I9I8; BouILlenNe, I930). Wir schließen uns in unserer Arbeit eng an die Definitionen SIOLIS (I950 und nach mündlicher Mitteilung) an, der diese drei Begriffe endlich klar und unmißverständlich dargestellt hat.

\section{Varzea}

Die Varzeagebiete sind typisch für die Ufer der Lehmwasserflüsse mit viel suspendiertem, feinem Material, also in erster Linie für den Haupt-

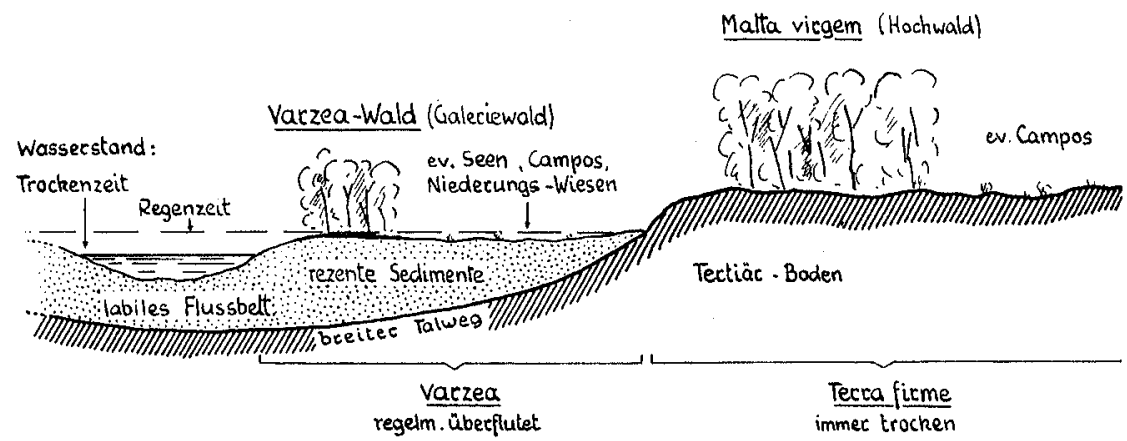

Abb. 2. Schematische Darstellung der Varzea- und Terrafirmegebicte.

(Hier bleibt noch die Frage abzuklären, ob nicht stellenweise die Tiefenerosion der Flüsse bis zum Tertiärboden reichen wird.)

strom selbst. Diese Suspensionen setzen sich dem Ufer entlang in Form von weitausgedehnten Ablagerungsgebieten ab. Die Flüsse haben vorher im Tertiärboden ihre breiten Talwege gegraben; diese werden durch die abgelagerten Suspensionen zum Teil wieder aufgefüllt. Eine grobschematische Darstellung dieser Verhältnisse zeigt Abbildung 2 . Während der Trockenzeit besitzt der Fluß einen niederen Wasserstand. Angrenzend an das Was- 
ser erhebt sich das aus den rezenten Alluvionen gebildete Varzealand. Meistens ist diese Varzea unmittelbar am Ufer etwas erhöht und senkt sich dann leicht landeinwärts. Zur Regenzeit hebt sich der Spiegel des Flusses stellenweise um mehrere Meter, so da 3 weite, vorher trockene Gebiete unter Wasser gesetzt werden. Die Varzea reicht nun bis dorthin, wo das Wasser während der Überschwemmungszeit hin gelangt. Bei jeder Regenperiode werden neue Sinkstoffe abgelagert, und die weite Wanne, die bei der Talwegformung entstanden ist, füllt sich immer mehr auf mit diesen rezenten Alluvionen. Die Varzea ist also junges Anschwemmungsland, bei dem noch aktipe Prozesse mitwirken; sie ist fortdauernden Erosionen einerseits und Ablagerungen anderseits ausgesetzt. Diese Varzeagebiete werden heute in steigendem Maße für landwirtschaftliche Zwecke benützt (zum Beispiel Jutekultur). Thre Böden sind sehr fruchtbar, denn bei jeder Regenzeit werden sie durch die abgelagerten Suspensionen neu gedüngt. Sie dürften nach Ansicht der Fachleute die Ackerbaugebiete der Zukunft darstellen.

Am Ufer selbst, wo die Varzea meistens etwas höher ist als weiter landeinwärts, erhebt sich der $V^{r}$ arzeawald, ein Galeriewald mit typischer Vegetation. Der Varzeawald wird also alljährlich von den Überschwemmungen crfaßt und steht etwa fünf bis sechs Monate unter Wasser. Hinter diesem Galeriewald breiten sich Niederungswiesen aus, die zur Regenzeit ebenfalls unter Wasser stehen. Sie werden Inundationscampos genannt. Auch Seen von geringer Tiefe, jedoch mit sehr großer Flächenausdehnung, können sich in dieser Region bilden. Sie trocknen während der Trockenzeit meistens aus.

\section{Terrafirme}

Anschließend an die Varzea erhebt sich die Terrafirme, unter der man allgemein diejenigen Landgebiete versteht, die nie von den jährlichen Überschwemmungen erfaßt werden, gleich welcher geologischen Formation sie angehören. Im Gebiet des Amazonashauptstromes selbst wird die Terrafirme von den Ablagerungen des tertiären Binnenmeeres gebildet. An einigen Seitenflüssen kann die Terrafirme auch aus Gesteinsschichten älterer Formation bestehen. Die Terrafirme kann auch in Form diluvialer Ablagerungen erscheinen, die sich manchmal bis $50 \mathrm{~m}$ Höhe über das gegenwärtige Flußniveau erheben (KATZER, I903).

Die Grenzen Varzea-Terrafirme können sehr leicht verwischt werden, indem sich unter Umständen Terrafirme in Varzealand umwandeln kann. Die Gesteinsschichten der Terrafirme können unterspült und abgetragen 
werden, daß zum Beispiel in Flußschleifen die flachen Ufer an der konvexen Seite so niedrig werden, daß sie eines Tages überschwemmt werden und sich damit zu Varzealand umformen (Beispiel von KaTZer, 1903).

Der Urwald, der auf der Terrafirme wächst, ist die Matta virgem, der eigentliche, immer trockene Hochwald des Amazonasgebietes. Auch er trägt eine typische Vegetation; eine Charakterpflanze ist zum Beispiel Bertbolletia excelsa H. P. K., der Paranußbaum. Hinter der Matta virgem können sich stellenweise Trockenkämpe ausbreiten mit magerer Gras- und Buschvegetation.

\section{Fgapó (Abb. 3)}

Beim dritten Begriff, dem Jgapó, handelt es sich um überschwemmten Wald, der die meiste Zeit des Jahres im Wasser steht. Jgapóbildungen treffen wir in erster Linie an Flüssen mit klarem Wasser ohne nennenswerte Suspensionen (im Gegensatz zur Varzea!). Vom Varzeawald, der ja auch periodisch überschwemmt ist, unterscheidet sich der Jgapó grundsätzlich dadurch, daß er kein Galeriewald ist; das Gelände dahinter senkt sich nicht, sondern es ist mehr oder weniger eben oder sogar leicht ansteigend. Ferner ist der Untergrund des Jgapós nicht junges, angeschwemmtes Land wie dasjenige des Varzeawaldes, sondern alter, erodierter Boden. Hier steht Srouls Anschauung bzw. Definition in einem gewissen Widerspruch mit KATZER, der als Jgapó jüngstes Schwemmland bezeichnet (KATZER, I903, S. 43) und als Varzea älteres. KATZER stellt dies als häufigsten Fall dar, läßt aber noch andere Möglichkeiten offen. Ebenso unklar ist die Bemerkung Katzers (S. 43): "Nicht das relative Alter ist für die drei Begriffe, wie sie am Amazonas selbst verstanden werden, ausschlaggebend, sondern, wie nochmals betont sei, nur die Höhenlage dieser Landbildungen bzw. die Art und Dauer ihrer Úberflutung.» Daraus ergibt sich die Notwendigkeit, einmal ganz klar und eindeutig diese drei Begriffe auseinanderzuhalten.

Während der Untergrund des Varzeawaldes sich durch große Labilität auszeichnet, bei dem fortwährend neue Ablagerungen stattfinden, ist der Boden des Jgapós viel dauerhafter und stabiler, es finden in ihm weder Deponierung noch Erosion in nennenswertem Ausmaße statt. Auch die Gewässer in diesen beiden Waldarten unterscheiden sich grundlegend: das Wasser im Jgapó ist meistens Schwarzwasser mit sehr niederem pH-Wert und reichlichen Mengen von Humusstoffen; das Wasser im Varzeawald dagegen - in den meisten Fällen ist es Lehmwasser - lagert immer wieder eine neue Isolierschicht aus feinen Sedimenten am Grunde ab und verhindert dadurch eine Extrahierung der organischen Substanz. Es besitzt auch 


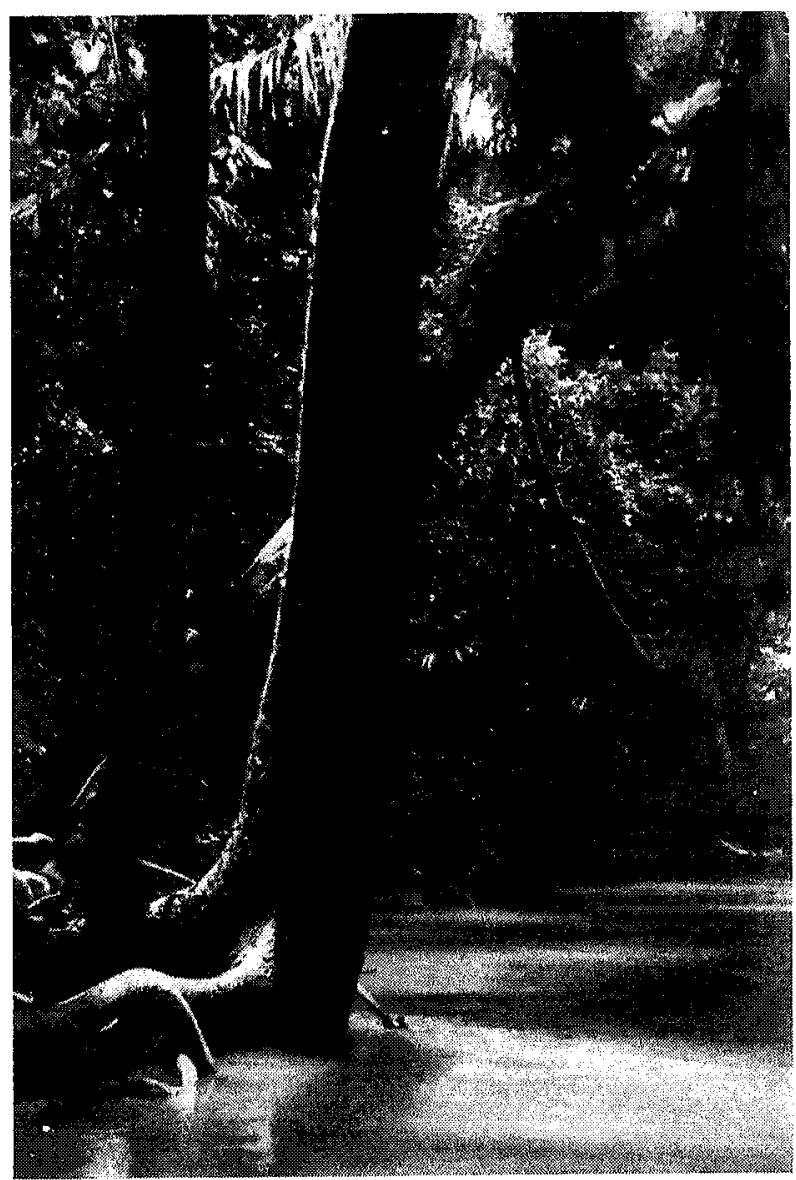

Abb. 3

Jgapó in der Gegend des Rio Branco de Obidos Aufuahme dies Verfassers 
viel höhere $\mathrm{pH}$-Werte (um den Neutralpunkt herum) und bildet niemals Schwarzwasser. Auf diese Verhältnisse, denen namentlich SioLI seine Aufmerksamkeit geschenkt hat, kommen wir später zurück.

\section{b) Das Klima im Untersuchungsgebiet}

Eine so ausgedehnte, im Tropengebiet gelegene, periodisch überschwemmte und zum größten Teil mit Urwald bedeckte Ebene, wie sie das untere Amazonasgebiet darstellt, muß naturgemäß ein feuchtwarmes Klima besitzen. Die im Gebiet am häufigsten auftretenden Nordost- und Südostwinde streichen vom Atlantik her ungehindert durch das ganze Amazonastal, das ihnen keine nennenswerten Hindernisse entgegenstellt. Die dadurch geförderte Verdunstung verhindert eine extreme Steigerung der Temperatur, wie dies sonst in manchen andern Tropengebieten der Fall ist. Die höchsten Temperaturen werden im unteren Amazonasgebiet gemessen. Diese Gegenden sind naturgemäß auch die ungesundesten.

Typisch für das amazonische Klima ist die regelmäßig hohe Temperatur mit geringen Jahres- und Tagesschwankungen. Während sich die von RUTTNER (I93I) untersuchten Seen in Gebieten mit großen Amplituden und starker nächtlicher Abkühlung befinden, so daß in manchen dieser Seen nachts sogar eine leichte Temperaturinversion stattfinden kann, lassen im Amazonasgebiet die hohe Luffeuchtigkeit und der dichte Mantel der umgebenden Urwälder eine starke nächtliche Wärmeausstrahlung nicht zu. Die Zusammenstellung der Temperaturen (in Grad Celsius) in Tabelle I zeigt uns diese Regelmäßigkeit in eindrücklicher Weise:

Tabelle 1

Temperaturen von Belém und Obidos

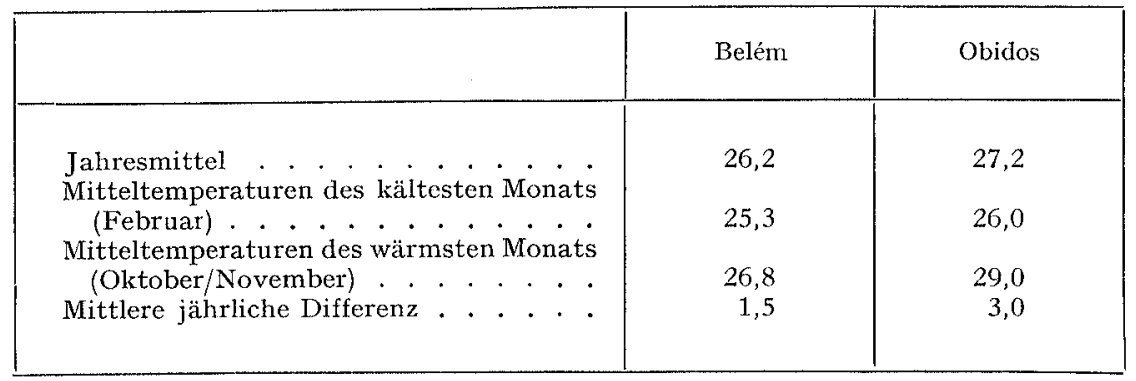


Tabelle 1 (Fortsetzung)

Mittlere Tagestemperaturen von Obidos

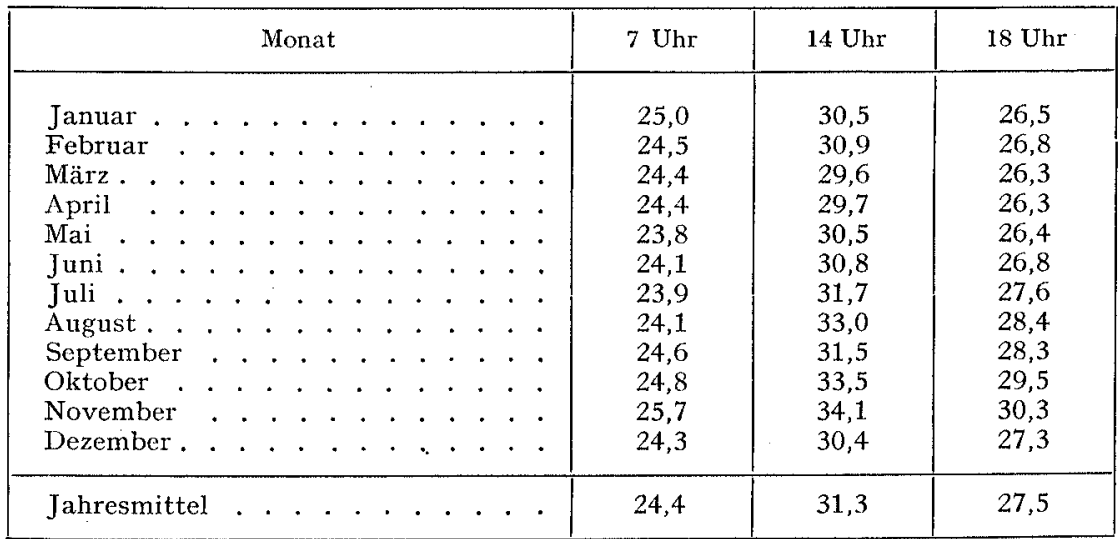

In Abbildung 4 (oben) ist die Kurve der Durchschnittstemperaturen von Obidos eingetragen. Auch diese Kurve zeigt deutlich die geringen Schwankungen im Laufe des Jahres.

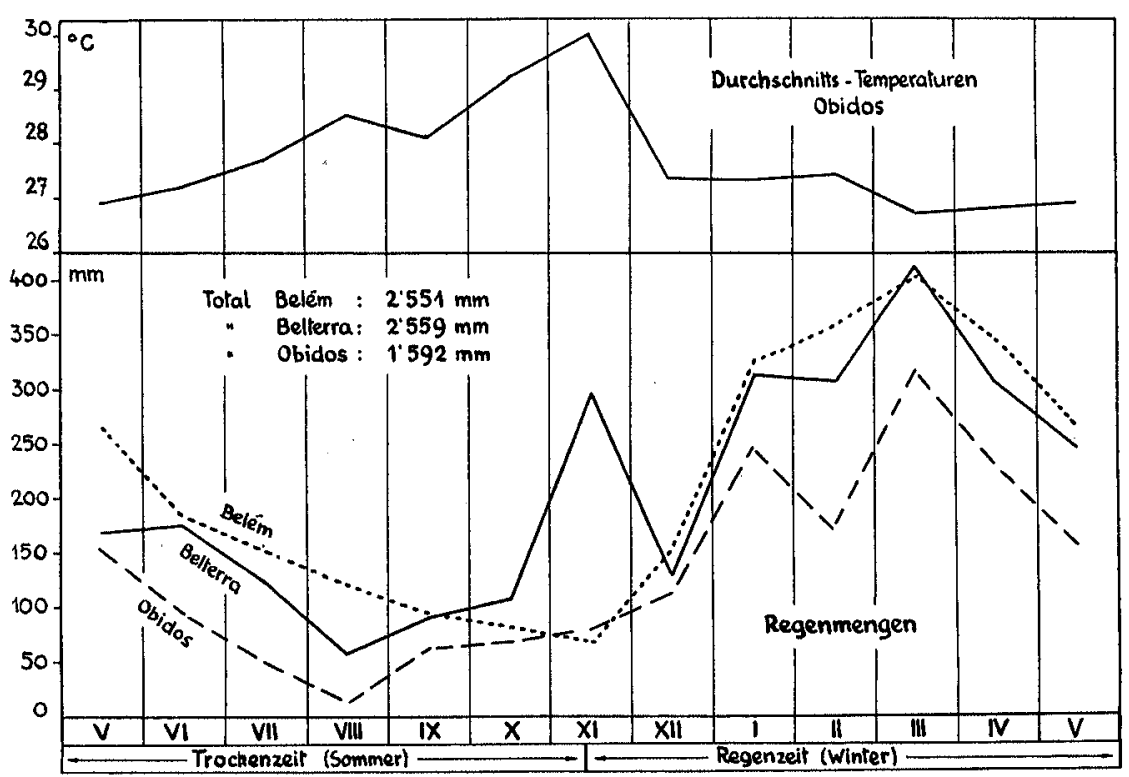

Abb. 4 
Während die Temperaturen bzw. deren Schwankungen nicht ausreichen, um einzelne jahreszeitliche Perioden zu kennzeichnen, so sind die Regenmengen so charakteristisch verteilt, daß man dadurch deutlich eine Trokkenzeit und eine Regenzeit unterscheiden kann. Die Regenzeit wird zuweilen auch als «Winter», die Trockenzeit als «Sommer» bezeichnet (siehe Abb.4).

Die Regenmenge im unteren Amazonasgebiet ist verhältnismäßig hoch, das heißt nicht in erster Linie die Gesamtmenge, sondern die Zahl der Regentage. Anderseits ist der Sommer nicht so extrem trocken wie zum Beispiel in den angrenzenden Staaten Ceará und Rio Grande do Norte, die stark unter Dürreperioden zu leiden haben. Die hauptsächlichsten Winde sind Passate, welche vom Atlantik her große Feuchtigkeitsmengen ins Innere tragen, so daß eine nur geringfügige Temperaturerniedrigung Kondensation hervorrufen kann. Wir erlebten es wiederholt, wenn wir im feuchtheißen Jgapó übernachteten, daß in den frühen Morgenstunden im Wald ein leichter Regen fiel bei klarem Himmel!

In Belém regnet es das ganze Jahr hindurch reichlich. Man erlebt praktisch keine Woche ohne Niederschläge. Die großen Regen beginnen Ende Dezember und sind im Januar bis April am stärksten. Die Regenzeit ist in Belém etwa im August zu Ende, die trockensten Monate sind September, Oktober und November. Im Gegensatz dazu haben wir in Obidos und Belterra manchmal mehrere Wochen ohne einen Tropfen Regen. Diese Verschiedenheit kommt in Tabelle 2 gut zum Ausdruck:

Tabelle 2

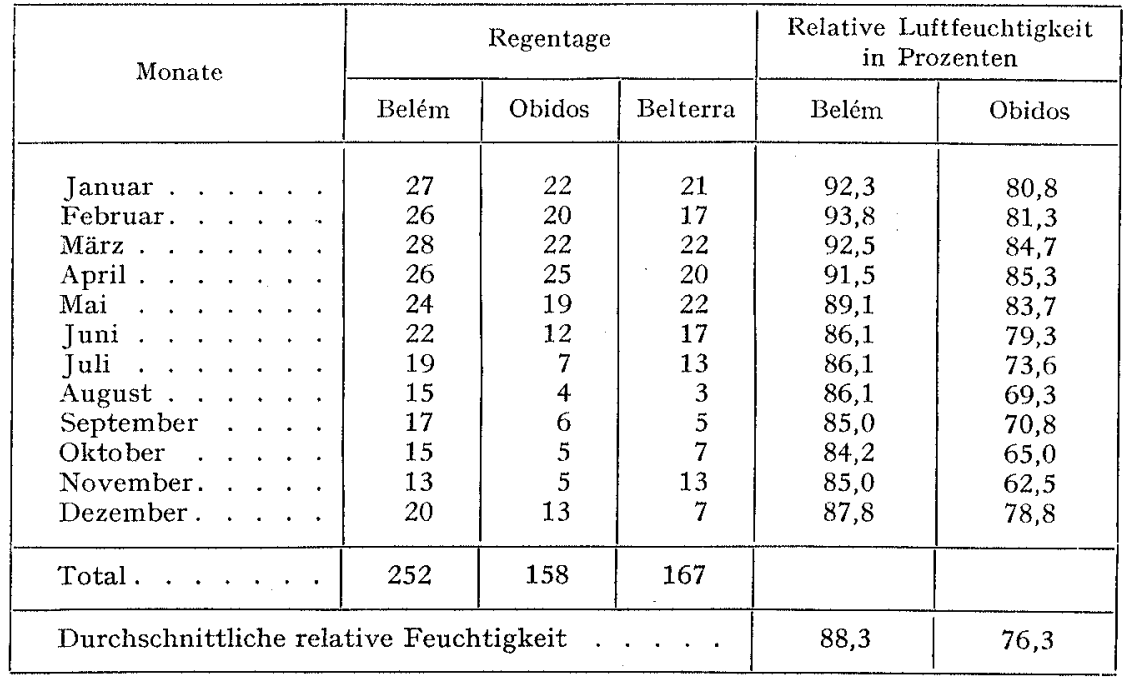


Die klimatischen Daten für Belém und Obidos sind dem Werk von LE CoINTE (I945) entnommen. Für Belterra standen uns die Resultate der Regenmessungen zur Verfügung, welche die «Plantação Ford» regelmäßig, vornimmt. In Abbildung 4 (unten) sind die durchschnittlichen Niederschlagsmengen von Obidos und Belém sowie die Niederschläge des Jahres 1947/48 von Belterra graphisch dargestellt. Unsere Untersuchungen fielen in ein Jahr mit nicht ganz normalen Niederschlagsverhältnissen, denn in Belterra fiel bereits im November starker Regen, was in einem deutlichen Schönheitsfehler in der Kurve von Belterra zum Ausdruck kommt. In allen übrigen Monaten verläuft unsere Kurve normal. Obschon allgemein Belterra etwas trockener ist als Belém, ist die totale Regenmenge Belterras im Untersuchungsjahr 1947/48 größer als die durchschnittliche von Belém, eben weil der November 1947 abnorm feucht war.

Die relative Luftfeuchtigkeit ist immer sehr hoch. Die Daten von Belém und Obidos sind ebenfalls in Tabelle 2 eingetragen. Leider standen uns in unserem eigentlichen Untersuchungsgebiet keine Feuchtigkeitsmesser zur Verfügung. Die Luftfeuchtigkeit in Belterra ist jedoch erfahrungsgemäß etwas größer als in Obidos und etwas geringer als in Belém, so daß wir als durchschnittliches Jahresmittel etwa $80 \%$ annehmen können.

Zusammenfassend können wir also das Klima unseres Untersuchungsgebietes als ausgesprochen ozeanisches, feuchtwarmes Klima mit großen Niederschlagsmengen und gleichförmig hoher Temperatur bezeichnen.

\section{c) Die untersuchten Seen}

Wie schon bei der Besprechung der geologisch-geographischen Verhältnisse kurz erwähnt wurde, ist das untere Amazonasgebiet reich an Seen. Ihr gemeinsames Merkmal ist ihre geringe Tiefe, die während der Regenzeit zwischen 6 und Io $\mathrm{m}$ und während der Trockenzeit zwischen 2 und $5 \mathrm{~m}$ schwankt. Einzelne Seen verschwinden sogar vollkommen während der Trockenzeit. Der Grund des Fehlens tiefer Seen liegt in der geologischen Vergangenheit des Gebietes begründet. Das flache Amazonastiefland, die mächtige Ablagerung des tertiären Binnenmeeres, brachte keine tektonischen Bewegungen der Erdoberfläche hervor, wie zum Beispiel Grabenbrïche, Verwerfungen usw., die eine tiefere Wannenbildung ermöglicht hätte, und die ausschürfende Gletschertätigkeit fehlte ebenfalls. Alle Seen im unteren Amazonasgebiet sind durchwegs Austiefungs-, Abdämmungs- und Dünenseen. Schon dadurch unterscheiden sie sich von den zu 
Vergleichszwecken herangezogenen Seen im Sundagebiet, die zum großen Teil vulkanischen Ursprungs, also Maare und echte Kraterseen sind. Demzufolge besitzen die von RUTTNER untersuchten Tropenseen auch eine viel größere Tiefe, die meistens 60 bis Ioo oder mehr Meter beträgt. Auch die Höhenlage ist verschieden. Die von uns untersuchten amazonischen Seen liegen fast auf Meereshöhe (etwa to bis $20 \mathrm{~m}$ ü. M.), die Seen im Sundagebiet meistens 400 , einige sogar $1000 \mathrm{~m}$ ü. M., was natürlich auf die klimatischen Verhältnisse einen sehr großen Einfluß ausübt, namentlich auf den Temperaturhaushalt der Seen. Die nächtliche Abkühlung in den tiefgelegenen Amazonasseen ist aus den im Kapitel Klima dargelegten Gründen gering, im Gegensatz zu den Ruttnerschen hochgelegenen Seen, die im vulkanischen Gebiet mit starker nächtlicher Wärmeausstrahlung liegen.

Im Unterlauf des Rio Tapajoz ziehen sich ausgedehnte Dünengebiete aus hellem Quarzsand hin, in denen in der Gegend von Pindobal (Hafen der Fordplantage «Belterra») einige kleinere Seen eingebettet liegen. Es sind dies die Seen Jurucui, Caxambú, Muretá, Alter do Chão, Pindobal, Maritima und Jruçanga. Da namentlich die ersten drei dieser Seen sich ganz in der Nähe unseres Standquartieres befanden, hatten wir Gelegenheit, sie während mehrerer Monate periodisch zu untersuchen (November 1947 bis Mai 1948). Die ungefähre Lage dieser im Tertiärgebiet gelegenen Seen ist auf der geologischen Karte (Abb. I) mit den Ziffern I bis 7 angegeben.

Von Belterra aus führten wir einzelne größere und kleinere Reisen durch, teils in die südlich vom Amazonas gelegenen Karbongegenden mit den Seen Curuçá, do Caxias, Timbó, Curí (Lagebezeichnung 8, 9; IO, II), teils in die nördlich des Amazonas sich hinziehende Karbonregion mit den Seen Salgado, Tracoá, Pauxis usw. (Ziffern I2, I3; I4, I5). So hatten wir Gelegenheit, Seen verschiedener geologischer Gebiete einander vergleichend gegenüberzustellen. Da ein genaues Kartenmaterial über diese Gebiete fehlt, müssen wir uns auf eine skizzenhafte Beschreibung dieser Seen beschränken. Die eingeklammerte Zahl hinter dem Namen des Sees bezeichnet die Lage auf der Karte.

Der Lago Furucui ( $\mathrm{I}$ ), einer dieser Dünenseen am rechten Tapajozufer, liegt etwa $40 \mathrm{~km}$ oberhalb des Städtchens Santarém. Der See wird gestaut durch eine große Düne des Tapajoz und gespiesen durch die beiden $\mathrm{Zu}-$ flüsse Jgarapé do Tento und Jgarapé Grande ( ggarapé $=$ Bach), die vor der Einmündung in den See durch ausgedehnte Terrafirmewälder fließen. Eine grobschematische Kartenskizze (Abb. 5) zeigt uns diese Verhältnisse: Längs der Seeufer zieht sich ein Strand aus hellem Quarzsand hin. Sehr wahrscheinlich bestehen diese Dünen und Sandstrande, die sich viele Kilo- 
meter weit am Ufer des unteren Tapajoz dahinziehen, nicht aus Material, das vom Fluß hieher transportiert worden ist, sondern aus ausgewaschenem autochthonem Terrafirmematerial. Der Rio Tapajoz weist nämlich in seinem Unterlauf kaum Sedimente auf, durch die eine solche Dünen- und

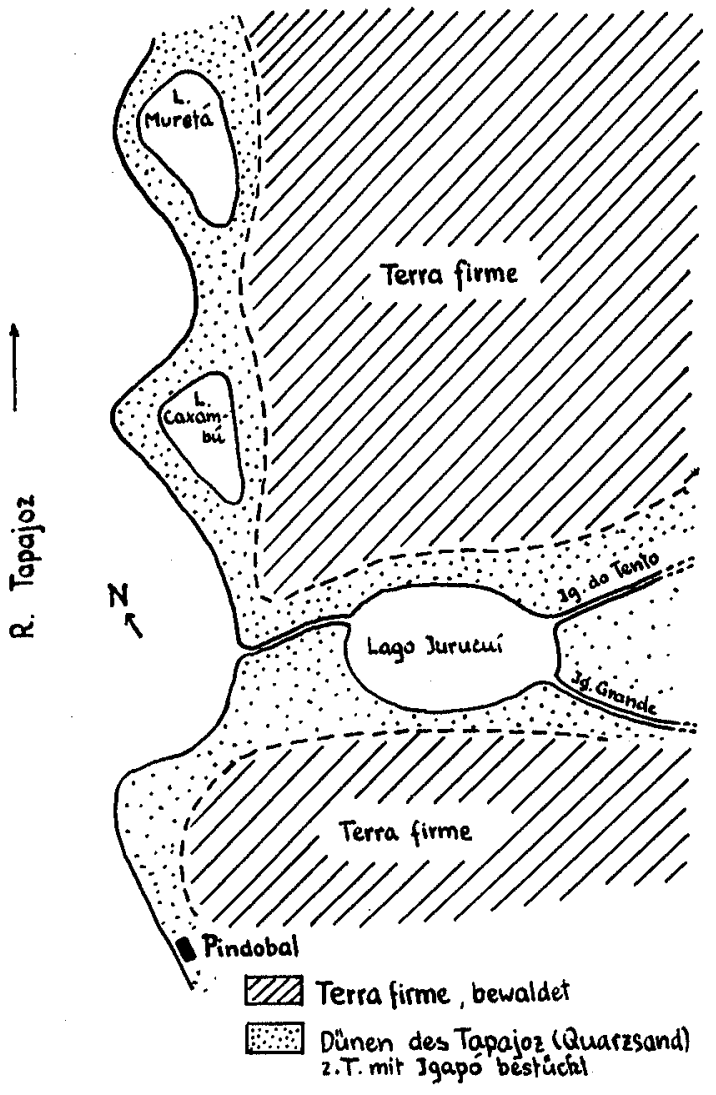

Abb. 5

Strandbildung erklärt werden könnte. Das absetzbare Schwebegut hat bereits im Mittel- und Oberlauf ausgedehnte Aufschüttungsgebiete und Inseln gebildet. Schon in Fordlandia, etwa $140 \mathrm{~km}$ oberhalb von Pindobal, weist der Tapajoz bedeutend mehr Sedimente auf.

Am Lago Jurucui herrscht fast immer leichter Ostwind. Das Brandungsufer (Westufer) ist fast vegetationslos, die uibrigen Ufer sind mehr oder weniger flach und tragen niederen Jgapó. Die bewaldete Terrafirme zieht 
sich in einiger Entfernung vom See bogenförmig herum (vgl. Abb. 5). Auch die große Düne, welche den Lago Jurucui vom Rio Tapajoz trennt, trägt niederen Jgapó in etwas lichterer Ausbildung. Diese Vegetation besteht zur Hauptsache aus: Palmen (Astrocardium sp., Leopoldinia sp.); Malpigiazeen (Banisteria coapi Spruce); Kombretazeen (Terminalia tanibouca Smith, Bucbenavia grandis Ducke); Bignoniazeen (Tecoma sp.); Myrtazeen (Myrcia sp.); Leguminosen (Macbarium sp., Dalbergia monetaria L., Ormosia sp., Campsiandra laurifolia Genth., Acacia sp.); Rubiazeen (Alibertia sp., Borreria sp.); Polygalazeen (Securidaca sp.); Polygonazeen (Triplaris sp.); Rosazeen (Chrysobalamus sp., Hirtella sp.); Loranthazeen (Psitacantus sp.); verschiedene Mimosazeen; Apokinazeen (Aspidosperma sp.); Melostomazeen (Mouriria apiranga Spruce); Lythrazeen (Cuphea sp.); Borraginazeen (Heliotropium sp.); Anakardiazeen (Anacardium sp.); Kompositen (Vernonia sp.); Verbenazeen (Vitex duckei Hub.); Humiriazeen (Humiria balsamifera Aubl.).

Der Lago Jurucui ist schätzungsweise $600 \mathrm{~m}$ lang und $450 \mathrm{~m}$ breit. Die Maximaltiefe während der Regenzeit beträgt $5,5 \mathrm{~m}$, während der Trockenzeit $2 \mathrm{~m}$. Der Untergrund des Sees besteht aus hellem Quarzsand (Dünensand); an den tieferen Stellen ist der Sand von einer mehrere Zentimeter dicken Schicht aus dunklem Schlick überlagert, die aus feinem pflanzlichem Detritus besteht.

Die Seen Muretá (2) und Caxambú (3), die sich etwa $2 \mathrm{~km}$ weit entfernt vom Lage Jurucui befinden, unterscheiden sich von diesem dadurch, daß sie abflußlos sind. Ihre Lage ist ebenfalls aus der schematischen Kartenskizze (Abb. 5) ersichtlich. In der Trockenzeit trocknen sie jedoch nicht aus, obschon sie abflußlos sind; offenbar dringt von unten her Tapajozwasser in die Seen.

Obschon diese nahe beieinander gelegenen Seen äußerlich ziemlich gleich aussehen, sind sie doch in mancher Hinsicht verschieden. Während der Untergrund des Lago Caxambú aus grobem Quarzsand, fast ohne Schlickbildung, besteht, ist derjenige des Lago Muretás mit einer mehrere Zentimeter dicken Schicht aus weichem schwarzem Schlick mit bräunlichem Einschlag bedeckt, in dem massenhaft kleine Gehäuse von Chironomiden liegen. Unter diesem Schlick erscheint dann derselbe sandige Untergrund wie beim Lago Caxambú.

Der Lago Alter do Chão (4) ist ein im Ufergebiet des Rio Tapajoz.gelegener, in zwei mehrere Kilometer lange Hauptarme geteilter See (Südcabeçeira, Ostcabeçeira). Der Abfluß des Sees mündet in den Tapajoz, etwa $35 \mathrm{~km}$ oberhalb des Städtchens Santarém. Der See ist von Jgapó umgeben, manchmal in dichterer, stellenweise in lockerer Ausbildung. 
Die Entstehung des Sees ist nicht ganz klar. Sicher ist der Lago Alter do Chão nicht ein Dünensee, wie die bereits besprochenen, denn die Terrafirme reicht stellenweise bis unmittelbar an den See heran. Er kann auch kaum durch Abdämmung entstanden sein, wie zum Beispiel der später zu besprechende Lago Pauxis, denn das Tapajozwasser besitzt an dieser Stelle keine nennenswerten Geschiebemengen mehr. Man könnte sich höchstens die Entstehung dieses Sees so vorstellen, daß sich durch geringe Absenkung der Erdoberfläche eine flache Wanne bildete, deren Wasser sich zum Tapajoz einen Abfluß suchten (?).

Der Untergrund des Sees besteht aus äußerst feinem Quarzsand, vermischt mit wenig Detritus und weichem Schlick.

Der Lago Pindobal ( 5 ) ist ein etwa 15 mal $5 \mathrm{~m}$ großer Schwarzwassertümpel beim Hafen Pindobal (Belterra). Während der Trockenzeit verschwindet er vollkommen und besitzt während der Regenzeit eine Tiefe von etwa $50 \mathrm{~cm}$. Er liegt am Rande des Terrafirmewaldes in einer Düne des Tapajoz eingebettet. Der aus Quarzsand bestehende Untergrund ist mit einem lockeren Polster von abgestorbenen Pflanzenresten bedeckt, woraus sich der Schwarzwassercharakter des Tümpels erklärt. Das Wasser ist zum größten Teil Regenwasser; wahrscheinlich drückt auch von unten her Tapajozwasser in den Tümpel.

Der Lago Maritima (6) ist ebenfalls ein kleiner Schwarzwassersee in der Nähe von Pindobal, der in einer Düne des Tapajoz eingebettet liegt. Während der Trockenzeit verschwindet auch er vollkommen. Am Untersuchungsdatum (I9. Februar 1948) war er bereits zwei Monate mit Wasser gefüllt. Der See wird vom Tapajoz durch eine etwa $30 \mathrm{~m}$ breite Sanddüne getrennt, stellt also einen richtigen Dünensee dar wie der Lago Jurucui, Lago Muretá und Lago Caxambú. Wie die beiden letzteren besitzt auch der Lago Maritima keine $\mathrm{Zu}$ - und Abflüsse, sondern Wasser vom Tapajoz drückt von unten her in den See, außerdem wird er vom Regen gespiesen. Am Untersuchungsdatum war er etwa $80 \mathrm{~m}$ breit und $300 \mathrm{~m}$ lang, mit einer Tiefe von I m. Am Ufer zieht sich buschartiger Jgapó mit ähnlicher Zusammensetzung wie derjenige am Lago Jurucui hin. Der Untergrund des Sees besteht aus einer durchschnittlich $3 \mathrm{~cm}$ dicken Schicht aus schwarzen Pflanzenresten. Darunter liegt Quarzsand. Das Wasser ist klar, jedoch von kaffeebrauner Farbe.

Der Lago Fruçanga (7), ebenfalls zur Reihe der in den Tapajozdünen eingebetteten Seen in der Nähe Belterras gehörend, ist ein fast verlandeter, dichtbewachsener kleiner See. Seine freie Wasserfläche beträgt nur etwa Ioo $\mathrm{m}^{2}$. Ausgedehnte Bestände von Zyperazeen und Montrichardia arbo- 


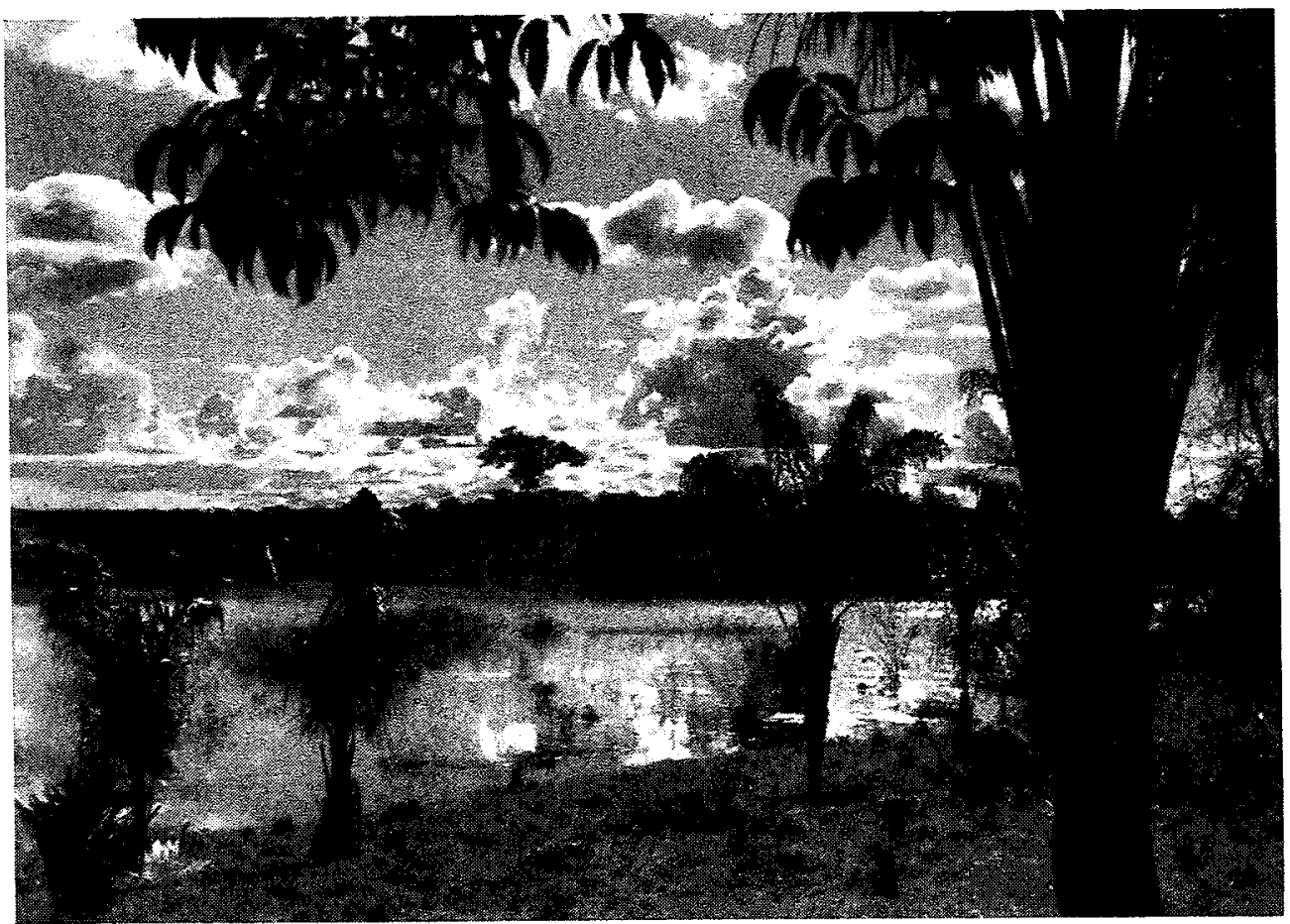

Abb. 6

Am Lago Salgado

Aufnahme des Verfassers 
rescens engen den See immer weiter ein. Der aus Quarzsand bestehende Untergrund ist von einer mehrere Zentimeter hohen Schicht aus dunkelbraunem Schlick überlagert.

Der Lago do Caxias (8) ist ein im Jgapó am rechten Ufer des unteren Rio Cupari gelegener Waldsee mit einer Ausdehnung von etwa $70 \mathrm{mal} 40 \mathrm{~m}$. Er stellt eigentlich mehr eine Lichtung im überschwemmten Jgapó dar. Etwa drei Viertel der Wasseroberfläche sind bedeckt mit Schwimmpflanzen (Salvinia, Eichhornia und andere). Sein Wasser stammt vom Rio Cupari und ist stark trübe. Der Untergrund besteht aus Grasresten, schwarzem Schlick und riecht stark nach Schwefelwasserstoff.

Der Lago Curuçá (9) ist ebenfalls wie der Lago do Caxias ein Jgapósee, etwa dreimal so groß wie der soeben besprochene. Er liegt ebenfalls im Ufergebiet des unteren Cupari, bildet jedoch nicht ein einheitliches Ganzes, sondern ist durch einen schmalen Streifen von Jgapó in zwei ungleich große Teile getrennt. Im kleineren Teil war die Uferregion dicht bewachsen mit "Aninga» (Montrichardia arborescens); wir nannten diesen Seeteil deshalb « Aningateil». Auf der Wasseroberfläche des andern, größeren Teiles lag in prachtvollster Ausbildung Victoria regia, daher wurde dieser Teil «Victoriateil» benannt.

Lago Timbó (Io) und Lago Curí (II) gehören der großen Seenregion an, die sich in der Nähe der Ortschaft Curí am linken Ufer des unteren Tapajoz hinzieht. Die beiden Seen sind keine eigentlichen Dünenseen, wie zum Beispiel der Lago Jurucui, sondern sie sind von dichtbewaldeter Varzea umgeben. Der Lago Timbó ist etwa $2 \mathrm{~km}$ lang und $400 \mathrm{~m}$ breit. Seine größte Tiefe betrug am Untersuchingsdatum $4 \mathrm{~m}$. Der Lago Curí besitzt ungefähr dieselbe Ausdehnung und Tiefe. Der Untergrund dieser Seen besteht nicht, wie bei den Dünenseen, aus grobem Quarzsand, sondern aus äußerst feinem, grauockerfarbenem Sand. Die beiden Seen unterscheiden sich äußerlich nicht sehr stark voneinander.

Lago Pauxis (I2): Von der Ortschaft Obidos bis zur Mündung des Trombetas zieht sich dem Amazonas entlang eine ganze Reihe von Uferseen hin, unter anderen auch der Lago Pauxis, ein zwischen der Serra da Escama und Obidos liegender kleiner See von grobdreieckiger Form. Er ist etwa $200 \mathrm{~m}$ lang und $100 \mathrm{~m}$ breit, mit einer Maximaltiefe (am 25.Juli 1947) von $4 \mathrm{~m}$. Er ist flach-wannenförmig und mit dem Amazonas in ständiger Verbindung durch einen seichten, kaum fließenden Verbindungsbach (Jgarapé), der dicht bewachsen ist.

Schon KaTZER (1903) hat diesen See in den Bereich seiner geologischen Untersuchungen einbezogen. Nach seiner Ansicht hat der Lago Pauxis fol- 
gende Entstehungsgeschichte: Ein Blick auf die Karte zeigt, daß der Amazonas in der Gegend von Obidos einen nach Norden geschwungenen Bogen beschreibt. Das Wasser wird also nach außen, nach Norden gepreßt, weitet die schon bestehenden Austiefungen und Buchten, so daß sich diese zu Seebecken erweitern bzw. vertiefen, was namentlich bei Hochwasser der Fall ist. Mit beginnender Trockenzeit, wenn der Spiegel des Amazonas sich senkt, fließt das Wasser jener zu Seebecken erweiterten Buchten ab in den Amazonas, doch bei der Einmündung kann es durch den Druck des entgegenströmenden Flusses gestaut werden. Die Folge ist, daß sich die Sedimente, die der Amazonas in reichlicher Menge führt, hier absetzen und eine Barrikade bilden in Form zahlreicher Aufschüttungsinseln, so daß sich der ursprüngliche Austiefungssee in einen Abdämmungssee verwandelt.

Die Terrafirme reicht unmittelbar bis ans Ufer des Sees heran und bricht hier brüsk ab, ohne einen eigentlichen Strand zu bilden, wie zum Beispiel bei den reinen Dünenseen. Ein dichter Gürtel von Gebüschen zieht sich dem Ufer entlang hin, dahinter folgt der Hochwald der Terrafirme. Wir haben also hier keine ausgesprochene Jgapóbildung.

Unmittelbar am Seeufer fanden wir in Mengen Eleocbaris und Mimosen, ferner Montrichardia arborescens Schott und die Zyperazee Scleria tenacissima Nees., das berüchtigte Schneidegras mit den kieselsäurehaltigen Blättern, die mit Leichtigkeit messerartig in die Haut eindringen. Ferner ist in reicher Ausbildung die Bignoniazee Couralia toxophora Benth. et Hoock vorhanden, und unter den Gramineen wiegt Leercia bexandra Sw. vor. Unterbrochen wird diese Vegetation von hohen, schlanken Karanapalmen, Mauritia martiana Spruce.

Das Wasser des Sees hat schwarzbraune Färbung, es stellt also ein richtiges Schwarzwasser dar, wie sich dies auch in seinen chemischen Eigenschaften zeigen wird. Gespiesen wird der See ebenfalls von einem Schwarzwasserjgarapé namens Engenho. Der Untergrund des Sees besteht aus braunem, feinem Sand, vermischt mit dunklem Detritus. Die Grundfauna fehlt praktisch vollkommen, auch das Plankton ist extrem arm. Der Grundschlamm ist sehr sauer. Unmittelbar auf der Schlammoberfläche stellten wir einen $\mathrm{pH}-$ Wert von 4,75 fest, in $30 \mathrm{~cm}$ Tiefe bereits $\mathrm{pH} 5,65$. Die $\mathrm{Zu}-$ nahme des basischen Charakters des Schlammes mit zunehmender Tiefe ist also augenfällig.

Der Lago Verde (I3): In nördlicher Richtung, vom Lago Pauxis durch einen schmalen, etwa $60 \mathrm{~m}$ langen Jgarapé getrennt, befindet sich der Lago Verde, eigentlich mehr ein deutlich abgegrenzter Seitenarm des Lago Pau- 
xis. Der Lago Verde ist etwa $60 \mathrm{~m}$ lang und $50 \mathrm{~m}$ breit, mit einer Maximaltiefe (am 25.Juli I947) von $3 \mathrm{~m}$. Sein Wasser fließt in den Lago Pauxis, von dort in den Amazonas.

Die Ufer dieses Sees werden wiederum von Terrafirme gebildet, mit einem schmalen Strandgürtel aus grobem Quarzsand. Auch hier wieder

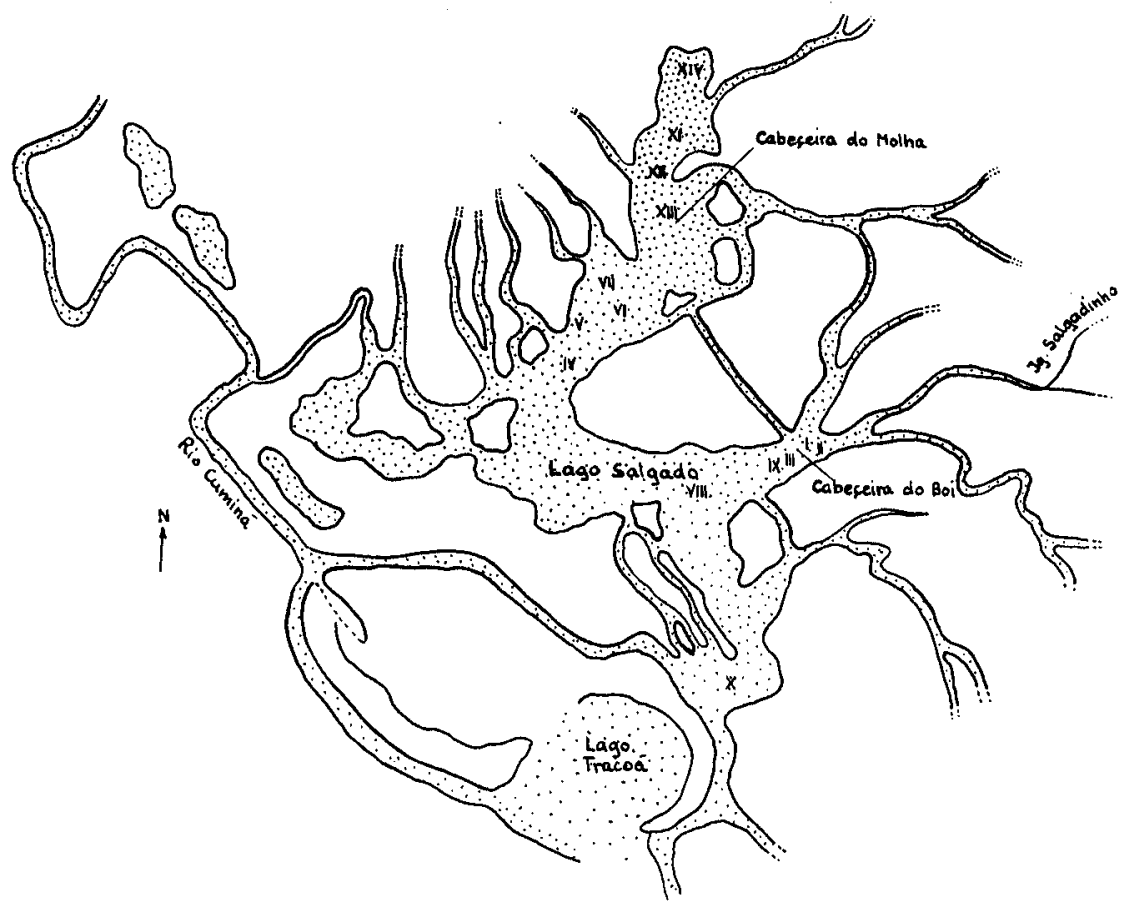

Abb. 7

am Ufer dichtes Gebüsch von ähnlicher Zusammensetzung wie am Lago Pauxis, jedoch mit deutlich mehr Scleria tenacissima.

Der größte Unterschied liegt jedoch in der Wasserfarbe. Im Gegensatz zum Lago Pauxis (Schwarzwasser) ist das Wasser des Lago Verde außerordentlich klar, mit einem grünlichen Farbton. Auch hier ist das Plankton spärlich. Der Untergrund des Sees besteht aus kastanienbraunem, äußerst feinem Schlick, der aus Pflanzenresten und Detritus besteht. Wie im Lago Pauxis ist auch im Lago Verde der Grundschlamm praktisch frei von Organismen und sauer. An der Schlammoberfläche stellten wir $\mathrm{pH}$-Werte von 5,0 fest, in $\mathrm{r} 5 \mathrm{~cm}$ Tiefe bereits $\mathrm{pH} 5,5$ und in $30 \mathrm{~cm}$ Tiefe $\mathrm{pH} 5,9$. 
Der Lago Salgado (14) wird vom Rio Cuminá gebildet, einem Zufluß des Rio Trombetas, der seinerseits ein nördlicher Zufluß des Amazonas ist. Der See befindet sich etwa $50 \mathrm{~km}$ nördlich vom Orte Oriximina (Mündungsgebiet des Trombetas) im Karbongebiet. Er hat eine komplizierte, fingerförmige Gestalt und ist mit zahlreichen größeren und kleineren Inseln durchsetzt, wie dies die Kartenskizze (Abb. 7) veranschaulicht. Er besitzt zahlreiche Zuflüsse, unter denen der Jgarapé Salgadinho besondere Bedeutung besitzt, da er dem See ansehnliche Mengen von Salzen (in erster Linie Magnesiumsulfat) zuführt, was für seine Namensgebung bestimmend war (salgado = salzig). Wir wählten für unsere Untersuchung die beiden Hauptarme Cabeçeira do Boi und Cabeçeira do Molha. Der See wies am Untersuchungstag eine Tiefe von knapp $5 \mathrm{~m}$ auf. Der Untergrund besteht im allgemeinen aus grauem Schlick, der an manchen Stellen durch schwefeleisenhaltigen Faulschlamm schwarz gefärbt ist und stark nach Schwefelwasserstoff riecht.

Der Lago Tracoá (I5) ist ein See auf der andern Seite des Rio Cuminá, gegenüber dem Lago Salgado (Abb. 7), das heißt, er stellt mehr eine seenartige Verbreiterung dieses Flusses dar.

II.

DIE PHYSIKALISCH-CHEMISCHEN EIGENSCHAFTEN DER UNTERSUCHTEN SEEN

\section{a) Der Temperaturhaushalt}

RUTTNER (I940) bezeichnet die Thermik als Angelpunkt jeder limnologischen Forschung. Sie stellt nicht nur den wichtigsten Regulator aller Lebensvorgänge dar, sondern bewirkt auch infolge der durch Temperaturänderungen hervorgerufenen Dichteunterschiede die Schichtung der Wassermassen.

Eines der Hauptprobleme, mit dem sich die tropische Limnologie beschäftigte, war die Frage, ob sich in äquatorialen Seen eine thermische Schichtung ausbilde. In der gemäßigten Zone weisen die Seen des temperierten Typus einen jahreszeitlich bedingten periodischen Wechsel von scharf begrenzter Schichtung mit Voll- bzw. Teilzirkulationen auf, und 
zwar in so ausgeprägtem Maße, daß wir an Hand der Jahreskurven der Temperatur direkt ein «Seejahr» herauslesen können. Im Frühjahr besitzt die Wassermasse eines temperierten Sees in einem gewissen Zeitpunkt eine von der Oberfläche bis zur Tiefe reichende gleichmäßige Temperatur, die in der Nähe des Dichtemaximums liegt. Es ist die Periode der Frübjabrsvollzirkulation, deren Dauer von den Witterungsverhältnissen abhängt. Der See erwärmt sich im Laufe des Frühsommers immer mehr, der größte Teil der eingestrahlten Wärme wird in den obersten Wasserschichten absorbiert, so da $\beta$ sich diese stärker erwärmen als die tiefer liegenden. Es bildet sich daher bald (Juni oder Juli) eine Temperaturkurve mit steilem Abfall von der Oberfläche zur 'Tiefe, also eine deutliche Schichtung. Die Wassermasse ist stabil, es herrscht die Sommerstagnation. Das Gebiet des plötzlichen steilen Temperaturabfalles bezeichnet man als Sprungschicht oder Metalimnion, die darüber liegende, thermisch nicht oder schwach geschichtete Wassermasse als Epilimnion und die unterhalb der Sprungschicht ruhende als Hypolimnion. Die Sprungschicht stellt also die Grenze der Ausbreitung der von der Oberfläche ausgehenden Austauschströme dar und scheidet die Wassermassen in zwei in ihrem Verhalten grundsätzlich verschiedene Teile (RutTNER, 1940). Das Epilimnion wird infolge der turbulenten Strömungen in ständiger Zirkulation gehalten, in der Sprungschicht und im Hypolimnion dagegen sind solche Konvektionsströmungen auf ein Minimum reduziert. Die Sprungschicht stellt also eine Sperre nach oben dar. Im Laufe des Spätsommers beginnen die Schichten der Oberfl̈̈che sich abzukühlen, werden spezifisch schwerer, und die Folge ist eine zirkulare Konvektionsströmung, die Sommerteilzirkulation. Nach und nach erfaßt diese Konvektionsströmung auch die tieferen und zuletzt die tiefsten Wasserschichten, so daß die ganze Wassermasse des Sees in Zirkulation gerät, man spricht daher von Herbstpollzirkulation. Sie dauert so lange, bis mit Beginn der kalten Jahreszeit die Wasseroberfläche sich unter $4^{\circ} \mathrm{C}$ abkühlt, demnach spezifisch leichter wird und die Wassermasse zur Ruhe kommt. Es ist die Zeit der Winterstagnation. Nach dem Temperaturminimum erwärmen sich wieder die obersten Wasserschichten, werden schwerer, und analog der Sommerteilzirkulation tritt eine Winterteilzirkulation in Funktion. Erreicht diese den Seegrund, so wird sie abgelöst von der schon besprochenen Frühjahrsvollzirkulation.

In den Seen der gemäßigten Zone herrscht also jahraus, jahrein am Grunde eine gleichmäßig tiefe Temperatur von 4 bis $7^{\circ} \mathrm{C}$. Diese niedere Tiefentemperatur hat, wie sich RUTTNER (I93I) ausdrückt, eine konservierende «Kühlschrankwirkung» auf die Lebewesen. 
Anders verhält es sich in den Seen der rein tropischen Zone. Hier herrscht das ganze Jahr hindurch eine mehr oder weniger konstant hohe Temperatur. Die Frage, ob sich auch in solchen Seen eine stabile thermische Schichtung ausbilde, wurde bereits von Downes (I9II) in bejahendem Sinne beantwortet, da er in Wasserreservoiren in Panama in $3 \mathrm{~m}$ Tiefe schon eine Temperaturverminderung um einige Zehntelsgrade gegenüber der Oberfläche feststellen konnte. Ferner führten GRAHAM (I929) und WORTHINGTON (I930) bei ihren fischereilichen Untersuchungen am Victoria- und Albert-Nyanza einige Temperaturmessungen durch und fanden maximale Temperaturdifferenzen bis $\mathrm{I}, 6^{\circ} \mathrm{C}$ zwischen Oberfläche und $65 \mathrm{~m}$ Tiefe. RuTTNER hat dann diese Frage durch zahlreiche Messungen in genügend tiefen Seen Sumatras, Javas und Balis weitgehend abgeklärt, das heißt er wies nach, daß sich in den Tropenseen eine ausgesprochene, zeitweise sogar sehr stabile thermische Schichtung mit scharf abgegrenztem Epi-, Meta- und Hypolimnion ausbildet. RUT'TNER stellte dabei folgenden Grundsatz auf: Die Lage der Sprungschicht ist in hohem Maße vom Oberflächenareal des betreffenden Sees abhängig. Bei Seen unter $2 \mathrm{~km}^{2}$ Oberfläche befindet sich die Sprungschicht in Tiefen zwischen 4 und $8 \mathrm{~m}$; bei den Seen mit großer Oberfläche (bis $100 \mathrm{~km}^{2}$ ) in Tiefen von $\mathrm{I} 2$ bis $\mathrm{I} 5 \mathrm{~m}$ und im mehr als Iooo $\mathrm{km}^{2}$ großen Tobasee etwa in $30 \mathrm{~m}$ Tiefe. RUTTNER hebt also ausdrücklich den Zusammenhang zwischen Oberflächenareal und Temperaturschichtung hervor.

Dieser Zusammenhang dürfte klar aus folgender Überlegung hervorgehen : Die eingestrahlte Sonnenwärme wird zum größten'Teil in den ersten paar Zentimetern der Wasseroberfläche absorbiert. Durch Windwirkung werden diese oberflächlich stark erwärmten Wassermassen in größere Tiefen verfrachtet. Je größer das Oberflächenareal, desto größer ist auch die der Windwirkung ausgelieferte Angriffsfläche und um so stärker tritt demnach auch die Durchmischungskraft des Windes in Erscheinung und drückt die Sprungschicht nach unten.

In scheinbarem Gegensatz zu dieser durch RUTTNERs Beobachtungen gestützten Theorie stehen die Feststellungen Damas (I939). Dieser Forscher fand große afrikanische Seen (l'Albert, le Rodolphe) obne jegliche Temperaturschichtung. Als Erklärung führt Damas die geringe Tiefe $(45 \mathrm{~m})$ dieser Seen an, die gar keine Schichtung auf kommen lasse, mit andern Worten, daß das Verhältnis Oberfläche:Tiefe so groß und demnach die Windwirkung so stark sei, daß es zu keiner Schichtbildung komme. DAMAS stellt die Behauptung auf, daß es in großen Seen mit weniger als so $\mathrm{m}$ Tiefe zu keiner thermischen Schichtung komme. 
Wir können dieser Ansicht nur teilweise beipflichten. Es ist klar, je seichter ein See ist, desto höher liegt die Sprungschicht und um so rascher kann die thermische Schichtung zerstört werden. Wenn es aber in den nur 5 bis $6 \mathrm{~m}$ tiefen Amazonasseen zu scharf ausgeprägten Temperaturschichtungen kommen kann, wie wir gleich sehen werden, so werden sich auch in afrikanischen Tropenseen von geringer Tiefe solche Schichtungen ausbilden, falls einigermaßen windstille Tage vorausgesetzt werden können; nur werden diese Schichtungen sehr leicht gestört durch geringe Windwirkungen, und es wird dann vom Zufall abhängen, ob man gerade eine solch kurzdauernde Stagnationsperiode untersuchungsmäßig erfassen kann. Solche Beispiele fanden wir bei der Untersuchung der amazonischen Seen mehrere.

In Tabelle 3 sind einige Temperaturmessungen in amazonischen Seen dargestellt, die wir kurz diskutieren wollen, um namentlich die prinzipiellen Unterschiede der Verhältnisse tropischer Seen gegenüber denjenigen der temperierten aufzuzeigen.

Während in den temperierten Seen im Laufe des Jahres die Oberflächentemperatur zwischen o und etwa $20^{\circ} \mathrm{C}$ schwankt, ist diejenige der Tropenseen nur ganz geringfügigen Änderungen unterworfen. Im Lago Jurucui zum Beispiel beträgt diese Schwankung kaum $2^{\circ} \mathrm{C}$. Die Durchschnittstemperatur des Oberflächenwassers sämtlicher untersuchten Amazonasseen betrug 28,6 $6^{\circ}$. Die extremen Werte waren 24,6 $6^{\circ} \mathrm{C}$ (Lago do Caxias) und $32,0^{\circ} \mathrm{C}$ (Lago Caxambú). Bei dieser Betrachtung bleibt die nächtliche Abkühlung allerdings unberücksichtigt; sie kann jedoch in unserem Falle vernachlässigt werden, denn auch die Abkühlung der umgebenden Luft ist in unserem Untersuchungsgebiet ebenfalls sehr geringfügig, wie wir im Kapitel Klima ausf ührten, weil die mit Wasserdampf fast stets gesättigte Luft und der dichte Mantel der umgebenden Urwälder eine nächtliche Wärmeausstrahlung in großem Ausmaße verunmöglichen. Dagegen sind die Nächte in den von RUTTNER untersuchten hochgelegenen vulkanischen Gebieten so kühl, daß in jenen Tropenseen nachts leichte Temperaturinversionen stattfinden konnten. Außerdem ist zu bemerken, daß wir bei unseren Untersuchungen nicht einen vollständigen Jahreszyklus erfassen konnten. Es fehlen uns die Monate Juni bis Oktober. Doch wir können annehmen, daß sich in diesen Monaten die Temperaturverhältnisse der Seen in Prinzip nicht stark ändern, da ja während des ganzen Jahres in diesen Gebieten eine gleichmäßig hohe Temperatur herrscht.

Es zeigte sich, daß selbst diese so seichten amazonischen Seen zeitweise deutlich ausgeprägte thermische Schichtungen aufweisen. Greifen wir ein 
Tabelle 3

Temperaturen der Seen in Grad Celsius

Lago Furucui und Zuflüsse

\begin{tabular}{|c|c|c|c|c|c|c|c|}
\hline In & $\begin{array}{c}\text { 13. Nov. } \\
1947\end{array}$ & $\begin{array}{c}2 . \text { Februar } \\
1948\end{array}$ & $\begin{array}{c}12 . \text { Februar } \\
1948\end{array}$ & $\begin{array}{c}14 . \text { Februar } \\
1948\end{array}$ & $\begin{array}{c}4 . \text { März } \\
1948\end{array}$ & $\begin{array}{c}30 . \text { März } \\
1948\end{array}$ & $\begin{array}{c}17 . \text { Mai } \\
1948\end{array}$ \\
\hline 0 & 27,8 & 28,1 & 28,5 & 28,7 & 28,3 & 28,6 & 29,2 \\
1 & & & & 28,7 & 28,3 & 28,5 & 28,9 \\
2 & 27,5 & \multirow{2}{*}{28,4} & 28,7 & 28,3 & 28,4 & 28,7 \\
3 & & & & 28,5 & 28,1 & 28,2 & 27,8 \\
4 & & 28,0 & \multirow{2}{*}{27,3} & 27,7 & 27,6 & 27,9 & 27,7 \\
4,5 & & & & & 27,2 & & 27,5 \\
5 & & & & & & 27,6 & 27,5 \\
\hline
\end{tabular}

\begin{tabular}{|c|c|c|c|}
\hline Zuflüsse & 15. November 1947 & 12. Februar 1948 & 19. Mai 1948 \\
\hline Igarapé Tento & 29,3 & 27,9 & 29,0 \\
Igarapé Grande & 29,2 & 28,1 & 29,0 \\
\hline
\end{tabular}

Lago Muretá

\begin{tabular}{|l|c|c|c|c|}
\hline mi & $\begin{array}{c}\text { 2. Dezember } \\
1947\end{array}$ & $\begin{array}{c}20 . \text { Februar } \\
1948\end{array}$ & $\begin{array}{c}\text { 1. April } \\
1948\end{array}$ & $\begin{array}{c}25 . \text { Mai } \\
1948\end{array}$ \\
\hline 0 & 30,5 & 28,8 & 29,9 & 29,7 \\
0,5 & 30,0 & & 29,7 & 29,5 \\
1 & & & 29,7 & 29,4 \\
3 & & & 29,7 & 29,3 \\
4 & & & 29,7 & 29,3 \\
5 & & & 29,7 & 29,1 \\
\hline
\end{tabular}

Lago Caxambú

\begin{tabular}{|c|c|c|c|c|}
\hline $\mathrm{m}$ & $\begin{array}{c}24 . \text { November } \\
\mathbf{1 9 4 7}\end{array}$ & $\begin{array}{c}20 . \text { Februar } \\
\mathbf{1 9 4 8}\end{array}$ & $\begin{array}{c}31 . \text { März } \\
1948\end{array}$ & $\begin{array}{c}20 . \text { Mai } \\
1948\end{array}$ \\
\hline 0 & 32,0 & 29,0 & 30,1 & 30,1 \\
1 & & & & 29,9 \\
2 & & & & 29,8 \\
3 & & & 29,7 & 29,8 \\
4,5 & & & & 29,7 \\
5,5 & & & & 29,6 \\
\hline
\end{tabular}




\section{Lago Salgado}

\begin{tabular}{|c|c|c|}
\hline $\mathrm{m}$ & $\begin{array}{c}\text { Cabeçeira do Molha } \\
\text { 22. April 1948 }\end{array}$ & $\begin{array}{c}\text { Cabeçeira do Boi } \\
\text { 13. April 1948 }\end{array}$ \\
\hline 0 & 30,0 & 28,8 \\
1 & 29,8 & 28,5 \\
2 & 28,6 & 28,3 \\
3 & 28,4 & 27,5 \\
3,5 & 27,7 & \\
\hline 4,5 & 27 & \\
\hline
\end{tabular}

Lago Alter do Chão (1о. Dezember 1947)

\begin{tabular}{|c|c|c|c|}
\hline $\mathrm{m}$ & Süd-Cabeçeira & Seemitte & Ost-Cabeçeira \\
\hline 0 & 28,0 & $\begin{array}{l}31,3 \\
30,3\end{array}$ & 31,0 \\
\hline
\end{tabular}

\begin{tabular}{|c|c|c|c|c|}
\hline $\mathrm{m}$ & $\begin{array}{c}\text { Lago Pauxis } \\
\text { 25. Juli 1947 }\end{array}$ & $\begin{array}{c}\text { Lago Verde } \\
\text { 27. Juli 1947 }\end{array}$ & $\begin{array}{c}\text { Lago do Caxias } \\
\text { 31. Dezember 1947 }\end{array}$ & $\begin{array}{c}\text { Lago do Tracoá } \\
\text { 20. April 1948 }\end{array}$ \\
\hline $\begin{array}{l}1,5 \\
2 \\
3\end{array}$ & $\begin{array}{l}31,0 \\
30,5\end{array}$ & 26,4 & 24,6 & 27,2 \\
6 & 28,8 & 26,1 & 24,6 & 26,6 \\
\hline
\end{tabular}

\begin{tabular}{|c|c|c|c|c|c|}
\hline \multirow[b]{2}{*}{$\mathrm{m}$} & \multicolumn{2}{|c|}{ Lago Curuçá } & \multirow{2}{*}{$\begin{array}{l}\text { L. Timbó } \\
\text { 11. Januar } \\
1948\end{array}$} & \multirow{2}{*}{$\begin{array}{l}\text { L. Curí } \\
\text { 9. Januar } \\
1948\end{array}$} & \multirow{2}{*}{$\begin{array}{c}\text { L.Maritima } \\
\text { 19. Februar } \\
1948\end{array}$} \\
\hline & $\begin{array}{c}\text { Aningateil } \\
\text { 1. Januar } \\
1948\end{array}$ & $\begin{array}{l}\text { Victoriateil } \\
\text { 3. Januar } \\
1948\end{array}$ & & & \\
\hline 0 & \multirow{4}{*}{$\begin{array}{l}27,2 \\
25,4\end{array}$} & 26,6 & \multirow[t]{4}{*}{28,6} & 29,8 & \multirow[t]{4}{*}{25,5} \\
\hline 1 & & & & 29,5 & \\
\hline 1,5 & & 258 & & 28.9 & \\
\hline 3,5 & & & & 28,2 & \\
\hline
\end{tabular}

\section{Lago Fruçanga}

\begin{tabular}{|c|c|c|c|}
\hline $\mathrm{m}$ & 1. Dezember 1947 & 21. Februar 1948 & 26. Mai 1948 \\
\hline 0 & 26,3 & 27,4 & 26,3 \\
\hline
\end{tabular}


besonders eindrückliches Bild dieser Schichtungsverhältnisse unter den zahlreichen Beispielen heraus (Abb. 8). Im zu jenem Zeitpunkt $5,5 \mathrm{~m}$ tiefen Lago Jurucui fanden wir am I7. Mai 1948 eine scharf abgegrenzte Temperaturschichtung mit den charakteristischen Zonen Epi-, Meta-, Hypolimnion, wobei sich die Sprungschicht in einer Tiefe von 2 bis $3 \mathrm{~m}$ befand. Auch an den meisten übrigen Untersuchungstagen befand sie sich in dieser Tiefe. Zeitweise kann sie jedoch auf 3 bis $4 \mathrm{~m}$ heruntergedrückt

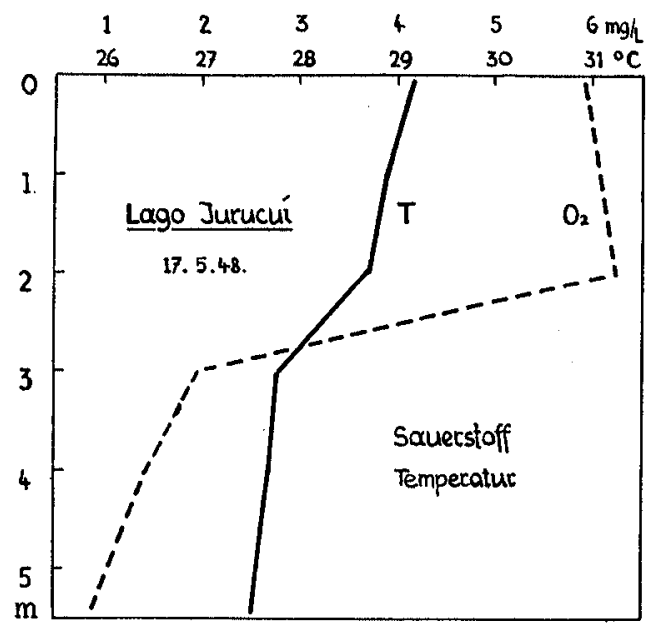

Abb. 8

werden (zum Beispiel am I4. Februar 1948), durch geringe Abkühlung der Luft oder wenn Winde in Erscheinung treten. Es ist jedoch in diesen Seen auch möglich, daß sich die Sprungschicht schon in Tiefen von $\mathrm{I}$ bis $2 \mathrm{~m}$ ausbildet, wie das Beispiel des Lago Salgado am 22. April I948 zeigt. Es hängt weitgehend vom Zufall $a b$, ob man eine solch hochgelegene Sprungschicht erfassen kann, denn eine geringe Störung - sei es Wind oder leichte Abkühlung - reicht aus, um sie nach unten zu drücken oder sie überhaupt ganz zu verwischen.

So können wir also die von RUTTNER aufgestellten Gesetzmäßigkeiten über die Höhe der Sprungschichtbildungen in tropischen Seen in dem Sinne erweitern, als wir feststellen können, daß sich in Tropenseen unter 
$2 \mathrm{~km}^{2}$ Oberfläche die Sprungschicht schon in Tiefen von $\mathrm{I}$ bis $3 \mathrm{~m}$ ausbilden kann.

In den amazonischen Seen treffen wir also zu gewissen Zeiten ähnliche Verhältnisse an, wie wir sie in den temperierten Seen zur Zeit der Sommerstagnation finden, mit dem Unterschied,

I. daß das ganze Temperaturgefälle in den amazonischen Seen in einen rund $20^{\circ} \mathrm{C}$ höheren Bereich verschoben ist,

2. daß die Sprungschicht viel höher liegt als in den temperierten Seen,

3. daß sich die Sprungschicht in den amazonischen Seen in einem Temperaturbereich von 28 bis $30^{\circ} \mathrm{C}$ befindet, während sie in den temperierten Seen zwischen $10^{\circ}$ und $15^{\circ} \mathrm{C}$ liegt,

4. daß der Unterschied zwischen Oberflächen- und Tiefentemperatur in den amazonischen Seen viel geringer ist als in den temperierten Seen. Die maximalen Temperaturgefälle zwischen Oberfläche und Tiefe, die wir in den amazonischen Seen feststellen konnten, sind folgende:

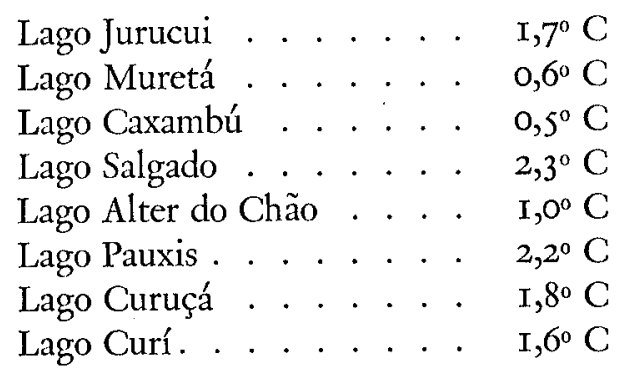

Das höchste Temperaturgefälle betrug also $2,3^{\circ} \mathrm{C}$ (Lago Salgado). RuTTNER stellte bei einem See in Sumatra ein solches von $5,5^{\circ} \mathrm{C}$ fest (Ranu Klindungan) und bemerkt dazu, daß dieser Wert wohl dem im eigentlichen Tropengebiet erreichbaren Maximum entsprechen werde. Auch JUDAY (I915), LENZ (1937) und andere bestätigten diese geringen Temperaturgef älle tropischer Seen. In den temperierten Seen beträgt es $15^{\circ}$ oder mehr.

Bei dieser Gelegenheit seien kurz noch die Stabilitätsverhältnisse der Seen erwähnt. SCHMIDT (I9I5) bezeichnet als Stabilität der Schichtung denjenigen Arbeitsaufwand, der erforderlich ist, eine bestehende thermische Schichtung zu zerstören, das heißt den geschichteten Zustand der Wassermassen in einen homogenen umzuwandeln. RuTTNER (I940) legt diesem Begriff der Stabilität eine besondere Wichtigkeit für die Limnologie bei, weil die Stabilität ein Maß für den Widerstand ist, den eine geschich- 
tete Wassermasse der Durchmischungskraft des Windes entgegensetzt, das heißt ein Maß für den Grad jener Absperrung des Hypolimnions gegen das Epilimnion.

Auf den ersten Blick scheint es uns, daß die soeben besprochenen sehr geringen Temperaturgefälle in den amazonischen Seen nicht zu sehr stabilen Schichtungen führen können. Wenn wir jedoch in Betracht ziehen, daß die Änderung des spezifischen Gewichtes zwischen $29^{\circ}$ und $30^{\circ} \mathrm{C}$ rund $37 \mathrm{mal}$ größer ist als zwischen $4^{\circ}$ und $5^{\circ} \mathrm{C}$, so kommen wir zum Schluß, $\mathrm{da} \beta$ in einem Amazonassee in der Sprungschicht (Temperaturbereich 28 bis $30^{\circ} \mathrm{C}$ ) eine rund dreimal größere Stabilität herrschen muß als in der Sprungschicht eines temperierten Sees (Temperaturbereich Io $^{\circ}$ bis $15^{\circ} \mathrm{C}$ ) bei gleicbem Temperaturunterschied! RUTTNER (I93I) berechnete für einige Seen Javas, Sumatras und Balis die Stabilität und fand, daß trotz der geringen Temperaturgefälle die Stabilitäten Werte erreichen können, die denjenigen der temperierten Seen zur Zeit der Sommerstagnation nahekommen.

Mit zahlenmäßigen Angaben der Stabilitätsverhältnisse der amazonischen Seen können wir leider nicht aufwarten, weil dafür viel zu wenig Temperaturmeßresultate vorliegen und weil ein entsprechendes Kartenmaterial und damit auch die Unterlagen, das heißt genaue Ausmessungen der Seen, für eine Berechnung fehlen.

Ein besonders auffallendes Merkmal der amazonischen Seen - wohl auch der übrigen Tropenseen ist die Unbeständigkeit der Schichtungsverhältnisse. So stellten wir zum Beispiel am 25.Juli 1947 im Lago Pauxis (siehe Abb. 9, oben) eine deutlich ausgeprägte Schichtung fest, mit Sprungschicht $z$ wischen $\mathrm{I}$ und $2 \mathrm{~m}$ und einem Temperaturgefälle von $2,2^{\circ} \mathrm{C}$. Diese Schichtung, die sich damals auch im pH-Wert ausdrückte, dürfte dadurch zustande gekommen sein, daß der eine $\mathrm{Zu}-$ fluß des Sees (Jgarapé Engenho) deutlich basischer war, mit kälterem Wasser; dieses sank im Lago Pauxis in die Tiefe, blieb dort liegen und bewirkte die Schichtung. Der andere Zufluß (Abfluß des Lago Verde) mit einem tieferen $\mathrm{pH}$-Wert und wärmerem Wasser schichtete sich an der
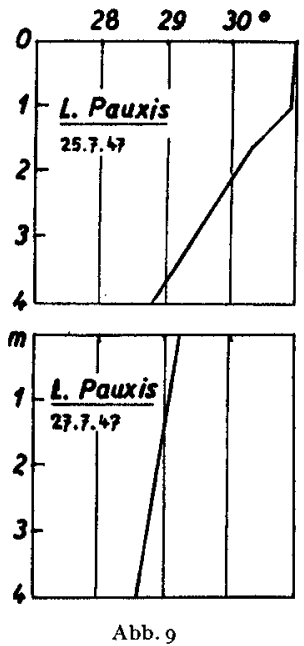
Oberfläche auf. Zwei Tage später, am 27. Juli I947 (Abb. 9, unten) war diese Schichtung fast vollkommen verwischt (Gefälle $0,7^{\circ} \mathrm{C}$ ). Beim 
Lago Jurucui fanden wir ähnliche Verhältnisse vor. Deutliche Schichtungen wechselten ab mit Zirkulationsperioden. Durch anhaltend schönes Wetter mit starker Erwärmung der Wasseroberfläche entstehen in kurzer Zeit Schichtungen, die beim nächsten Gewitter wieder zerstört werden können. In diesen Fällen ist jedoch nicht die Windwirkung der zerstörende Faktor, sondern die momentane Abkühlung.

$\mathrm{Zu}$ ähnlichen Resultaten gelangten vON BRANDT (1936) und WEIMANN (I933) bei der Untersuchung von kleinen Tümpeln. Sie stellten fest, daß bei Teichen von weniger als $2 \mathrm{~m}$ Tiefe der tägliche Wechsel von Homo-

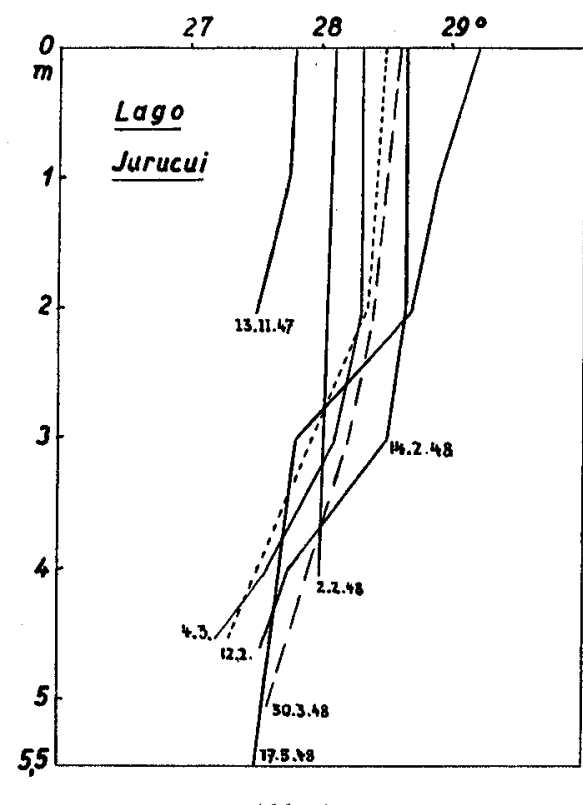

Abb. 10

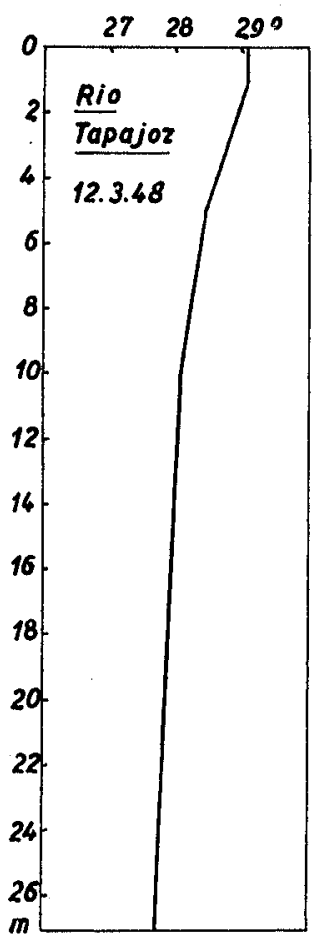

Abb. 11

thermie und Stabilität charakteristisch ist. Durch wenige kühle Nächte mitten im Hochsommer kann Homothermie hervorgerufen werden.

Aus den genannten Beispielen geht deutlich hervor, wie verfehlt es ist, aus Einzelmessungen irgendwelche Schlußfolgerungen über die Schichtungsverhältnisse in tropischen Seen zu ziehen, denn wir haben es hier 
nicht mit gesetzmäßig verlaufenden, durch die Jahreszeiten gesteuerten Schichtungsperioden zu tun wie in den temperierten Seen der gemäßigten Zone, sondern mit vollkommen vom Zufall bzw. von der momentan herrschenden Witterung abhängigen Schichtungsverhältnissen. Es folgt daraus, daß wir aus den Temperaturjahreskurven der amazonischen und sicher auch der anderen tropischen Seen kein «Seejahr» herauslesen können, wie wir dies von den temperierten Seen her gewohnt sind.

Einige Temperaturprofile aus dem Lago Jurucui in Abbildung ro sollen das Gesagte veranschaulichen.

Ein überraschendes Ergebnis zeigten die Temperaturmessungen im Rio Tapajoz, einem der größten südlichen Zuflüsse des Amazonas. In der Nähe von Santarém (Zusammenfluß von Tapajoz und Amazonas, siehe Karte) besitzt der Tapajoz eine Tiefe von nahezu $30 \mathrm{~m}$ und eine Fließgeschwindigkeit von etwa $200 \mathrm{~m} / \mathrm{h}$. Trotzdem stellten wir am I2. März I948 eine deutliche Temperaturschichtung fest mit einem Gefälle von $\mathrm{I}, 4^{\circ} \mathrm{C}$ und einer wenn auch nur andeutungsweise vorhandenen Sprungschicht zwischen 2 und $4 \mathrm{~m}$ Tiefe (siehe Abb. II). In thermischer und, wie wir später sehen werden, auch in biologischer Hinsicht können sich also Ströme wie Seen verhalten, das heißt, die Begriffe «See» und «Fluß» verwischen sich hier vollkommen.

\section{b) Der Sauerstoffhaushalt}

In Tabelle 4 sind die Resultate der Sauerstoffbestimmungen einiger amazonischer Seen dargestellt (in Milligramm pro Liter und in Prozent der Sättigung) und in Abbildung 12 einige Sauerstoffprofile des Lago Jurucui in verschiedenen Monaten. Die Sättigung wurde aus dem absoluten Sauerstoffgehalt berechnet, unter Berücksichtigung der Temperatur und auf Meereshöhe bezogen. Nicht berücksichtigt wurde der hydrostatische Druck.

Überraschende Resultate weisen unsere Sauerstoffbestimmungen nicht auf. Sie fügen sich ins allgemeine Schichtungsbild, das durch die Thermik und, wie wir später noch sehen werden, durch die biologischen Verhältnisse vorgezeichnet ist. Sie bestätigen im allgemeinen die Resultate RutTNERS. Wir hatten die Möglichkeit, ein und denselben Tropensee während einer längeren Zeitspanne zu beobachten, so daß wir einen wertvollen Einblick in die jahreszeitlichen Abläufe gewinnen konnten.

Ein Blick auf Abbildung I2 zeigt uns, daß die Sauerstoffkurven in genau gleichem Sinne verlaufen wie die Temperaturkurven. An den Tagen mit 
Tabelle 4

\section{Sauerstoff in mg/1 und Sättigung}

Lago Furucui und Zuflüsse

\begin{tabular}{|c|c|c|c|c|c|c|}
\hline $\mathrm{m}$ & $\begin{array}{l}\text { 13. Nov. } \\
1947\end{array}$ & $\begin{array}{c}\text { 2. Februar } \\
1948\end{array}$ & $\begin{array}{l}\text { 12. Februar } \\
1948\end{array}$ & $\begin{array}{c}\text { 4. März } \\
1948\end{array}$ & $\begin{array}{c}\text { 30. März } \\
1948\end{array}$ & $\begin{array}{l}\text { 17. Mai } \\
1948\end{array}$ \\
\hline 0 & $\begin{array}{c}7,04 \\
89,90 \%\end{array}$ & $\begin{array}{c}6,77 \\
86,90 \%\end{array}$ & $\begin{array}{c}6,83 \\
88,40 \%\end{array}$ & $\begin{array}{c}6,77 \\
87,20 \%\end{array}$ & $\begin{array}{c}9,05 \\
117,20 \%\end{array}$ & $\begin{array}{c}5,93 \\
77,70 \%\end{array}$ \\
\hline 2 & $\begin{array}{c}7,04 \\
89,30 \%\end{array}$ & & $\begin{array}{c}6,60 \\
85,20 \%\end{array}$ & $\begin{array}{c}6,50 \\
83,70 \%\end{array}$ & $\begin{array}{c}8,40 \\
108,50 \%\end{array}$ & $\begin{array}{c}6,28 \\
81,50 \%\end{array}$ \\
\hline 3 & & & & $\begin{array}{c}4,70 \\
60,30 \%\end{array}$ & $\begin{array}{c}7,00 \\
90,00 \%\end{array}$ & $\begin{array}{c}2,07 \\
26,40 \%\end{array}$ \\
\hline 4 & & $\begin{array}{c}6,36 \\
81,40 \%\end{array}$ & & & & $\begin{array}{c}1,45 \\
18,50 \%\end{array}$ \\
\hline 4,5 & & & $\begin{array}{c}4,25 \\
53,90 \%\end{array}$ & $\begin{array}{c}3,63 \\
45,70 \%\end{array}$ & & \\
\hline 5 & & & & & $\begin{array}{c}5,27 \\
67,10 \%\end{array}$ & \\
\hline \multirow[t]{2}{*}{5,5} & & & & & & $\begin{array}{c}0,91 \\
11,60 \%\end{array}$ \\
\hline & $\begin{array}{c}\text { 15. Nov. } \\
1947\end{array}$ & & $\begin{array}{c}\text { 12. Februar } \\
1948\end{array}$ & & & $\begin{array}{l}\text { 19. Mai } \\
1948\end{array}$ \\
\hline Jg.Tento & $\begin{array}{c}7,77 \\
101,90 \%\end{array}$ & & $\begin{array}{c}5,59 \\
71,40 \%\end{array}$ & & & $\begin{array}{c}5,31 \\
69,30 \%\end{array}$ \\
\hline Jg.Grande & & & $\begin{array}{c}6,21 \\
79,70 \%\end{array}$ & & & $\begin{array}{c}5,12 \\
66,80 \%\end{array}$ \\
\hline
\end{tabular}

Lago Muretá

\begin{tabular}{|c|c|c|c|c|}
\hline $\mathrm{m}$ & $\begin{array}{c}\text { 2. Dezember } \\
1947\end{array}$ & $\begin{array}{c}\text { 20. Februar } \\
1948\end{array}$ & $\begin{array}{c}\text { 1. April } \\
1948\end{array}$ & $\begin{array}{c}25 . \mathrm{Mai} \\
1948\end{array}$ \\
\hline 0 & 7,42 & 9,01 & 10,41 & 7,85 \\
& $99,50 \%$ & $117,20 \%$ & $138,20 \%$ & $103,80 \%$ \\
5 & & & 8,95 & \\
& & & $118,30 \%$ & \\
5,5 & & & & 7,55 \\
& & & & $98,80 \%$ \\
\hline
\end{tabular}


Lago Caxambú

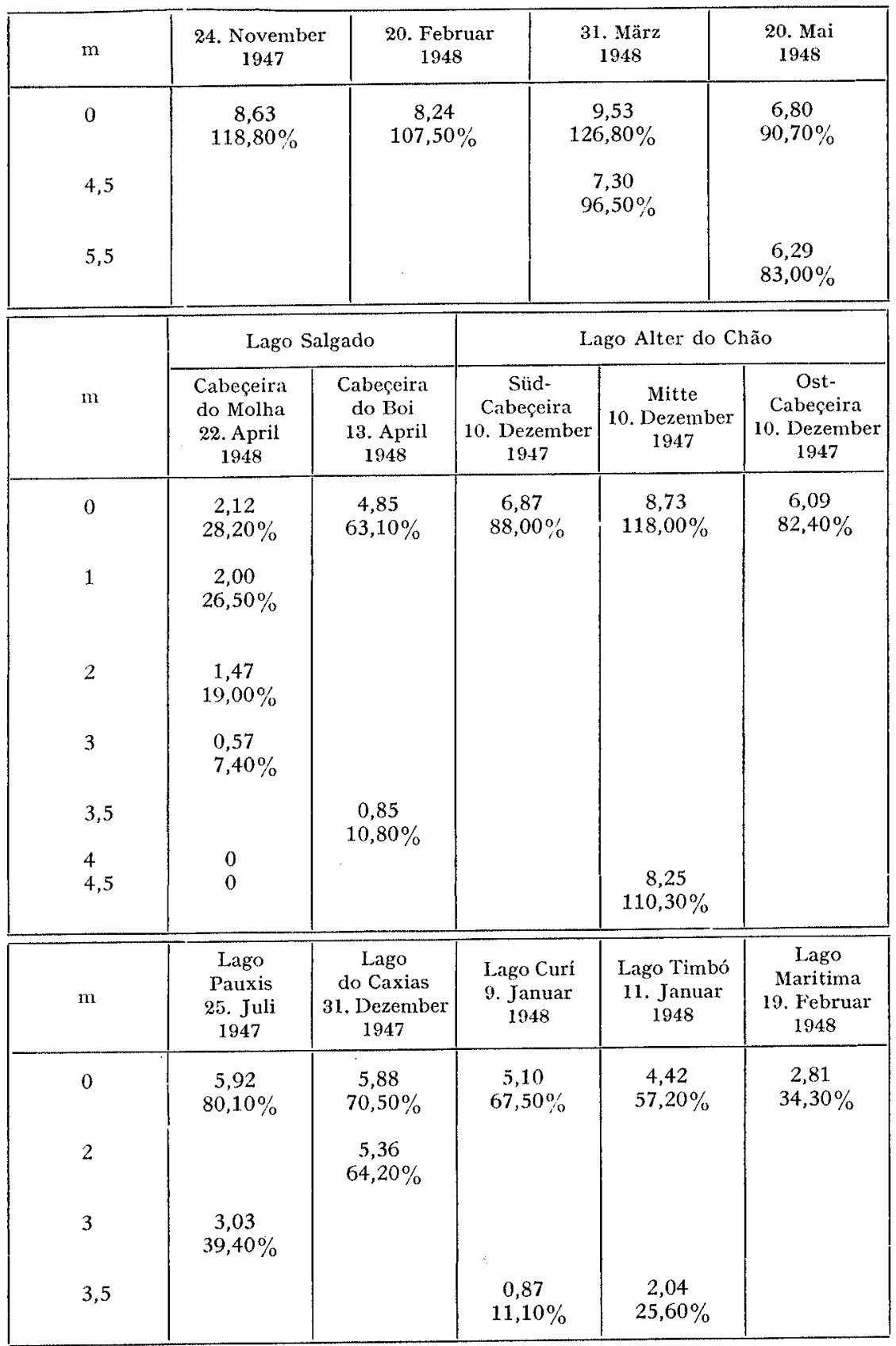




\begin{tabular}{|c|c|c|c|c|c|}
\hline \multirow[b]{2}{*}{$\mathrm{m}$} & \multicolumn{2}{|c|}{ Lago Curuçá } & \multicolumn{3}{|c|}{ Lago Jruçanga } \\
\hline & $\begin{array}{l}\text { Aningateil } \\
\text { 1. Januar } \\
1948\end{array}$ & $\begin{array}{l}\text { Victoria- } \\
\text { teil } \\
\text { 3. Januar } \\
1948\end{array}$ & $\begin{array}{c}\text { 1. Dezember } \\
1947\end{array}$ & $\begin{array}{l}\text { 21. Februar } \\
1948\end{array}$ & $\begin{array}{l}\text { 26. Mai } \\
1948\end{array}$ \\
\hline 0 & $\begin{array}{c}4,12 \\
52,00 \%\end{array}$ & $\begin{array}{c}2,05 \\
25,50 \%\end{array}$ & $\begin{array}{c}9,73 \\
120,70 \%\end{array}$ & $\begin{array}{c}6,02 \\
76,30 \%\end{array}$ & $\begin{array}{c}0,98 \\
12,10 \%\end{array}$ \\
\hline 1,5 & $\begin{array}{c}2,04 \\
24,80 \%\end{array}$ & & & & \\
\hline 2 & & $\begin{array}{c}0,87 \\
10,60 \%\end{array}$ & & & \\
\hline
\end{tabular}

ausgeprägter Temperaturschichtung finden wir auch eine solche des Sauerstoffs vor, und sobald die thermische Schichtung gestört wird, verschwindet die Sauerstoffschichtung. Tage mit starker Schichtung und Sauerstoffschwund in der Tiefe wechseln ab mit Tagen ohne oder mit geringem Sauerstoffgefälle. Wir können Seen mit kaum nennenswerter Schichtung antreffen, dann wieder solche mit starkem Sauerstoffabfall in der Tiefe. Es gelten also auch hier die gleichen Gesetze der Unbeständigkeit der Schichtung wie bei der Temperatur.

Auffallend waren zum Beispiel die Resultate im Lago Salgado am 22. April 1948. Das Oberflächenwasser wies einen Sauerstoffgehalt von nur $2, \mathrm{Img} / \mathrm{l}$ und $28,2 \%$ Sättigung auf. In $3 \mathrm{~m}$ Tiefe betrug der Gehalt noch $0,7 \mathrm{mg} / \mathrm{l}$, um in $4 \mathrm{~m}$ Tiefe aufo abzusinken. Wie können wir uns eine solche Sauerstoffarmut des Oberflächenwassers erklären? Einerseits stellten wir an diesem Tage in den oberflächlichen Wasserschichten eine sehr reiche Entfaltung von Zooplankton fest (Daphnien, Bosminen), mit verhältnismäßig geringen Mengen an autotrophem Plankton. Schöpfte man mit einem Glas etwas Oberflächenwasser heraus, so wimmelte es von Krustazeen (große Formen). Die Sauerstoffzehrung infolge dieser Zooplanktonentwicklung muß also schon sehr groß gewesen sein. Anderseits wissen wir, daß die Schichtungsverhältnisse in den amazonischen Seen sehr unbeständig sind und das Tiefenwasser zeitweise äußerst sauerstoffarm ist. So können wir uns vorstellen, daß wir am 22. April gerade jenen Moment erwischt haben, wo sauerstoffarmes Tiefenwasser durch Konvektionsströmungen heraufgebracht wurde und, unterstützt durch die Zooplanktonentfaltung, zu diesem niederen Gehalt an Sauerstoff im Oberflächenwasser führte. Es stellt sich jedoch die Frage, ob nicht sogar die starke Entfaltung 
des Zooplanktons allein genügt hätte, diese intensive Sauerstoffzehrung im Oberflächenwasser herbeizuführen.

Auch RutTNER (I93I) berichtet von ähnlichen Fällen in den Seen des Sundagebietes und betont, daß durch plötzlich einsetzende Zirkulationen der Sauerstoffgehalt in den obersten Wasserschichten stark herabgesetzt werden kann, namentlich in Seen mit hochgelegener Sprungschicht, und um solche handelt es sich ja in unserem Falle, wie aus dem Kapitel Temperatur ersichtlich war.

In Abbildung $\mathrm{r}_{3}$ ist der Sauerstoffgehalt einiger Seen (Oberfläche und unmittelbar ob Grund) graphisch dargestellt, um das Gefälle zu veran-

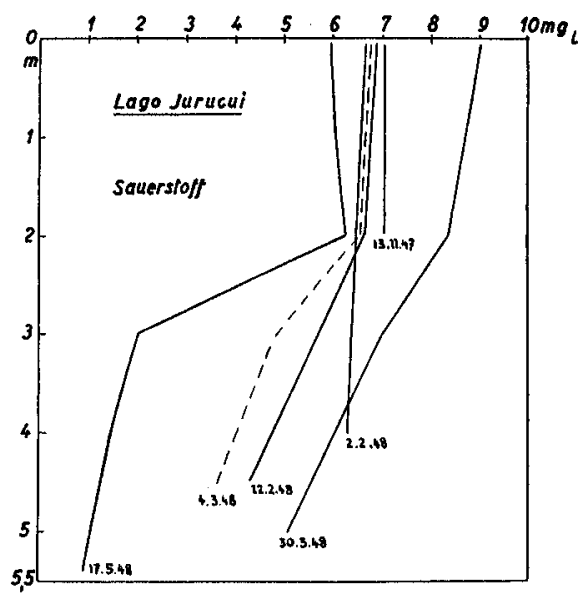

Abb. 12

schaulichen. Irgendwelche gesetzmäßigen Zusammenhänge zwischen Jahreszeit und Sauerstoffschichtung lassen sich nicht feststellen. Es können sowohl in der Regenzeit als auch in der Trockenzeit abwechselnd Schichtungen und Zirkulationen auftreten. In andern tropischen Gebieten, die eine ausgeprägtere jahreszeitliche Periode besitzen als das Amazonasgebiet, werden sich wohl auch die Schichtungsverhältnisse konstanter halten.

Zusammenfassend und in Úbereinstimmung mit den Resultaten anderer Autoren für andere Tropenseen können wir also festhalten, daß sich in den amazonischen Seen allgemein ein starker Sauerstoffmangel in der Tiefe bemerkbar macht, daß aber diese Sauerstoffarmut nicht von längerer Dauer ist, weil entsprechend den durch die Thermik bedingten Zirkulations- 
strömungen das Tiefenwasser bald wieder mit Sauerstoff angereichert werden kann.

Betrachten wir die Sauerstoffkurven in den Abbildungen 8 und I2, so fällt uns auf, daß sie zur Zeit der Stagnation vollkommen denjenigen Kur-
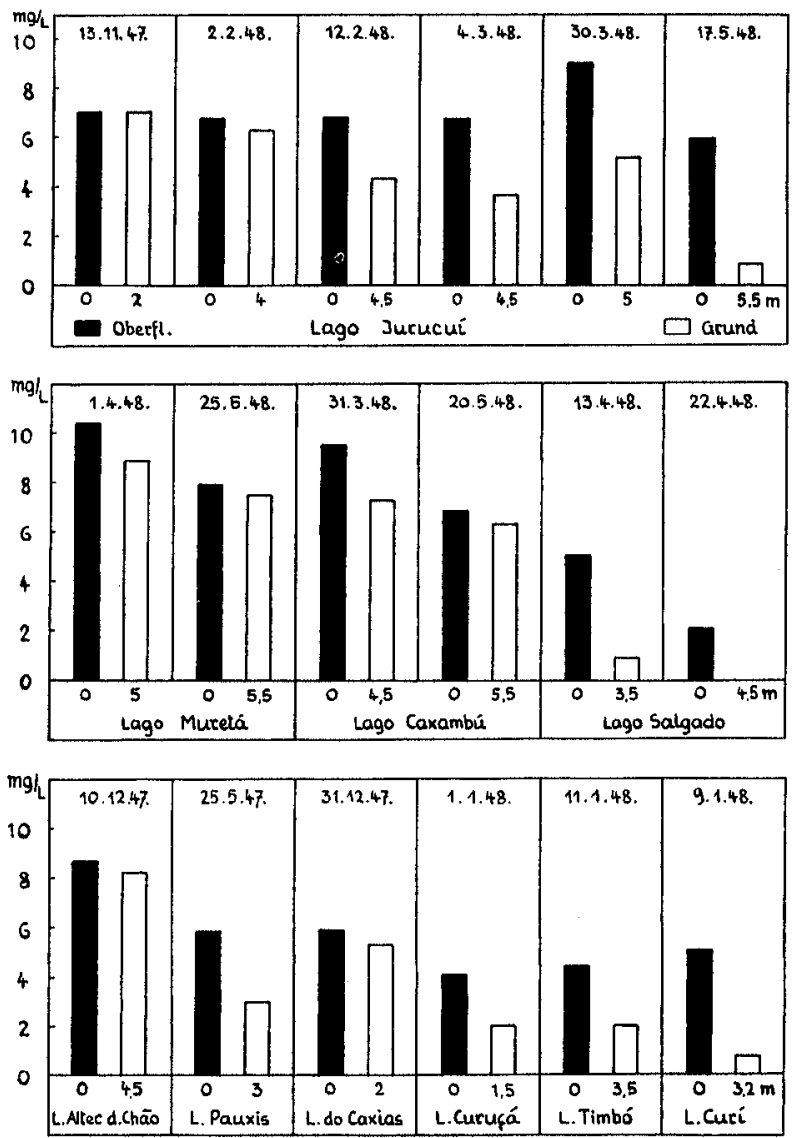

Abb. 13

Sauerstoffgehalt einiger Seen an der Oberfläche und am Grunde.

ven entsprechen, wie sie für eutrophe Seen der gemäßigten Zone üblich sind, also mit steilem Abfall gegen die Tiefe zu (siehe JAAG, I949). Die Sauerstoffkurven der Seen der gemäßigten Zone können wir nach RUTTNER als Indizium für die organische Produktion des betreffenden Sees auf- 
fassen. Je mehr organische Substanz in der trophogenen Schicht produziert und in der tropholytischen Zone abgebaut wird, desto steiler fällt die Sauerstoffkurve gegen die Tiefe $a b$.

Wie wir noch sehen werden, ist die organische Produktion in den meisten amazonischen Seen nicht übermäßig hoch; das Wasser ist arm an Nährstoffen. Von diesem Gesichtspunkt aus können wir also dieses Wasser nicht als eutroph bezeichnen, und trotzdem stellen wir "eutrophe" Sauerstoffkurven fest. Genau dasselbe hat auch RUTTNER (I93I) in den Sundaseen beobachtet und eine allgemein befriedigende Erklärung dazu gegeben, die auch für die amazonischen Seen Geltung hat: Die Sauerstoffzehrung in der tropholytischen Schicht ist einerseits abhängig von der abzubauenden organischen Masse, anderseits aber von der Temperatur, bei der dieser Abbau vor sich geht. Nach dem van't-Hoffschen Gesetz ist die Reaktionsgeschwindigkeit des Abbaues bei einer Erhöhung der Temperatur um $10^{\circ} \mathrm{C}$ rund zwei- bis dreimal größer. In den Seen der gemäßigten Zone mit der niedrigen Tiefentemperatur fällt also nur die Menge der organischen Substanz ins Gewicht. Es herrscht in der Tiefe jener Seen eine «konservierende Kühlschrankwirkung», wie sich RUTTNER treffend ausdrückt. Wenn die organische Produktion jedoch sehr hoch ist (eutrophe Seen), wird eben trotzdem eine große Sauerstoffzehrung im Hypolimnion stattfinden. Anders in den Tropenseen: Die geringe organische Produktion kann hier durch die hohe Temperatur wettgemacht werden! Wir haben gesehen, da $\beta$ die Tiefentemperatur in den amazonischen Seen durchschnittlich um $20^{\circ} \mathrm{C}$ höher ist als in den Seen der gemäßigten Zone. Eine bestimmte Menge organischer Substanz wird also in einem Amazonassee rund sechsmal rascher abgebaut und der Sauerstoff aufgebraucht sein, als zum Beispiel im Zürichsee. RuTT'NER vermutet sogar, daß der größte Teil der in die Tiefe absinkenden abgestorbenen Lebewesen schon während des Absinkens bereits vollständig oder doch teilweise zersetzt werde. Er kommt zu diesem Schluß aus der Beobachtung, daß der Schlamm der von $\mathrm{ihm}$ untersuchten Tropenseen fast ausschließlich ausgefaultes, mineralisiertes Aussehen hatte. Für die Ruttnerschen Tropenseen mit zum Teil sehr großer Tiefe mag dies zutreffen, nicht aber für die seichten Amazonasseen. Wir stellten wiederholt schwefeleisenreichen, schwarzen, nach Schwefelwasserstoff riechenden Faulschlamm fest.

Wir halten also fest, daß auch in den seichten Amazonasseen infolge der hohen Temperatur des Tiefenwassers die Oxydationsvorgänge so rasch verlaufen können, daß die im Hypolimnion vorhandene Sauerstoffmenge in kurzer Zeit aufgebraucht ist. 
Bei den temperierten eutrophen Seen herrscht bekanntlich während der ganzen Dauer der Stagnation in der Tiefe Sauerstoffschwund, der ja erst mit Beginn der neuen Zirkulationsperiode aufgehoben wird. In den amazonischen Seen hingegen kann die Sauerstoffschichtung, genau wie diejenige der Temperatur, durch starke Regengüsse, plötzliche Abkühlung usw. wieder verwischt werden, mit andern Worten: Die Dauer und Periodizität der Schichtung verläuft nicht gesetzmäßig und ist nicht konstant wie bei unsern temperierten Seen, sondern wird durch zufällige Witterungseinflïsse bedingt und wiederholt sich in unregelmäßigen Abständen. Wenige Tage mit starker Sonnenbestrahlung und Bildung einer thermischen Stagnation genügen, um den Sauerstoffschwund in der Tiefe wieder herzustellen.

$\mathrm{Zu}$ ähnlichen Ergebnissen gelangte auch RuTTNER. Er betont, daß der Verlauf der Sauerstoffkurve in den Tropenseen nicht als Indikator der Produktionstypen angesehen werden kann wie bei den temperierten Seen.

Es deuten sich hier bereits die Schwierigkeiten an, die amazonischen Seen in das System der Seetypenlehre einzufügen.

\section{c) Das System Bikarbonat-freie Kohlensäure-pH -Wert}

Neben dem Temperatur- und Sauerstoffregime ist das System Bikarbonat-freie Kohlensäure-pH-Wert für die Limnologie von grundlegender Bedeutung. Vom Bikarbonatgehalt hängt ja weitgehend die Menge freier Kohlensäure im Wasser ab, und beide zusammen bilden das Puffersystem, aus welchem schließlich die Wasserstoffionenkonzentration des Wassers resultiert. Es dürfte deshalb angebracht sein, etwas eingehender darüber zu diskutieren.

Es ist bekannt, daß zwischen dem geologischen Untergrund eines Sees und dem Bikarbonatgehalt des Wassers ein enger Zusammenhang besteht. RUTTNER (193I) stellte diesen Zusammenhang dar, indem er nachwies, daß die Bikarbonatgehalte der Seen in Gebieten mit basischen, an Erdalkalien reichen Laven als Untergrund hohe Werte erreichen, niedere Werte hingegen in Gebieten mit saurem Untergrund.

Im Gegensatz zu den von RuTTNER untersuchten Tropenseen, die im wesentlichen eine mehr oder weniger verdünnte Lösung von $\mathrm{Ca}-\mathrm{Mg}$ Bikarbonat darstellen und demnach mit der Großzahl der übrigen Binnengewässer übereinstimmen, zeigen unsere amazonischen Seen auffallend niedere Werte an Bikarbonatkohlensäure, wie dies aus Tabelle 5 ersichtlich ist. Diese Mengen schwanken zwischen o und dem Maximalwert $\mathrm{r} 4 \mathrm{mg} / \mathrm{l}$. 
Tabelle 5

Freie Kohlensäure ( $\left.\mathrm{CO}_{2}\right)$, Bikarbonatkohlensäure (Bik.) und pH

Lago Furucui und Zuflüsse

\begin{tabular}{|c|c|c|c|c|c|c|c|c|c|c|c|c|c|c|c|c|c|c|}
\hline & \multicolumn{3}{|c|}{ 13. November 1947} & \multicolumn{3}{|c|}{ 2. Februar 1948} & \multicolumn{3}{|c|}{ 12. Februar 1948} & \multicolumn{3}{|c|}{ 4. März 1948} & \multicolumn{3}{|c|}{ 30. März 1948} & \multicolumn{3}{|c|}{ 17. Mai 1948} \\
\hline $\mathrm{m}$ & $\mathrm{CO}_{2}$ & Bik. & $\mathrm{pH}$ & $\mathrm{CO}_{2}$ & Bik. & $\mathrm{pH}$ & $\mathrm{CO}_{2}$ & Bik. & $\mathrm{pH}$ & $\mathrm{CO}_{2}$ & Bik. & $\mathrm{pH}$ & $\mathrm{CO}_{2}$ & Bik. & $\mathrm{pH}$ & $\mathrm{CO}_{2}$ & Bik. & $\mathrm{pH}$ \\
\hline $\begin{array}{l}0 \\
2 \\
4 \\
4,5 \\
5 \\
5,5\end{array}$ & $\begin{array}{l}3,50 \\
4,15\end{array}$ & $\begin{array}{l}5,10 \\
5,10\end{array}$ & $\begin{array}{l}5,10 \\
5,10\end{array}$ & $\begin{array}{l}5,00 \\
5,25\end{array}$ & $\begin{array}{l}2,06 \\
0,74\end{array}$ & $\begin{array}{r}5,00 \\
5,50\end{array}$ & $\begin{array}{r}5,00 \\
11,00\end{array}$ & $\begin{array}{l}2,06 \\
1,00\end{array}$ & $\begin{array}{l}5,50 \\
5,50\end{array}$ & $\begin{array}{r}4,50 \\
13,00\end{array}$ & 0 & $\begin{array}{l}5,90 \\
5,45\end{array}$ & 5,25 & 0 & $\begin{array}{l}5,55 \\
5,35\end{array}$ & $\begin{array}{r}6,85 \\
6,90 \\
19,40 \\
19,70\end{array}$ & 0 & 5,45 \\
\hline & \multicolumn{3}{|c|}{ 15. November 1947} & & & & \multicolumn{3}{|c|}{ 12. Februar 1948} & & & & & & & \multicolumn{3}{|c|}{ 19. Mai 1948} \\
\hline $\begin{array}{l}\text { Jgarapé do Tento } \\
\text { Jgarapé Grande }\end{array}$ & $\begin{array}{r}11,40 \\
8,50\end{array}$ & $\begin{array}{l}1,32 \\
1,75\end{array}$ & $\begin{array}{l}4,95 \\
4,80\end{array}$ & & & & $\begin{array}{l}8,00 \\
6,25\end{array}$ & $\begin{array}{l}1,35 \\
1,57\end{array}$ & $\begin{array}{l}5,30 \\
5,30\end{array}$ & & & & & & & $\begin{array}{r}10,25 \\
8,50\end{array}$ & $\begin{array}{l}0 \\
0\end{array}$ & $\begin{array}{l}5,40 \\
5,55\end{array}$ \\
\hline
\end{tabular}

Lago Muretá

\begin{tabular}{|c|c|c|c|c|c|c|c|c|c|c|c|c|}
\hline \multirow[b]{2}{*}{$\mathrm{m}$} & \multicolumn{3}{|c|}{ 2. Dezember 1947} & \multicolumn{3}{|c|}{ 20. Februar 1948} & \multicolumn{3}{|c|}{ 1. Aprîl 1948} & \multicolumn{3}{|c|}{ 25. Mai 1948} \\
\hline & $\mathrm{CO}_{2}$ & Bik. & $\mathrm{pH}$ & $\mathrm{CO}_{2}$ & Bik. & $\mathrm{pH}$ & $\mathrm{CO}_{2}$ & Bik. & $\mathrm{pH}$ & $\mathrm{CO}_{2}$ & Bik. & $\mathrm{pH}$ \\
\hline $\begin{array}{l}0 \\
5 \\
5,5\end{array}$ & 2,00 & 1,32 & 5,50 & 0,75 & 0 & 5,50 & $\begin{array}{l}1,75 \\
3,90\end{array}$ & $\begin{array}{l}0 \\
0\end{array}$ & $\begin{array}{l}5,30 \\
5,30\end{array}$ & $\begin{array}{l}2,30 \\
2,50\end{array}$ & $\begin{array}{l}0 \\
0\end{array}$ & $\begin{array}{l}4,95 \\
4,95\end{array}$ \\
\hline
\end{tabular}




\section{Lago Caxambú}

\begin{tabular}{|c|c|c|c|c|c|c|c|c|c|c|c|c|}
\hline & \multicolumn{2}{|c|}{ 24. November 1947 } & \multicolumn{2}{|c|}{ 20. Februar 1948 } & \multicolumn{2}{|c|}{ 31. März 1948 } & \multicolumn{3}{|c|}{ 20. Mai 1948 } \\
\hline $\mathrm{m}$ & $\mathrm{CO}_{\mathbf{2}}$ & Bik. & $\mathrm{pHI}$ & $\mathrm{CO}_{\mathbf{2}}$ & $\mathrm{Bik}$. & $\mathrm{pH}$ & $\mathrm{CO}_{2}$ & $\mathrm{Bik}$. & $\mathrm{pH}$ & $\mathrm{CO}_{2}$ & $\mathrm{Bik}$ & $\mathrm{pH}$ \\
\hline 0 & 0,60 & 2,20 & 5,80 & 3,00 & 0 & 6,10 & 2,50 & 0 & 5,95 & 3,50 & 1,05 & 5,80 \\
$\mathbf{4 , 5}$ & & & & & & & 6,25 & 0 & 5,90 & 4,25 & 0 & $\mathbf{5 , 9 0}$ \\
\hline
\end{tabular}

\begin{tabular}{|c|c|c|c|c|c|c|c|c|c|c|c|c|}
\hline & \multicolumn{5}{|c|}{ Lago Salgado } & \multicolumn{6}{c|}{ Lago Curuçá } \\
\hline & \multicolumn{2}{|c|}{ Cabeçeira do Molha } & \multicolumn{2}{c|}{ Cabeçeira do Boi } & \multicolumn{3}{c|}{ Aningateil } & \multicolumn{3}{c|}{ Victoriateil } \\
\hline $\mathrm{m}$ & $\mathrm{CO}_{2}$ & $\mathrm{Bik}$. & $\mathrm{pH}$ & $\mathrm{CO}_{2}$ & $\mathrm{Bik}$ & $\mathrm{pH}$ & $\mathrm{CO}_{2}$ & $\mathrm{Bik}$ & $\mathrm{pH}$ & $\mathrm{CO}_{2}$ & $\mathrm{Bik}$ & $\mathrm{pH}$ \\
\hline 0 & 15,10 & 8,36 & 6,20 & 9,30 & 8,36 & 6,45 & 11,00 & 9,19 & 6,35 & 14,50 & 7,87 & 6,10 \\
1,5 & & & & & & & 14,00 & 7,61 & 6,25 & & & \\
2 & 17,05 & & & & & & & & & 16,50 & 2,59 & 6,10 \\
3 & 20,10 & & & 18,60 & 8,36 & 6,35 & & & & & & \\
3,5 & 31,50 & 14,08 & 6,20 & & & & & & & & & \\
\hline
\end{tabular}

\begin{tabular}{|c|c|c|c|c|c|c|c|c|c|c|c|}
\hline & \multicolumn{9}{|c|}{ Lago Alter do Chão } & \multirow{2}{*}{\multicolumn{2}{|c|}{$\begin{array}{l}\text { Lago Pindobal } \\
\text { 24. Mai } 1948\end{array}$}} \\
\hline & \multicolumn{3}{|c|}{$\begin{array}{l}\text { Süd-Cabeçeira } \\
\text { 10. Dezember } 1947\end{array}$} & \multicolumn{3}{|c|}{$\begin{array}{l}\text { Mitte } \\
\text { 10. Dezember } 1947\end{array}$} & \multicolumn{3}{|c|}{$\begin{array}{l}\text { Ost-Cabeçeira } \\
\text { 10. Dezember } 1947\end{array}$} & & \\
\hline $\mathrm{m}$ & $\mathrm{CO}_{2}$ & Bik. & $\mathrm{pH}$ & $\mathrm{CO}_{2}$ & Bik. & $\mathrm{pH}$ & $\mathrm{CO}_{z}$ & Bik. & $\mathrm{pH}$ & Bik. & $\mathrm{pH}$ \\
\hline $\begin{array}{c}0 \\
4,5\end{array}$ & 6,75 & 0 & 5,10 & $\begin{array}{l}1,10 \\
2,25\end{array}$ & $\begin{array}{l}0 \\
0\end{array}$ & $\begin{array}{l}5,70 \\
5,50\end{array}$ & 6,75 & 0 & 5,15 & 0 & 5,30 \\
\hline
\end{tabular}

\begin{tabular}{|c|c|c|c|c|c|c|c|c|c|c|c|c|}
\hline & \multicolumn{7}{|c|}{ Lago Jruçanga } & \multicolumn{2}{c|}{ Lago Maritima } \\
\hline & 1. Dezember 1947 & \multicolumn{2}{|c|}{ 21. Februar 1948 } & \multicolumn{2}{c|}{ 26. Mai 1948 } & \multicolumn{2}{c|}{ 19. Februar 1948 } \\
\hline $\mathrm{m}$ & $\mathrm{CO}_{2}$ & Bik. & $\mathrm{pH}$ & $\mathrm{CO}_{2}$ & Bik. & $\mathrm{pH}$ & $\mathrm{CO}_{2}$ & Bik. & $\mathrm{pH}$ & $\mathrm{CO}_{2}$ & Bik. & $\mathrm{pH}$ \\
\hline 0 & 5,50 & 1,32 & 5,15 & 28,25 & 0 & 4,90 & 42,50 & 0 & 4,60 & 28,25 & 0 & 5,05 \\
\hline
\end{tabular}




\begin{tabular}{|c|c|c|c|c|c|c|c|c|c|c|c|c|}
\hline & \multicolumn{3}{|c|}{ Lago Pauxis } & \multicolumn{3}{|c|}{ Lago do Caxias } & \multicolumn{3}{|c|}{ Lago Timbó } & \multicolumn{3}{|c|}{ Lago Curí } \\
\hline & \multicolumn{3}{|c|}{ 25. Juli 1947} & \multicolumn{3}{|c|}{ 31. Dezember 1947} & \multicolumn{3}{|c|}{ 11. Januar 1948} & \multicolumn{3}{|c|}{ 9. Januar 1948} \\
\hline $\mathrm{m}$ & $\mathrm{CO}_{2}$ & Bik. & $\mathrm{pH}$ & $\mathrm{CO}_{2}$ & Bik. & $\mathrm{pH}$ & $\mathrm{CO}_{2}$ & Bik. & $\mathrm{pH}$ & $\mathrm{CO}_{2}$ & Bik. & $\mathrm{pH}$ \\
\hline $\begin{array}{l}0 \\
2 \\
3 \\
3,5\end{array}$ & $\begin{array}{l}21,65 \\
43,00\end{array}$ & - & $\begin{array}{l}5,15 \\
5,75\end{array}$ & $\begin{array}{l}6,75 \\
7,50\end{array}$ & $\begin{array}{l}5,76 \\
5,76\end{array}$ & $\begin{array}{l}6,30 \\
6,40\end{array}$ & $\begin{array}{l}10,00 \\
14,25\end{array}$ & $\begin{array}{l}3,65 \\
3,65\end{array}$ & $\begin{array}{l}6,25 \\
6,25\end{array}$ & $\begin{array}{r}8,65 \\
16,65\end{array}$ & 10,47 & 6,55 \\
\hline
\end{tabular}

\begin{tabular}{|c|c|c|}
\hline & \multicolumn{2}{|c|}{$\begin{array}{c}\text { Lago do Tracoá } \\
\text { 20. April 1948 }\end{array}$} \\
\hline $\mathrm{m}$ & $\mathrm{CO}_{2}$ & $\mathrm{pH}$ \\
\hline 0 & 11,50 & 5,90 \\
6 & 11,50 & 5,90 \\
\hline
\end{tabular}

Bei der Mehrzahl der Untersuchungen fanden wir überhaupt keine Bikarbonatkohlensäure! Diese überraschende Kalkarmut der amazonischen Seen liegt an der geologisch-mineralogischen Beschaffenheit des Untergrundes. Wie bereits dargelegt, hatten wir die Möglichkeit, Seen in geologisch verschiedenen Gebieten zu untersuchen, und es dürfte interessant sein, zu prüfen, ob sich irgendwelche Gesetzmäßigkeiten und Zusammenhänge zwischen dem geologischen Untergrund einerseits und dem Chemismus dieser Seen anderseits zeigen.

Aus der geologischen Karte ist ersichtlich, daß die untersuchten Seen eingebettet liegen im:

a) Tertï̈rgebict: Lago Jurucui, Lago Muretá, Lago Jruçanga, Lago Caxambú, Lago Alter do Chão; Untergrund: Zur Hauptsache nährstoffarmer Quarzsand. Sehr sauer.

b) Karbongebiet: Lago Curuçá,Lago do Caxias, Lago Timbó, Lago Curí, Lago Salgado. Untergrund: Sandstein, zum Teil Kalk oder Gips. Nährstoffreich und basischer als a.

Betrachten wir nun die Bikarbonatgehalte in Tabelle 5 , so erkennen wir sofort, daß sich die in den beiden Karbonstreifen liegenden Seen durch einen deutlich höheren Bikarbonatgehalt auszeichnen, der zwischen 2,59 und $14,08 \mathrm{mg} / \mathrm{l}$ schwankt. Die im Tertiär liegenden Seen sind jedoch extrem arm an Bikarbonaten (o bis $5, \mathrm{I} \mathrm{mg} / \mathrm{l}$ ). 
Diese Unterschiede kommen nach dem oben Gesagten erwartungsgemä $\beta$ auch in den pH-Werten zum Ausdruck. In Abbildung I4 haben wir von je fünf Seen im Karbon- und im Tertiärgebiet die Durchschnittsresultate der $\mathrm{pH}-$ und Bikarbonatbestimmungen graphisch dargestellt, um diese Unterschiede besser zu veranschaulichen. Darin kommt nun diese Abhängigkeit

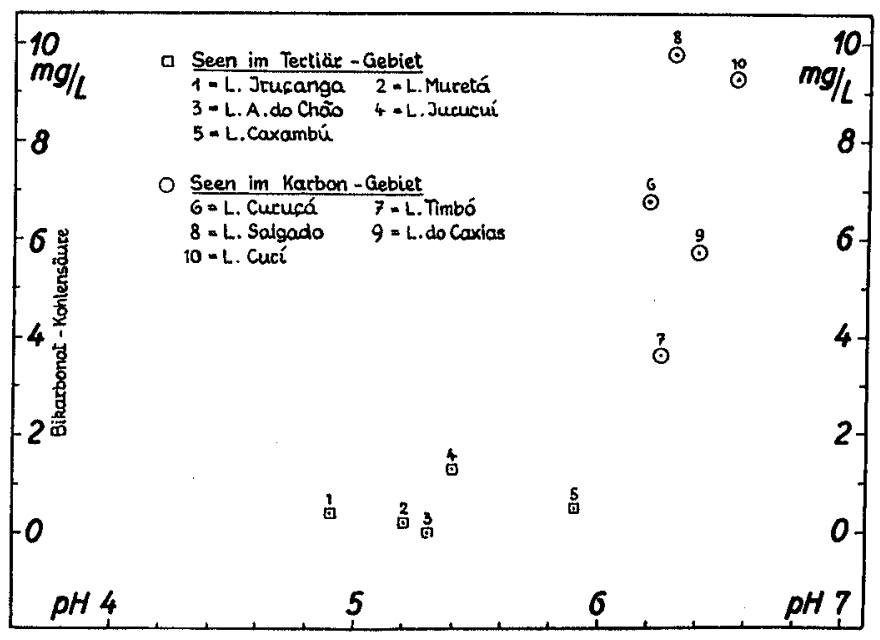

Abb. 14

sehr eindeutig zum Ausdruck. Wir sehen eine Gruppierung der «Tertiärseen» im pH-Bereich von 4,9 bis 5,9 und im Bikarbonatbereich von o bis $\mathrm{I}, 4 \mathrm{mg} / \mathrm{l}$. Die «Karbonseen» jedoch gruppieren sich im $\mathrm{pH}$-Bereich von 6,2 bis 6,5 und im Bikarbonatbereich von 3,7 bis $9,8 \mathrm{mg} / \mathrm{l}$.

In den temperierten Seen Mitteleuropas gilt es als Norm, daß der Bikarbonatgehalt mit zunehmender Tiefe ansteigt. Durch die Photosynthese der autotrophen Organismen wird dem Oberflächenwasser freie Kohlensäure entzogen, so daß der Kohlensäuregehalt an der Oberfläche meistens auf Null absinkt, das heißt, die Menge der Gleichgewichtskohlensäure sinkt ebenfalls rasch $a b$, was zur Folge hat, daß eine bestimmte Menge Kalk in Form unlöslichen, biogenen Monokarbonats ausfallen wird (siehe MiNDER, I923). Dadurch sinkt also der Bikarbonatgehalt in der trophogenen Schicht, und zwar um so stärker, je größer die assimilatorische Tätigkeit der Organismen ist. Am Grunde der Seen bewirken die intensiven Abbauvorgänge der organischen Substanz eine Anreicherung an freier Kohlensäure, und diese ist imstande, das von oben anfallende Monokarbonat zum 
Teil wieder als Bikarbonat zu lösen. Dieser Anstieg des Bikarbonatgehaltes in den temperierten Seen ist also eindeutig zu erklären.

RUTTNER bestätigte diese Gesetzmäßigkeiten auch für die von ihm untersuchten Tropenseen, mit Ausnahme von zwei kleinen Seen, in denen er im Epilimnion höhere Bikarbonatgehalte feststellte. Er führt diese $\mathrm{Ab}$ weichung von der Regel darauf zurïck, daß in der Tiefe jener Seen noch verdünntes Wasser von der letzten Regenzeit lagert, auf das sich dann nachher konzentriertes Quellwasser aufschichtet.

In unseren Messungen an den amazonischen Seen kommt diese Gesetzmäßigkeit überraschenderweise gar nicht zum Ausdruck, höchstens im Lago Salgado (Cabeçeira do Molha, 22. April 1948) und im Lago Curí (9. Januar 1948). Aber in allen andern Seen, soweit Bikarbonat überhaupt nachgewiesen werden konnte, blieb der Gehalt im Hypolimnion gleich wie im Epilimnion, oder wir konnten sogar direkt das Gegenteil beobachten. Der Bikarobnatgehalt verringerte sich mit zunehmender Tiefe (Lago Jurucui, I2. Februar 1948; Lago Caxambú, 20. Mai I948; Lago Curuçá, Aningateil, I. Januar 1948, Victoriateil 3. Januar 1948). Für diese Abweichung von der Regel haben wir folgende Erklärung:

Dieser soeben besprochene Anstieg des Bikarbonatgehaltes nach der Tiefe zu wird in den temperierten Seen um so ausgesprochener, je mehr Bikarbonate vorhanden sind. Es ist also zum vornherein anzunehmen, daß in den bikarbonatarmen amazonischen Seen diese Gesetzmäßigkeit nicht deutlich zum Ausdruck kommen wird. Der Hauptgrund ist jedoch der, daß der Gehalt an freier Kohlensäure auch in den epilimnischen Schichten trotz der Assimilationstätigkeit der Pflanzen noch verhältnismäßig hoch ist, das heißt, die Assimilation kann niemals zu einer so starken Verarmung an freier Kohlensäure führen, daß es zu einer biogenen Kalkfällung kommen kann, denn die betreffende Gleichgewichtskohlensäure fällt ja für diese geringen Bikarbonatgehalte gar nicht in Betracht.

Was bei den temperierten Seen und bei den Ruttnerschen Tropenseen Ausnahme ist, gilt gewissermaßen bei den amazonischen Seen als Regel und umgekehrt. Der Anstieg des Bikarbonatgehaltes mit zunehmender Tiefe im Lago Salgado und Lago Curí (also das «normale» Verhalten) hat nicht dieselben Ursachen wie in den temperierten Seen, sondern liegt einfach in der Tatsache begründet, daß jene Untersuchungen am Ende der Regenzeit durchgeführt wurden; es hat sich Regenwasser auf die bikarbonathaltige Wassermasse aufgelagert. Wir haben also hier genau die umgekehrten Verhältnisse bzw. Erklärungen, wie sie RuTTNER für jene beiden Tropenseen anwendete, die von der Regel abwichen. 
In den temperierten Seen Mitteleuropas und Nordamerikas liegt der Gehalt an freier Kohlensäure in den oberflächlichen Wasserschichten meistens um den Nullpunkt herum - namentlich in der warmen Jahreszeit ( $\mathrm{CO}_{2}$-Entzug durch das assimilierende Plankton) -, um dann spiegelbildlich zur Sauerstoff kurve mit zunehmender Tiefe anzusteigen und unmittelbar ob Grund Maximalwerte zu erreichen. Auch in den amazonischen Seen fanden wir prinzipiell dieselben Verhältnisse, jedoch mit dem Unterschied, daß der Gehalt an freier Kohlensäure allgemein viel höher lag, sogar in den epilimnischen Wasserschichten. Wir fanden überhaupt nie Seen ohne

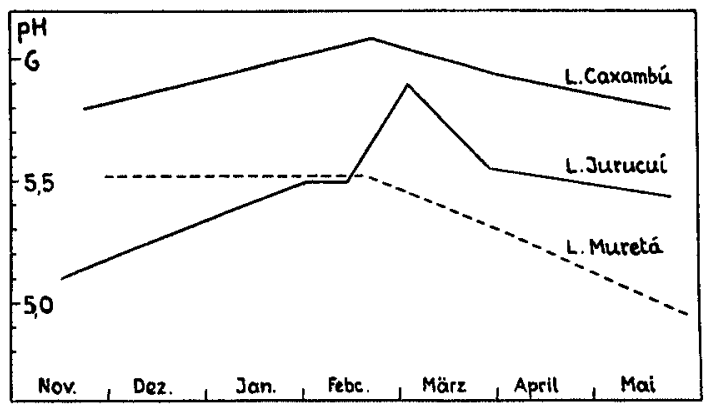

Abb. 15

Kohlensäure an der Oberfläche. Der Gehalt konnte sogar Werte von $20 \mathrm{mg} / \mathrm{l}$ und mehr erreichen. Allgemein stieg der Gehalt mit zunehmender Tiefe an und erreichte ob Grund $40 \mathrm{mg} / \mathrm{l}$ und mehr.

Dieser hohe Gehalt an freier Kohlensäure ist in erster Linie durch die reichliche organische Substanz erklärlich, die namentlich zur Regenzeit in die Seen gelangt und bei deren durch die hohe Temperatur geförderten Abbau viel $\mathrm{CO}_{2}$ frei wird. Wir gehen später näher darauf ein.

Wie bereits erwähnt, ist der $\mathrm{pH}$-Wert natürlicher Gewässer vom System Karbonat-Bikarbonat-freie Kohlensäure abhängig, das heißt, je mehr Bikarbonate im Wasser enthalten sind, desto größer ist die Fähigkeit des Wassers, Schwankungen im Gehalt an freier Kohlensäure auszugleichen und den pH-Wert konstant zu halten, mit anderen Worten: Je größer der Bikarbonatgehalt, desto größer die Pufferungskapazität des Wassers.

Entsprechend dem auffallend geringen Bikarbonat- und hohen Kohlensäuregehalt sind die $\mathrm{pH}-W e r t e$ in den amazonischen Seen erwartungsgemäß sehr tief. In Tabelle 5 sind diese Werte eingetragen. Auf Grund der geringen Pufferungskapazität des Wassers sind diese pH-Werte im Laufe 
des Jahres gewissen Schwankungen unterworfen, im Lago Jurucui zum Beispiel zwischen $\mathrm{pH}$ 5,I bis 5,9. Auf das biologische Geschehen im See müssen natürlich diese geringe Pufferungskapazität bzw. die $\mathrm{pH}-$ Schwankungen einen Einfluß ausüben.

Die pH-Schwankungen im Laufe der Untersuchungsperiode sind für die Seen Jurucui, Caxambú und Muretá in Abbildung I 5 graphisch dargestellt. Die stärksten Schwankungen weist der Lago Jurucui auf. Wir können feststellen, daß allgemein zu Beginn der Regenzeit der pH-Wert dieser Seen ansteigt, ungefähr in der Mitte der Regenzeit das Maximum erreicht, um gegen Ende der Regenzeit wieder abzusinken. Dieser Anstieg kann folgendermaßen erklärt werden: $\mathrm{Zu}$ Beginn der Regenzeit steigt die Wasserführung der Flüsse äußerst stark an. Diese treten über die Ufer, überschwemmen weite Landgebiete. Das Wasser hat Gelegenheit, sich mit Bodensalzen verschiedenster Art anzureichern, und diese werden schließlich auch in die Seen geführt. Dieser vermehrte Salzgehalt (eventuell $\mathrm{NH}_{3}$-Verbindungen, K-Na-Karbonate usw.) zu Beginn der Regenzeit kann zu dieser leichten Erhöhung des $\mathrm{pH}$-Wertes führen.

$\mathrm{Ob}$ dieser Anstieg der $\mathrm{pH}-$ Werte mit der Regenzeit allgemeine Gültigkeit besitzt, können wir aus den wenigen Resultaten nicht entscheiden; dazu müßten mehrere Seen in Form eines ganzen Jahreszyklus erfaßt werden können.

Eine Schichtung des pH-Wertes konnten wir nur in wenigen Fällen nachweisen. Meistens war es so, daß die $\mathrm{pH}$-Werte mit zunehmender Tiefe geringer wurden (Lago Jurucui, 4. März 1948). Dies war durch den höheren Gehalt an freier Kohlensäure in der Tiefe nicht anders zu erwarten.

Merkwürdigerweise fallen aber die pH-Schichtungen nicht mit den besonders ausgeprägten Kohlensäureschichtungen zusammen. Im Lago Jurucui zum Beispiel fanden wir am I7. Mai 1948 die am stärksten ausgeprägte Kohlensäureschichtung: $6,85 \mathrm{mg} / \mathrm{l}$ in o m Tiefe, $19,7 \mathrm{mg} / 1$ in $5,5 \mathrm{~m}$ 'Tiefe. Das $\mathrm{pH}$ war jedoch vollkommen ohne Schichtung. Anderseits stellten wir im gleichen See am 4. März I948 die schon oben erwähnte pH-Schichtung fest (Unterschied 0,5 Einheiten), wobei aber die Kohlensäure nur unbedeutend geschichtet war. Eine weitere Merkwürdigkeit in den pH-Verhältnissen zeigte sich im Lago Pauxis (25. Juli 1947), in dem ein deutlicher Anstieg des $\mathrm{pH}$ nach der Tiefe feststellbar war.

Zu ganz ähnlichen Feststellungen gelangte KLEEREKoper (1939), als er einen bei São Paulo (Südbrasilien, subtropische Zone) gelegenen Stausee untersuchte. KLEEREKOPER führt diese Unregelmäßigkeit auf vorläufig noch unbekannte pufferungsfähige Stoffe (Nichtkarbonate) - wahrschein- 
lich organischer Natur - zurück, und zwar als Folge der intensiven Abbauvorgänge der Ufervegetation. Auch wir können vorläufig nur dieselbe Erklärung für das zeitweise merkwürdige Bild der pH-Verhältnisse in den amazonischen Seen geben.

\section{d) Die Stickstoffverbindungen}

In natürlichen Gewässern sind die Stickstoffverbindungen in der Regel in nur geringen Mengen vorhanden, in erster Linie in Form von Nitraten, Nitriten und Ammoniak.

In Nitratform erscheinen diese Stickstoffverbindungen als Endprodukt der Mineralisation stickstoff haltiger Substanzen, in Nitritform eventuell als Zwischenstufe bei der Mineralisation. Es sind also Oxydationsprodukte. Erwartungsgemäß sollten in den tieferen Wasserschichten, vor allem aber am Grunde der Gewässer, die größten Nitratmengen anzutreffen sein. In den oberflächlichen Schichten werden die Nitrate - wie auch die Phosphate - bei der Ernährung des Planktons bald aufgebraucht, das seinerseits bei seiner Zersetzung in der Tiefe wieder eine Anreicherung an Nitraten herbeiführt.

Nitrate sind in unseren amazonischen Seen im allgemeinen sehr wenig vorhanden. Die größten Nitratmengen fanden wir im Lago Caxambú (20. Februar 1948) mit dem Maximum von $1,7 \mathrm{mg} / \mathrm{l}$. Diesen Nitratreichtum können wir uns nur so erklären: Seit der vorhergehenden Untersuchung (24. November 1947), bei der wir keine Nitrate nachweisen konnten, war der Wasserspiegel des Sees mit beginnender Regenzeit so weit gestiegen, daß weite Ufergebiete und damit große Vegetationsgebiete überschwemmt wurden, wobei die sich zersetzende Vegetation diese Nitratanreicherung bewirkte. Aber bereits am 3I. März I948 und am 20. Mai 1948 waren gar keine Nitrate mehr nachweisbar; offenbar wurden sie durch das Phytoplankton in kurzer Zeit aufgebraucht (der Lago Caxambú war der planktonreichste aller untersuchten Seen!). Die Regenzeit hat also auch hier als Nährstoffanreicherung gewirkt.

Ähnliches stellten wir beim Lago Jurucui fest. Am 2. Februar 1948 fanden wir dort Nitrate in Mengen bis zu 0,I3 mg/l. Vorher, am I3. November 1947, fanden wir im See selbst nur Spuren, wogegen in den beiden Zuflüssen Jgarapé do Tento und Jgarapé Grande immerhin Mengen bis zu o, I mg/l feststellbar waren. Diese Nitratmengen wurden aber sofort vom Phytoplankton verbraucht. In allen nachfolgenden Untersuchungen konnten sie nicht mehr nachgewiesen werden. Thre Natur als Minimumstoff ist 
also hier augenfällig! Im Lago Muretá konnten wir überhaupt nie Nitrate nachweisen. Auch im Lago Salgado fanden wir sie höchstens in Spuren. Diese Stickstoffarmut der amazonischen Gewässer steht im Einklang mit den stickstoffarmen Böden des Untersuchungsgebietes.

Im Gegensatz zu den Nitraten als Oxydationsprodukte stehen die Ammoniakverbindungen. Diese entstehen durch Reduktionsvorgänge rein chemisch-physikalischer Art -, indem das durch die Erde sickernde Regenwasser Nitrate und Nitrite auflöst, sich mit Kohlensäure anreichert und mit Schwefeleisen (Schwefelkies) in Berïhrung kommt. Dieses wird durch Kohlensäure und Druck in Ferrokarbonat und Schwefelwasserstoff verwandelt. Durch im Schwefelkies meist noch in elementarer Form vorhandenes Eisen wird Wasserstoff frei gemacht, der mit dem $\mathrm{H}_{2} \mathrm{~S}$ zusammen Nitrate und Nitrite $z u$ reduzieren vermag, wobei sich als Endprodukt Ammoniak bildet. So werden namentlich in eisenhaltigen Grundwässern solche Ammoniakvorkommen erklärt.

Für die amazonischen Seen fällt diese Bildungsmöglichkeit des Ammoniaks kaum in Betracht. Wenn wir hier $\mathrm{NH}_{3}$ feststellen, kann es wohl nur auf biochemischem Wege entstanden sein, unter dem Einfluß von Organismen. Entweder entstehen die Ammoniakverbindungen durch Verwesung organischer, stickstoff haltiger Substanzen, oder aber sie sind als Stoffwechselprodukte von Lebewesen ins Wasser gekommen (menschliche oder tierische Abfallstoffe). Bei den Amazonasseen kommt wohl hauptsächlich die erste Möglichkeit in Betracht (Zersetzung organischer Sub-

Tabelle 6

\section{Freies Ammoniak und Nitrate}

Lago Furucui und Zuflüsse

\begin{tabular}{|c|c|c|c|c|c|c|c|c|c|c|c|c|}
\hline \multirow[b]{2}{*}{$\mathrm{m}$} & \multicolumn{2}{|c|}{$\begin{array}{c}\text { 13. Nov. } \\
1947\end{array}$} & \multicolumn{2}{|c|}{$\begin{array}{l}\text { 2. Februar } \\
1948\end{array}$} & \multicolumn{2}{|c|}{$\begin{array}{l}\text { 12. Februar } \\
1948 \\
\end{array}$} & \multicolumn{2}{|c|}{$\begin{array}{c}\text { 4. März } \\
1948\end{array}$} & \multicolumn{2}{|c|}{$\begin{array}{c}\text { 30. März } \\
1948\end{array}$} & \multicolumn{2}{|c|}{$\begin{array}{c}\text { 17. Mai } \\
1948 \\
\end{array}$} \\
\hline & $\mathrm{NH}_{3}$ & $\mathrm{~N}_{2} \mathrm{O}_{5}$ & $\mathrm{NH}_{3}$ & $\mathrm{~N}_{2} \mathrm{O}_{5}$ & $\mathrm{NH}_{3}$ & $\mathrm{~N}_{2} \mathrm{O}_{5}$ & $\mathrm{NH}_{3}$ & $\mathrm{~N}_{2} \mathrm{O}_{5}$ & $\mathrm{NH}_{3}$ & $\mathrm{~N}_{2} \mathrm{O}_{5}$ & $\mathrm{NH}_{3}$ & $\mathrm{~N}_{2} \mathrm{O}_{5}$ \\
\hline \multirow[t]{2}{*}{$\begin{array}{l}0 \\
2 \\
4 \\
4,5\end{array}$} & - & $\begin{array}{c}\text { Spur } \\
0\end{array}$ & $\begin{array}{l}0,17 \\
0,10\end{array}$ & $\begin{array}{l}0,13 \\
0,10\end{array}$ & $\begin{array}{l}0,13 \\
0,13\end{array}$ & Spur & $\begin{array}{l}0,05 \\
0,05\end{array}$ & 0 & 0,15 & 0 & 0,17 & 0 \\
\hline & \multicolumn{2}{|c|}{$\begin{array}{l}\text { 15. Nov. } \\
1947\end{array}$} & & & \multicolumn{2}{|c|}{\begin{tabular}{|c|} 
12. Februar \\
1948
\end{tabular}} & & & & & \multicolumn{2}{|c|}{$\begin{array}{c}\text { 19. Mai } \\
1948 \\
\end{array}$} \\
\hline $\begin{array}{l}\text { Jg.Tento } \\
\text { Jg.Grande }\end{array}$ & - & $\begin{array}{l}0,08 \\
0,10\end{array}$ & & & $\begin{array}{l}0,15 \\
0,15\end{array}$ & $\begin{array}{l}0 \\
0\end{array}$ & & & & & $\begin{array}{l}0,15 \\
0,17\end{array}$ & $\begin{array}{l}0 \\
0\end{array}$ \\
\hline
\end{tabular}


Lago Muretá

\begin{tabular}{|c|c|c|c|c|c|c|c|c|}
\hline \multirow[b]{2}{*}{$\mathrm{m}$} & \multicolumn{2}{|c|}{$\begin{array}{c}\text { 2. Dezember } \\
1947\end{array}$} & \multicolumn{2}{|c|}{$\begin{array}{l}\text { 20. Februar } \\
1948\end{array}$} & \multicolumn{2}{|c|}{$\begin{array}{l}\text { 1. April } \\
1948\end{array}$} & \multicolumn{2}{|c|}{$\begin{array}{l}\text { 25. Mai } \\
1948\end{array}$} \\
\hline & $\mathrm{NH}_{3}$ & $\mathrm{~N}_{2} \mathrm{O}_{5}$ & $\mathrm{NH}_{3}$ & $\mathrm{~N}_{2} \mathrm{O}_{5}$ & $\mathrm{NH}_{3}$ & $\mathrm{~N}_{2} \mathrm{O}_{5}$ & $\mathrm{NH}_{3}$ & $\mathrm{~N}_{2} \mathrm{O}_{5}$ \\
\hline $\begin{array}{l}0 \\
5 \\
5,5\end{array}$ & - & 0 & Spur & 0 & $\begin{array}{l}\text { Spur } \\
\text { Spur }\end{array}$ & $\begin{array}{l}0 \\
0\end{array}$ & $\begin{array}{l}\text { Sp. } \\
0,09\end{array}$ & $\begin{array}{l}0 \\
0\end{array}$ \\
\hline
\end{tabular}

\section{Lago Caxambú}

\begin{tabular}{|l|c|c|c|c|c|c|c|c|}
\hline & \multicolumn{2}{|c|}{$\begin{array}{c}\text { November } \\
1947\end{array}$} & \multicolumn{2}{c|}{$\begin{array}{c}20 . \text { Februar } \\
1948\end{array}$} & \multicolumn{2}{c|}{$\begin{array}{c}31 . \text { März } \\
1948\end{array}$} & \multicolumn{2}{|c|}{$\begin{array}{c}\text { 20. Mai } \\
1948\end{array}$} \\
\hline $\mathrm{m}$ & $\mathrm{NH}_{3}$ & $\mathrm{~N}_{2} \mathrm{O}_{5}$ & $\mathrm{NH}_{3}$ & $\mathrm{~N}_{2} \mathrm{O}_{5}$ & $\mathrm{NH}_{3}$ & $\mathrm{~N}_{2} \mathrm{O}_{5}$ & $\mathrm{NH}_{3}$ & $\mathrm{~N}_{2} \mathrm{O}_{5}$ \\
\hline 0 & - & 0 & 0,10 & 1,70 & 0,12 & 0 & 0,10 & 0 \\
4,5 & & & & & 0,30 & 0 & 0,12 & 0 \\
\hline
\end{tabular}

\begin{tabular}{|c|c|c|c|c|c|c|c|c|c|c|}
\hline & \multicolumn{4}{|c|}{ Lago Salgado } & \multicolumn{4}{|c|}{ Lago Curuçá } & \multicolumn{2}{|c|}{ Lagodo Caxias } \\
\hline & \multirow{2}{*}{\multicolumn{2}{|c|}{$\begin{array}{c}\begin{array}{c}\text { Cabeçeira } \\
\text { do Molha }\end{array} \\
\begin{array}{c}\text { 22. April } \\
1948\end{array}\end{array}$}} & \multirow{2}{*}{\multicolumn{2}{|c|}{$\begin{array}{c}\begin{array}{c}\text { Cabeçeira } \\
\text { do Boi }\end{array} \\
\begin{array}{c}\text { 13. April } \\
1948\end{array}\end{array}$}} & \multirow{2}{*}{\multicolumn{2}{|c|}{$\begin{array}{l}\text { Aningateil } \\
\begin{array}{l}\text { 1. Januar } \\
1948\end{array}\end{array}$}} & \multirow{2}{*}{\multicolumn{2}{|c|}{$\begin{array}{l}\text { Victoriateil } \\
\text { 3. Januar } \\
1948\end{array}$}} & & \\
\hline & & & & & & & & & 31. $\frac{\mathrm{D}}{1}$ & $\begin{array}{l}\text { zember } \\
47\end{array}$ \\
\hline $\mathrm{m}$ & $\mathrm{NH}_{3}$ & $\mathrm{~N}_{2} \mathrm{O}_{5}$ & $\mathrm{NH}_{3}$ & $\mathrm{~N}_{2} \mathrm{O}_{5}$ & $\mathrm{NH}_{3}$ & $\mathrm{~N}_{2} \mathrm{O}_{5}$ & $\mathrm{NH}_{3}$ & $\mathrm{~N}_{2} \mathrm{O}_{5}$ & $\mathrm{NH}_{3}$ & $\mathrm{~N}_{2} \mathrm{O}_{5}$ \\
\hline $\begin{array}{l}0 \\
1,5 \\
2 \\
3,5 \\
4,5\end{array}$ & 0,25 & 0 & $\begin{array}{l}0,17 \\
0,15\end{array}$ & $\begin{array}{c}0 \\
\text { Spur }\end{array}$ & - & $\begin{array}{l}0,20 \\
0,50\end{array}$ & - & $\begin{array}{l}0 \\
0\end{array}$ & - & $\begin{array}{l}0,80 \\
0,70\end{array}$ \\
\hline
\end{tabular}

\begin{tabular}{|c|c|c|c|c|}
\hline & Lago Tímbó & Lago Curí & \multicolumn{2}{|c|}{ Lago Maritima } \\
\hline & $\begin{array}{l}\text { 11. Januar } \\
1948\end{array}$ & $\begin{array}{l}\text { 9. Januar } \\
1948\end{array}$ & \multicolumn{2}{|c|}{ 19. Februar 1948} \\
\hline $\mathrm{m}$ & $\mathrm{N}_{2} \mathrm{O}_{5}$ & $\mathrm{~N}_{2} \mathrm{O}_{5}$ & $\mathrm{NH}_{3}$ & $\mathrm{~N}_{2} \mathrm{O}_{5}$ \\
\hline $\begin{array}{l}0 \\
3,5\end{array}$ & $\begin{array}{l}0,04 \\
\text { Spur }\end{array}$ & $\begin{array}{l}0 \\
0\end{array}$ & 0,20 & 0 \\
\hline
\end{tabular}


stanz), denn von einer eigentlichen Beeinflussung durch den Menschen im Sinne einer Verschmutzung kann man bei diesen Seen kaum sprechen!

In Tabelle 6 sind einige Resultate der Ammoniakbestimmungen eingetragen. Aus technischen Gründen konnte Ammoniak nur im Lago Jurucui und seinen Zuflüssen, ferner im Lago Caxambú, Lago Muretá und Lago Salgado bestimmt werden. Allgemein sind die Ammoniakmengen sehr gering; sie schwanken zwischen 0 und $0,3 \mathrm{mg} / \mathrm{l}$. Auch hier scheint es, die Menge freier $\mathrm{NH}_{3}$ steige mit beginnender Regenzeit an (siehe Lago Jurucui, Lago Caxambú), doch genügen die wenigen Resultate keineswegs, definitive Schlußfolgerungen daraus zu ziehen. Immerhin sehen wir die Quelle des Ammoniaks im Lago Jurucui in Form der Zuflüsse (Jgarapé do Tento und Jgarapé Grande), die längere Zeit durch Jgapó fließen, wobei das Wasser ausreichend Gelegenheit hat, sich mit organischem Material anzureichern, das infolge der hohen Temperatur sehr rasch in Zersetzung übergeht.

Die höchsten Ammoniakwerte fanden wir im Lago Salgado, Cabeçeira do Molha, in 4,5 $\mathrm{m}$ Tiefe, wo wir auch große Mengen an oxydierbaren Stoffen $\left(\mathrm{KMnO}_{4}\right.$-Verbrauch $\left.57,2 \mathrm{mg} / \mathrm{l}\right)$ sowie Schwefelwasserstoff und sauerstofffreies Tiefenwasser angetroffen haben.

Über die Schichtungsverhältnisse des Ammoniaks können wir nichts Bestimmtes aussagen, denn die kleine Zahl der Untersuchungen genügt nicht dazu. Immerhin hat es den Anschein, daß mit zunehmender Tiefe der Ammoniakgehalt - wie auch der $\mathrm{KMnO}_{4}$-Verbrauch - mit einigen wenigen Ausnahmen ansteigt.

\section{e) Die Phosphate}

Sie bilden mit den Nitraten zusammen die wichtigsten Nährstoffe für die pflanzlichen Organismen im Wasser und nehmen daher bei allen Stoffwechselvorgängen eine Sonderstellung ein.

Obschon mit der angewandten kolorimetrischen Bestimmungsmethode außerordentlich geringe Mengen von Phosphaten bestimmt werden können, verliefen unsere Bestimmungen fast alle negativ. In nur zwei Fällen konnten wir Phosphate nachweisen, und zwar am I3. November 1947 im Lago Jurucui eine Spur in $2 \mathrm{~m}$ Tiefe und am I5. November 1947 in einem der Zuflüsse (Jgarapé do Tento) eine überraschend hohe Menge von o, I mg/l. Diese einmalige, große Phosphatmenge können wir uns nur durch eine Störung erklären, zum Beispiel durch einen intensiven Zersetzungs- 
prozeß tierischen Eiweißes (?), denn in der Regel zeigen nichtverunreinigte Quellen und Bäche Phosphate nur in Spuren.

Diese Armut der amazonischen Seen an Phosphaten und Nitraten erinnert an oligotrophe Verhältnisse. Eutrophe Gewässer zeichnen sich bekanntlich durch höhere Gehalte aus.

Phosphate gelangen durch Verwitterung phosphathaltiger Gesteine (Apatit) ins Wasser. Dem Phosphatgehalt kommt in den Seen zweifellos die Rolle des Minimumfaktors zu. Die hohe Planktonproduktion einerseits und die geringen Phosphatmengen anderseits bewogen ELSTER und EINSELE (1937), von einem innerhalb der Biozönose sich abspielenden Phosphatkreislauf zu sprechen. Die frei werdenden Phosphatmengen werden sofort wieder von den Organismen aufgenommen und entziehen sich demnach unserer Feststellung. Damit können wir uns die fast immer negativ verlaufenden Phosphatbestimmungen der amazonischen Gewässer erklären. STEINER (1938) zeigte, daß auch ohne Mitwirkung von Organismen, rein durch Autolyse des Planktons, der organisch gebundene Phosphor in Phosphate und demnach wieder in aufnehmbare Form übergeführt werden kann. Dabei spielen Fermente (Phosphatasen) eine Rolle, welche die Phosphate aus Nukleoproteiden abspalten. Auch in bezug auf den Stickstoff vermutet STEINER eine ähnliche Beziehung.

Leider war es uns nicht möglich, den organisch gebundenen Phosphor zu bestimmen, dessen Menge in der Regel erheblich größer ist als diejenige des anorganisch gebundenen, wie dies JUDAY (1928) und Mitarbeiter in den nordamerikanischen Seen nachgewiesen haben.

In auf fallendem Gégensatz zu den amazonischen Seen mit ihrer extremen Armut an Phosphaten stehen die von RUTTNER untersuchten niederländisch-indischen Tropenseen, in denen er an der Oberfläche Phosphatmengen bis zu 0,02 mg/l, in der Tiefe bis $0,47 \mathrm{mg} / \mathrm{l}$ feststellen konnte. Die Phosphorquelle dieser Seen liegt im phosphatreichen vulkanischen Untergrund.

\section{f) Der $\mathrm{KMnO}_{4}$-Verbrauch und die Huminsäuren}

Die Bestimmung des $\mathrm{KMnO}_{4}$-Verbrauches gibt uns ein brauchbares $\mathrm{Maß}$ für die Menge der oxydierbaren Substanzen im Wasser, allerdings nicht für die organischen Substanzen schlechthin, denn diese zeigen nach KLUT (I93I) bei der Oxydation mit $\mathrm{KMnO}_{4}$ abweichende Werte, je nach der Natur dieser Stoffe. Wir können also nicht ohne weiteres vom $\mathrm{KMnO}_{4}^{-}$ Verbrauch auf die Menge der organischen Substanz schließen, doch gibt 
Tabelle 7

\section{$\mathrm{KMnO}_{4}$-Verbrauch (mg/l) und Huminsäure (mval/1)}

\section{Lago Furucui und Zuflüsse}

\begin{tabular}{|c|c|c|c|c|c|c|c|c|c|c|c|c|}
\hline \multirow[b]{2}{*}{$\mathrm{m}$} & \multicolumn{2}{|c|}{$\begin{array}{l}\text { 15. Nov. } \\
1947\end{array}$} & \multicolumn{2}{|c|}{$\begin{array}{l}\text { 2. Februar } \\
1948\end{array}$} & \multicolumn{2}{|c|}{$\begin{array}{l}\text { 12. Februar } \\
1948\end{array}$} & \multicolumn{2}{|c|}{$\begin{array}{l}\text { 4. März } \\
1948\end{array}$} & \multicolumn{2}{|c|}{$\begin{array}{l}\text { 30. März } \\
1948\end{array}$} & \multicolumn{2}{|c|}{$\begin{array}{l}\text { 17. Mai } \\
1948\end{array}$} \\
\hline & $\mathrm{KMnO}_{4}$ & Humin. & $\mathrm{KMnnO}_{4}$ & Humin. & $\mathrm{KMnO}_{4}$ & Humin. & $\mathrm{KMnO}_{4}$ & Humin & $\mathrm{KMnO}_{1}$ & Humin. & $\mathrm{KMnO}_{4}$ & Humin. \\
\hline \multirow[t]{2}{*}{$\begin{array}{l}0 \\
2 \\
4 \\
4,5 \\
5 \\
5,5\end{array}$} & $\begin{array}{l}7,77 \\
9,10\end{array}$ & $\begin{array}{l}0 \\
0\end{array}$ & $\begin{array}{l}17,59 \\
21,72\end{array}$ & $\begin{array}{l}0 \\
0\end{array}$ & $\begin{array}{l}19,02 \\
17,91\end{array}$ & $\begin{array}{l}0,011 \\
0,028\end{array}$ & $\begin{array}{l}17,44 \\
21,17\end{array}$ & 0 & $\begin{array}{l}18,26 \\
23,60\end{array}$ & 0 & $\begin{array}{r}22,52 \\
22,85\end{array}$ & 0 \\
\hline & \multicolumn{2}{|c|}{$\begin{array}{l}\text { 15. Nov. } \\
1947\end{array}$} & & & \multicolumn{2}{|c|}{$\begin{array}{l}\text { 12. Februar } \\
1948\end{array}$} & & & & & \multicolumn{2}{|c|}{$\begin{array}{l}\text { 19. Mai } \\
1948\end{array}$} \\
\hline $\begin{array}{l}\text { Jg.Tento } \\
\text { Jg.Grande }\end{array}$ & $\begin{array}{r}7,33 \\
10,75\end{array} \mid$ & $\begin{array}{l}0 \\
0\end{array}$ & & & $\begin{array}{l}17,26 \\
21,82\end{array}$ & $\begin{array}{l}0,011 \\
0,011\end{array}$ & & & & & $\begin{array}{l}20,38 \\
29,90\end{array}$ & $\begin{array}{l}0 \\
0\end{array}$ \\
\hline
\end{tabular}

\section{Lago Muretá}

\begin{tabular}{|l|c|c|c|c|c|c|c|c|}
\hline & \multicolumn{2}{|c|}{$\begin{array}{c}\text { 2. Dezember } \\
1947\end{array}$} & \multicolumn{2}{c|}{$\begin{array}{c}\text { 20. Februar } \\
1948\end{array}$} & \multicolumn{2}{|c|}{$\begin{array}{c}\text { 1. April } \\
1948\end{array}$} & \multicolumn{2}{c|}{$\begin{array}{c}25 . \text { Mai } \\
1948\end{array}$} \\
\hline & $\mathrm{KMnO}_{4}$ & Humin. & $\mathrm{KMnO}_{4}$ & Humin. & $\mathrm{KMnO}_{4}$ & Humin. & $\mathrm{KMnO}_{4}$ & Humin. \\
\hline & 24,19 & 0 & 39,99 & 0 & $\begin{array}{l}52,26 \\
58,46\end{array}$ & $\begin{array}{c}0 \\
\text { Spur }\end{array}$ & 36,71 & 0 \\
5 & & & & & & & 39,86 & 0 \\
\hline
\end{tabular}

\section{Lago Caxambú}

\begin{tabular}{|l|c|c|c|c|c|c|c|c|}
\hline & \multicolumn{2}{|c|}{$\begin{array}{c}\text { November } \\
1947\end{array}$} & \multicolumn{2}{c|}{$\begin{array}{c}20 . \text { Februar } \\
1948\end{array}$} & \multicolumn{2}{|c|}{$\begin{array}{c}31 . \mathrm{März} \\
1948\end{array}$} & \multicolumn{2}{|c|}{$\begin{array}{c}\text { 20. Mai } \\
1948\end{array}$} \\
\hline & $\mathrm{KMnO}_{4}$ & Humin. & $\mathrm{KMnO}_{4}$ & Humin. & $\mathrm{KMnO}_{4}$ & Humin. & $\mathrm{KMnO}_{4}$ & Humin. \\
\hline $\begin{array}{l}0 \\
4,5\end{array}$ & 21,48 & 0 & 15,95 & 0 & $\begin{array}{l}14,28 \\
19,71\end{array}$ & 0 & 12,77 & 0 \\
\hline 5,5 & & & & & & & 13,78 & 0 \\
\hline
\end{tabular}




\begin{tabular}{|c|c|c|c|c|c|c|c|c|c|c|}
\hline \multirow[b]{3}{*}{$\mathrm{m}$} & \multicolumn{4}{|c|}{ Lago Salgado } & \multicolumn{6}{|c|}{ Lago Alter do Chão } \\
\hline & \multicolumn{2}{|c|}{$\begin{array}{c}\text { Cabeçeira } \\
\text { do Molha } \\
\text { 22. April } \\
1948\end{array}$} & \multicolumn{2}{|c|}{$\begin{array}{c}\text { Cabeçeira } \\
\text { do Boi } \\
\text { 13. April } \\
1948\end{array}$} & \multicolumn{2}{|c|}{$\begin{array}{c}\text { Süd- } \\
\text { Cabeçeira } \\
\text { 10. Dezember } \\
1947\end{array}$} & \multicolumn{2}{|c|}{$\begin{array}{c}\text { Mitte } \\
\text { 10. Dezember } \\
1947\end{array}$} & \multicolumn{2}{|c|}{$\begin{array}{c}\text { Ost- } \\
\text { Cabeçeira } \\
\text { 10. Dezember } \\
1947\end{array}$} \\
\hline & $\mathrm{KMnO}_{4}$ & Iumin & $\mathrm{KMnO}_{4}$ & Humin. & $\mathrm{KMnO}_{4}$ & Humin. & $\mathrm{KMnO}_{4}$ & Humin. & $\mathrm{KMnO}_{4} \mid$ & Humin \\
\hline $\begin{array}{l}0 \\
3,5 \\
4,5\end{array}$ & $\begin{array}{r}29,81 \\
57,19\end{array}$ & $\begin{array}{l}0 \\
0\end{array}$ & $\begin{array}{l}24,85 \\
113,1\end{array}$ & $\begin{array}{l}0 \\
0\end{array}$ & 16,27 & 0 & \begin{tabular}{|l|}
17,91 \\
13,61
\end{tabular} & $\begin{array}{l}0 \\
0\end{array}$ & 15,35 & 0 \\
\hline
\end{tabular}

\begin{tabular}{|c|c|c|c|c|c|c|c|c|c|c|}
\hline \multirow[b]{2}{*}{$\mathrm{m}$} & \multicolumn{2}{|c|}{$\begin{array}{c}\text { Lago } \\
\text { Pauxis } \\
\text { 25. Juli } \\
1947\end{array}$} & \multicolumn{2}{|c|}{$\begin{array}{l}\text { Lago } \\
\text { Verde } \\
25 \text {. Juli } \\
1947\end{array}$} & \multicolumn{2}{|c|}{$\begin{array}{c}\text { Lago } \\
\text { do Caxias } \\
\text { 31. Dezember } \\
1947\end{array}$} & \multicolumn{2}{|c|}{$\begin{array}{c}\text { Lago } \\
\text { Timbó } \\
\text { 11. Januar } \\
1948\end{array}$} & \multicolumn{2}{|c|}{$\begin{array}{l}\text { Lago } \\
\text { Curí } \\
\text { 9. Januar } \\
1948\end{array}$} \\
\hline & $\mathrm{KMnO}_{4}$ & ${ }_{4}$ Humin. & $\mathrm{KMnO}_{4}$ & Humin. & $\mathrm{KMnO}_{4}$ & Humin & $\mathrm{KMnO}_{4}$ & Humin & $\mathrm{KMnO}_{4}$ & 4 Humin. \\
\hline $\begin{array}{l}0 \\
2 \\
3 \\
3,5\end{array}$ & $\begin{array}{l}12,75 \\
15,51\end{array}$ & - & 12,39 & - & $\begin{array}{l}49,51 \\
54,07\end{array}$ & $\begin{array}{l}0,085 \\
0,056\end{array}$ & $\begin{array}{l}30,67 \\
29,95\end{array}$ & 0 & $\begin{array}{l}37,73 \\
34,52\end{array}$ & 0,028 \\
\hline
\end{tabular}

\begin{tabular}{|c|c|c|c|c|c|c|c|c|c|c|}
\hline \multirow[b]{3}{*}{$\mathrm{m}$} & \multicolumn{4}{|c|}{ Lago Curuçá } & \multicolumn{6}{|c|}{ Lago Jruçanga } \\
\hline & \multicolumn{2}{|c|}{$\begin{array}{l}\text { Aningateil } \\
\text { 1. Januar } \\
1948\end{array}$} & \multicolumn{2}{|c|}{$\begin{array}{l}\text { Victoriateil } \\
\text { 3. Januar } \\
1948\end{array}$} & \multicolumn{2}{|c|}{$\begin{array}{c}\text { 1. Dezember } \\
1947\end{array}$} & \multicolumn{2}{|c|}{$\begin{array}{l}\text { 21. Februar } \\
1948\end{array}$} & \multicolumn{2}{|c|}{$\begin{array}{l}\text { 26. Mai } \\
1948\end{array}$} \\
\hline & $\mathrm{KMnO}_{4} \mid$ & Humin. & $\mathrm{KMnO}_{4}$ & Humin & $\mathrm{KMnO}_{4}$ & umin. & $\mathrm{KMnO}_{4}$ & Humin. & $\mathrm{KMnO}_{4}$ & Humin. \\
\hline $\begin{array}{l}0 \\
1,5 \\
2\end{array}$ & $\begin{array}{l}56,54 \\
55,49\end{array}$ & $\begin{array}{l}0,073 \\
0\end{array}$ & $\begin{array}{r}49,37 \\
50,68\end{array}$ & $\begin{array}{l}0,056 \\
0,426\end{array}$ & 18,70 & 0 & 12,30 & 0 & 36,97 & 0 \\
\hline
\end{tabular}

\begin{tabular}{|c|c|c|c|c|}
\hline & \multicolumn{2}{|c|}{$\begin{array}{c}\text { Lago Maritima } \\
\text { 19. Februar 1948 }\end{array}$} & \multicolumn{2}{|c|}{$\begin{array}{c}\text { Lago Pindobal } \\
\text { 24. Mai 1948 }\end{array}$} \\
\hline $\mathrm{m}$ & $\mathrm{KMnO}_{4}$ & Huminsäure & $\mathrm{KMnO}_{4}$ & Huminsäure \\
\hline 0 & 90,27 & 0,100 & 105,67 & 1,150 \\
\hline
\end{tabular}


uns diese Bestimmung immerhin einen Fingerzeig und kann, wenn genügend Resultate vorliegen, zu Vergleichszwecken wertvoll sein.

Der $\mathrm{KMnO}_{4}$-Verbrauch in den amazonischen Seen schwankt zwischen 7,7 und $\mathrm{I}_{3} \mathrm{mg} / \mathrm{l}$. Einige Resultate sind aus der Tabelle 7 ersichtlich. In den meisten Seen stellten wir ungewöhnlich hohe Werte fest (Lago Muretá, Lago Salgado, Lago Caxias, Lago Curuçá, Lago Timbó, Lago Curí, Lago Maritima), in einigen wenigen jedoch für europäische Begriffe «normale» Mengen (ro bis $20 \mathrm{mg} / \mathrm{l}$ ), wie im Lago Jurucui, Lago Caxambú, Lago Alter do Chão, Lago Pauxis und Lago Verde.

Diese hohe Permanganatzahl wird uns verständlich, wenn wir bedenken, $\mathrm{da} B$ in jenen tropischen Gegenden die Zufuhr organischen Materials infolge üppigster Vegetation ungleich größer ist als in europäischen Gegenden. Die Zersetzungsgeschwindigkeit dieser organischen Substanz ist bei der hohen Temperatur sehr groß, außerdem werden durch das Fehlen der kalten Jahreszeit diese Zersetzungsvorgänge nicht periodisch verringert wie in der gemäßigten Zone, sondern sie gehen das ganze Jahr kontinuierlich weiter.

Huminsäuren fanden wir nur vereinzelt in den Seen Jurucui, Caxias, Curuçá, Curí, Maritima und im Schwarzwassertümpel Pindobal, im letzteren das Maximum von I, I5 mval/l. Dies ist weiter nicht erstaunlich, denn dieses Gewässer liegt direkt im Jgapó; um den See herum sowie am Grunde desselben liegen in großer Menge abgestorbene Reste der Vegetation. Auch der $\mathrm{KMnO}_{4}$-Verbrauch ist entsprechend hoch ( $105 \mathrm{mg} / \mathrm{l}$ ).

Auch bei der Huminsäure erkennen wir einen mehr oder weniger deutlichen Anstieg während der Regenzeit, besonders im Lago Jurucui am I2. Februar I948. Wie beim Ammoniak bilden auch hier die Zuflüsse Jgarapé do Tento und Jgarapé Grande die Huminsäurezufuhr mit o, I I bzw. o,or I mval/l, deren Ursprung in den Jgapós mit ihrem großen Gehalt an zersetzender Vegetation zu suchen ist.

In den Seen Caxambú und Muretá, Salgado, Timbó und Jruçanga konnten wir, abgesehen von Spuren, keine Huminsäuren nachweisen, obschon der $\mathrm{KMnO}_{4}$-Verbrauch - namentlich im Lago Muretá - beträchtlich hoch war, wogegen in den Seen Caxias, Curí und Curuçá zum Teil sehr' reichliche Humussäuremengen feststellbar waren. Die Ursache dieser Inkorrelation vermögen wir nicht anzugeben.

\section{g) Der Eisen- und Mangangehalt}

Mit dem Kohlensäure- und Sauerstoffhaushalt in enger Beziehung stehend, treten Eisen und Mangan in den Gewässern in Form von gelöstem 
Bikarbonat auf(Ferro- bzw. Manganobikarbonat). Dabei steigt die Löslichkeit dieser Bikarbonate mit der Sauerstoffarmut des Wassers. Kommt zu einem sauerstoff freien, eisenbikarbonathaltigen Wasser Sauerstoff, so wird das Ferrobikarbonat zu unlöslichem Ferrihydroxyd unter Abgabe von Kohlensäure oxydiert:

$$
2 \mathrm{Fe}\left(\mathrm{HCO}_{3}\right)_{2}+\frac{1}{2} \mathrm{O}_{2}+\mathrm{H}_{2} \mathrm{O}=2 \frac{\mathrm{Fe}(\mathrm{OH})_{3}}{\downarrow}+4 \mathrm{CO}_{2} .
$$

Das Ferrihydroxyd fällt unter Bildung von rotbraunen Flocken aus. Daraus folgt, daß wir in den oberflächlichen sauerstoffreichen Wasserschichten - namentlich der alkalischen Seen - kein Eisen oder dann nur in sehr geringen Mengen nachweisen können. Eine Ausnahme bilden die Humusseen. Gelöstes Eisen in größeren Mengen kann daher normalerweise nur im sauerstoffarmen Hypolimnion eutropher Seen nachgewiesen werden. Auch hier bilden Ausnahmen natürliche Gewässer, die in stark eisenhaltigem Untergrund eingebettet liegen. Auch sauerstoffarme Quellen können erhebliche Mengen davon enthalten.

Über die Bedeutung des Eisens als Spurenelement im normalen Stoffwechsel eines Sees brauchen wir weiter keine Worte zu verlieren. Es sei nur daran erinnert, daß eine Eisenanreicherung im Tiefenwasser nicht nur als Folge des organischen Stoffwechsels möglich ist, sondern daß es auch durch spezielle Eisenorganismen unter den Planktern in Spuren gespeichert werden kann, so daß beim Absterben bzw. Absinken dieser Organismen der Eisengehalt am Grunde der Seen erheblich erhöht wird. Wird dieses eisenhaltige, sauerstofffreie Tiefenwasser durch Konvektionsströmungen in die oberen Wasserschichten verfrachtet, so kann durch Zutritt von Sauerstoff Eisenhydroxyd in Form mikroskopisch kleiner Flocken ausfallen; diese sinken wieder auf den sauerstoffarmen Grund, wo sie wiederum aufgelöst werden. Durch Austauschströmungen können dann auch darüberlagernde Wasserschichten vorübergehend an Ferrobikarbonaten angereichert werden. Außer der Bikarbonatform kann das Eisen auch in Form echt oder kolloidal gelöster organischer Verbindungen im Wasser vorkommen. Diese Bestimmungen waren für uns aus technischen Gründen undurchführbar.

Normalerweise haben wir in den temperierten Seen Mitteleuropas folgende Schichtungsverhältnisse des Eisens: In den epilimnischen, sauerstoffreichen Wasserschichten finden wir kein Eisen oder nur in geringen Mengen. Im Hypolimnion jedoch kann sich das Eisen bis zu mehreren Milligramm pro Liter anreichern. Der Anstieg des Eisengehaltes beginnt 
meistens an der oberen Grenze des Hypolimnions, um am Grunde das Maximum zu erreichen. Hie und da beobachtet man mit zunehmender Tiefe wieder eine Abnahme, und zwar dann, wenn im betreffenden Wasser reichlich Schwefelwasserstoff vorhanden ist (zum Beispiel in extrem eutrophen Seen), welcher das Eisen in Sulfidform auszufällen vermag (siehe RUTTNER, I93I).

Auch RUTTNER fand in den Tropenseen Niederländisch-Indiens prinzipiell dieselben Verhältnisse vor. Manche dieser Seen zeichnen sich durch hohen Eisengehalt aus (bis $2,3 \mathrm{mg} / \mathrm{l}$ ), in andern konnte RUTTNER nur Spuren nachweisen, was er zum Teil auf Anwesenheit genügender Sauerstoffmengen im Tiefenwasser und auf Eisenarmut des Untergrundes zurückführt.

Über die Rolle bzw. die Verteilung des Mangans in den Seen ist man heute noch sehr wenig unterrichtet. Meistens stimmt der Mangankreislauf mit dem Eisenkreislauf überein. RUTTNER hat jedoch in den javanischen Seen vollkommen unerklärliche Manganverhältnisse angetroffen, indem er in manchen Seen knapp unterhalb der Sprungschicht an der oberen Grenze der sauerstofflosen Zone bis zu I $5 \mathrm{mg} / \mathrm{l}$ Mangan nachweisen konnte. Mit zunehmender Tiefe sank der Gehalt ab. In manchen Fällen konnte RUTTNER auch zwei Manganmaxima feststellen.

Betrachten wir nun unsere Eisenbestimmungen in den amazonischen Seen, die in Tabelle 8 dargestellt sind. Im Vergleich zu den temperierten Seen und den von RUTTNER untersuchten Tropenseen sind die amazonischen allgemein eisenarm, was in den geologisch-mineralogischen Verhältnissen begründet liegt. Im Lago Alter do Chão lag der Eisengehalt unter der Nachweisbarkeitsgrenze, im Lago Muretá und Lago Caxambú knapp darüber. Einigen Aufschluß über die Verteilung des Eisens in den amazonischen Seen gibt uns die Untersuchungsserie im Lago Jurucui. Den höchsten Eisengehalt stellten wir dort am I7. Mai 1948 in $5,5 \mathrm{~m}^{\prime}$ Tiefe fest $(0,16 \mathrm{mg} / \mathrm{l})$. Auch die Schichtungsverhältnisse entsprachen durchaus den Erwartungen, indem mit zunehmender Tiefe ein deutlicher Anstieg feststellbar war. Die beiden Zuflüsse Jgarapé do Tento und Jgarapé Grande sind etwas eisenärmer als das Seewasser; das Eisen wird am Grunde des Sees offenbar angereichert und gespeichert.

Auch beim Eisen erkennen wir eine deutliche Abhängigkeit von der Regenzeit. Zu Beginn derselben lag der Eisengehalt unter der Nachweisbarkeitsgrenze, stieg dann langsam an und erreichte gegen Ende der Regenperiode das Maximum. Auch im Lago Muretá und Lago Caxambú ist diese Abhängigkeit, wenn auch nur andeutungsweise, ersichtlich. 
Tabelle 8

\section{Gesamteisen}

\section{Lago Furucui und Zuflüsse}

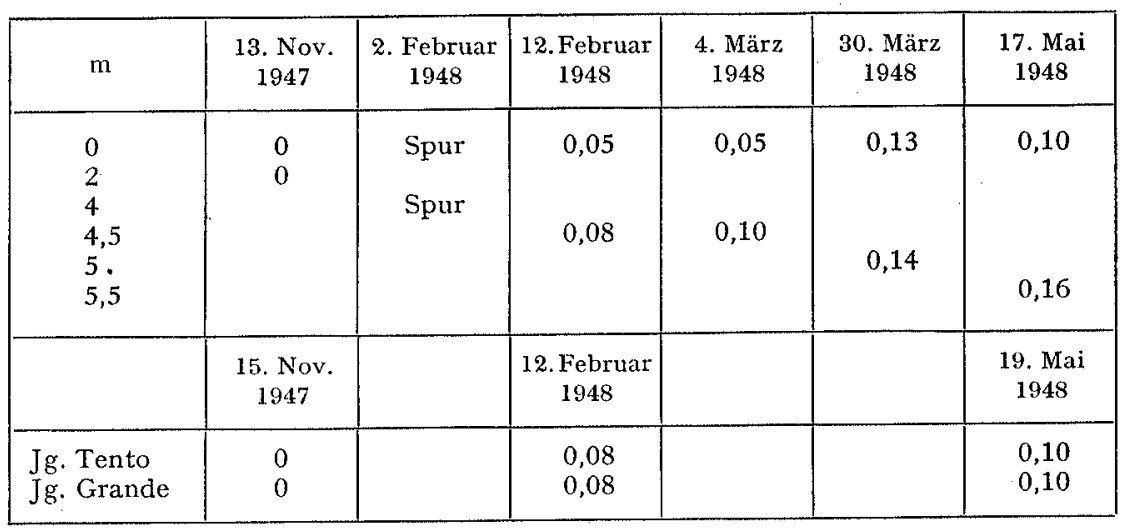

\section{Lago Muretá}

\begin{tabular}{|c|c|c|c|c|}
\hline $\mathrm{m}$ & 2. Dezember 1947 & 20. Februar 1948 & 1. April 1948 & 25. Mai 1948 \\
\hline 0 & 0 & 0 & $\begin{array}{c}0 \\
\text { Spur }\end{array}$ & 0 \\
5 & & & 0 \\
\hline
\end{tabular}

\section{Lago Caxambú}

\begin{tabular}{|c|c|c|c|c|}
\hline $\mathrm{m}$ & 24. November 1947 & 20. Februar 1948 & 31. März 1948 & 15. Mai 1948 \\
\hline 0 & 0 & 0 & $\begin{array}{l}0,05 \\
0,05\end{array}$ & 0 \\
4,5 & & 0 & 0 \\
\hline
\end{tabular}

\begin{tabular}{|c|c|c|c|c|}
\hline & \multicolumn{2}{|c|}{ Lago Salgado } & Lago do Caxias & Lago Maritima \\
\hline $\mathrm{m}$ & $\begin{array}{c}\text { Cabeçeira } \\
\text { do Molha } \\
22 . \text { April 1948 }\end{array}$ & $\begin{array}{c}\text { Cabeçeira } \\
\text { do Boi } \\
\text { 12. Februar 1948 }\end{array}$ & $\begin{array}{c}\text { 13. Dezember } \\
1947\end{array}$ & 19. Februar 1948 \\
\hline $\begin{array}{l}3,5 \\
4,5\end{array}$ & 0,27 & 0,20 & $\begin{array}{c}0,29 \\
0,40\end{array}$ & 0,40 \\
\hline
\end{tabular}




\begin{tabular}{|c|c|c|c|c|c|c|c|}
\hline $\mathrm{m}$ & \multicolumn{2}{|c|}{ Lago Curuçá } & $\begin{array}{r}\text { Lago } \\
\text { Timbó }\end{array}$ & Lago Curi & \multicolumn{3}{c|}{ Lago Jruçanga } \\
\hline $\mathrm{m}$ & $\begin{array}{c}\text { Aninga- } \\
\text { teil } \\
\text { 1. Januar } \\
\mathbf{1 9 4 8}\end{array}$ & $\begin{array}{c}\text { Victoria- } \\
\text { teil } \\
\text { 3. Januar } \\
\mathbf{1 9 4 8}\end{array}$ & $\begin{array}{c}\text { 11. Januar } \\
\mathbf{1 9 4 8}\end{array}$ & $\begin{array}{c}\text { 9. Januar } \\
\mathbf{1 9 4 8}\end{array}$ & $\begin{array}{c}\text { 1. Dez. } \\
\mathbf{1 9 4 7}\end{array}$ & $\begin{array}{c}\text { 21. Februar } \\
1948\end{array}$ & $\begin{array}{c}\text { 26. Mai } \\
\mathbf{1 9 4 8}\end{array}$ \\
\hline $\begin{array}{l}\mathbf{1}, 5 \\
\mathbf{3}\end{array}$ & $\begin{array}{l}0,20 \\
0,30\end{array}$ & 0,20 & 0,18 & 0,10 & Spur & 0 & 0,50 \\
\hline
\end{tabular}

Auch in bezug auf den geologischen Untergrund scheint uns eine Abhängigkeit des Eisengehaltes zu bestehen. Einerseits haben wir die Tertiärseen Lago Jurucui, Lago Muretá, Lago Caxambú und Lago Alter do Chão mit einem äußerst geringen Eisengehalt von maximal o, $16 \mathrm{mg} / \mathrm{l}$, anderseits die Karbonseen mit einem auffallend höheren Gehalt bis $0,7 \mathrm{mg} / \mathrm{l}$. Etwas aus der Reihe tanzen dabei der Lago Jruçanga mit einem Eisengehalt bis 0,5 mg/l (26. Mai 1948) und der Lago Maritima mit 0,4 mg/l (I9. Februar I948). Ist schon allein die Tatsache bemerkenswert, daß in einem Oberflächenwasser, das ja normalerweise genügend Sauerstoff besitzt, so große Mengen Eisen in Lösung enthält, so passen diese beiden Seen auch nicht in unser Schema über die Abhängigkeit mit dem geologischen Untergrund. Es sind Tertiärseen mit einem zu hohen Eisengehalt! Wir könnten uns diese Inkorrelation so erklären: Diese beiden Gewässer besitzen sehr weiches Wasser, wie alle Tertiärseen; außerdem sind sie reich an Humusstoffen und Kohlensäure, wie dies aus den vorhergehenden Kapiteln ersichtlich ist. Es ist bekannt, daß solche Wässer viel leichter Eisen in Lösung halten können als humusarme alkalische, denn das Eisen ist in Humuswässern zum Teil komplex an Huminsäuren gebunden und nur teilweise als Bikarbonat! Es ist daher verständlich, daß sich im Lago Jruçanga und im Lago Maritima trotz dem Sauerstoff soviel Eisen in Lösung halten kann. Aber auch beim längeren Stehenlassen an der Luft wurde dann namentlich das Wasser des Lago Maritima zusehends trüber und verfärbte sich bräunlich, was die Bestimmung des Ammoniaks damals empfindlich störte.

Es bleibt uns noch der relativ hohe Eisengehalt dieser Tertiärseen zu erklären. Der eigentliche Untergrund ist ja derselbe wie bei den übrigen, normaleisenarmen Tertiärseen. Offenbar spielt hier die Speicherung bzw. Anreicherung des Eisens durch die Mikroorganismen eine Hauptrolle. Der Lago Jruçanga ist ein verlandender See im letzten Stadium, der Lago 
Maritima ein in reichlichen Resten der abgestorbenen Vegetation eingebetteter Schwarzwassertümpel. In beiden Fällen ist also die Grundlage für eine intensive mikrobiotische Tätigkeit geschaffen.

Ob nun nicht eventuell derselbe Grund für die eisenreichen Karbonseen geltend gemacht werden könnte oder ob dort wirklich der andere geologische Untergrund für die Eisenanreicherung verantwortlich zu machen ist, vermögen wir nicht mit Sicherheit zu entscheiden; dazu wären ausgedehntere Untersuchungen notwendig.

Obschon wir bei allen unseren Proben auch immer auf Mangan prüften, konnten wir diesen Stoff in keinem einzigen Falle nachweisen. Auch in dieser Hinsicht stehen die amazonischen Seen in deutlichem Gegensatz zu den von RutTNER untersuchten Tropenseen. Doch hier kann wohl mit Sicherheit gesagt werden, daß für den Manganreichtum jener Seen der geologisrhe Untergrund bestimmend war.

\section{h) Chloride, Kieselsäure, Aluminium und Sulfate}

\section{Chloride}

Aus der Tatsache, daß in den Niederländisch-Indischen Seen eine nennenswerte Schichtung der Chloride fehlt, schließt RuTTNER (1931), daß sie im Stoffwechsel des Sees keine Rolle spielen. RuttNer fand in jenen Tropenseen - mit einigen Ausnahmen - nur geringe Mengen an Chloriden.

Für die Beurteilung der Gewässer in Europa in hygienischer Hinsicht spielt bekanntlich der Chloridgehalt eine große Rolle, indem erhebliche Mengen an Cl-Ionen als Belastung des Gewässers mit Schmutzstoffen angesehen werden können, falls nicht ein entsprechender geologischer Untergrund für den Chloridgehalt maßgebend wirkt.

In Tabelle 9 sind die Chloridgehalte unserer amazonischen Seen eingetragen. Diese Mengen sind sehr gering. Wenn wir diese Werte zum Beispiel mit schweizerischen Mittellandseen vergleichen (siehe MärKI, I944), so würden sie denjenigen eines sauberen, oligotrophen Sees entsprechen (Langensee, Vierwaldstättersee).

Der Anstieg des Chloridgehaltes mit fortschreitender Regenzeit ist auch hier wieder in der Untersuchungsserie des Lago Jurucui augenfällig. Im Gegensatz zu RUTTNER, der, wie oben erwähnt wurde, in den niederländisch-indischen Tropenseen keine Schichtungen des Chloridgehaltes feststellte, konnten wir in den amazonischen Seen doch einige Schichtungsbilder festhalten, so im Lago Jurucui am 2. Februar I948, 4. März I948, 
Tabelle 9

\section{Chloride und Kieselsäure}

Lago Furucui und Zuflüsse

\begin{tabular}{|c|c|c|c|c|c|c|c|c|c|c|c|c|}
\hline \multirow[b]{2}{*}{$\mathrm{m}$} & \multicolumn{2}{|c|}{$\begin{array}{c}\text { 13. Nov. } \\
1947\end{array}$} & \multicolumn{2}{|c|}{$\begin{array}{c}\text { 2. Februar } \\
1948\end{array}$} & \multicolumn{2}{|c|}{$\begin{array}{l}\text { 12. Februar } \\
1948\end{array}$} & \multicolumn{2}{|c|}{$\begin{array}{l}\text { 4. März } \\
1948\end{array}$} & \multicolumn{2}{|c|}{$\begin{array}{c}\text { 30. März } \\
1948\end{array}$} & \multicolumn{2}{|c|}{$\begin{array}{l}\text { 17. Mai } \\
1948\end{array}$} \\
\hline & $\mathrm{Cl}$ & $\mathrm{SiO}_{2}$ & $\mathrm{Cl}$ & $\mathrm{SiO}_{2}$ & $\mathrm{Cl}$ & $\mathrm{SiO}_{2}$ & $\mathrm{Cl}$ & $\mathrm{SiO}_{2}$ & CI & $\mathrm{SiO}_{2}$ & $\mathrm{Cl}$ & $\mathrm{SiO}_{2}$ \\
\hline \multirow[t]{2}{*}{$\begin{array}{l}0 \\
2 \\
4 \\
4,5 \\
5 \\
5,5\end{array}$} & $\begin{array}{c}0 \\
\text { Spur }\end{array}$ & $\begin{array}{l}6,5 \\
6,5\end{array}$ & $\begin{array}{l}0,30 \\
0,10\end{array}$ & $\begin{array}{l}6,0 \\
6,0\end{array}$ & $\begin{array}{l}0,30 \\
0,25\end{array}$ & $\begin{array}{l}6,0 \\
5,6\end{array}$ & $\begin{array}{l}0,50 \\
0,10\end{array}$ & 5,0 & $\begin{array}{l}0,50 \\
0,1.5\end{array}$ & 4,0 & 0,10 & 5,0 \\
\hline & \multicolumn{2}{|c|}{$\begin{array}{c}\text { 15. Nov. } \\
1947\end{array}$} & & & \multicolumn{2}{|c|}{$\begin{array}{l}\text { 12. Februar } \\
1948\end{array}$} & & & & & \multicolumn{2}{|c|}{$\begin{array}{l}\text { 19. Mai } \\
1948\end{array}$} \\
\hline $\begin{array}{l}\text { Jg. Tento } \\
\text { Jg. Grande }\end{array}$ & $\begin{array}{c}0 \\
0,3\end{array}$ & $\begin{array}{l}6,0 \\
4,5\end{array}$ & & & $\begin{array}{l}0,40 \\
0,30\end{array}$ & $\begin{array}{l}6,0 \\
6,0\end{array}$ & & & & & $\begin{array}{l}0,20 \\
0,30\end{array}$ & $\begin{array}{l}5,0 \\
5,4\end{array}$ \\
\hline
\end{tabular}

\section{Lago Muretá}

\begin{tabular}{|c|c|c|c|c|c|c|c|c|}
\hline \multirow[b]{2}{*}{$\mathrm{m}$} & \multicolumn{2}{|c|}{ 2. Dezember 1947} & \multicolumn{2}{|c|}{ 20. Februar 1948} & \multicolumn{2}{|c|}{ 1. April 1948} & \multicolumn{2}{|c|}{ 25. Mai 1948} \\
\hline & $\mathrm{Cl}$ & $\mathrm{SiO}_{2}$ & $\mathrm{Cl}$ & $\mathrm{SiO}_{2}$ & $\mathrm{Cl}$ & $\mathrm{SiO}_{2}$ & $\mathrm{Cl}$ & $\mathrm{SiO}_{2}$ \\
\hline $\begin{array}{l}0 \\
5 \\
5,5\end{array}$ & 0,70 & 5,2 & 0,60 & 5,6 & $\begin{array}{l}0,40 \\
0,20\end{array}$ & $\begin{array}{l}4,0 \\
4,1\end{array}$ & $\begin{array}{l}0,40 \\
\text { Spur }\end{array}$ & $\begin{array}{l}3,6 \\
3,6\end{array}$ \\
\hline
\end{tabular}

\section{Lago Caxambú}

\begin{tabular}{|c|c|c|c|c|c|c|c|c|}
\hline & \multicolumn{2}{|c|}{ 24. November 1947 } & \multicolumn{2}{|c|}{ 20. Februar 1948 } & \multicolumn{2}{c|}{$31 . \mathrm{März} 1948$} & \multicolumn{2}{c|}{ 20. Mai 1948 } \\
\hline $\mathrm{m}$ & $\mathrm{Cl}$ & $\mathrm{SiO}_{2}$ & $\mathrm{Cl}$ & $\mathrm{SiO}_{2}$ & $\mathrm{Cl}$ & $\mathrm{SiO}_{2}$ & $\mathrm{Cl}$ & $\mathrm{SiO}_{2}$ \\
\hline $\begin{array}{l}0,5 \\
5,5\end{array}$ & 0,50 & 3,5 & 0,70 & 4,8 & $\begin{array}{c}\mathrm{Spur} \\
0\end{array}$ & $\begin{array}{c}3,6 \\
3,8\end{array}$ & $\begin{array}{c}0,30 \\
\text { Spur }\end{array}$ & 3,0 \\
\hline
\end{tabular}




\begin{tabular}{|c|c|c|c|c|c|c|c|c|}
\hline \multirow[b]{3}{*}{$\mathrm{m}$} & \multicolumn{4}{|c|}{ Lago Salgado } & \multirow{2}{*}{\multicolumn{2}{|c|}{$\begin{array}{l}\text { Lago do Caxias } \\
\text { 31.Dezember } 1947\end{array}$}} & \multirow{2}{*}{\multicolumn{2}{|c|}{$\begin{array}{l}\text { Lago Maritima } \\
\text { 19. Februar } 1948\end{array}$}} \\
\hline & \multicolumn{2}{|c|}{$\begin{array}{l}\text { Cabeçeira do } \\
\text { Molha } \\
\text { 22. April } 1948\end{array}$} & \multicolumn{2}{|c|}{$\begin{array}{c}\text { Cabeçeira } \\
\text { do Boi } \\
\text { 13. April } 1948\end{array}$} & & & & \\
\hline & $\mathrm{Cl}$ & $\mathrm{SiO}_{2}$ & $\mathrm{Cl}$ & $\mathrm{SiO}_{2}$ & $\mathrm{Cl}$ & $\mathrm{SiO}_{2}$ & $\mathrm{Cl}$ & $\mathrm{SiO}_{2}$ \\
\hline $\begin{array}{l}0 \\
2 \\
3,5 \\
4,5\end{array}$ & 0 & 5,6 & $\begin{array}{l}\text { Spur } \\
\text { Spur }\end{array}$ & 5,6 & $\begin{array}{l}\text { Spur } \\
\text { Spur }\end{array}$ & $\begin{array}{l}5,0 \\
4,8\end{array}$ & 0,10 & 5,0 \\
\hline
\end{tabular}

\begin{tabular}{|c|c|c|c|c|c|c|c|c|c|c|}
\hline \multirow[b]{3}{*}{$\mathrm{m}$} & \multicolumn{6}{|c|}{ Lago Alter do Chão } & \multicolumn{4}{|c|}{ Lago Curuçá } \\
\hline & \multicolumn{2}{|c|}{$\begin{array}{c}\text { Süd-Cabeçeira } \\
\text { 10. Dezember } \\
1947\end{array}$} & \multicolumn{2}{|c|}{$\begin{array}{c}\text { Mitte } \\
\text { 10. Dezember } \\
1947\end{array}$} & \multicolumn{2}{|c|}{$\begin{array}{c}\text { Ost-Cabeçeira } \\
\text { 10. Dezember } \\
1947\end{array}$} & \multicolumn{2}{|c|}{$\begin{array}{l}\text { Aningateil } \\
\text { 1. Januar } \\
1948\end{array}$} & \multicolumn{2}{|c|}{$\begin{array}{l}\text { Vic toriateil } \\
\text { 3. Januar } \\
1948\end{array}$} \\
\hline & $\mathrm{Cl}$ & $\mathrm{SiO}_{2}$ & $\mathrm{Cl}$ & $\mathrm{SiO}_{2}$ & $\mathrm{Cl}$ & $\mathrm{SiO}_{2}$ & $\mathrm{Cl}$ & $\mathrm{SiO}_{2}$ & $\mathrm{Cl}$ & $\mathrm{SiO}_{2}$ \\
\hline $\begin{array}{l}0 \\
1,5 \\
2 \\
4,5\end{array}$ & 0,40 & 5,7 & 0,70 & $\begin{array}{l}5,1 . \\
5,5\end{array}$ & 0 & 5,0 & $\begin{array}{l}0,90 \\
\text { Spur }\end{array}$ & $\begin{array}{l}5,6 \\
5,2\end{array}$ & $\begin{array}{l}\text { Spur } \\
\text { Spur }\end{array}$ & $\begin{array}{l}5,0 \\
5,0\end{array}$ \\
\hline
\end{tabular}

\begin{tabular}{|c|c|c|c|c|c|c|c|c|c|c|}
\hline & \multicolumn{5}{|c|}{ Lago Jruçanga } & \multicolumn{2}{c|}{ Lago Tim bó } & \multicolumn{2}{|c|}{ Lago Curí } \\
\hline & $\begin{array}{c}\text { 1. Dezember } \\
1947\end{array}$ & $\begin{array}{c}\text { 21. Februar } \\
1948\end{array}$ & 26. Mai 1948 & \multicolumn{2}{c|}{$\begin{array}{c}\text { 11. Januar } \\
1948\end{array}$} & \multicolumn{2}{c|}{$\begin{array}{c}\text { 9. Januar } \\
1948\end{array}$} \\
\hline $\mathrm{m}$ & $\mathrm{Cl}$ & $\mathrm{SiO}_{2}$ & $\mathrm{Cl}$ & $\mathrm{SiO}_{2}$ & $\mathrm{Cl}$ & $\mathrm{SiO}_{2}$ & $\mathrm{Cl}$ & $\mathrm{SiO}_{2}$ & $\mathrm{Cl}$ & $\mathrm{SiO}_{2}$ \\
\hline 0 & 2,0 & 5,9 & 0,40 & 6,0 & $\mathrm{Spur}$ & 6,0 & $\begin{array}{c}5,4 \\
0\end{array}$ & $\begin{array}{c}\text { Spur } \\
\text { Spur }\end{array}$ & $\begin{array}{c}3,1 \\
3,2\end{array}$ \\
\hline
\end{tabular}

30. März 1948, ferner im Lago Muretá am I. April I948, 25. Mai 1948, dann im Lago Alter do Chão am Io. Dezember I947 und im Lago Curuçá am I. Januar 1948. In andern Seen jedoch war gar keine Schichtung der Chloride zu beobachten, obschon Sauerstoff und Kohlensäure deutlich geschichtet waren. In den meisten Fällen war eine Abnahme des $\mathrm{Cl}^{-}$-Gehalts nach der Tiefe zu feststellbar.

Da die Chloride allgemein als unwichtig für den Stoff haushalt angesehen werden, erübrigt es sich, näher auf diese Schichtung einzutreten, die offenbar durch hydrographische Momente bedingt ist. 


\section{Kieselsäure und Aluminium}

Die Kieselsäure, an und für sich von geringer Bedeutung als Baustoff der organischen Substanz, spielt im Stoff haushalt der Seen insofern eine Rolle, als sie den Grundstoff für die Schalen der Diatomeen liefert. Außerdem wird Kieselsäure von verschiedenen anderen Mikroorganismen (Chrysomonaden, Protozoen) zur Verfestigung mancher Organe verwendet. Hingegen am eigentlichen Nährstoffwechsel nimmt Kieselsäure wohl kaum teil. Sie ist in gelöster oder kolloidaler Form im Wasser vorhanden.

Entsprechend ihrer Bedeutung als Baustoff für die Kieselalgen ist zu erwarten, daß Kieselsäure nicht regelmäßig im See verteilt, sondern in Schichtung vorliegt, und zwar derart, daß im Epilimnion mit reicher Diatomeenentwicklung eine Kieselsäurezehrung, an Grunde des Sees eine Anreicherung durch die abgestorbenen und abgesunkenen Diatomeen stattfindet.

Unsere Kieselsäurebestimmungen (als $\mathrm{SiO}_{2}$ ) sind in Tabelle 9 eingetragen. In jedem der untersuchten Gewässer konnten wir Kieselsäure in Mengen nachweisen, die sich in normalem Rahmen bewegen, das heißt zwischen 3 und $6,5 \mathrm{mg} / \mathrm{l}$. Die theoretisch zu erwartende Schichtung kommt im Lago Jurucui, Lago Caxambú und Lago Alter do Chão in Form einer leichten 'Zunahme nach der Tiefe einigermaßen zum Ausdruck. Zeitweise konnten wir gar keine Schichtung feststellen, manchmal sogar eine leichte Abnahme. Prinzipiell dieselben Verhältnisse fand RutTNER in den niederländisch-indischen Tropenseen sowie YoshImuRA (I930, zitiert nach RUTTNER, 193I) in einigen japanischen Seen.

Aluminium, obschon immer darauf gepruff, konnte in keiner Wasserprobe nachgewiesen werden. Auch SIOLI (I950) gelang es bei seinen Flußuntersuchungen im Amazonasgebiet nicht, Aluminium festzustellen. Er gibt dazu folgende Erklärung, der wir uns anschließen:

«Die auffallende vollständige Abwesenheit von Aluminium in allen bisher untersuchten Gewässern mag ebenfalls zum Teil auf eine solche Armut an Kationen im Boden hinweisen. Es ist bekannt, daß, während in kühleren Klimaten die Bodenverwitterung zu Sand als Endprodukt führt, in den Tropen Aluminiumhydrargillit die Endstufe der Verwitterung darstellt, das heißt, in den Böden kühlerer Klimate wandert das Aluminium, und die Kieselsäure ist stationär - in tropischen Böden ist das Umgekehrte der Fall. Aluminium im Boden ist eine austauschfähige Substanz: Führen wir zum Beispiel Kaliumkationen in den Boden ein, so geht das Aluminium heraus. Damit wird vielleicht verständlich, daß wir in amazonischen Wäs- 
sern kein Aluminium antreffen, da, wie wiederum die Wasseranalysen zeigen, im Boden und Bodenwasser starke Kationen nur in so geringer Menge vorhanden sind, daß sie keinen Ionenaustausch bewirken können.»

\section{Sulfate}

In den natürlichen Gewässern Europas sind Sulfate fast immer in größeren oder kleineren Mengen vorhanden, meistens in Form von $\mathrm{CaSO}_{4}$ (Gips), das aus bestimmten geologischen Formationen stammt. Sulfatzehrung durch Organismen ist sehr gering, so daß es in natürlichen Gewässern kaum zu deutlichen Schichtungen kommt.

RUTTNER prüfte in den niederländisch-indischen Seen nur qualitativ, wobei er einige positive Befunde hatte. Eine Schichtung konnte er nicht nachweisen.

Wir konnten in den amazonischen Seen nur in einem einzigen Falle Sulfate feststellen, nämlich im Lago Salgado, Cabeçeira do Boi (r3. April 1948) in einer Menge von $16 \mathrm{mg} / \mathrm{l}$. Diese Sulfate gelangen durch den Jgarapé Salgadinho, einen kleinen Zufluß, in den See. Dieser Jgarapé wies damals einen Sulfatgehalt von $464 \mathrm{mg} / \mathrm{l}$ (!) auf (daher der Name).

\section{i) Die Gesamthärte}

Ein Blick auf Tabelle ro zeigt uns in eindrücklicher Weise die allgemeine Salzarmut der amazonischen Seen. Die Härte schwankt zwischen o und 3,86 französischen Graden. Solch extrem weiche Wässer sind in Europa selten, im Amazonasgebiet die Regel, namentlich in den Gewässern des Tertiärs. Eine deutlich höhere Gesamthärte finden wir in den Karbonseen, zum Beispiel im Lago Salgado mit dem Maximalwert von $3,86^{\circ}$. Verursacht wird diese relativ hohe Härte - für amazonische Begriffe! - im Lago Salgado durch den bereits erwähnten Jgarapé Salgadinho, in dem wir eine Gesamthärte von $28,6^{\circ}$, einen Bikarbonatgehalt von $77,44 \mathrm{mg} / \mathrm{l}$ und einen Sulfatgehalt von $464 \mathrm{mg} / \mathrm{l}$ feststellen konnten. Dieses Flüßchen, dessen Anreicherung an Bittersalz $\left(\mathrm{MgSO}_{4}\right)$ schon vor langer Zeit den Seeanwohnern aufgefallen war, hat dem ganzen Gebiet seinen Namen gegeben. Im Lago Salgado selbst wird dieses Salzwasser dann so weit verdünnt, daß wir in der Cabeçeira do Boi noch 3,8 Härte nachweisen konnten.

Auch in der Gesamthärte zeigt sich eine wenn auch nur schwach angedeutete Abhängigkeit von der Regenzeit, indem wir mit fortschreitender Regenzeit einen leichten Anstieg feststellen konnten (siehe auch Karbonathärte). 
Tabelle 10

Gesamthärte in französischen Härtegraden

Lago Furucui und Zuflüsse

\begin{tabular}{|c|c|c|c|c|c|c|}
\hline $\mathrm{m}$ & $\begin{array}{l}\text { 13. Nov. } \\
1947\end{array}$ & $\begin{array}{c}\text { 2. Februar } \\
1948\end{array}$ & $\begin{array}{c}\text { 12. Februar } \\
1948\end{array}$ & $\begin{array}{l}\text { 4. März } \\
1948\end{array}$ & $\begin{array}{c}\text { 30. März } \\
1948\end{array}$ & $\begin{array}{l}\text { 17. Mai } \\
1948\end{array}$ \\
\hline \multirow[t]{2}{*}{$\begin{array}{l}0 \\
2 \\
4 \\
4,5 \\
5 \\
5,5\end{array}$} & $\begin{array}{l}0,27 \\
0\end{array}$ & $\begin{array}{l}0,52 \\
0,43\end{array}$ & $\begin{array}{l}0,52 \\
0,40\end{array}$ & $\begin{array}{l}1,07 \\
1,44\end{array}$ & 0,57 & 0,93 \\
\hline & $\begin{array}{l}\text { 15. Nov. } \\
1947\end{array}$ & & $\begin{array}{c}\text { 12. Februar } \\
1948\end{array}$ & & & $\begin{array}{l}\text { 19. Mai } \\
1948\end{array}$ \\
\hline $\begin{array}{l}\text { Jg. Tento } \\
\text { Jg. Grande }\end{array}$ & $\begin{array}{l}0,37 \\
0,12\end{array}$ & & $\begin{array}{l}0,75 \\
0,75\end{array}$ & & & $\begin{array}{l}1,16 \\
1,70\end{array}$ \\
\hline
\end{tabular}

Lago Muretá

\begin{tabular}{|c|c|c|c|c|}
\hline $\mathrm{m}$ & 2. Dezember 1947 & 20. Februar 1948 & 1. April 1948 & 25. Mai 1948 \\
\hline 0 & 1,12 & 0,80 & 0,84 & 1,02 \\
5 & & & 0,96 & 0,80 \\
\hline
\end{tabular}

Lago Caxambú

\begin{tabular}{|c|c|c|c|c|}
\hline $\mathrm{m}$ & 24. November 1947 & 20. Februar 1948 & 31. März 1948 & 20. Mai 1948 \\
\hline 0 & 0,27 & 1,34 & 1,17 & 1,82 \\
4,5 & & & 0,93 & 0,80 \\
\hline 5,5 & & & & \\
\hline
\end{tabular}

\begin{tabular}{|c|c|c|c|c|}
\hline & \multicolumn{2}{|c|}{ Lago Salgado } & Lago do Caxias & Lago Maritima \\
\hline $\mathrm{m}$ & $\begin{array}{c}\text { Cabeçeira do Molha } \\
\text { 22. April 1948 }\end{array}$ & $\begin{array}{c}\text { Cabeçeira do Boi } \\
13 . \text { April 1948 }\end{array}$ & 31. Dezember 1947 & 19. Februar 1948 \\
\hline 0 & 3,08 & 2,36 & 1,12 & 0,66 \\
2 & 3,5 & 3,86 & 1,25 & \\
4,5 & 3,00 & & \\
\hline
\end{tabular}




\begin{tabular}{|c|c|c|c|c|c|c|c|}
\hline & \multicolumn{2}{|c|}{ Lago Curuçá } & LagoTimbó & Lago Curi & \multicolumn{3}{|c|}{ Lago Jruçanga } \\
\hline $\mathrm{m}$ & $\begin{array}{c}\text { Aninga- } \\
\text { teil } \\
\text { 1. Januar } \\
1948\end{array}$ & $\begin{array}{c}\text { Victoria- } \\
\text { teil } \\
\text { 3. Januar } \\
1948\end{array}$ & $\begin{array}{c}\text { 11. Januar } \\
1948\end{array}$ & $\begin{array}{c}\text { 9. Januar } \\
1948\end{array}$ & $\begin{array}{c}\text { 1. Dez. } \\
1947\end{array}$ & $\begin{array}{c}\text { 21. Februar } \\
1948\end{array}$ & $\begin{array}{c}\text { 26. Mai } \\
1948\end{array}$ \\
\hline $\begin{array}{l}1,5 \\
2\end{array}$ & $\begin{array}{l}1,79 \\
3,5\end{array}$ & 1,41 & 1,32 & 1,29 & 0,40 & 0,45 & 1,02 \\
\hline
\end{tabular}

\begin{tabular}{|c|c|c|c|}
\hline & \multicolumn{3}{|c|}{ Lago Alter do Chăo } \\
\hline $\mathrm{m}$ & $\begin{array}{c}\text { Süd-Cabeçeira } \\
\text { 10. Dezember 1947 }\end{array}$ & $\begin{array}{c}\text { Mitte } \\
\text { 10. Dezember 1947 }\end{array}$ & $\begin{array}{c}\text { Ost-Cabeçeira } \\
\text { 10. Dezember 1947 }\end{array}$ \\
\hline 0 & 0,32 & $\begin{array}{l}0,36 \\
0,45\end{array}$ & 0,36 \\
\hline 4,5 & & 0,36 & \\
\hline
\end{tabular}

Die damalige Bemerkung Katzers (1903), daß die amazonischen Gewässer die reinsten der Welt seien, dürfte also ziemlich begründet sein. Namentlich die Tertiärseen besitzen in bezug auf den Salzgehalt fast destilliertes Wasser.

\section{k) Die Farbe und die Transparenz}

Schon die ältesten Reiseschilderungen über das Amazonasgebiet berichten von verschiedenfarbigen Flüssen, von hellen Lehmwasser-, kaffeebraunen Schwarzwasser- und blaugrünen Klarwasserflüssen, was damals schon zur entsprechenden Namengebung beitrug (Rio Negro = schwarzer Fluß, Rio Branco = weißer Fluß usw.). Ule (I9IS) erwähnt in seiner Arbeit beiläufig das Zustandekommen dieser verschieden gefärbten Wässer: Die Lehmfarbe rührt von den feinverteilten Sedimenten her, die dunkelbraune Farbe der Schwarzwässer wird durch Humusstoffe, die wegen der großen Kalkarmut des Wassers leicht in Lösung gehen, hervorgerufen, während die Klarwasserflüsse durch ihre Armut an Sedimenten eine blaugrüne Farbe aufweisen.

Eine gut fundierte Zusammenstellung über die verschieden gefärbten Flüsse Amazoniens gibt uns SIOLI (1950). Er sieht die Gründe für die Bildung der drei Flußtypen in den geologisch-mineralogischen und klimatischen Eigenheiten der Quellgebiete. So führt er den Ursprung der Lehmwasserflüsse auf die Region der Anden und deren Vorgebirge zurück, also 
in Gebiete mit junger topographischer Gestaltung, mit starken Verwitterungs- und Auswaschungsprozessen, die zur Bildung der feinen Sedimente und demzufolge zur charakteristischen lehmgelben Farbe des Wassers führen, so da $\beta$ dessen Transparenz auf ein Minimum herabsinkt. Im Amazonas, dem Paradebeispiel .eines Lehmwasserflusses, stellten wir am r2. März 1948 eine Transparenz von nur $20-25 \mathrm{~cm}$ fest! Die Klarwasserflüsse mit ihrem gelb- bis dunkelolivgrünen Wasser stanmen nach SioLI zur Hauptsache aus den geologisch alten zentralbrasilianischen und guayanischen Massiven, in denen keine großen Erosionsvorgänge stattfinden und demzufolge auch keine großen Mengen an Schwebestoffen gebildet werden, so da $\beta$ diese Flüsse, namentlich durch ihren langen Lauf durch harte Granit- und Gneisgegenden, arm an Sedimenten und daher klar sind. Den dritten Flußtypus, das Schwarzwasser, leitet SIOLI vom zweiten Typus, vom Klarwasser, ab. Es besitzt, wenn sich zur Trockenzeit die abgestorbenen Pflanzenreste im Jgapó ansammeln und bei der nächsten Regenzeit überflutet werden, unmittelbaren Kontakt mit diesen reichlichen Mengen organischer Substanz. Diese vegetabilen Reste zersetzen sich, es bilden sich Humusstoffe, die in Lösung gehen, um so mehr, als dem Wasser eine aus Sedimenten gebildete Schutzschicht fehlt - also nicht wie bei den Lehmwässern -, so daß nach und nach das Wasser eine braune Farbe annimmt. Die Kalkarmut erhöht noch die Löslichkeit dieser Humusstoffe.

Diese Gruppierung der Flüsse nach ihrer Farbe gilt grosso modo auch für die Seen, bei denen wir Klarwasserseen, Lehmwasserseen und Schwarzwasserseen unterscheiden können.

Auf die Schwierigkeit bei der Bestimmung der Wasserfarbe haben wir bereits im Abschnitt Methodik hingewiesen. Die Farbe eines Gewässers auf solche Weise zu bestimmen, wie es in Europa üblich ist, indem man im Bootsschatten die Farbe des Wassers mit der Farbskala vergleicht, hat sich im Amazonasgebiet in keiner Weise bewährt. Je nach dem Stand der Sonne und der Beleuchtungsintensität änderte sich der Farbton des Wassers überraschend stark, viel stärker, als wie wir es von der gemäßigten Zone her gewohnt waren. Solche Bestimmungen wären vollkommen zwecklos gewesen. Um cinigermaßen vergleichbare Resultate zu bekommen, versenkten wir die Secchi-Scheibe bis zur Hälfte der Transparenz ins Wasser, dann verglichen wir den Farbton der Scheibe mit der Forel-Ule-Skala. Aber auch so ergaben sich wiederum Schwierigkeiten, indem sich die gelben und braunen Farblösungen des Uleschen Teiles der Skala nach kurzer Zeit zu zersetzen und auszuflocken begannen, so daß eine Bestimmung sehr er- 
schwert war. Die Lösungen des Forel-Teiles hielten sich bis zuletzt in einwandfreiem Zustande. Dieselben Erfahrungen machte auch KLEER EKOPER (I939, und nach mündlicher Mitteilung) bei seinen Gewässeruntersuchungen im subtropischen Brasilien (São Paulo). Offenbar ist die Ule-Skala in tropischen und subtropischen Gegenden nicht zu verwenden und sollte durch andere Farblösungen ersetzt werden.

Aus allen diesen Gründen sind unsere Farbbestimmungen nicht ganz einwandfrei. In manchen Fällen war es sogar unmöglich, die Farbe zahlenmäßig anzugeben, weil der betreffende Farbton mit keiner der Skalafarben übereinstimmte. Durch Versenken der Secchi-Scheibe und nachherigem Farbvergleich erhielten wir also viel konstantere und daher vergleichbarere Resultate als mit der Bootsschattenmethode. Nur müssen wir uns bei-der Auswertung der Resultate bewußt sein, daß der eigentliche Farbcharakter des betreffenden Gewässers anders ist, als die Ziffer angibt: Wenn wir zum Beispiel vom Bootsschatten aus ein Gewässer als Schwarzwasser mit dunkelbrauner Farbe bezeichnen müßten, so wird das Resultat der Bestimmung mit der Secchi-Scheiben-Methode « hellbraun» sein. Darauf müssen wir Rücksicht nehmen beim Vergleich der verschiedenen Resultate. Aber es war eben der einzig mögliche Weg, einigermaßen vergleichbare Resultate zu erhalten, die in Tabelle I r eingetragen sind.

Wir stellen fest, daß der Forel-Teil der Skala selten zur Anwendung kam, sondern meistens der Ule-Teil. Die untersuchten Seen besitzen also nur in wenigen Fällen (Lago Verde, Lago Caxambú und andere) klares, blaugrünes Wasser vom oligotrophen Typus, sondern der Farbton geht in der Regel gegen Gelbgrün-Gelbbraun bis Dunkelbraun. Als richtig oligotroph -was Farbe anbelangt - können wir den Lago Verde (ForEL Nr. 9-10), den Lago Caxambú, stellenweise den Lago Alter do Chão und zu gewissen Zeiten den Lago Jurucui bezeichnen. Die uibrigen Seen besitzen alle mehr oder weniger gelbes bis braunes Wasser, einige sogar richtiges Schwarzwasser, wie zum Beispiel der Lago Pindobal, Lago Pauxis, Lago Maritima usw.

Die Bestimmung der Transparenz, deren Resultate ebenfalls in Tabelle I I eingetragen sind, brachte keine besonderen Überraschungen. Die Serienuntersuchung im Lago Jurucui zeigte, daß die Durchsichtigkeit durchschnittlich geringer ist als in den meisten temperierten Seen und daß die jahreszeitlichen Schwankungen bei weitem nicht so groß sind wie in Europa, was nicht schwer zu erklären ist: In den temperierten Seen stirbt und sinkt in der kalten Jahreszeit ein großer Teil des Planktons ab, vergrößert dadurch die Transparenz des Wassers, die dann in der warmen 
Tabelle 11

Transparenz und Farbe

\begin{tabular}{|c|c|c|c|}
\hline See & Datum & $\begin{array}{c}\text { Trans- } \\
\text { parenz } \\
m\end{array}$ & Farbe (Forel-Ule-Nr.) \\
\hline $\begin{array}{l}\text { Lago } \\
\text { Jurucui }\end{array}$ & $\begin{array}{rr}\text { 13. } & 11.47 \\
\text { 2. } & 2.48 \\
12 . & 2.48 \\
\text { 4. } & 3.48 \\
\text { 30. } & 3.48 \\
17 . & 5.48\end{array}$ & $\begin{array}{l}2 \\
3,3 \\
2,5 \\
3,2 \\
2,8 \\
3,1\end{array}$ & $\begin{array}{l}\text { Nr. } 19 \quad \text { (gelbbräunlich) } \\
\text { Nr. } 19-20 \text { (bräunlich) } \\
\text { Nr. } 13 \\
\text { Nr. } 18 \quad \text { (etwas grüner) } \\
\text { Nr. } 13 \\
\text { Nr. } 13\end{array}$ \\
\hline Jgarapé do Tento & $\begin{array}{ll}\text { 12. } & 2.48 \\
\text { 19. } & 5.48\end{array}$ & $\begin{array}{l}2,4 \\
3,5\end{array}$ & $\begin{array}{l}\text { Nr. 13-14 (gelblich) } \\
\text { Nr. } 13 \quad \text { (gelblich) }\end{array}$ \\
\hline Jgarapé Grande & $\begin{array}{ll}\text { 12. } 2.48 \\
\text { 19. } 5.48\end{array}$ & $\begin{array}{l}2 \\
3\end{array}$ & $\begin{array}{l}\text { Nr. 13-14 (gelblich, gegen Braun) } \\
\text { Nr. } 13 \quad \text { (gelblich) }\end{array}$ \\
\hline $\begin{array}{l}\text { Lago Alter do Chão } \\
\text { Süd-Cabeçeira } \\
\text { Mitte } \\
\text { Ost-Cabeçeira }\end{array}$ & 10.12 .47 & 2,8 & $\begin{array}{ll}\text { Nr. 11-1. } & \text { (gelblich) } \\
\text { Nr. } 10 \quad \text { (etwas grünlichgelb) } \\
\text { Nr. } 13 \quad \text { (etwas brauner) }\end{array}$ \\
\hline Lago do Caxias & 31.12 .47 & 0,5 & Milchig-trübe, gelbbraun \\
\hline $\begin{array}{l}\text { Lago Curuçá } \\
\text { Aningateil } \\
\text { Victoriateil }\end{array}$ & 1. 1.48 & $\begin{array}{l}0,9 \\
1,2\end{array}$ & $\begin{array}{l}\text { Nr. } 22-23 \\
\text { Nr. } 23 \quad \text { viel rotbrauner }\end{array}$ \\
\hline Lago Curí & 9. 1.48 & 2 & Nr. $20-21$ \\
\hline Lago Timbó & 11. 1.48 & 1,9 & Nr. 23 viel brauner \\
\hline Lago Maritima & 19. 2.48 & 1,5 & Nr. 23 viel rotbrauner \\
\hline Lago Muretá & $\begin{array}{rr}20 . & 2.48 \\
1 . & 4.48 \\
25 . & 5.48\end{array}$ & $\begin{array}{l}1,8 \\
1,6\end{array}$ & $\begin{array}{l}\text { Nr. } 15 \text { grüngelbgegen Braun, sehrtrübe } \\
\text { Nr. 12-13 } \\
\text { Nr. } 12 \text { etwas grüner, trübe }\end{array}$ \\
\hline Lago Caxambú & $\begin{array}{ll}\text { 20. } & 2.48 \\
31 . & 3.48 \\
20 . & 5.48\end{array}$ & $\begin{array}{l}3 \\
3\end{array}$ & $\begin{array}{l}\text { Glasklar, bläulicher Ton } \\
\text { Nr. 12-13, etwas grïner } \\
\text { Nr. } 13 \quad \text { etwas grüner }\end{array}$ \\
\hline $\begin{array}{l}\text { Lago Salgado } \\
\text { Cab. do Boi } \\
\text { Cab. do Molha }\end{array}$ & $\begin{array}{ll}\text { 13. } & 4.48 \\
\text { 21. } & 4.48 \\
\text { 22. } & 4.48\end{array}$ & $\begin{array}{l}1,9 \\
2,1 \\
1,8\end{array}$ & $\begin{array}{l}\text { Nr. } 19 \\
\text { Nr. } 21 \\
\text { Nr. } 17\end{array}$ \\
\hline
\end{tabular}




\begin{tabular}{|l|c|c|l|}
\hline \multicolumn{1}{|c|}{ See } & Datum & $\begin{array}{c}\text { Trans- } \\
\text { parenz } \\
\mathrm{m}\end{array}$ & \multicolumn{1}{|c|}{ Farbe (Forel-Ule-Nr.) } \\
\hline Lago do Tracoá & 20.4 .48 & 1,7 & Nr. 20 \\
\hline Lago Jruçanga & 26.5 .48 & & Dunkelbraun, fast Schwarzwasser \\
\hline Lago Pauxis & 24.7 .47 & 2,9 & Nr. 17-18, dunkelbrauner \\
\hline Lago Verde & 27.7 .47 & 3 & Nr. 9-10, klares Grün \\
\hline Lago Pindobal & 24.5 .48 & & Kaffebraun \\
\hline Amazonas & 12.3 .48 & 0,25 & Lehmgelb \\
\hline Tapajoz & 12.3 .48 & 2 & Grüngelb \\
\hline
\end{tabular}

Jahreszeit infolge Hochproduktion des Planktons sehr rasch abnimmt. In den Tropenseen fällt eben diese jahreszeitlich bedingte Reduktion der Transparenz weg. Trotzdem können wir im Lago Jurucui geringe Schwankungen erkennen, die im Zusammenhang mit der Regenzeit stehen. Am Ende der Trockenzeit bzw. zu Beginn der Regenzeit (I3. November I947) war die Transparenz weit über $2 \mathrm{~m}$. Sie konnte damals der geringen Tiefe wegen nicht genau bestimmt werden. Mit fortschreitender Regenzeit erhöht sich der Planktongehalt merklich, weil durch die Überschwemmungen geringe Mengen Bodensalze in den See geführt werden und dadurch den Nährstoffgehalt erhöhen. Dieser Anstieg der Planktonquantität zeigt sich dann in einer leichten Reduktion der Transparenz.

Extrem niedere Durchsichtigkeit fanden wir im Lago do Caxias. Das Wasser war trübe und hatte eine gelbbraune Färbung. Dieser See, der ja mehr eine Lichtung im Jgapó darstellt, besitzt Wasser des Rio Cuparí, eines Lehmwasserflusses mit feinen Sedimenten. In diesem Falle sind also die Sedimente und nicht der Planktongehalt begrenzender Faktor der Transparenz, ebenso im Amazonas mit seiner Durchsichtigkeit von $25 \mathrm{~m}$.

Die größte'Transparenz fanden wir im Lago Verde mit weit über $3 \mathrm{~m}$ (nicht genau bestimmbar, weil zu seicht). Die Resultate der übrigen Seen stellen sich in den Bereich zwischen I und $3 \mathrm{~m}$ und weisen keine besonderen Eigentümlichkeiten auf. 


\section{1) Vergleich des Chemismus der Seen mit den Flüssen}

Wie wir schon in der Einleitung erwähnten, untersuchten wir im Rahmen unserer Arbeit für das Instituto Agronomico Seen und Flüsse. In dieser Arbeit sind jedoch nur die Seen berücksichtigt, weil wir damals die Arbeit so aufteilten, daß sich Dr. Siolr mehr den Flüssen und ich mich mehr den Seen widmete. In einer soeben erschienenen Arbeit legt nun Sioli (I950) eine übersichtliche Darstellung der Zusammenhänge des Chemismus der Flüsse mit dem geologisch-mineralogischen Untergrund vor, und es dürfte daher interessant sein, diese Resultate der Flußuntersuchungen denjenigen der Seen in Form einer allgemeinen Übersicht vergleichend gegenüberzustellen, denn es handelte sich bei allen unseren Untersuchungen in erster Linie darum, einen ersten Überblick über den limnologischen Charakter der diesbezüglich unbekannten amazonischen Gewässer zu schaffen, ohne vorerst auf Detailfragen einzutreten.

Die bei den Seen beobachteten Zusammenhänge zwischen Chemismus des Wassers und geologisch-mineralogischem Untergrund zeigen sich in den Flüssen, vor allem in den kleineren, in noch deutlicherem Maße. Wie SioLI darlegt, kann die Kenntnis dieser Zusammenhänge praktisch ausgewertet werden bei Studien über Brauchbarkeit der amazonischen Böden für eine spätere Kolonisation. Mit andern Worten: Aus den Kenntnissen des Chemismus der.kleinen Flüsse und Seen - die großen Ströme mit ihrem Mischwasser verschiedener Herkunft eignen sich weniger dafür - lassen sich gewisse Rückschlüsse auf die Bodenzusammensetzung des Ursprunggebietes ziehen. Gestützt werden diese Erhebungen durch die biologischen Untersuchungen, weil gewisse Pflanzen- und Tiergruppen so spezifische Umweltsbedingungen erfordern, daß aus der Kenntnis der Artenzusammensetzung ebenfalls auf das chemische Milieu des Wassers und damit auf dessen Untergrund geschlossen werden kann.

SIOLIS Untersuchungen gingen nun dahin, daß er gewissermaßen in Form eines Querschnittes durch die geologischen Formationen des Amazonasgebietes einzelne Flüsse der verschiedenen Regionen soweit als möglich chemisch zu erfassen suchte, indem er in nördlicher und südlicher Richtung vom Amazonas aus vordrang. Er untersuchte einige Flüsse der Tertiür- und Karbonregion genauer, in denjenigen des Devons bis Präsilurs machte er einige Stichproben. Diese Flußuntersuchungen ergaben ein auffallend ähnliches Bild, wie wir es in den vorangehenden Kapiteln über die Seen dargestellt haben. Charakteristisch für die Flüsse der Tertiärregion ist auch die auffallende Armut an gelösten Salzen, namentlich an Kalk, 
und die manchmal in sehr großer Menge vorhandene freie Kohlensäure. Als Folge davon weisen die Tertiärflüsse - ebenso wie die Seen - einen allgemein sehr niederen $\mathrm{pH}-$ Wert auf $(\mathrm{pH} 4,5$ bis 5). Eigentliche SchluBfolgerungen für die Praxis können aus dieser Salzarmut der Tertiärgewässer bzw. Tertiärböden insofern gezogen werden, als man mit Sicherheit aussagen kann, daß sich diese Böden für eine rationelle Landwirtschaft weniger eignen. SIOLI führt einige besonders drastische Beispiele an, wo man an die «unendliche Fruchtbarkeit» des Bodens glaubte, landwirtschaftliche Siedlungen anlegte und nach etwa drei Jahren diese wieder wegen der Unfruchtbarkeit des Bodens aufgeben mußte. Nach dem Schlagen des Urwaldes war die vorher vom Wald geschützte dünne Humusschicht bald aufgebraucht, unterstützt durch Auswaschung von Regenwasser, so daß sich das ursprüngliche Waldgebiet in eine Steppenlandschaft verwandelte (siehe RAwITSCHER, 1947). SioLI stellt folgerichtig fest: «Eine einfache chemische Wasseranalyse hätte rechtzeitig vor der wahren Beschaffenheit des Bodens warnen können, indem sie wie ein Indikator seine Armut angezeigt hätte, und hätte dazu dienen können, genauere Untersuchungen darüber anzuregen, wie das Land am besten zu behandeln wäre, um ein wirtschaftlich günstiges Resultat zu erzielen, bevor man den ursprünglichen Urwald zerstörte und das Risiko eines Fehlschlages in einem großzügigen Kolonisationsunternehmen auf sich nahm.»

Chemisch vollkommen verschieden von den Tertiärflüssen sind diejenigen des Karbons mit dem andern mineralogischen Untergrund. Hatten wir bei den Seen schon beträchtliche Unterschiede namentlich im Puffersystem Kalk-Kohlensäure feststellen können, so kommen sie in den Karbonflüssen noch stärker zum Ausdruck. Während die Tertiärflüsse und -seen einheitlich arm an gelösten Salzen und sehr sauer sind, fand Siout in den Karbonflïssen verschiedene Werte, einenteils elektrolytarme, saure - wie in der Tertiärregion -, wenn diese durch Sandsteingebiete flossen, andernteils an Salzen reiche, neutrale oder sogar alkalisch reagierende Flüsse, wenn sie durch Gebiete mit anderer mineralogischer Beschaffenheit flossen. SIOLI gibt in seiner Arbeit (1950) eine Übersicht über die chemischen Unterschiede der Tertiär- und Karbonflüsse. Wir versuchten, in Tabelle I2 diese Resultate mit den unsrigen über die Seen zu vereinigen und übersichtlich darzustellen.

Die Tabelle zeigt, daß sowohl in den Flüssen als auch in den Seen der verschiedenen geologischen Formationen deutliche Unterschiede in der chemischen Beschaffenheit des Wassers bestehen. Diese Unterschiede dürften um so schärfer hervortreten, je kleiner der Fluß und sein Einzugsgebiet 
Tabelle 12

Die chemischen Unterscbiede der Tertiär- und Karbongemässer

\begin{tabular}{|c|c|c|c|c|}
\hline & $\begin{array}{c}\text { Tertiärflüsse } \\
\text { mg/l }\end{array}$ & $\begin{array}{c}\text { Karbonflüsse } \\
\mathrm{mg} / \mathrm{l}\end{array}$ & $\begin{array}{l}\text { Tertiärseen } \\
\mathrm{mg} / 1\end{array}$ & $\begin{array}{l}\text { Karbonseen } \\
\mathrm{mg} / 1\end{array}$ \\
\hline Phosphate ... & 0 & 0 bis 0,03 & 0 bis Spur & 0 \\
\hline Sulfate ...... & 0 & 0 bis 557 & 0 & 0 bis 16 \\
\hline Aluminium ... & 0 & 0 & 0 & 0 \\
\hline Mangan.... & 0 & 0 bis 0,16 & 0 & 0 \\
\hline $\begin{array}{l}\text { Chloride ...... } \\
\text { Kalzium + Ma- }\end{array}$ & Spur bis \pm 3 & 0 bis 16,5 & 0 bis 2 & 0 bis 0,9 \\
\hline $\begin{array}{l}\text { gnesium (ausge- } \\
\text { drückt in } \mathrm{Ca}^{*} \text { ) }\end{array}$ & 0 bis fast 5 & 3 bis 204 & 0 bis 8 & 6 bis 22 \\
\hline $\begin{array}{l}\text { Gesamteisen } \\
\text { Bikarbonat- }\end{array}$ & 0 bis 0,5 & 0 bis 1,1 & 0 bis 0,5 & 0,1 bis 0,7 \\
\hline$\underset{\text { Gelöste }}{\mathrm{CO}_{2}} \ldots \ldots$ & 0 bis 7 & 0 bis 385 & 0 bis 5,1 & 0 bis 14 \\
\hline $\begin{array}{l}\text { Kieselsäure } \\
\text { Nitrate (als }\end{array}$ & & 3 bis 48 & 3 bis 6,5 & 3 bis 6 \\
\hline $\begin{array}{l}\left.\mathrm{N}_{2} \mathrm{O}_{5}\right) \ldots \ldots \\
\text { Freie Kohlen- }\end{array}$ & 0 bis 2 & 0 bis 2 & 0 bis 1,7 & 0 bis 0,8 \\
\hline säure $\ldots .$. & $\begin{array}{l}\text { bis zu } 90 \\
\text { (in Quellen) }\end{array}$ & 1,6 bis 82 & 0,6 bis 42 & 6,7 bis 43 \\
\hline $\begin{array}{l}\text { pH-Wert } \\
\text { KMnO }_{4^{-}}\end{array}$ & & 4,5 bis 7,8 & & \\
\hline $\begin{array}{l}\quad \text { Verbrauch } \\
\text { Freies } \mathrm{NH}_{3} \ldots \\
\text { Huminsäure . }\end{array}$ & & & $\begin{array}{l}7,7 \text { bis } 58,4 \\
0 \text { bis } 0,3 \\
0 \text { bis } \\
0,028 \mathrm{mval} / 1\end{array}$ & $\begin{array}{l}12,3 \text { bis } 113,1 \\
0,15 \text { bis } 0,30 \\
0 \text { bis } \\
\quad 0,426 \mathrm{mval} / 1\end{array}$ \\
\hline
\end{tabular}

sind, je kleiner der See ist und je weniger Zuflüsse er besitzt. (In dieser Tabelle sind bei den Tertiärseen der Lago Pindobal und der Lago Maritima als ausgesprochene Schwarzwassertümpel nicht berücksichtigt.)

Die Tabelle, die sich ja nur auf verhältnismäßig wenige Untersuchungsresultate stützt, erhebt nicht Anspruch auf unbedingte Gültigkeit. Je mehr Untersuchungen mit Hinblick auf diese Unterschiede in Zukunft durchgeführt werden, desto deutlicher werden sich Grenzwerte herausheben, die wir heute auf Grund der bisherigen Arbeiten noch keineswegs angeben können. Wir wollten nur versuchen, ob es möglich sei, rein an Hand chemischer Wasseranalysen zu entscheiden, ob der Untergrund eines Gewässers der Tertiär- oder der Karbonregion angehört, und wir sind der Ansicht, diese Möglichkeit bestehe. Diese Beurteilung des Bodens via Wasser ist nämlich wegen der leichten Durchführbarkeit der Wasseranalysen im Rahmen des Kolonisationsprogrammes von größter Wichtigkeit, hat es sich doch wiederholt gezeigt, daß sich die Böden der Karbonregion durch 
ihre größere Fruchtbarkeit ungleich besser für landwirtschaftliche Nutzung eignen als die Tertiärgebiete.

Natürlich lassen sich an Hand der geologischen Karte Tertiär- und Karbonregion unterscheiden, doch wie SIOL. in seiner Arbeit darlegt, können wir auch in Karbongewässern unter Umständen große Salzarmut antreffen, wenn sie in bestimmten Formationen liegen, und dann entscheidet eben nur die Wasseruntersuchung über Brauchbarkeit oder Untauglichkeit des betreffenden Bodens für eine spätere Kolonisation. Diese Analysen ersetzen natürlich keineswegs eigentliche Bodenuntersuchungen. Diese sind jedoch wegen der dichten Urwaldvegetation nicht ohne Schwierigkeiten durchführbar. Die Wasseruntersuchung soll bloß einen ersten Fingerzeig liefern über den Charakter des betreffenden Gebietes, damit nachher, wenn das Gebiet als geeignet befunden wurde, die eigentlichen detaillierten Bodenuntersuchungen eingesetzt werden können. Es zeigt sich immer mehr, daß nur durch eine enge Zusammenarbeit von Gewässerfachleuten mit Bodenspezialisten und Geologen eine zuverlässige Grundlagenforschung geschaffen werden kann, auf die dann die zukünftige Kolonisation des Amazonasgebietes aufbauen muß.

III.

\section{DIE BIOLOGISCHEN VERHÄLTNISSE}

\section{a) Die quantitative Entwicklung der Grundfauna}

In Tabelle I3 sind die Resultate der quantitativen Grundfaunabestimmungen dargestellt, unter Berücksichtigung der Tiefe und der Beschaffenheit des Untergrundes. Die Zahlen beziehen sich auf $\mathrm{I}^{2}{ }^{2}$ Schlammoberfläche.

\section{Lago Furucui}

Am 27./28. November 1947 (Beginn der Regenzeit) stellten wir Maximalwerte von 12600 Bodentieren pro Quadratmeter fest, und zwar Höchstwerte im weichen, aus feinen Pflanzenresten bestehenden Schlick. Aber auch im Sandboden (Quarzsand) ohne Schlickbildung fanden wir noch bis zu 5460 Organismen pro Quadratmeter. Bildeten im weichen Schlick die Chironomidenlarven die hauptsächlichsten Vertreter der Grundfauna mit Individuenzahlen über I2000 pro Quadratmeter, so waren im Sandboden 


\section{Grundfauna, quantitativ}

Lago Furucui

\begin{tabular}{|c|c|c|c|c|c|c|}
\hline Datum & Ort & $\begin{array}{c}\text { Tiefe } \\
\mathrm{m}\end{array}$ & Beschaffenheit des Untergrundes & $\begin{array}{l}\text { Anzahl Tiere } \\
\text { pro Quadratmeter }\end{array}$ & & Total \\
\hline 22. 11.47 & $\begin{array}{l}\text { Nähe Mündung des } \\
\text { Jgarapé do Tento }\end{array}$ & 0,6 & Weicher Schlick & $\begin{array}{l}\text { Chironomidenlarven } \\
\text { Chironomidenpuppen }\end{array}$ & $\begin{array}{r}450 \\
30\end{array}$ & 480 \\
\hline 27.11 .47 & Uferregion & 0,5 & Sandboden & $\begin{array}{l}\text { Chironomidenlarven } \\
\text { Chironomidenpuppen } \\
\text { Trichopterengehäuse } \\
\text { Keratopog.-Larven } \\
\text { Oligochäten } \\
\text { Kladozeren } \\
\text { Hydrakarinen }\end{array}$ & $\begin{array}{r}1170 \\
60 \\
1020 \\
150 \\
900 \\
120 \\
60\end{array}$ & 3480 \\
\hline 27.11 .47 & $\begin{array}{l}\text { Mündung des Jgarapé } \\
\text { Grande, neben Gras- } \\
\text { wiesen }\end{array}$ & 0,5 & Sandboden & $\begin{array}{l}\text { Chironomidenlarven } \\
\text { Trichopterengehäuse } \\
\text { Oligochäten } \\
\text { Hydrakarinen } \\
\text { Egel } \\
\text { Libellenlarven }\end{array}$ & $\begin{array}{r}750 \\
4500 \\
120 \\
30 \\
30 \\
30\end{array}$ & 5460 \\
\hline 28.11 .47 & Tiefer Seeteil & 2,3 & Weicher Schlick & $\begin{array}{l}\text { Chironomidenlarven } \\
\text { Chironomidenpuppen } \\
\text { Trichopterengehäuse } \\
\text { Oligochäten } \\
\text { Corethralarven }\end{array}$ & $\begin{array}{r}4230 \\
30 \\
30 \\
420 \\
30\end{array}$ & 4740 \\
\hline
\end{tabular}




\begin{tabular}{|c|c|c|c|c|c|}
\hline Datum & Ort & $\begin{array}{c}\text { Tiefe } \\
\mathrm{m}\end{array}$ & Beschaffenheit des Untergrundes & $\begin{array}{l}\text { Anzahl Tiere } \\
\text { pro Quadratmeter }\end{array}$ & Total \\
\hline 28.11 .47 & Tiefste Stelle & 2,6 & Weicher Schlick & $\begin{array}{lr}\text { Chironomidenlarven } & 12210 \\
\text { Trichopterengehäuse } & 210 \\
\text { Oligochäten } & 180\end{array}$ & 12600 \\
\hline 28.11 .47 & Nähe Ausfluß & 1,2 & Sandboden & $\begin{array}{lr}\text { Chironomidenlarven } & 600 \\
\text { Trichopterengehäuse } & 300 \\
\text { Keratopog.-Larven } & 30 \\
\text { Oligochäten } & 240\end{array}$ & 1170 \\
\hline 14.2 .48 & Seemitte & 4,8 & Weicher Schlick & $\begin{array}{lr}\text { Chironomidenlarven } & 270 \\
\text { Trichopterengehäuse } & 30 \\
\text { Oligochäten } & 240 \\
\text { Corethralarven } & 150\end{array}$ & 690 \\
\hline 14. 2.48 & $\begin{array}{l}\text { Ostufer, zwischen } \\
\text { Jgarapé do Tento u. } \\
\text { Jgarapé Grande }\end{array}$ & 3,5 & Weicher Schlick & $\begin{array}{lr}\text { Chironomidenlarven } & 300 \\
\text { Trichopterengehäuse } & 930 \\
\text { Oligochäten } & 60\end{array}$ & 1290 \\
\hline 14. 2.48 & Beim AusfluB & 5,1 & Weicher Schlick & $\begin{array}{l}\text { Chironomidenlarven } \\
\text { Oligochäten } \\
\text { Corethralarven } \\
\text { Hydrakarinen }\end{array}$ & 1500 \\
\hline 14. 2.48 & $\begin{array}{l}\text { Mündung des Jgarapé } \\
\text { do Tento }\end{array}$ & 3,2 & Weicher Schlick & $\begin{array}{lr}\text { Chironomidenlarven } & 180 \\
\text { Hydrakarinen } & 180 \\
\text { Egel } & 30\end{array}$ & 390 \\
\hline
\end{tabular}




\begin{tabular}{|c|c|c|c|c|c|c|}
\hline Datum & Ort & $\begin{array}{l}\text { Tiefe } \\
\text { m }\end{array}$ & Beschaffenheit des Untergrundes & $\begin{array}{l}\text { Anzahl Tiere } \\
\text { pro Quadratmeter }\end{array}$ & & Total \\
\hline 14. 2.48 & Beim Ausfluß & 4,0 & Sandboden & $\begin{array}{l}\text { Chironomidenlarven } \\
\text { Trichopterengehäuse } \\
\text { Oligochäten } \\
\text { Keratopog.-Larven } \\
\text { Egel }\end{array}$ & $\begin{array}{r}90 \\
210 \\
210 \\
30 \\
30\end{array}$ & 570 \\
\hline 14. 2.48 & Südufer & 4,8 & Sandboden & $\begin{array}{l}\text { Chironomidenlarven } \\
\text { Trichopterengehäuse } \\
\text { Oligochäten }\end{array}$ & $\begin{array}{r}90 \\
150 \\
60\end{array}$ & 300 \\
\hline 14. 2.48 & Seemitte & 4,8 & Weicher Schlick & $\begin{array}{l}\text { Chironomidenlarven } \\
\text { Trichopterengehäuse } \\
\text { Oligochäten } \\
\text { Corethralarven }\end{array}$ & $\begin{array}{r}150 \\
270 \\
90 \\
120\end{array}$ & 630 \\
\hline 19. 5.48 & $\begin{array}{l}\text { Uferregion, flacher } \\
\text { Teil }\end{array}$ & 1 & $\begin{array}{l}\text { Weicher Schlick, } \\
\text { Pflanzenreste, Sand }\end{array}$ & $\begin{array}{l}\text { Chironomidenlarven } \\
\text { Trichopterengehäuse } 2 \\
\text { Oligochäten } \\
\text { Corethralarven }\end{array}$ & $\begin{array}{r}60 \\
2850 \\
60 \\
60\end{array}$ & 3030 \\
\hline 19. 5.48 & Seemitte & 6,0 & $\begin{array}{l}\text { Weicher Schlick, ganz } \\
\text { wenig Sand }\end{array}$ & $\begin{array}{l}\text { Chironomidenlarven } \\
\text { Trichopterengehäuse } \\
\text { Oligochäten } \\
\text { Corethralarven }\end{array}$ & $\begin{array}{r}300 \\
60 \\
120 \\
90\end{array}$ & 570 \\
\hline 19.5 .48 & Seeausgang & 6,3 & Weicher Schlick & $\begin{array}{l}\text { Chironomidenlarven } \\
\text { Oligochäten } \\
\text { Corethralarven } \\
\text { Egel }\end{array}$ & $\begin{array}{r}240 \\
30 \\
270 \\
30\end{array}$ & 570 \\
\hline
\end{tabular}


Lago Muretá

\begin{tabular}{|c|c|c|c|c|c|c|}
\hline Datum & Ort & $\begin{array}{c}\text { Tiefe } \\
\mathrm{m}\end{array}$ & Beschaffenheit des Untergrundes & $\begin{array}{c}\text { Anzahl Tiere } \\
\text { pro Quadratmeter }\end{array}$ & & Total \\
\hline 8. 12.47 & Tiefste Stelle & 3,5 & $\begin{array}{l}\text { Weicher Schlick, darunter } \\
\text { Sand }\end{array}$ & $\begin{array}{l}\text { Chironomidenlarven } \\
\text { Ephemeridenlarven }\end{array}$ & $\begin{array}{r}390 \\
30\end{array}$ & 420 \\
\hline 1. 4.48 & Seemitte & 5,7 & $\begin{array}{l}\text { Weicher Schlick, darunter } \\
\text { Sand }\end{array}$ & $\begin{array}{l}\text { Chironomidenlarven } \\
\text { Trichopterengehäuse } \\
\text { Oligochäten } \\
\text { Hydrakarinen }\end{array}$ & $\begin{array}{r}30 \\
690 \\
60 \\
30\end{array}$ & 810 \\
\hline 1. 4.48 & Gleiche Stelle & 5,6 & $\begin{array}{l}\text { Mehr Schlick, weniger } \\
\text { Sand }\end{array}$ & $\begin{array}{l}\text { Chironomidenlarven } \\
\text { Trichopterengehäuse }\end{array}$ & $\begin{array}{l}60 \\
90\end{array}$ & 150 \\
\hline 25.5 .48 & Seemitte & 5,5 & Fast nur Sand & $\begin{array}{l}\text { Trichopterengehäuse } \\
\text { Oligochäten } \\
\text { Ostrakoden }\end{array}$ & $\begin{array}{r}360 \\
150 \\
60\end{array}$ & 570 \\
\hline 25.5 .48 & Seemitte & 6,0 & Weicher Schlick & $\begin{array}{l}\text { Trichopterengehäuse } \\
\text { Oligochäten }\end{array}$ & $\begin{array}{r}250 \\
30\end{array}$ & 280 \\
\hline 25.5 .48 & Uferregion & 5,0 & Sand & $\begin{array}{l}\text { Trichopterengehäuse } \\
\text { Oligochäten } \\
\text { Ephemeridenlarven } \\
\text { Ostrakoden } \\
\text { Kladozeren } \\
\text { Egel }\end{array}$ & $\begin{array}{r}120 \\
180 \\
180 \\
30 \\
450 \\
30\end{array}$ & 990 \\
\hline
\end{tabular}


Lago Caxambú

\begin{tabular}{|c|c|c|c|c|c|c|}
\hline Datum & Ort & $\begin{array}{c}\text { Tiefe } \\
\mathrm{m}\end{array}$ & Beschaffenheit des Untergrundes & $\begin{array}{l}\text { Anzahl Tiere } \\
\text { pro Quadratmeter }\end{array}$ & & Total \\
\hline 31.3 .48 & Seemitte & 5,0 & Grober Sand & $\begin{array}{l}\text { Chironomidenlarven } \\
\text { Trichopterengehäuse } \\
\text { Oligochäten } \\
\text { Ephemeridenlarven }\end{array}$ & $\begin{array}{r}90 \\
120 \\
30 \\
30\end{array}$ & 270 \\
\hline 20.5 .48 & Seemitte & 5,0 & Grober Sand & $\begin{array}{l}\text { Chironomidenlarven } \\
\text { Trichopterengehäuse } \\
\text { Oligochäten }\end{array}$ & $\begin{array}{l}30 \\
90 \\
30\end{array}$ & 150 \\
\hline 20.5 .48 & Seemitte & 6,0 & Schlick, wenig Sand & Kein eirziges Tier! & & 0 \\
\hline
\end{tabular}

Lago Alter do Cbão

\begin{tabular}{|c|c|c|c|c|c|c|}
\hline 10. 12.47 & $\begin{array}{l}\text { Beginn der Süd- } \\
\text { Cabeçeira }\end{array}$ & 1,9 & Sand, wenig Schlick & $\begin{array}{l}\text { Chironomidenlarven } \\
\text { Trichopterengehäuse } \\
\text { Keratopog.-Larven } \\
\text { Corethralarven } \\
\text { Ephemeridenlarven } \\
\text { Oligochäten } \\
\text { Wasserwanzen }\end{array}$ & $\begin{array}{r}570 \\
30 \\
120 \\
30 \\
60 \\
60 \\
60\end{array}$ & 930 \\
\hline 10. 12.47 & $\begin{array}{l}\text { Mitte der Süd- } \\
\text { Cabeçeira }\end{array}$ & 2,2 & Sand, wenig Schlick & $\begin{array}{l}\text { Chironomidenlarven } \\
\text { Trichopterengehäuse } \\
\text { Oligochäten } \\
\text { Corethralarven } \\
\text { Keratopog.-Larven }\end{array}$ & $\begin{array}{r}420 \\
360 \\
210 \\
30 \\
30\end{array}$ & 1050 \\
\hline
\end{tabular}




\begin{tabular}{|c|c|c|c|c|c|c|}
\hline Datum & Ort & $\begin{array}{c}\text { Tiefe } \\
\mathrm{m}\end{array}$ & Beschaffenheit des Untergrundes & \multicolumn{2}{|l|}{$\begin{array}{l}\text { Anzahl Tiere } \\
\text { pro Quadratmeter }\end{array}$} & Total \\
\hline 10.12 .47 & Ost-Cabeçeira & 2,0 & Sandboden & $\begin{array}{l}\text { Chironomidenlarven } \\
\text { Trichopterengehäuse } \\
\text { Oligochäten } \\
\text { Egel } \\
\text { Keratopg.-Larven } \\
\text { Ephemeridenlarven }\end{array}$ & $\begin{array}{r}1410 \\
1500 \\
600 \\
150 \\
120 \\
30\end{array}$ & 3810 \\
\hline 10. 12.47 & Seemitte & 5,0 & Sandboden & $\begin{array}{l}\text { Chironomidenlarven } \\
\text { Oligochäten } \\
\text { Corethralarven }\end{array}$ & $\begin{array}{r}150 \\
450 \\
60\end{array}$ & 660 \\
\hline 10.12 .47 & Vor Seeausgang & 7,0 & Feiner Sand und Schlick & $\begin{array}{l}\text { Chironomidenlarven } \\
\text { Oligochäten } \\
\text { Corethralarven }\end{array}$ & $\begin{array}{r}60 \\
660 \\
180\end{array}$ & 900 \\
\hline \multicolumn{7}{|c|}{ Lago Curi } \\
\hline 9.1 .48 & Seemitte & 4,0 & Feinster Sand und Schlick & $\begin{array}{l}\text { Chironomidenlarven } \\
\text { Corethralarven } \\
\text { Nematoden }\end{array}$ & & 600 \\
\hline \multicolumn{7}{|c|}{ Lago Salgado } \\
\hline 13.4 .48 & $\begin{array}{l}\text { Cabeçeira do Boi, } \\
\text { Mitte (I) }\end{array}$ & 4,7 & Harter Grund, wenig Sand & $\begin{array}{l}\text { Chironomidenlarven } \\
\text { Corethralarven }\end{array}$ & $\begin{array}{l}450 \\
750\end{array}$ & 1200 \\
\hline
\end{tabular}




\begin{tabular}{|c|c|c|c|c|c|c|}
\hline Datum & Ort & $\begin{array}{c}\text { Tiefe } \\
\mathrm{m}\end{array}$ & Beschaffenheit des Untergrundes & $\begin{array}{c}\text { Anzahl Tiere } \\
\text { pro Quadratmeter }\end{array}$ & & Total \\
\hline 13. 4.48 & $\begin{array}{l}\text { Cabeçeira do Boi, } \\
\text { offener Fleck } \\
\text { zwischen Gras- } \\
\text { inseln (II) }\end{array}$ & 4,6 & Feine Grasreste & $\begin{array}{l}\text { Chironomidenlarven } \\
\text { Corethralarven }\end{array}$ & $\begin{array}{r}60 \\
2430 !\end{array}$ & 2490 \\
\hline 13. 4.48 & $\begin{array}{l}\text { Cabeçeira do Boi, } \\
\text { Mitte III }\end{array}$ & 4,1 & Schlick & $\begin{array}{l}\text { Chironomidenlarven } \\
\text { Corethvalarven } \\
\text { Oligochäten } \\
\text { Kuliziden } \\
\text { Ephemeridenlarven } \\
\text { Hydrakarinen }\end{array}$ & $\begin{array}{r}2160 ! \\
2910 ! \\
240 \\
60 \\
90 \\
30\end{array}$ & 5490 \\
\hline 19.4 .48 & $\begin{array}{l}\text { Zwischen Seemitte } \\
\text { und Cabeçeira } \\
\text { do Molha (IV) }\end{array}$ & 7,5 & Weicher, grauer Schlick & $\begin{array}{l}\text { Chironomidenlarven } \\
\text { Corethralarven } \\
\text { Ostrakoden }\end{array}$ & $\begin{array}{r}330 \\
90 \\
30\end{array}$ & 450 \\
\hline 19.4 .48 & $\begin{array}{l}\text { Gleiche Stelle, } \\
\text { etwas gegen } \\
\text { NW-Ufer zu (V) }\end{array}$ & 7,0 & Sand boden & $\begin{array}{l}\text { Chironomidenlarven } \\
\text { Trichopterengehäuse } \\
\text { Covethralarven } \\
\text { Oligochäten }\end{array}$ & $\begin{array}{r}330 \\
60 \\
90 \\
510\end{array}$ & 990 \\
\hline 19.4 .48 & $\begin{array}{l}\text { Cabeçeira do Molha, } \\
\text { in der Bucht (VI) }\end{array}$ & 6,3 & $\begin{array}{l}\text { Weicher, grauer Schlick } \\
\text { mit Grasresten }\end{array}$ & $\begin{array}{l}\text { Chironomidenlarven } \\
\text { Corethralarven } \\
\text { Hydrakarinen }\end{array}$ & $\begin{array}{l}240 \\
660 \\
120\end{array}$ & 1020 \\
\hline 19. 4.48 & $\begin{array}{l}\text { Gleiche Stelle }(\mathrm{V}) \\
\text { etwas gegen W (VII) }\end{array}$ & 7,0 & $\begin{array}{l}\text { Schwarzer Schlick, darun- } \\
\text { ter mehr graubräunlich }\end{array}$ & $\begin{array}{l}\text { Chironomidenlarven } \\
\text { Corethralarven } \\
\text { Hydrakarinen }\end{array}$ & $\begin{array}{r}210 \\
420 \\
60\end{array}$ & 690 \\
\hline
\end{tabular}




\begin{tabular}{|c|c|c|c|c|c|c|}
\hline Datum & Ort & $\begin{array}{c}\text { Tiefe } \\
\mathrm{m}\end{array}$ & Beschaffenheit des Untergrundes & \multicolumn{2}{|l|}{$\begin{array}{l}\text { Anzahl Tiere } \\
\text { pro Qadratmeter }\end{array}$} & Total \\
\hline 19.4 .48 & $\begin{array}{l}\text { Zwischen Ilha do } \\
\text { Campo Santo und } \\
\text { Ilha Recreio (VIII) }\end{array}$ & 7,2 & Weicher, grauer Schlick & $\begin{array}{l}\text { Chironomidenlarven } \\
\text { Covethralarven } \\
\text { Oligochäten } \\
\text { Hydrakarinen }\end{array}$ & $\begin{array}{l}750 \\
240 \\
390 \\
120\end{array}$ & 1500 \\
\hline 19.4 .48 & $\begin{array}{l}\text { Zwischen Furo das } \\
\text { Cotias und Cabeçeira } \\
\text { do Boi (IX) }\end{array}$ & 6,9 & $\begin{array}{l}\text { Dünne Schicht aus schwar- } \\
\text { zem Schlick, darunter } \\
\text { fester Grund }\end{array}$ & $\begin{array}{l}\text { Chironomidenlarven } \\
\text { Covethralarven } \\
\text { Hydrakarinen }\end{array}$ & $\begin{array}{r}780 \\
1920 ! \\
210\end{array}$ & 2910 \\
\hline 19. 4.48 & Seeausgang $(\mathrm{X})$ & 8,0 & $\begin{array}{l}\text { Viel feines, pflanzliches } \\
\text { Material, weicher Schlick }\end{array}$ & $\begin{array}{l}\text { Chironomidenlarven } \\
\text { Corethralarven }\end{array}$ & $\begin{array}{l}510 \\
810\end{array}$ & 1320 \\
\hline 22.4 .48 & $\begin{array}{l}\text { Cabeçeira do Molha, } \\
\text { eigentliche Bucht, } \\
\text { ganz innen (XI) }\end{array}$ & 5,0 & $\begin{array}{l}\text { Dunkler Schlick aus } \\
\text { Pflanzenresten } \\
\text { Stark nach } \mathrm{H}_{2} \mathrm{~S} \text { riechend! }\end{array}$ & $\begin{array}{l}\text { Corethralarven } \\
\text { Hydrakarinen }\end{array}$ & $\begin{array}{r}8850 ! \\
450\end{array}$ & 9300 \\
\hline 22.4 .48 & $\begin{array}{l}\text { Cabeçeiro do Molha, } \\
\text { etwas weiter auBen }\end{array}$ & 6,5 & $\begin{array}{l}\text { Dunkelgrauer, brauner } \\
\text { Schlick, nach } \mathrm{H}_{2} \mathrm{~S} \\
\text { riechend! }\end{array}$ & $\begin{array}{l}\text { Corethralarven } \\
\text { Hydrakarinen }\end{array}$ & $\begin{array}{r}4140 ! \\
60\end{array}$ & 4200 \\
\hline 22.4 .48 & $\begin{array}{l}\text { Cabeçeira do Molha, } \\
\text { noch weiter außen } \\
\text { (XIII) }\end{array}$ & 6,8 & $\begin{array}{l}\text { Graubrauner Schlick, fast } \\
\text { keine Pflanzenreste, } \\
\text { wenig nach } \mathrm{H}_{2} \mathrm{~S} \text { riechend! }\end{array}$ & $\begin{array}{l}\text { Chironomidenlarven } \\
\text { Corethralarven } \\
\text { Hydrakarinen }\end{array}$ & $\begin{array}{r}60 \\
1140 \\
90\end{array}$ & 1290 \\
\hline 22.4 .48 & $\begin{array}{l}\text { Cabeçeira do Molha, } \\
\text { Beginn der Bucht } \\
\text { (XIV) }\end{array}$ & 7,5 & $\begin{array}{l}\text { Graubrauner Schlick ohne } \\
\text { Pflanzenreste, ganz wenig } \\
\text { nach } \mathrm{H}_{2} \text { S riechend }\end{array}$ & $\begin{array}{l}\text { Chironomidenlarven } \\
\text { Corethralarven } \\
\text { Hydrakarinen }\end{array}$ & $\begin{array}{r}90 \\
1110 \\
120\end{array}$ & 1320 \\
\hline
\end{tabular}


in erster Linie Trichopterenlarven mit ihren aus feinstem Quarzsand gefertigten Gehäusen anzutreffen, und zwar bis zu 4500 Stück pro Quadratmeter. Daneben spielten auch Oligochäten, darunter hauptsächlich Tubifiziden, eine maßgebende Rolle in der Zusammensetzung der Grundfauna, mit Individuenzahlen bis zu 900 pro Quadratmeter. Coretbralarven stellten wir an diesem Datum nur im tiefen Seeteil (Schlick!) fest, in Mengen von 30 Stück pro Quadratmeter. Keratopogonidenlarven fehlten im Schlick vollständig, waren dagegen im Sandboden bis zu I50 Stück pro Quadratmeter vorhanden. Hydrakarinen und Libellenlarven spielten zahlenmäßig eine untergeordnete Rolle bei der Zusammensetzung der Grundfauna.

Am 14. Februar 1948 (Mitte der Regenzeit) war die Besiedlung des Untergrundes deutlich schwächer, mit Gesamtindividuenzahlen von höchstens I 500 pro Quadratmeter. Obschon die Sauerstoffversorgung der tieferen Wasserschichten nicht mehr so gut war wie zu Beginn der Regenzeit, ist für diesen Rückgang in der Entwicklung der Grundfauna ein anderer Faktor verantwortlich zu machen, nämlich die durch die Regenzeit bedingte Erhöhung des Feingeschiebes, das durch die beiden Zuflüsse Jgarapé do Tento und Jgarapé Grande sowie durch die überschwemmten Landgebiete in den See geführt wird und das durch seine Sedimentation die Entwicklung der Grundfauna offenbar zu hemmen vermag. Diese Zufuhr von Feingeschiebe kommt auch in der leicht verminderten Transparenz zum Ausdruck.

Auch an diesem Datum bildeten die Chironomidenlarven und Trichopterenköcher die Hauptmenge der Bodenfauna. Die Zahl der Coretbralarven hat jedoch im Laufe der Regenzeit (im Gegensatz zu den andern Organismen) deutlich zugenommen. Waren sie zu Beginn der Regenzeit in unbedeutender Menge vorhanden (3o Stück pro Quadratmeter), so stieg die Individuenzahl bis zum Untersuchungsdatum auf I20 Stïck pro Quadratmeter.

Am 19. Mai 1948 (Ende der Regenzeit) war die Verarmung der Grundfauna noch weiter fortgeschritten, mit Ausnahme derjenigen in der flachen Uferregion, wo wir noch Individuenzahlen bis zu 3000 pro Quadratmeter vorfanden, und zwar in erster Linie Trichopterenlarven. Doch die tiefen Seepartien waren ziemlich arm ( 570 Individuen pro Quadratmeter).

Diese Armut an Bodentieren wird verständlich, wenn wir die Sauerstoffversorgung des Tiefenwassers berücksichtigen. Sie hat sich im Laufe der Regenzeit immer mehr verschlechtert, und am Untersuchungstag betrug der Sauerstoffgehalt in den tieferen Wasserschichten weniger als $\mathrm{I} \mathrm{mg/l}$. Während sich die Gesamtindividuenzabl stark reduziert hat, so hat sich Co- 
retbra im Laufe der Regenzeit in auffallendem Maße vermehrt. Wir konnten sie in Mengen bis zu 270 Stück pro Quadratmeter feststellen (geringe Sauerstoffansprüche!).

Die Verarmung der Bodenfauna mit zunehmender Regenzeit ist also im Lago Jurucui augenfällig.

\section{Lago Muretá}

Im Vergleich zum Lago Jurucui ist der Lago Muretá sehr arm an Bodentieren. Die höchste Individuenzahl betrug 990 pro Quadratmeter. Während wir im Lago Jurucui im Laufe der Regenzeit eine deutliche Abnahme der Bodenfauna beobachten konnten, stellten wir im Lago Muretá das Gegenteil fest: Zu Beginn der Regenzeit betrug die Gesamtindividuenzahl $4^{20}$ pro Quadratmeter, crhöhte sich dann bis zum Ende der Regenzeit auf mehr als das Doppelte. Ein ganz anderes Bild ergibt sich jedoch, wenn wir die einzelnen 'Tiergruppen betrachten: Die Chironomidenlarven nahmen im Verlauf der Regenzeit in ihrer Häufigkeit auffallend ab. Waren sie zu Beginn der Regenzeit noch in Mengen bis zu 400 Stück pro Quadratmeter vorhanden, so verringerte sich ihre Zahl immer mehr, und am Ende der Regenzeit konnten wir überhaupt keine Chironomiden mehr feststellen. Einen ähnlichen Rückgang in ihrer Entwicklung zeigten auch die Trichopteren. Im Gegensatz dazu nahm die Zahl der Kladozeren, Oligochäten (Tubifiziden) und Ephemeriden auffallend zu.

\section{Lago Caxambú}

Dieser See zeigte ähnliche Verhältnisse wie der Lago Muretá. Hier fanden wir eine noch schwächere Entfaltung der Bodentiere als im Lago Muretá, obschon hier wie dort die Sauerstoffversorgung des Tiefenwassers sehr gut war. Am 31. März I948 stellten wir noch 270 Tiere pro Quadratmeter fest, und am 20. Mai 1948 zeigte an der tiefsten Stelle die Schlammprobe kein einziges Tier. Diese Armut an Bodentieren war für uns um so überraschender, als der Lago Caxambú von allen untersuchten Seen der planktonreichste war. Es ist möglich, daß diese Armut der Grundfauna in der geringen Schlickbildung begründet liegt. Wie bereits im ersten Teil (Beschreibung der Seen) erwähnt wurde, unterscheiden sich die beiden Seen Caxambú und Muretá grundlegend durch ihren Untergrund: Im Lago Muretá liegt eine mehrere Zentimeter dicke Schicht weichen organischen Schlicks auf dem sandigen Dünenboden, im Lago Caxambú fehlt diese Schlickbildung oder ist nur äußerst schwach entwickelt. Die geringe Ent- 
faltung der Bodenfauna dieses Sees dürfte also schließlich auf Nahrungsmangel zurückzuführen sein, trotz der reichen Entwicklung des Planktons, das jedoch nach dem Absterben infolge der durch die hohe Temperatur bedingten raschen Zersetzungsprozesse für die Bodenfauna nicht mehr als Nahrungsquelle in Frage kommt.

\section{Lago Alter do Chra}

Die Untersuchung am 1o. Dezember 1947 ergab eine verhältnismäßig reiche Bodenfauna mit Organismenzahlen bis zu 38 Io pro Quadratmeter. Chironomiden, Trichopteren und Oligochäten (in erster Linie Tubifiziden) bildeten den Hauptanteil. Aber auch Keratopogonidenlarven waren, ähnlich wie im Lago Jurucui, in Mengen bis zu I20 Stïck pro Quadratmeter zu finden. Obschon auch im Lago Alter do Chão die Sauerstoffversorgung der tieferen Wasserschichten sehr gut war, zeigte sich Corethra in ziemlich reicher Menge ( 180 pro Quadratmeter).

\section{Lago Curí}

Die einzige dem Lago Curí entnommene quantitative Bodenfaunaprobe mit einer Gesamtzahl von 600 Individuen pro Quadratmeter bestand zum großen Teil aus Nematoden, neben Chironomiden- und Coretbralarven von je 60 Stück.

\section{Lago Salgado}

Ausgedehntere Untersuchungen der Bodenfauna konnten wir im Lago Salgado in beiden Cabeçeiras vornehmen. Die Proben wurden an verschiedenen Stellen im See entnommen, die auf der Kartenskizze(Abb. 7, Seite 28) durch römische Ziffern bezeichnet sind.

Cabeçeira do Boi (Probestellen I, II, III, IX): Der feste Untergrund war namentlich an den tiefen Stellen mit grauem, dunklem, mit sehr feinen Grasresten vermischtem Schlick bedeckt, der eine überraschend große Menge von Coretbralarven barg. Namentlich an den mit starker Schlickbildung versehenen Stellen fanden wir bis zu 2900 Coretbralarven pro Quadratmeter, ebenso rote Chironomidenlarven in ähnlich reicher Entfaltung. Die Sauerstoffversorgung des Tiefenwassers war auffallend ungünstig (unter $\mathrm{I} \mathrm{mg} / \mathrm{l}$ ).

Cabeçeira do Molha (Probestellen IV, V, VI, VII, XI, XII, XIII, XIV): Die an verschiedenen Stellen in der Bucht entnommenen Proben vervollständigten das in der Cabeçeira do Boi bereits angedeutete Bild: Massenentwicklung von Coretbralarven, vollständiger Sauerstoffschwund in der 
Tiefe, dunkler, stellenweise schwarzer, nach Schwefelwasserstoff riechender Faulschlamm. Auffallend war die verhältnismäßig reiche Entfaltung der Hydrakarinen gerade an denjenigen Stellen, wo Coretbra zu Massenentfaltung gelangte, Chironomiden sich jedoch gar nicht mehr entwickelten. Namentlich an Stelle XI fanden wir extreme Besiedlungsverhältnisse: Im schwarzen, nach $\mathrm{H}_{2} \mathrm{~S}$ riechenden Faulschlamm fanden wir 8850 Coretbralarven und 450 Hydrakarinen, sonst überhaupt nichts! In der Seemitte (Stelle VIII) und am Seeausgang (Stelle X) waren die Verhältnisse etwas besser.

Coretbralarven geben also der Bodentierwelt des Lago Salgado ihr Gepräge. Durch ihre Massenentwicklung bis zu 8850 Individuen pro Quadratmeter, vereint mit roten Chironomidenlarven, dazu der schwarze, nach $\mathrm{H}_{2} \mathrm{~S}$ riechende Faulschlamm und der vollständige Sauerstoffschwund der tieferen Wasserschichten zeigen uns das typische Bild eines eutrophen Sees.

\section{b) Die quantitative Entwicklung des Planktons}

RutTner (I93Ia) beschreibt in seiner Arbeit über die Schichtungsverhältnisse der von ihm untersuchten Tropenseen einige Diagramme der räumlichen Verteilung des Planktons. Er kommt dabei zu der Feststellung, daß, im Gegensatz zu den Seen der gemäßigten Zone, wo die räumliche Verteilung des Planktons in erster Linie vom Temperaturgefälle, vom Lichtgefälle und von der chemischen Schichtung abhängt, in den rein tropischen Seen der Faktor Temperaturgefälle wegen der geringen Größe außer Betracht falle. RuTtNER fand in jenen Seen zwei Schichtungstypen: Einerseits Ansammlung der autotrophen Organismen in den gut durchleuchteten oberen Wasserschichten (abhängig vom Lichtgefälle), anderseits Anhäufung von Organismen in der Tiefe (zum Beispiel Schwefelorganismen an der Sauerstoffgrenze). RuTTNER erhielt dabei Schichtungsbilder, die praktisch mit denjenigen der temperierten Seen übereinstimmten, und zog daraus den Schluß, daß diese Schichtungsbilder des Planktons in den Tropenseen unabhängig von der Temperatur seien, daß sie nur unter dem Einfluß des Lichtgefälles einerseits und der chemischen Schichtung anderseits stehen würden.

In Tabelle I4 sind die Individuenzahlen des Planktons pro Liter Wasser eingetragen. Da diese absoluten Zahlen keinen guten Úberblick über die Besiedlungsdichte und Verteilung der Organismen im Raum geben, wurden für die graphische Darstellung nicht diese Individuenzahlen selbst, sondern deren dritte Wurzel in das Koordinatensystem eingetragen, in Form 
Tabelle 14

Planktonmenge in einem Liter Wasser

Lago Furucui (3o. März I948)

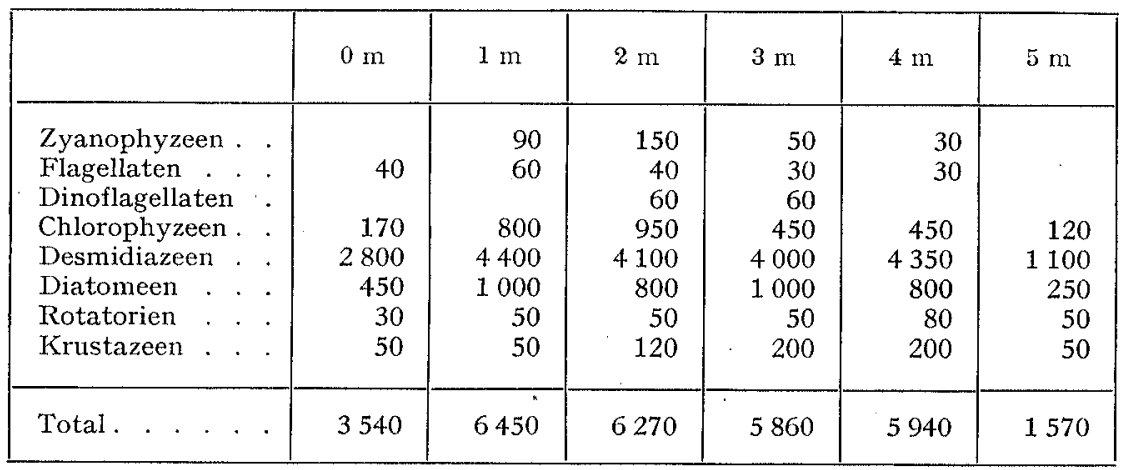

Lago Furucui (17. Mai 1948)

\begin{tabular}{|l|r|r|r|r|r|r|}
\hline & $0 \mathrm{~m}$ & \multicolumn{1}{|c|}{$1 \mathrm{~m}$} & $2 \mathrm{~m}$ & $3 \mathrm{~m}$ & $4 \mathrm{~m}$ & $5,5 \mathrm{~m}$ \\
\hline Zyanophyzeen. . & 40 & 90 & 90 & 70 & 20 & 50 \\
Flagellaten . . & & 60 & & & & \\
Dinoflagellaten . & 800 & 2400 & 1300 & 1000 & 300 & 200 \\
Chlorophyzeen. . & 250 & 230 & 100 & 150 & 50 & 50 \\
Desmidiazeen. . & 4000 & 4000 & 2500 & 2000 & 1000 & 1000 \\
Diatomeen . . . & 1000 & 850 & 600 & 750 & 400 & 450 \\
Rotatorien .. & 30 & 70 & 100 & 50 & 30 & 150 \\
Krustazeen .. & & 50 & 100 & 150 & 150 & 100 \\
\hline Total . . . . & 6120 & 7750 & 4790 & 4170 & 1950 & 2000 \\
\hline
\end{tabular}

Lago Muretá (I. April I948)

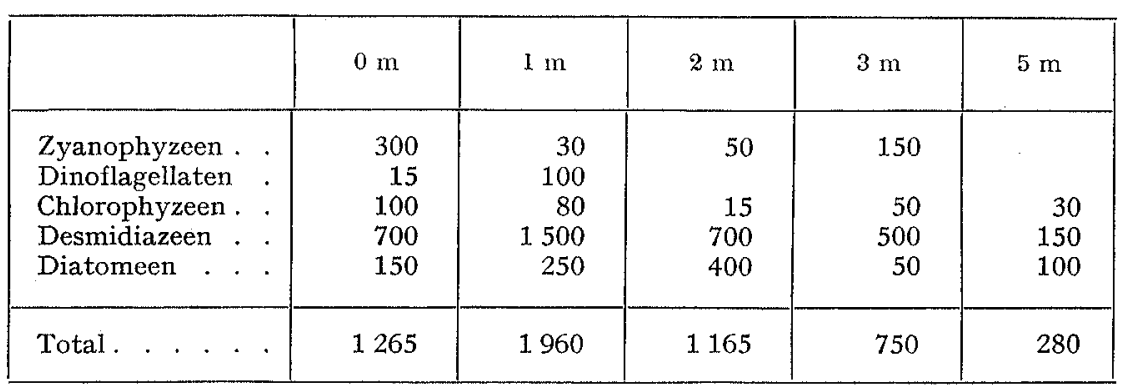


Lago Muretá (25. Mai 1948)

\begin{tabular}{|c|c|c|c|c|c|c|}
\hline & $0 \mathrm{~m}$ & $\mathrm{I} \mathrm{m}$ & $2 \mathrm{~m}$ & $3 \mathrm{~m}$ & $4 \mathrm{~m}$ & $5,5 \mathrm{~m}$ \\
\hline Zyanophyzeen. . & 270 & 450 & 200 & 100 & 200 & \\
\hline $\begin{array}{l}\text { Dinotragellaten } \\
\text { Chlorophyzeen. }\end{array}$ & 500 & 500 & 900 & 1000 & 100 & \\
\hline Desmidiazeen . & 5500 & 5000 & 4500 & 6300 & 5000 & 3000 \\
\hline Diatomeen . & 700 & 400 & 3300 & 1600 & 600 & 500 \\
\hline Protozoen. . & 200 & & & & & \\
\hline Rotatorien . & & & & 200 & 350 & 200 \\
\hline Krustazeen . . & & 100 & & & & \\
\hline Total. . & 7170 & 6450 & 8900 & 9200 & 6250 & 3700 \\
\hline
\end{tabular}

Lago Caxambú (3 I. März I948)

\begin{tabular}{|c|c|c|c|c|}
\hline & $0 \mathrm{~m}$ & $1 \mathrm{~m}$ & $3 \mathrm{~m}$ & $5 \mathrm{~m}$ \\
\hline $\begin{array}{l}\text { Zyanophyzeen . } \\
\text { Flagellaten . } \\
\text { Dinoflagellaten } \\
\text { Chlorophyzeen. } \\
\text { Desmidiazeen . } \\
\text { Diatomeen . } \\
\text { Protozoen. } \\
\text { Rotatorien . . } \\
\text { Krustazeen . . }\end{array}$ & $\begin{array}{r}2000 \\
2400 \\
100 \\
500 \\
50000 \\
700 \\
1800\end{array}$ & $\begin{array}{r}6700 \\
600 \\
2500 \\
1300 \\
123000 \\
1000 \\
300 \\
2600 \\
200\end{array}$ & $\begin{array}{r}7000 \\
600 \\
1400 \\
4000 \\
100000 \\
4000 \\
2200 \\
200\end{array}$ & $\begin{array}{r}7500 \\
600 \\
650 \\
4000 \\
100000 \\
6000 \\
\\
500 \\
200\end{array}$ \\
\hline Total. . . . . & 55500 & 138200 & 119400 & 119450 \\
\hline
\end{tabular}

Lago Caxambú (20. Mai 1948)

\begin{tabular}{|c|c|c|c|c|c|c|}
\hline & $0 \mathrm{~m}$ & $1 \mathrm{~m}$ & $2 \mathrm{~m}$ & $3 \mathrm{~m}$ & $4 \mathrm{~m}$ & $5,5 \mathrm{~m}$ \\
\hline $\begin{array}{l}\text { Zyanophyzeen } \\
\text { Flagellaten }\end{array}$ & 100 & $\begin{array}{l}500 \\
150\end{array}$ & 550 & 100 & 100 & 200 \\
\hline Chlorophyzeen & 260 & 700 & 1300 & 300 & 300 & 600 \\
\hline Desmidiazeen & 16000 & 16000 & 19500 & 11000 & 11000 & 11. 500 \\
\hline Diatomeen & 500 & 650 & 1000 & 700 & 500 & 800 \\
\hline Protozoen. & & & & 100 & 100 & 100 \\
\hline Rotatorien & 100 & 130 & 300 & 300 & 200 & 300 \\
\hline Krustazeen & 200 & 300 & 300 & 500 & 500 & 550 \\
\hline Total & 17160 & 18430 & 22950 & 13000 & 12700 & 13850 \\
\hline
\end{tabular}


Lago Salgado, Cabegeira do Boi (I3. April I948)

\begin{tabular}{|c|c|c|c|c|}
\hline & $0 \mathrm{~m}$ & I m & $2 \mathrm{~m}$ & $3,5 \mathrm{~m}$ \\
\hline $\begin{array}{l}\text { Zyanophyzeen . } \\
\text { Flagellaten . } \\
\text { Dinoflagellaten } \\
\text { Chlorophyzeen } \\
\text { Desmidiazeen } \\
\text { Diatomeen . } \\
\text { Protozoen. } . \\
\text { Rotatorien . } . \\
\text { Krustazeen . } \\
\text { Corethralarven : }\end{array}$ & $\begin{array}{r}100 \\
100 \\
700 \\
250 \\
400 \\
\\
50 \\
450 \\
30\end{array}$ & $\begin{array}{r}200 \\
200 \\
100 \\
3000 \\
300 \\
450 \\
100 \\
50 \\
1000 \\
100\end{array}$ & $\begin{array}{r}150 \\
100 \\
3000 \\
150 \\
200 \\
30 \\
50 \\
550 \\
100\end{array}$ & $\begin{array}{r}400 \\
30 \\
20 \\
800 \\
150 \\
200 \\
\\
30 \\
300 \\
140\end{array}$ \\
\hline Total. & 2080 & 5500 & 4330 & 1970 \\
\hline
\end{tabular}

Lago Salgado, Cabegeira do Molha (22. April 1948)

\begin{tabular}{|c|c|c|c|c|c|}
\hline & $0 \mathrm{~m}$ & $1 \mathrm{~m}$ & $2 \mathrm{~m}$ & $3 \mathrm{~m}$ & $4,5 \mathrm{~m}$ \\
\hline Zyanophyzeen & 200 & 400 & 200 & 100 & 100 \\
\hline Flagellaten . . & 560 & 300 & 100 & 100 & 30 \\
\hline Dinoflagellaten . & & & & & 30 \\
\hline Chlorophyzeen. . & & 300 & 560 & 300 & 200 \\
\hline Desmidiazeen & 1600 & 400 & 750 & 300 & 200 \\
\hline Diatomeen . & 200 & 700 & 700 & 200 & 700 \\
\hline Protozoen. . . & & & 100 & & \\
\hline Rotatorien . . & 100 & 800 & 800 & 100 & 15 \\
\hline Krustazeen . . & 300 & 1400 & 1000 & 500 & 70 \\
\hline Total. . . & 4760 & 4300 & 4210 & 1600 & 1345 \\
\hline
\end{tabular}

Rio Tapajoz (12. März 1948)

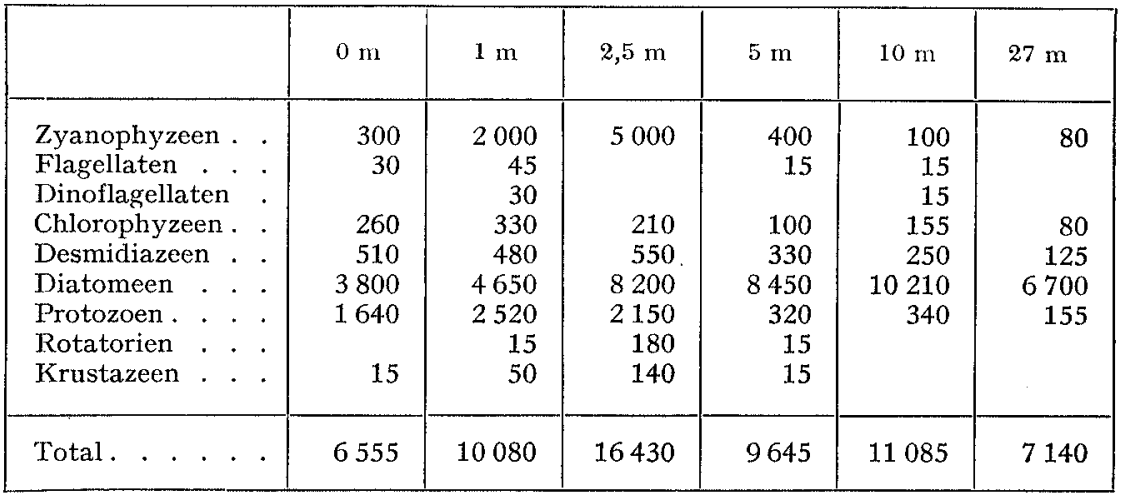


Amazonas (12. März r948)

\begin{tabular}{|l|r|}
\hline & $0 \mathrm{~m}$ \\
\hline Chlorophyzeen . . . & $\mathbf{1 5}$ \\
Desmidiazeen . . . & 85 \\
Diatomeen . . . & 840 \\
\hline Total. . . . . . & 940 \\
\hline
\end{tabular}

sogenannter «Kugelkurven» nach LOHMANN (siehe RUTTNER, I940). Durch diese Darstellung werden geringe, bedeutungslose Unterschiede in den Individuenzahlen unterdrückt, extreme Werte gedämpft. Außerdem, und dies dürfte der Hauptvorteil dieser Methode sein, geben uns solche Diagramme ein viel besseres Bild über die Besiedlungsdichte und Verteilung im Raum, als wie es durch die graphische Darstellung der Individuenzahlen möglich wäre. Diese Diagramme stellen also gewissermaßen den Längsschnitt durch den die Organismendichte verkörpernden Würfel dar.

Diese Diagramme der Planktondichte sind in den Abbildungen 16 und 17 dargestellt, und zwar in Abbildung 16 die gesamte Planktonmenge pro Liter Wasser in den verschiedenen Tiefen, das heißt diejenige Planktonmenge, die durch das Netzchen des Filtertrichters zurückgehalten wurde; die absolute Planktonmenge läßt sich ja mit dieser Methode nicht genau bestimmen.

Wie aus unseren Temperaturmessungen hervorgegangen ist, bewegt sich das Temperaturgefälle in den amazonischen Seen im Vergleich zu den temperierten in sehr geringen Grenzen. Für die Bildung der biologischen Schichtung verliert also dieser Faktor an Bedeutung, wie dies RUTTNER schon für die von ihm untersuchten Tropenseen festgestellt hat. Allerdings möchten wir, im Gegensatz zu RuTTNER, dem, wenn auch nur geringen, Temperaturgefälle doch eine gewisse Bedeutung beimessen, denn die Stabilität, namentlich im Gebiete der Sprungschicht, muß ja in diesem hohen Temperaturbereich relativ groß sein und deshalb für gewisse Plankter ohne aktive Eigenbewegung als Sperrschicht wirken. Die beiden andern die biologische Schichtung bewirkenden Faktoren, nämlich das Lichtgefälle und die chemische Schichtung, sind in den amazonischen Seen sehr gering, im Gegensatz zu den Ruttnerschen Tropenseen, und es war nun reizvoll, $z u$ untersuchen, ob und wie sich diese von jenen im biologischen Schichtungsbild unterscheiden. Durch die geringe Tiefe der amazonischen Seen 
ist eine gute Durchleuchtung auch der tieferen Regionen gewährleistet, die es den meisten autotrophen Organismen erlaubt, sich bis fast zum Seegrunde zu entwickeln, wenigstens, was das Licht anbelangt. Die chemische Schichtung ist, abgesehen von Sauerstoff- und Kohlensäuregehalt, ebenfalls nicht sehr groß, so daß wir also a priori keine sehr ausgeprägten

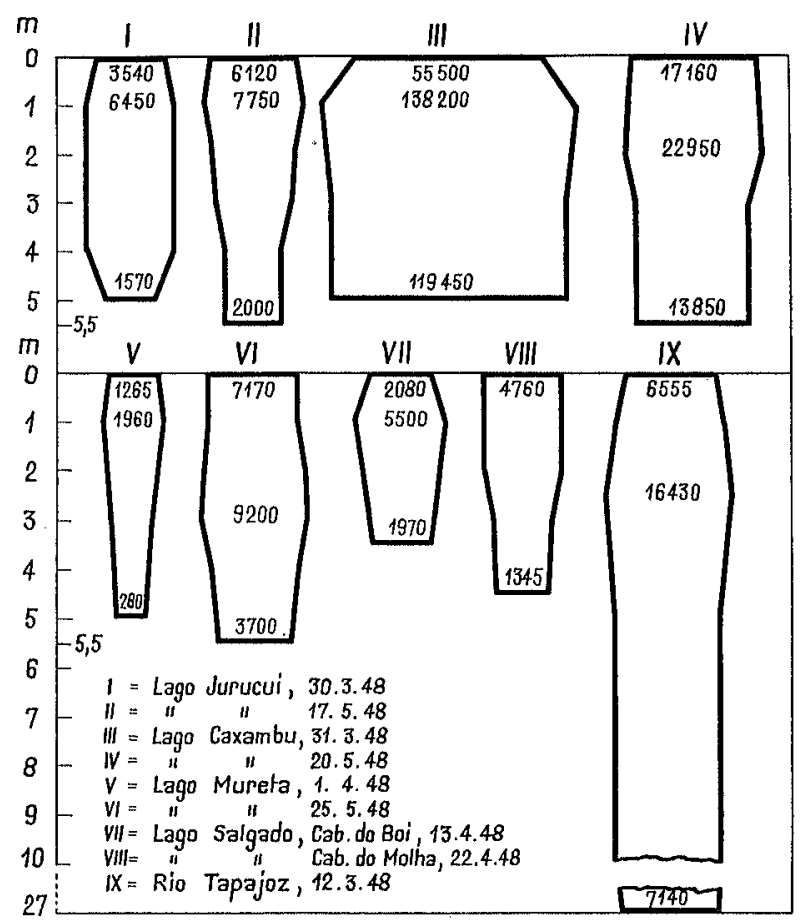

Abb. 16

Schichtungsbilder des Planktons erwarten, wie wir es von den temperierten und von den tiefen Tropenseen RUTTNERS gewohnt sind.

Die Raumdiagramme des Gesamtplanktons (Abb. I6) scheinen diese Erwartungen zu bestätigen. In allen untersuchten Seen finden wir auch in den tiefsten Wasserschichten noch eine reiche Entfaltung des Planktons. Von einer ausgesprochenen Schichtung können wir also nicht gut sprechen, obschon wir ein deutliches Maximum der Plankter in Tiefen von I bis 2 Metern feststellen können. Ausnahmsweise kann sich das Maximum auch in $3 \mathrm{~m}$ Tiefe ausbilden. Der Rio Tapajoz, als Beispiel eines «Flußsees», fügt 

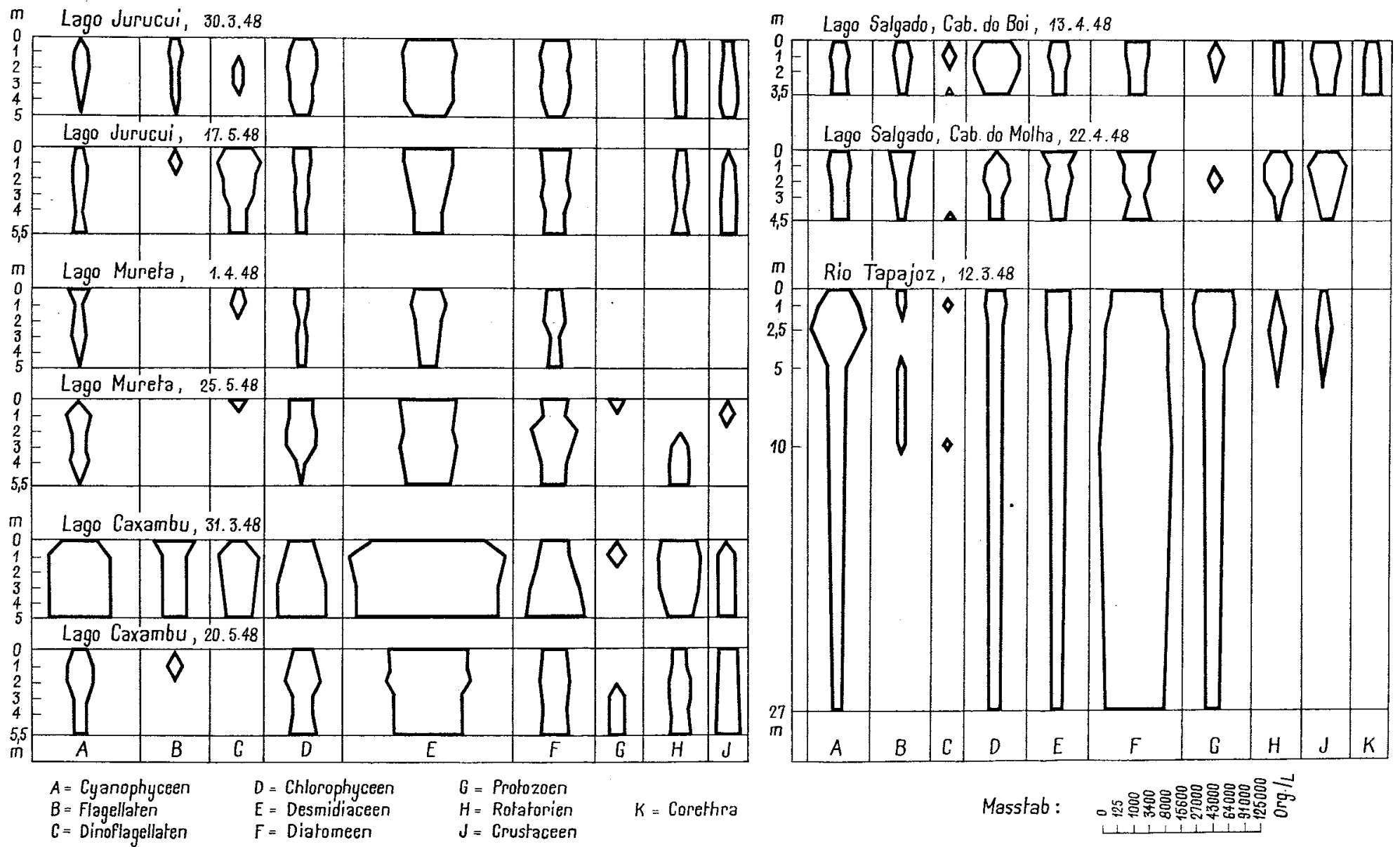

Abb. 17 
sich ebenfalls in dieses Bild und zeigt wie die Seen andeutungsweise ein Schichtungsbild. Die Abbildung I6 zeigt uns ferner, wie unterschiedlich sich das Plankton in den einzelnen Seen entwickelt. Einenteils sehr starke Entfaltung zum Beispiel im Lago Caxambú mit Individuenzahlen bis zu I38200 pro Liter, andernteils schwache Entfaltung, zum Beispiel im Lago Jurucui und Lago Salgado mit Maximalzahlen von 7750 bzw. 5500 Organismen pro Liter. Die Kugelkurven der gesamten Planktonmenge zeigen uns also keine besonders ausgeprägten Schichtungsbilder.

Doch dieses Bild ändert sich in frappanter Weise, wenn wir eine detaillierte Planktonanalyse vornehmen. In Abbildung I 7 sind die Kugelkurven der einzelnen Tier- und Pflanzengruppen des Planktons dargestellt. Und da zeigt sich nun, daß auch in den seichten amazonischen Seen gewisse Organismengruppen sich ganz scharf in engbegrenzten Gebieten anhäufen, obschon die drei genannten Faktoren, die für die biologische Schichtung verantwortlich sind, sehr gering sind, wenigstens für unsere bisherigen Begriffe.

Wir können aus Abbildung I7 vier Schichtungstypen erkennen, die alle zusammen im gleichen See und im gleichen Zeitpunkt auftreten können: Typus I: Die Organismen sind im ganzen Raum mehr oder weniger gleichmäßig verteilt.

Typus II: Die Organismen häufen sich in den obersten Wasserschichten an.

Typus III: Die Organismen entwickeln sich hauptsächlich in den tiefsten Wasserschichten.

Typus IV: Die Organismen häufen sich in bestimmten Tiefen an, nicht aber unmittelbar an der Oberfläche und nicht am Grunde.

Im folgenden soll nun die Organismenverteilung in den einzelnen Seen kurz besprochen werden:

\section{Lago Furucui}

30. März 1948: Die Zyanophyzeen, zur Hauptsache vertreten durch Oscillatoria- und Anabaenaarten, schichten sich hauptsächlich in $2 \mathrm{~m}$ Tiefe auf bis zu I 50 Individuen pro Liter. In den obersten Wasserschichten sowie unterhalb von $3 \mathrm{~m}$ Tiefe ist ihre Entwicklung sehr schwach, sie folgen also Schichtungstypus IV. Die Flagellaten - zur Hauptsache Dinobryon cylindricum - verteilen sich ebenfalls nach Typus IV mit Hauptentwicklung in I $m$ Tiefe, und die Dinoflagellaten - verschiedene Peridiniumarten - zeigen diesen Schichtungstypus in noch ausgeprägterem Maße, indem sie sich 
scharf zwischen I und $4 \mathrm{~m}$ anhäufen. Die Chlorophyzeen - Volvocales in erster Linie - repräsentieren den Schichtungstypus I; sie sind mehr oder weniger gleichmäßig im Raum verteilt, mit einem kleinen Maximum in $2 \mathrm{~m}$ Tiefe. Noch eindrücklicher zeigen die Desmidiazeen diesen Typus. Sie spielen in allen untersuchten Tertiärseen die dominierende Rolle im Plankton, wogegen ihnen im Lago Salgado, einem Vertreter der Karbonseen, sowie im Rio Tapajoz eine untergeordnete Rolle zukommt. Im Lago Jurucui sind die Desmidiazeen in erster Linie durch ein feines Closterium mit Individuenzahlen bis zu 3000 pro Liter charakterisiert, aber auch Artbrodesmus incus und Staurastrum sp. sind stark entwickelt. Die Gesamtindividuenzahl im Lago Jurucui bewegt sich an diesem Tag zwischen I 100 und 4400 pro Liter, wie aus Tabelle I4 ersichtlich ist. Die Diatomeen, vertreten in erster Linie durch verschiedene Melosiraarten, die Rotatorien und Krustazeen schichten sich nach Typus I ein. Die beiden letzteren treten weder durch große Häufigkeit noch durch besondere Schichtungen hervor, wogegen die Diatomeen im Lago Jurucui an diesem Tage durch ihre relativ reiche Entfaltung mit Individuenzahlen bis Iooo pro Liter maßgebend am allgemeinen Planktonbild beteiligt sind.

Die Sauerstoff kurve zeigte an diesem Tag eine deutliche Schichtung mit schwacher Sprungschicht zwischen 2 und $3 \mathrm{~m}$ und anschließendem raschem Abfall gegen die Tiefe, wie aus Abbildung 12 ersichtlich ist. Das Temperaturgefälle war gering $\left(\mathrm{I}^{\circ} \mathrm{C}\right)$ und ohne ausgesprochene Sprungschicht.

17. Mai 1948: Starke Veränderungen im Schichtungsbild gegenüber der Untersuchung vom 30. März I948 zeigen nur die Flagellaten, Dinoflagellaten und Chlorophyzeen; alle Organismen der übrigen Gruppen sind im großen und ganzen in ähnlicher Verteilung und Zahl anzutreffen.

Die Flagellaten sind jedoch in ihrer Gesamtzahl stark zurückgegangen und schichten sich nach Typus II in I $m$ Tiefe scharf ein. Die Dinoflagellaten, am 30. März 1948 in sehr schwacher Entfaltung begriffen (bis 60 Individuen pro Liter) und Typus IV folgend, sind am 17. Mai I948 mit Organismenzahlen bis zu 2400 pro Liter vertreten und zeigen ihre hauptsächlichste Verbreitung in $\mathrm{I} \mathrm{m}$ Tiefe. Die Chlorophyzeen sind seit der letzten Untersuchung in ihrer Individuenzahl stark zurïckgegangen; in ihrer Verteilung in Raum zeigen sie jedoch keine großen Veränderungen.

Auch in den Kugelkurven des Gesamtplanktons (Abb. I6) tritt das veränderte Schichtungsbild am 17. Mai 1948 gegenüber demjenigen vom 30. März I948 einigermaßen zutage.

Werfen wir jedoch noch einen Blick auf die chemisch-physikalischen Verhältnisse, die an diesem Tage herrschten. Die Temperatur zeigte eine 
auffallend ausgeprägte Schichtung mit Sprungschicht zwischen 2 und $3 \mathrm{~m}$ Tiefe. Ebenfalls scharf geschichtet war der Sauerstoffgehalt mit prägnantem Abfall der Kurve in der Sprungschicht (siehe Abb. 8) und fast vollständigem Sauerstoffschwund in der Tiefe $(=\mathrm{Img} / \mathrm{l})$. Dieser niedere Sauerstoffgehalt des Tiefenwassers deutet darauf hin, daß es sich bei den in $5 \mathrm{~m}$ Tiefe gezählten Organismen offenbar um abgestorbene und abgesunkene Formen handelt. Der leichte Anstieg der Sauerstoff kurve in I und $2 \mathrm{~m}$ Tiefe zeigt uns die gesteigerte Assimilationstätigkeit des autotrophen Planktons an, das seinerseits zusammen mit dem Zooplankton beim $\mathrm{Ab}$ sterben und Absinken bereits in $3 \mathrm{~m}$ Tiefe durch seine Zersetzung den scharfen Knick der Sauerstoffkurve bewirkt. Vervollständigt wird dieses Bild noch durch die Kohlensäure, deren Menge genau spiegelbildlich zum Sauerstoffgehalt mit zunehmender Tiefe ansteigt, und zwar von $6,8 \mathrm{mg}$ $\mathrm{CO}_{2} / \mathrm{l}$ in o $\mathrm{m}$ auf $\mathrm{r} 9,7 \mathrm{mg} / \mathrm{l}$ in $5 \mathrm{~m}$ Tiefe.

Was uns diese Tatsachen lehren, ist folgendes: In den seichten amazonischen Seen finden wir prinzipiell dieselben Gesetze und Eigentümlichkeiten des biologisch-chemischen Geschehens wie in den tiefen temperierten Seen der gemäßigten Zone, wenn auch in greringerem Umfang. Doch alle diese Vorgänge sind gewissermaßen auf ganz engem Raume zusammengepreßt und durch die hohe Temperatur intensiviert. $W$ as sich in den tiefen temperierten Seen innerbalb von 5, 10 oder mebr Metern abspielt - Sprungschicht, intensive Sauerstoffproduktion der autotrophen Organismen, Sauerstoffzehrung durch abgestorbene Organismen usw. -, zeigt sich in den amazoniscben Seen innerbalb von 2 bis $3 \mathrm{~m}$.

\section{Lago Muretá}

1. April 1948: Die Zyanophyzeen zeigen eine etwas uneinheitliche Verteilung: einerseits Anhäufung der Organismen unmittelbar an der Wasseroberfläche, anderseits aber auch starke Entwicklung in $3 \mathrm{~m}$ Tiefe. Bei den in den oberen Wasserschichten angesammelten Formen handelt es sich um Anabaena sp., die sich dank ihrem geringen spezifischen Gewicht auch in den temperierten Seen hauptsächlich in den obersten Regionen aufhalten (Wasserbliiten!). In $3 \mathrm{~m}$ Tiefe macht sich, neben wenigen Exemplaren von Anabaena, in erster Linie Microcystis sp. bemerkbar. Die Grenzzone, einerseits von Anabaena, anderseits von Microcystis, liegt ziemlich genau in I m Tiefe, was sich in unseren Kugelkurven in Abbildung 17 deutlich als Einschnitt bemerkbar macht. Die Flagellaten konnten im Lago Muretá weder am I. April 1948 noch am 25. Mai 1948 zahlenmäßig erfaßt werden. Die Dinoflagellaten - Peridinium und Gymnodinium sp. - verhalten sich im Gegen- 
satz zum Lago Jurucui nach Schichtungstypus II, das heißt, sie entwickeln sich nur in den obersten Wasserschichten. Die Chlorophyzeen, bestehend aus Mougeotia sp. und wenigen Exemplaren von Botryococcus Braunii, sind nach Typus I im See verteilt. Die Desmidiazeen, die wie in allen Tertiärseen auch hier im Lago Muretá die überragende Rolle im Plankton spielen, sind vertreten durch Artbrodesmus sp., Artbrodesmus incus, Staurastrum sp., Cosmarium sp. und Micrasterias radiata. Thre Hauptverbreitungszone liegt in I $m$ Tiefe, doch kann diese Gruppierung noch als dem Typus I angehörend betrachtet werden. Die neben den Desmidiazeen wichtigsten Vertreter des Planktons, die Diatomeen, verteilen sich nach Typus I, doch es ist sehr wahrscheinlich, daß es sich bei den in der Tiefe festgestellten Diatomeen um abgestorbene Formen handelt. In erster Linie sind es verschiedene Melosira und Navicula sp., die das Diatomeenplankton charakterisieren. Protozoen, Rotatorien und Krustazeen konnten wir am I. April I948 zahlenmäßig nicht erfassen.

25. Mai 1948: Das Schichtungsbild der Zyanophyzeen hat seit der letzten Untersuchung insofern eine Änderung erfahren, als ihre Hauptentwicklung nicht mehr unmittelbar an der Oberfläche, sondern in I $m$ Tiefe erfolgt. In ihrer Individuenzahl - bei gleicher Artenzusammensetzung haben sie etwas zugenommen. Flagellaten konnten, wie bei der letzten Untersuchung, zahlenmäßig nicht erfaßt werden. Die Dinoflagellaten, diesmal nur durch Gymnodinium sp. repräsentiert, gruppieren sich wie am I. April I948 nach Typus II. Doch die Chlorophyzeen zeigen gegenüber der letzten Probenahme einen enormen Anstieg in ihrer Individuenzahl. Stellten wir am I. April I948 eine maximale Organismenzahl von roo pro Liter fest, so stieg sie bis zum 25. Mai I948 auf das Zehnfache an. Auch im Schichtungsbild ist eine Änderung eingetreten: Am I. April 1948 repräsentierten die Grünalgen den Schichtungstypus I, am 25. Mai I948 waren sie bis zu $3 \mathrm{~m}$ Tiefe, wo sich ihr Maximum befand, in reicher Entfaltung begriffen, um nachher gegen die Tiefe $z u$ in ihrer Entwicklung plötzlich abzuklingen. Auch in der Zusammensetzung stellten wir Unterschiede fest: Zu den am r. April 1948 bereits vorhandenen Mougeotia sp. und Botryococcus Braunii kommen am 25. Mai 1948 noch Scenedesmus sp. und Eudorina elegans. Auch bei den Desmidiazeen fanden wir starke Veränderungen: Zunahme der maximalen Individuenzahl von r 500 (I. April 1948) auf 6300 pro Liter (25. Mai 1948). Diese Zunahme wurde hauptsächlich durch Artbrodesmus incus bewirkt, die dem Plankton ihr eigentliches Gepräge verlieh. Aber auch die Diatomeen haben in ihrer Zahl äußerst stark zugenommen (in erster Linie Melosira). Protozoen, Rotatorien und Krusta- 
zeen, am r. April r948 quantitativ nicht erfaßbar, verteilten sich am 25. Mai I948 nach Typus II (Protozoen und Krustazeen) und Typus III (Rotatorien).

Diese bei allen Tier- und Pflanzengruppen seit der letzten Probenahme deutlich feststellbare Zunahme der Planktonentwicklung kommt auch in den Kugelkurven des Gesamtplanktons sehr deutlich zum Ausdruck (Abb. I6).

\section{Lago Caxambú}

31. März 1948: Ein Blick auf die Kurven des Gesamtplanktons läßt uns schon die Sonderstellung erkennen, die der Lago Caxambú mit Hinsicht auf seine Planktonproduktion einnimmt. Mit Individuenzahlen von I38 200 pro Liter steht dieser See weitaus an der Spitze. Die Hauptrolle spielen dabei die Desmidiazeen, wie aus Abbildung I7 zu erkennen ist, die mit Zahlen bis zu I23 000 pro Liter das Caxambúplankton charakterisieren. Sie gruppieren sich nach Typus I, sind also in allen Wassertiefen in großer Zahl vorhanden. Darunter ist namentlich ein Staurastrum besonders häufig (bis I20000 pro Liter). Die übrigen Vertreter der Desmidiazeen bilden Artbrodesmus sp. und Cosmarium sp., die aber neben Staurastrum vollkommen bedeutungslos sind.

Der Lago Caxambú ist nicht nur der desmidiazeen-, sondern auch der zyanophyzeenreichste von allen untersuchten Seen, charakterisiert durch Anabaena sp., die sich ebenfalls nach Typus I im ganzen Raum fast gleichmäßig verteilt. Auch die Flagellaten haben in diesem See am Untersuchungsdatum eine sehr große, dem Typus I folgende Verbreitung. Darunter treten namentlich Mallomonas sp. und Dinobryon cylindricum hervor, mit besonders starker Anhäufung in den obersten Wasserschichten. Die Dinoflagellaten, wie im Lago Jurucui aus Peridinium und Gymnodinium zusammengesetzt, haben ihre größte Häufigkeit in I $m$ Tiefe, liegen aber noch in den tiefsten Wasserschichten in starker Entfaltung vor. Ob es sich in der Tiefe um abgestorbene und abgesunkene Exemplare handelt, die dank ihrem soliden Gehäuse der Zersetzung noch nicht anheimfielen, konnte nicht eindeutig festgestellt werden. Die Chlorophyzeen zeigen eine eigenartige Verteilung. Von der Oberfläche nach der Tiefe zu nimmt ihre Zahl ständig $\mathrm{zu}$, um in 3 bis $5 \mathrm{~m}$ das Maximum mit 4000 Organismen pro Liter zu erreichen. Interessant war die Verbreitung der einzelnen Arten: In der obersten Wasserschicht entwickelten sich Pediastrum und Euglena in ungefähr gleicher Zahl mit zusammen soo Organismen pro Liter. In der Tiefe von 3 bis $5 \mathrm{~m}$ dominierten Pediastrum und Scenedesmus, neben ganz schwacher 
Entwicklung von Eudorina. Die Diatomeen mit ihrem Maximum von 6000 Organismen pro Liter am Grunde des Sees sind ebenfalls am allgemeinen Planktonbild beteiligt. Wie im Lago Muretá bildet auch hier Melosira den Hauptbestandteil. Protozoen sind im Lago Caxambú an diesem Datum sehr schwach entwickelt (Euglypha sp.); sie folgen dem Schichtungstypus II. Die Rotatorien, in den bereits besprochenen Seen Jurucui und Muretá nur schwach vertreten, sind im Lago Caxambú in Mengen bis zu 2600 Individuen pro Liter vorhanden, wobei Keratella eine große Rolle spielt; ihr hauptsächlichstes Ausbreitungsgebiet sind die Tiefen von o bis $3 \mathrm{~m}$. Die Krustazeen zeigen weder durch ihre Zahl noch durch ihre Verteilung irgendwelche Besonderheiten.

20. Mai 1948: Aus der Darstellung des Gesamtplanktons (Abb. I6) geht hervor, daß die Planktonentwicklung seit der letzten Untersuchung in überraschender Weise zurückgegangen ist. Konnten wir am 3I. März I948 Maximalzahlen von $\mathrm{I} 38200$ Organismen pro Liter feststellen, so waren es am 20. Mai 1948 noch 22950 ! Dies war um so merkwürdiger, als wir ja im Lago Muretá genau das Gegenteil beobachteten, nämlich eine starke $\mathrm{Zu}$ nahme!

Dieser Rückgang der Planktonentwicklung im Lago Caxambú am Ende der Regenzeit war bei allen Organismengruppen feststellbar, ausgenommen bei den Protozoen und Krustazeen, die eine leichte Steigerung aufwiesen. Am auffallendsten war der Rückgang bei den Dinoflagellaten. Am 3I. März I948 noch mit 2500 Organismen pro Liter vorhanden, konnten sie am 20. Mai 1948 überhaupt nicht mehr quantitativ festgehalten werden, nicht einmal die leeren Gehäuse der Peridineen! Auch die Flagellaten wurden bis auf klägliche Reste eliminiert.

Wie können wir uns diese merkwürdige Differenz in der Planktonentwicklung der beiden Seen erklären? Die durch die Regenzeit bedingte leichte Erhöhung des Nährstoffgehaltes bewirkte, daß sich das Plankton sehr stark entwickelte. Die Nährstoffe wurden dadurch in relativ kurzer Zeit aufgebraucht, wodurch sich die Verminderung am Ende der Regenzeit erklären läßt. Neuerliche Nährstoffzufuhr fand nicht statt, denn der See besitzt ja keine Zufliisse, und außerdem war ja das Maximum der Überschwemmung umliegender Landgebiete schon vor Ende der Regenzeit vorhanden. Im Lago Muretá jedoch, der im Gegensatz zum Lago Caxambú reiche Schlickbildung am Seegrunde aufweist, wirkte dieser organische Schlick offenbar als Nährstoffreserve, die es dem Plankton ermöglichte, sich weiter zu entwickeln. Auch bei der Grundfauna haben wir ja ein ähnliches Verhalten beobachten können: Äußerst geringe Entfaltung 
im Lago Caxambú infolge Nährstoffmangels (kein Schlick), und im Lago Muretá verhältnismäßig starke Entwicklung der Grundfauna im weichen organischen Schlick! Eine plausiblere Erklärung für das gegenteilige biologische Verhalten der beiden Seen können wir vorläufig nicht geben.

\section{Lago Salgado}

Cabeçeira do Boi (13. April 1948) und Cabeçeira do Molha (22. April 1948): Dieser See, als Beispiel eines typischen Karbonsees im Gegensatz zu den bisher besprochenen Tertiärseen, zeigt in verschiedener Beziehung andere Verhältnisse im Planktonbild. Aus der Darstellung des Gesamtplanktons (Abb. I6) geht hervor, daß er im Vergleich zu den andern untersuchten Seen eine mittelstarke Planktonproduktion aufweist, mit Individuenzahlen von höchstens 5500 pro Liter. In der Verteilung und mengenmäßigen Zusammensetzung der einzelnen Organismengruppen ergeben sich gegenüber den Tertiärseen einige Unterschiede. Spielten bei diesen die Desmidiazeen die dominierende, die Chlorophyzeen und Diatomeen aber eine untergeordnete Rolle in Aspekt des Planktons, so geht aus Abbildung I7 hervor, daß im Planktonbild des Lago Salgado das Gegenteil der Fall ist: Die Desmidiazeen haben ihre überragende Rolle zugunsten der Chlorophyzeen eingebüßt, die namentlich in der Cabeçeira do Boi das Bild vollkommen beherrschen, und der Diatomeen, die hauptsächlich in der Cabeçeira do Molha tonangebend sind. Bei den Diatomeen ist besonders die zierliche Rbizasolenia zu nennen, die in der Cabeçeira do Molha bis zu 800 Individuen pro Liter feststellbar war, neben reichlicher Entfaltung verschiedener Melosiraarten. In beiden Cabeçeiras gruppierten sich die Diatomeen nach dem Typus I. Die Chlorophyzeen, dominierend in der Cabeçeira do Boi, etwas schwächer entwickelt in der Cabeçeira do Molha, haben namentlich in Tiefen von $\mathrm{I}$ bis $2 \mathrm{~m}$ ihre Hauptentwicklung, doch auch am Seegrunde stellten wir sie noch in Mengen bis zu 800 Stück pro Liter fest, eine Tatsache, die angesichts der sehr schlechten Sauerstoffversorgung des Tiefenwassers ( $\mathrm{mg}$ in der Cabeçeira do Molha, $0,85 \mathrm{mg} / \mathrm{l}$ in der Cabeçeira do Boi) äußerst iiberraschend und schwer erklärlich ist. Handelt es sich dabei um abgestorbene Organismen, die trotz der hohen Temperatur noch nicht zersetzt wurden?

Die Krustazeen sind im Lago Saldago, wie sonst in keinem der untersuchten Seen, in auffallend großer Menge entwickelt, namentlich in der Cabeçeira do Molha. Obschon ein großer Teil der größeren Formen sich durch Flucht aus der geöffneten Schöpfflasche der Zählung zu entziehen 
vermag, stellten wir noch Individuenzahlen bis I400 pro Liter fest. Diese Tatsache wurde beim Kapitel Sauerstoffhaushalt als Ursache für den niederen Sauerstoffgehalt des Oberflächenwassers in der Cabeçeira do Molha angegeben.

\section{Rio Tapajoz}

12. März 1948: Es dürfte in diesem Zusammenhang nicht uninteressant sein, den «Flußsee» Rio Tapajoz und seine Planktonproduktion den besprochenen Tertiär- und Karbonseen vergleichend gegenüberzustellen.

Kurz vor dem Zusammenfluß mit dem Amazonas in der Nähe von Santarém wurde am I2. März 1948 im Rio Tapajoz ein $27 \mathrm{~m}$ tiefes Planktonprofil aufgenommen. In Abbildung I6 sind die Kugelkurven des Gesamtplanktons, in Abbildung I7 die detaillierte Planktonauszählung dargestellt. Die Kurven der totalen Planktonmenge zeigen nichts Besonderes, weder im Hinblick auf die Schichtung noch auf die Organismenzahl. Zwischen 2 und $3 \mathrm{~m}$ befand sich an diesem Tage eine schwache thermische Sprungschicht (siehe Abb. II), worin sich auch ein Maximum an Planktonorganismen mit Individuenzahlen bis zu r6 430 pro Liter befand. Auch die unteren Schichten bis in $27 \mathrm{~m}$ Tiefe waren mit 7r4o Organismen pro Liter noch sehr stark bevölkert. Weit aufschlußreicher als die Totalmenge sind jedoch die Kurven der detaillierten Analyse. Sofort fällt uns die dominierende Rolle der Diatomeen auf, die nach Typus I in sehr großer Menge von der Oberfläche bis zur Tiefe das Tapajozplankton kennzeichnen, worunter verschiedene Melosiraarten die Hauptrolle spielen. In Io m Tiefe haben sie mit roooo Individuen pro Liter ihr Maximum. Auch Rbizosolenia fällt uns auf, weniger durch ihre Häufigkeit als durch ihre scharfe Schichtung zwischen 5 und Io m Tiefe (Typus IV). Die Zyanophyzeen zeigen ein sehr charakteristisches Bild: Sie entfalten sich in erster Linie in den obersten Wasserschichten mit einem Maximum von 5000 Stück pro Liter in 2,5 m Tiefe, also genau in der Mitte der Sprungschicht. Gegen die Tiefe zu nehmen sie in ihrer Entwicklung stark ab; am Grunde sind sie nur mit Zahlen von 80 Individuen pro Liter zu finden. Dem Zyanophyzeenplankton des Tapajoz verleiht Anabaena sp. ihr Gepräge. An diesem Tag konnten wir sie bis zu 4650 Individuen pro Liter - wieder genau in der Mitte der Sprungschicht feststellen. Anabaena vermag im Tapajoz sogar ausgesprochene Wasserblüten zu bilden. Eine solche konnten wir im November 1947 beobachten. Diese Anabaenawasserblüte wiederholt sich, wie man uns versichert hat, regelmäßig Jahr für Jahr am Ende der Trockenzeit oder zu Beginn der Regenzeit. 
Die Flagellaten zeigen ein uneinheitliches Bild: Einesteils schwache Entfaltung zwischen o und I $m$ Tiefe (Typus II), andernteils schwache Entfaltung zwischen 5 und to $\mathrm{m}$ (Typus IV) bei gleicher Zusammensetzung (in erster Linie Dinobryon cylindricum). Das Gebiet der Sprungschicht war frei von Flagellaten. Ähnlich verteilen sich die Dinoflagellaten (Peridinium), ebenfalls nur schwach entwickelt in I $\mathrm{m}$ sowie in Io $\mathrm{m}$ Tiefe. Die Chlorophyzeen (Eudorina, Scenedesmus, Pediastrum und andere) sind nach Typus I im ganzen Raum regelmäßig verteilt, ebenso und in fast gleicher Anzahl die Desmidiazeen (Staurastrum, Artbrodesmus, Closterium). Deutlich geschichtet wie die Zyanophyzeen zeigen sich die Protozoen, die hier wie sonst in keinem der untersuchten Gewässer durch ihre Häufigkeit auffallen. Auch sie sammeln sich im Gebiet der Sprungschicht an. Hier ist es eine Codonella sp., die sich mit 2400 Individuen pro Liter auffallend bemerkbar macht. Daneben stellten wir noch Amöben, Vortizellen und Difflugien fest, die allerdings mengenmäßig bedeutungslos waren. Die Rotatorien - in erster Linie Keratella cocblearis - und Krustazeen - Naupliuslarven, Bosmina schichten sich nach Typus II zwischen o und $5 \mathrm{~m}$ auf.

Wir haben also hier im Rio Tapajoz ein Planktonbild vor uns, das genau demjenigen eines Sees mit seiner typischen Schichtung der einzelnen Organismengruppen entspricht, die auch in chemischer und thermischer Hinsicht angedeutet ist. Der Tapajoz kann als richtiger Grenzfall See-Fluß aufgefaßt werden; dank seiner geringen Fließgeschwindigkeit, die ein paar Zentimeter pro Minute beträgt, vermag er ein autochthones Plankton zu bilden. Anderseits aber finden wir in ihm Formen, die von den Uferseen - zum Beispiel vom Lago Jurucui und vom Lago Jruçanga - eingeschwemmt werden. Ob und wie sich diese Formen im Tapajoz weiterentwickeln, werden spätere Untersuchungen zeigen. Wir haben das Plankton des Tapajoz in regelmäßigen Abständen fast ein Jahr lang gefaßt, doch es harrt noch der Bearbeitung und Auswertung. Vielleicht wird diese Spezialuntersuchung einige interessante Gesichtspunkte über den jahreszeitlichen Verlauf der Planktonproduktion eines tropischen «Flußsees» vermitteln.

$\mathrm{Zu}$ Vergleichszwecken zogen wir noch eine Planktonzählung im Amazonas bei Santarém bei - vom gleichen Tage -, kurz vor der Einmündung des Rio Tapajoz (siehe Tabelle I4). Wir waren von der extremen Armut an Organismen im Amazonaswasser überrascht. Im Oberflächenwasser fanden wir eine totale Planktonmenge von bloß 940 Individuen prò Liter, bestehend aus $1_{5}$ Chlorophyzeen (Scenedesmus), 85 Desmidiazeen (Staurastrum) und 840 Diatomeen (Melosira, Navicula). Dieser Unterschied im Organismenbestand der beiden Ströme - Amazonas 840, Tapajoz 6555 pro Liter - 
ist frappant, wird uns aber einigermaßen verständlich, wenn wir die Transparenzverhältnisse ins Auge fassen. Das Wasser des Amazonas ist äußerst trübe, durch feinste Sedimente lehmgelb gefärbt, wie aus dem zweiten Teil dieser Arbeit hervorgeht. Am gleichen Tag stellten wir im Amazonas eine Transparenz von 0,25 , im Tapajoz aber von $2 \mathrm{~m}$ fest! Im Amazonas kann sich infolge der reichen Menge an Feingeschieben und der dadurch hervorgerufenen geringen Transparenz kein autotrophes Plankton größeren Ausmaßes bilden, wohl aber im gut durchlichteten, klaren Tapajozwasser.

Zusammenfassend halten wir fest: Das Plankton der untersuchten amazonischen Seen kann sich in Form von scharf ausgeprägten Schichtungsbildern zeigen, worunter wir vier charakteristische Schichtungstypen unterscheiden können, die manchmal durch Übergänge miteinander verbunden sind. Die Schichtungsbilder entstehen unter der Einwirkung des Licht- und Temperaturgefälles und der chemischen Schichtung. Diese drei Faktoren können antagonistisch wirken oder sich summieren. Trotz der geringen Tiefe und der an und für sich unbedeutenden Größe dieser drei Faktoren entstehen die Planktonschichtungsbilder, welche für die Beurteilung des biologisch-chemischen Geschehens im Tropensee von größter Wichtigkeit sind.

Das Plankton der bis jetzt untersuchten Tertiärseen scheint in erster Linie ein Desmidiazeenplankton zu sein, dasjenige der Karbonseen ein Cbloropbjzeenplankton. Im Amazonas und Tapajoz, haben die Diatomeen die Oberherrschaft.

Auch in bezug auf das allgemeine Planktonbild stellen wir bei den Amazonasseen gegenüber den von RUTTNER untersuchten Tropenseen in Java, Sumatra und Bali Unterschiede fest. Sind es in den letzteren in erster Linie kleine Formen von Zyanophyzeen, die das Plankton charakterisieren, und in zweiter Linie Desmidiazeen, so sind die Verhältnisse in den amazonischen Tertiärseen genau umgekehrt. 
IV.

\section{SCHLUSSFOLGERUNGEN}

\section{a) Der Einfluß der Regenzeit auf den Chemismus und auf die Biologie der Seen}

\section{Die chemischen Veränderungen}

Im zweiten Teil dieser Arbeit wurde der chemische Charakter der untersuchten Seen an Hand einiger Analysenresultate skizziert, und im dritten Teil wurde die Grundfauna und das Plankton beschrieben. In den einzelnen Kapiteln legten wir bereits einige Beobachtungen über den Einfluß der Regenzeit auf Chemismus und Biologie dar, und nun sollen diese Beobachtungen zusammengefaßt und durch ein paar Bemerkungen allgemeiner Art ergänzt werden.

Für dieses Problem standen uns die Messungen der periodisch untersuchten Seen Jurucui (mit Zuflüssen), Muretá und Caxambú zur Verfügung, die wir noch ergänzten durch Analysen des Rio Tapajoz als Beispiel eines Grenzfalles See-Fluß.

Theoretisch ist zu erwarten, daß die Regenperiode durch die starke Erhöhung der Wasservolumina eine starke Verdünnung und demzufolge eine Senkung des Salzgehaltes in den Gewässern verursacht. Dies wäre denkbar, wenn der betreffende See abflußlos ist, also eine allseits abgeschlossene Wanne darstellt, und wenn die Beeinflussung der Uferzone vermieden werden könnte. Dieser Fall wird jedoch in der Natur selten verwirklicht werden, denn bei den Seen mit natürlichen Ufern werden diese von der durch die Regenzeit verursachten Überschwemmung erfaßt, ihre Ufervegetation stirbt $a b$, zersetzt sich und verändert dadurch das chemische Bild des Wassers. Wir haben es also mit zwei Beeinflussungsfaktoren zu tun: mit einem Verdünnungsfaktor einerseits und mit dem Uferfaktor anderseits, die beide als Gegenspieler wirken. Über den Verdünnungsfaktor weitere Worte zu verlieren, erübrigt sich. Die Wirkung des Uferfaktors ist jedoch ziemlich kompliziert: Einerseits werden bei den Überschwemmungen weite Ufergebiete unter Wasser gesetzt. Das Oberflächenareal der Seen kann sich während der Regenzeit unter Umständen verdoppeln und verdreifachen. Dadurch ist die Möglichkeit geboten, daß sich Bodensalze im Wasser lösen und eine Konzentrationssteigerung herbeiführen. Bei den Seen mit Zuflüssen - zum Beispiel beim Lago Jurucui kann diese Konzentrationssteigerung noch ausgeprägter werden, wenn 
die Zuflüsse vorher ausgedehnte Landgebiete überschwemmen. Anderseits wird bei der Überschwemmung die Vegetation erfaßt und bewirkt durch ihre Zersetzung eine Anreicherung an gelösten Stoffen, was nament-

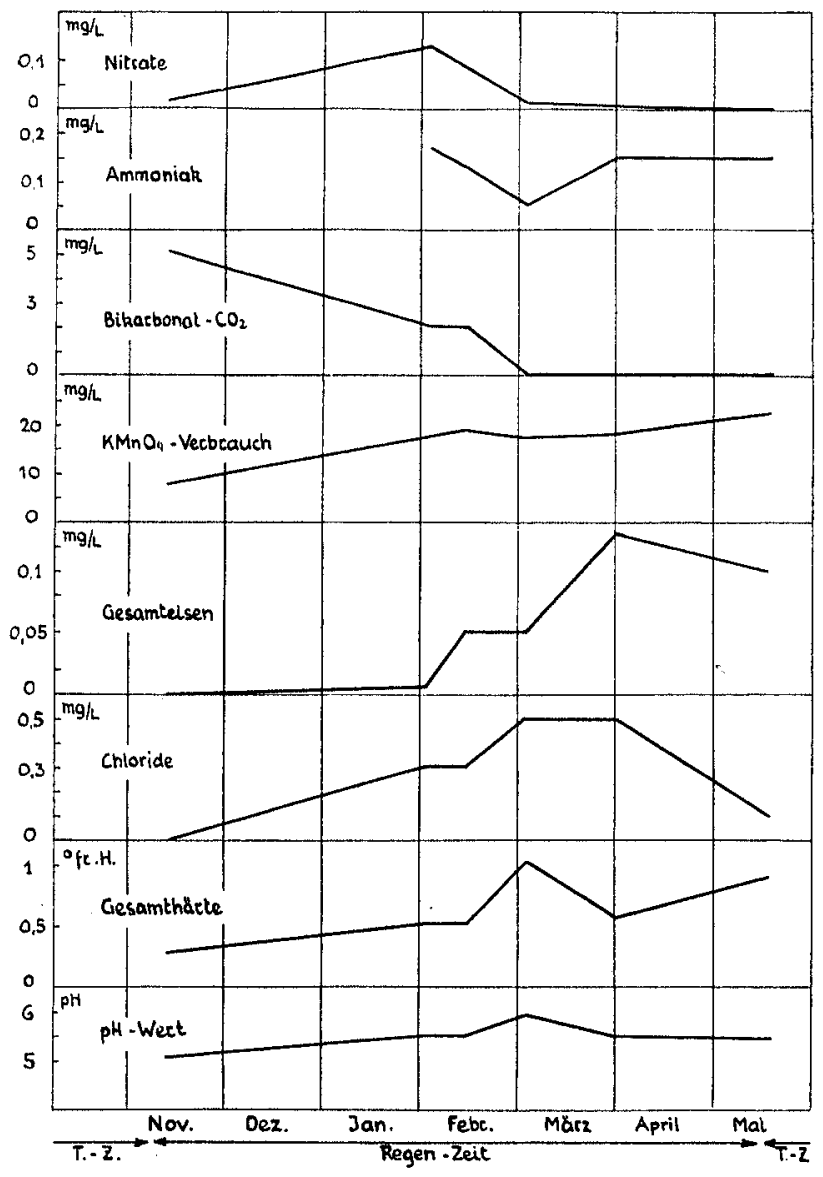

Abb. $18 a$

lich in denjenigen Gewässern der Fall ist, wo Jgapós oder bewaldete Varzea die Ufer bilden.

In Abbildung I 8 haben wir die Änderungen im Chemismus im Laufe der Regenzeit graphisch dargestellt, und zwar in Abbildung I $8 a$ für den Lago Jurucui, in Abbildung $18 b$ für den Lago Caxambú und Lago Muretá und in Abbildung I $8 c$ für die Zuflüsse des Lago Jurucui, nämlich Jgarapé do 
Tento und Jgarapé Grande sowie für den Rio Tapajoz. Besprechen wir vorerst die Verhältnisse im Lago furucui:

Das Ende der Trockenzeit und der unmittelbare Beginn der Regenzeit zeigen sich

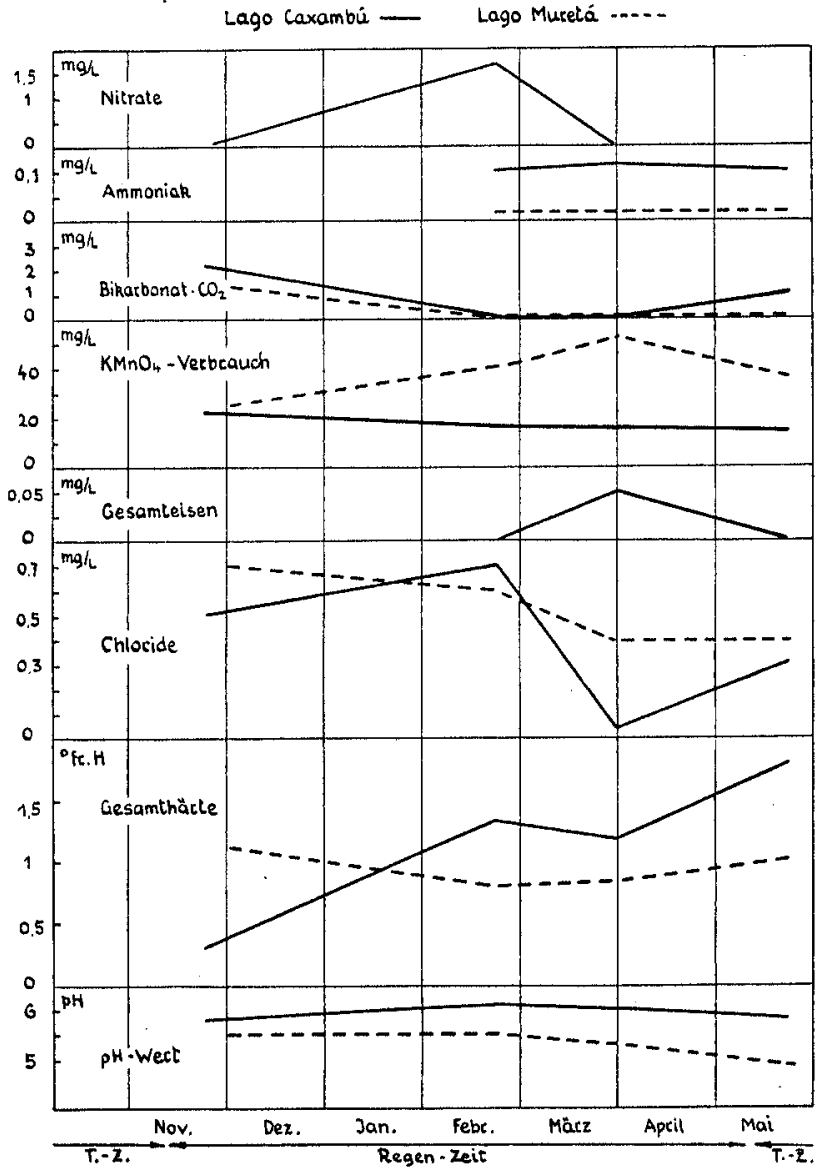

Abb. $18 b$

im chemischen Bild dadurch, daß der Gehalt an gelösten Stoffen sehr gering ist. Die Gesamthärte erreicht nicht einmal einen halben französischen Härtegrad. Chloride, Eisen und Nitrate sind nicht oder nur in Spuren nachweisbar, und der $\mathrm{KMnO}_{4}$-Verbrauch ist ebenfalls unbedeutend. Verhältnismäßig hoch ist jedoch der Bikarbonatgehalt $(5 \mathrm{mg} / \mathrm{l})$, das heißt hoch für europäische Begriffe! Der pH-Wert liegt tief. Im Verlauf der 
Regenzeit treten folgende Veränderungen auf: Der Bikarbonatgehalt nimmt mit fortschreitender Regenzeit immer mehr ab und erreicht anfangs März

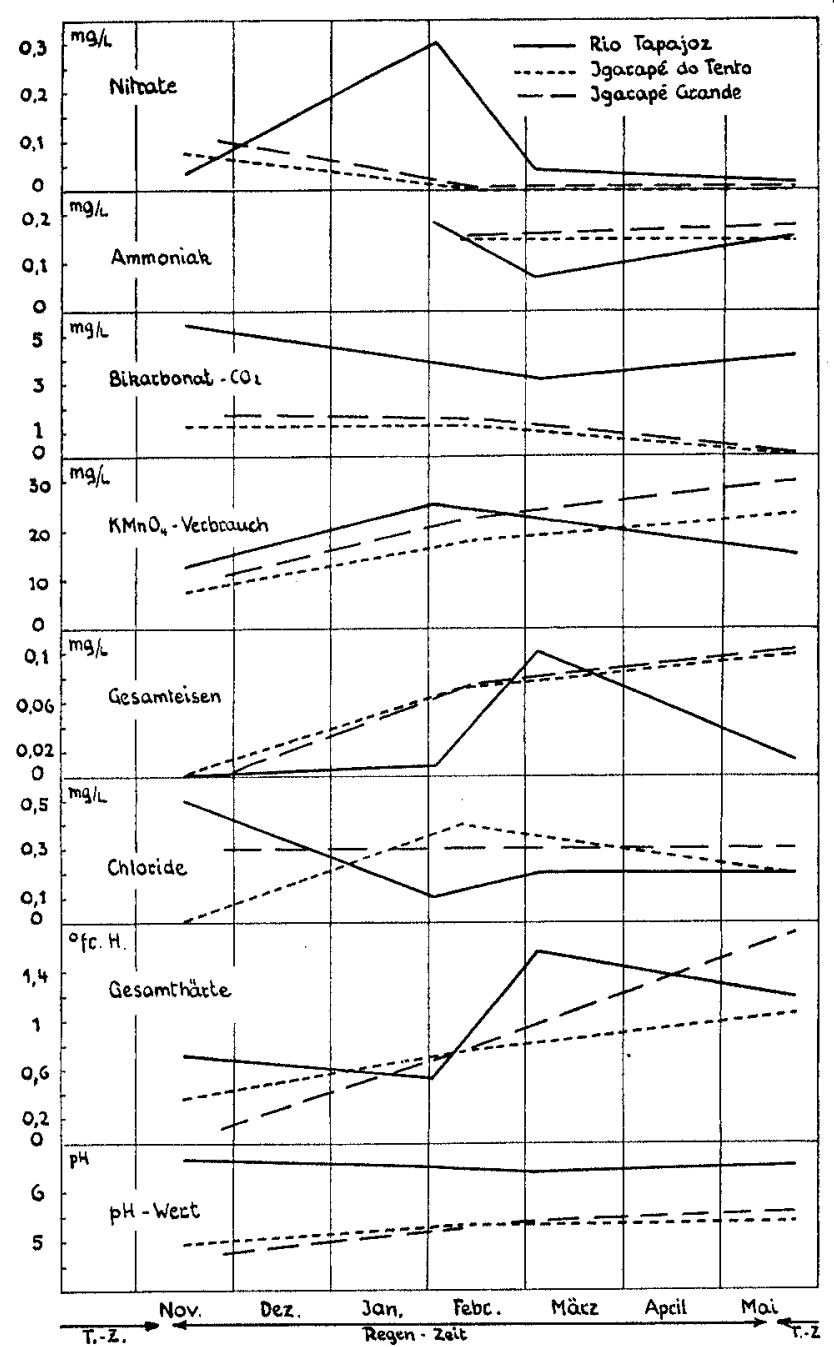

Abb. $18 c$

den Nullpunkt (Verdünnungsfaktor). Offenbar sind die umgebenden Landgebiete so extrem kalkarm, daß sie trotz UUberschwemmungen nicht mehr als Lieferanten in Frage kommen. Dies zeigt sich auch in den Zuflüssen Jgarapé do Tento und Jgarapé Grande. Dagegen steigt der allgemeine 
Salzgehalt deutlich an, sowohl im See selbst als auch in den Zuflüssen: Die Nitrate erreichen anfangs Februar ihren Höhepunkt und sinken dann infolge Zehrung des sich reich entwickelnden Phytoplanktons bald wieder auf Null ab. Auffallend ist der Anstieg des Eisens von Null bis zum Maximum anfangs April (Uferfaktor). Ungefähr gleich verläuft die Kurve der Chloride. Gegen das Ende der Regenzeit senken sich die Kurven wieder deutlich. Auch der pH-Wert ist diesen Schwankungen unterworfen, wobei das Maximum mit demjenigen der Gesamthärte zusammenfällt. Die durch die Überschwemmungen verursachte Zufuhr an gelösten Bodensalzen ist also deutlich feststellbar, und danach richtet sich im großen und ganzen die Planktonentwicklung, die im nächsten Kapitel beschrieben wird. Der $\mathrm{KMnO}_{4}$-Verbrauch steigt erwartungsgemäß sowohl im See als auch in den Zufluissen mit den zunehmenden Überschwemmungen an, da immer mehr Zersetzungsvorgänge und damit Anreicherung an organischer oxydierbarer Substanz stattfinden. Diese Zunahme des $\mathrm{KMnO}_{4}$-Verbrauches ist in den Zuflüssen noch weit ausgeprägter als im See selbst (Wirkung des Jgapós!). Etwas überraschend war der entgegengesetzte Verlauf der Bikarbonat- und der Gesamthärtekurve. Er wird jedoch verständlich, wenn wir bedenken, daß die Gesamthärte in diesen extrem kalkarmen Gewässern wahrscheinlich zum geringsten Teil aus Bikarbonatkohlensäure resultiert!

Da es uns erst anfangs Februar möglich war, freies Ammoniak zu bestimmen, ist diese Kurve unvollständig, doch es ist wohl anzunehmen, $\mathrm{da} ß$ auch sie mit Beginn der Regenzeit ansteigt und nachher wieder abfällt, etwa im Sinne der $\mathrm{KMnO}_{4}$-Kurve. Der auffallende Knick der Ammoniakkurve anfangs März, der sich auch im Rio Tapajoz zeigt, bleibt allerdings noch unabgeklärt.

Betrachten wir nun kurz die Verhältnisse im Lago Caxambú und Lago Muretá (Abb. I8b). Auch in diesen Seen treffen wir prinzipiell dieselben Veränderungen des Chemismus mit fortschreitender Regenzeit an. Bei den Nitraten ist wieder die kurzdauernde Anreicherung typisch, doch diese Mengen sind nach kurzer Zeit durch die sich entwickelnden Phytoplankter aufgebraucht. Auch die Bikarbonatkohlensäure fällt entsprechend derjenigen im Lago Jurucui ab. Die Chloride sind jedoch in den beiden Seen, im Gegensatz zum Lago Jurucui, in relativ großen Mengen vorhanden und haben Ende März ihr Minimum. Der Verlauf der Chloridkurven ist uns nicht ganz klar. Thr Anstieg dürfte durch die zunehmende Zersetzungstätigkeit, eventuell auch durch Auslaugung der umgebenden Landgebiete verursacht sein, doch wie soll der brüske Abfall der Kurve Ende Februar - im Lago Jurucui Ende März - erklärt werden? Sollten vielleicht doch die 
Chloride im Stoffwechsel des Sees eine gewisse Rolle spielen - zum Beispiel bei der Planktonentwicklung -, entgegen der Annahme RuTTNERs (I93 I, S. 443)? Der Verdünnungsfaktor ist wohl kaum dafür verantwortlich zu machen.

Zum Vergleich für dieses Problem haben wir auch den Rio Tapajoz zugezogen. Seine Kurven sind in Abbildung I $8 c$ dargestellt. Auch hier zeigt sich uns ein ähnliches Bild, wie wir es für die Seen beschrieben haben. Die Nitrate zeigen im Tapajoz ebenfalls in der Mitte der Regenzeit ihr Maximum, doch sind sie in größerer Menge vorhanden als in den Seen, denn durch die Zuflüsse und ausgedehnten Überschwemmungsgebiete ist die Zufuhr von Nährstoffen im Tapajoz bedeutend größer. Aber auch die Nitrate fallen sofort auf kaum nachweisbare Mengen ab, sobald die Entwicklung des Planktons einsetzt. Die Ammoniakkurve verläuft ungefähr wie im Lago Jurucui, mit dem Minimum anfangs März (offenbar Verdünnungsfaktor) und steigt nachher wieder leicht an, was durch Zersetzungsvorgänge des auch in diesem Fluß zu reicher Entfaltung gelangten Planktons erklärt werden kann. Der Abfall der Bikarbonatkurve ist nicht so ausgeprägt wie in den Seen, der Gehalt sinkt nie auf den Nullpunkt ab, doch der Kurvenverlauf entspricht genau demjenigen der Seen (Verdünnungsfaktor und Aufnahme durch die Organismen). Der $\mathrm{KMnO}_{4}$-Verbrauch entspricht genau den Erwartungen: Anstieg zu Beginn der Regenzeit auf das Maximum (Uferfaktor), nachher wieder regelmäßiges Absinken (Verdünnungsfaktor). Der Gang der Chloridkurve ist jedoch von derjenigen der Seen sehr verschieden: Sofortiges $A$ bsinken zu Beginn der Regenzeit, nachher bleibt der Chloridgehalt gering. Hier spielt offenbar nur der Verdünnungsfaktor eine Rolle. Die Gesamthärte fügt sich soweit ins allgemeine Bild, allerdings sinkt die Kurve zuerst leicht ab, um dann nachher um so steiler auf ein Maximum anfangs März anzusteigen (Uferfaktor). Später sinkt die Härte wieder langsam ab (Verdünnungsfaktor und Aufnahme durch die Organismen). Die Schwankungen des pH-Wertes sind im Rio Tapajoz sehr gering, was immerhin auf eine etwas höhere Pufferungskapazität als im Lago Jurucui schließen läßt.

\section{Die biologischen Veränderungen}

a) Plankton im Lago Jurucui

Wir hatten Gelegenheit, bereits im Juli I947, also etwa Mitte der Trokkenzeit, mit den qualitativen Planktonuntersuchungen zu beginnen. Bis 
zur einsetzenden Regenzeit zeigten jedoch die Fänge eine enttäuschend große Armut an Planktonorganismen; der größte Teil des Netzinhaltes bestand aus pflanzlichem Detritus mit einigen Diatomeen und Desmidiazeen. Das Zooplankton fehlte praktisch, abgesehen von ein paar wenigen Rädertieren. Der See machte also am Ende der Trockenzeit einen planktologisch ausgesprochen armen Eindruck.

Mit dem Beginn der Regenzeit stellten wir nun im Plank tonbild starke Veränderungen fest, die offenbar durch die bereits besprochene leichte Erhöhung des Salzgehaltes bewirkt wurden. Je weiter die Regenzeit fortschritt, desto reicher an Arten und Individuen wurden die Planktonfänge. Bereits am 2. Februar I948 (Mitte der Regenzeit) beobachteten wir neben zahlreichen anderen Desmidiazeenarten eine äußerst starke Entwicklung von Artbrodesmus incus, die dem Plankton ihr Gepräge verliehen, während sich die Diatomeen in mäßigen Grenzen hielten. Aber auch das Zooplankton war an diesem Datum schon reich mit Bosmina- und Diaptomusarten entwickelt. Noch Ende März beherrschten die Desmidiazeen das Feld mit Individuenzahlen bis 4350 pro Liter, neben reichlich entwickeltem Zooplankton, das noch durch Cyclopsarten ergänzt wurde, während die Diatomeen weiter auf Individuenzahlen von Iooo pro Liter zurückwichen. Doch im April änderte sich das Bild wieder vollkommen: Das Zooplankton ging in seiner Entwicklung stark zurück, ebenso das Phytoplankton, das zur Hauptsache nur noch aus Desmidiazeen bestand. Wir stellten uns vor, daß nun mit dem Ausklingen der Regenzeit die Verarmung des Planktons weiter fortschreite, erlebten dann aber eine Úberraschung, als plötzlich, fast schlagartig, Mitte Mai, also am Ende der Regenzeit, Peridineen sich stark entwickelten, mit Zahlen bis zu 2400 pro Liter, und auch die Desmidiazeen wieder einen Aufschwung bis zu 4000 Individuen pro Liter zeigten. Unmittelbar anschließend machte sich eine starke Zunahme des Zooplanktons bemerkbar. Der Gang der Planktonveränderung war also zusammengefaßt folgender: Ende der Trockenheit: große Armut. Beginn und Mitte der Regenzeit: reiche Entwicklung. Ende der Regenzeit: zuerst Rückgang der Entwicklung, dann neuerlicher Anstieg.

Für die zu Beginn bis Mitte der Regenzeit auffallende Zunahme der Planktonentfaltung ist, wie bereits erwähnt, die Erhöhung des Salzgehaltes verantwortlich zu machen. Bis etwa zur Mitte der Regenzeit waren jedoch die Nährstoffe soweit aufgebraucht; es erfolgte nach dem Maximum der Überschwemmungen kein weiterer Nachschub mehr aus den umliegenden Landgebieten, und dies zeigte sich in einer sukzessiven Verarmung des Planktons. Was nun allerdings nicht einfach zu erklären ist, das ist die am 
Ende der Regenzeit festgestellte neuerliche Entfaltung des Planktons. Ist sie auf die durch Autolyse der vorhergehenden Planktonentwicklung bewirkte Anreicherung an Nährstoffen zurückzuführen? Leider war es uns aus technischen Gründen nicht mehr möglich, zu Beginn der neuen Trockenzeit weitere chemische Analysen durchzuführen; vielleicht hätten sie unsere Fragen beantwortet.

\section{B) Grundfauna im Lago Jurucui}

$\mathrm{Zu}$ Beginn der Regenzeit war sie sehr stark mit Maximalwerten von I2 600 Bodentieren proQuadratmeter entwickelt. Coretbralarven hielten sich in niederen Grenzen (30 pro Quadratmeter). Mit fortschreitender Regenzeit ging ein Rückgang der Grundfaunaentwicklung Hand in Hand, bis am Ende der Regenzeit die höchste Individuenzahl nur noch 570 pro Quadratmeter betrug. Doch Coretbra nahm fortlaufend in ihrer Zahl zu, bis zum Maximum am Ende der Regenzeit. Diese Verarmung der Grundfauna im Laufe der Regenzeit hat wahrscheinlich ihre Ursache in der Vergrößerung der Geschiebeführung, die durch die beiden Zuflüsse bewirkt worden sind. Die Zunahme von Corethra kann als Zeichen fortschreitender Eutrophierung mit der Regenzeit gedeutet werden, wie dies im nächsten Kapitel noch ausführlicher besprochen wird.

Zusammenfassend können wir also festhalten, daß bei diesem Problem « Einfluß der Regenzeit» ein Wechselspiel der zwei Hauptfaktoren, nämlich $V$ erdünnung einerseits und Zufubr von gelösten Stoffen durch Auslaugung des Bodens und durch Zersetzungsvorgänge am Ufer anderseits, maßgebend wirkt. Das sich daraus ergebende Bild wird dann noch stark durch die biologischen Vorgänge verändert, wie Massenentfaltung von Plankton, einmal durch die Stoffaufnahme, nachher durch die Zersetzung der Planktonorganismen. Der Beginn der Regenzeit wird also charakterisiert durch eine deutliche Stoffzufuhr, was eine Anreicherung des anfänglich kaum nennenswerten Planktons herbeiführt. Mitte und Ende der Regenzeit sind gekennzeichnet durch langsames Absinken des Nährstoffgehaltes, parallel dazu Abklingen der Planktonentwicklung. Die neue Anreicherung des Planktons zu Beginn der neuen Trockenzeit muß durch eine plötzliche Nährstoffquelle unbekannter Natur (eventuell Autolyse) als unabgeklärt gelten.

Nicht alle Kurven (Abb. I8) passen in die soeben dargelegte, etwas schematisierte Darstellung der Verhältnisse. Das ganze Problem ist so komplexer Natur, und es spielen offenbar noch so zahlreiche Imponderabi- 
lien dabei eine Rolle, daß wir uns darauf beschränken müssen, vorläufig in ganz groben Zügen den Gang dieser Entwicklung der Seen während der Regenzeit festzuhalten.

Die Regenzeit wirkt also auf diese amazonischen Gewässer eutrophierend, wie eine jährlich wiederholte Düngung, und diese bewirkt eine periodische Veränderung der biologischen Verhältnisse, zum Beispiel des Planktonbestandes. Ähnlich wirken in den Seen der gemäßigten Zone die verschiedenen Jahreszeiten: Durch den Wechsel der Temperatur entstehen periodische Veränderungen in der Planktonzusammensetzung (qualitativ und quantitativ). Diese Perieden sind also in den temperierten Seen durch die Temperatur verursacht, im Gegensatz zu den amazonischen Seen, wo diese Veränderungen durch die eutrophierende Wirkung der Regenzeit, das heißt durch die Näbrstoffzufubr, bewirkt werden. Es stellt sich nun dieFrage: Sind diese periodischen Veränderungen konstant, das heißt, spielt sich der Wechsel immer zwischen den gleichen Artgesellschaften $a b$, oder sind die biologischen Verhältnisse wirklich so unstabil, wie es nach unseren bisherigen Untersuchungen den Anschein hat? Diese Frage zu beantworten, bleibt weiteren Arbeiten im Amazonasgebiet vorbehalten. Jedenfalls konnten wir beobachten, daß geringe äußere Umweltseinflüsse, wie zum Beispiel starker Regenfall, langanhaltende Trockenperiode usw., starke Veränderungen in den biologischen Verhältnissen herbeiführen können. Diese Unstabilität der biologischen Verbältnisse ist charakteristisch für die amazonischen Gewässer; sie bat ibre tiefere Ursache in der äußerst geringen Pufferungskapazität des $W$ assers.

Diese Zunahme der gelösten Stoffe zu Beginn der Regenzeit ist ja an und für sich gering - bloß Bruchteile von Milligrammen im Liter -, und in den Gewässern der gemäßigten Zone mit ihrem ungleich höheren Gehalt an gelösten Salzen wird eine Zunahme des Salzgehaltes um diesen geringen Betrag wohl kaum zu großen biologischen Umwälzungen führen. In den chemisch armen amazonischen Gewässern hingegen, wo dieser Betrag Ioo und mehr Prozente bedeutet, können sich diese Änderungen des chemischen Milieus grundlegend auf das ganze Lebensgeschehen auswirken. Es deuten sich hier bereits weitere Schwierigkeiten an, die Seen zum Beispiel an Hand der Planktonzusammensetzung zu klassifizieren, wie es bei den temperierten Seen der gemäßigten Zone ohne weiteres möglich ist, und es zeigt sich nach allen den soeben dargelegten Tatsachen die Wertlosigkeit, Aussagen über den chemischen und biologischen Haushalt eines Tropensees auf Grund einer einmaligen Untersuchung zu machen, wie dies oft geschehen ist. Auch wir haben ja neben den periodisch untersuchten Seen 
solche Momentbilder aufgenommen - zum Beispiel die Seen im Karbongebiet -, haben jedoch damit ganz andere Zwecke verfolgt, nämlich das Studium der Abhängigkeit des Chemismus der Seen und Flüsse vom geologischen Untergrund. Solche Momentbilder haben aber erst dann einen gewissen Wert, wenn wir mehrere in geologisch verschiedenen Gebieten gelegene Seen zu Vergleichszwecken einander gegenuiberstellen können.

\section{b) Versuch einer Einfügung der amazonischen Seen in das System der Seetypenlehre}

Die heute allgemein gebräuchlichen Systeme der Seetypenlehre THIENEMANNS (1922) und NAUMANNS (1932) sind auf Grund ausgedehnter Untersuchungen in der gemäßigten Zone der nördlichen Halbkugel entstanden. Wegweisend für die Aufstellung dieser Scetypenlehre waren allein die Verhältnisse Nord- und Mitteleuropas.

Die limnologische Forschungsreise Thienemanns, Ruttners und FEUERborns (I93I) nach Java, Sumatra und Bali brachte nun plötzlich ganz neue Probleme. Die Seetypenlehre erschien « in einem ganz neuen Lichte», wie sich ThIENEMAnN (1932) in seiner Arbeit Tropische Seen und Seetypenlebre ausdriickt. Er versucht darin, die in Java, Sumatra und Bali gewonnenen Erkenntnisse in das Gebäude der Seetypenlehre einzubauen, was nicht ohne wesentliche Abänderungen bzw. Ergänzungen vor sich gehen konnte.

Thienemann kommt in seiner Arbeit zum Schluß, daß der extrem eutrophe See - darunter versteht er nicht nur Reichtum an Stickstoff und Phosphor, sondern allgemein reiche Gesamtentfaltung des Lebens - an feucbte Tropengebiete gebunden sei, also an Gebiete mit hoher Temperatur und nährstoffreichem Gelände, das durch regelmäßige starke Niederschläge erschlossen ist. Ein für die gemäßigten Klimate wichtiges Kriterium für die Typisierung der Seen, nämlich der Bau des Seebeckens bzw. das Verhältnis der Volumina der trophogenen zur tropholytischen Schicht, schließt ThIEnEmanv für die Tropenseen aus, mit der Begründung, daß auch ein großes Hypolimnion in den Tropenseen infolge der hohen Temperatur die vom Epilimnion anfallende organische Produktion nie gänzlich zu mineralisieren vermag. Nach Ansicbt ThIENEMANns kann sich überbaupt in Tropengebieten kein See vom oligotropben Typus ausbilden. Als Gegenpol zum extrem eutrophen See der Tropen stellt ThIEnEMann den extrem oligotrophen See in die kalten Klimate. 
Thienemann gruppiert die Naumannschen Seetypen etwas um, indem er zwei Hauptgruppen unterscheidet:

I. Harmonische Seetypen:

eutropher Seetypus [(N + P)-Meso- bis Polytrophie], oligotropher Seetypus [(N+P)-Oligotrophie].

2. Einseitig charakterisierte Seetypen:

dystropher Seetypus (Humusstoffe Meso- bis Polytrophie),

alkalitropher Seetypus (Ca-Polytrophie),

siderotropher Seetypus (Fe-Meso- bis Polytrophie), azidotropher Seetypus ( $\mathrm{pH}$-Werte auffallend tief, 5,5 oder weniger).

Unter barmonischen Seetypen versteht THIENEMANN solche, die durch gleichmäßige Vertretung aller lebensnotwendigen Stoffe und demzufolge durch harmonische Entwicklung des ganzen Lebensgeschehens charakterisiert sind. Bei den einseitig charakterisierten Seetypen sind ein oder mehrere Stoffe, die nicht zu den allgemeinen Lebensbedingungen gehören, im Úbermaß vorhanden, was eine einseitige Lebensgemeinschaft hervorruft; die Gesamtentfaltung ist in diesen Seen disharmonisch.

Ein wichtiges Merkmal in der Seetypenlehre Thienemanns (1928) waren bzw. sind - wenn wir die tropischen Verhältnisse ausschließen - die morphologischen Verhältnisse eines Sees. Bei einem oligotrophen See ist das Volumen des Epilimnions kleiner als dasjenige des Hypolimnions, bei einem eutropben See ist es größer. Damit ist auch zur Zeit der Sommerstagnation der Gesamtsauerstoffgehalt des Epilimnions im oligotrophen See kleiner als im eutrophen, verglichen mit dem Hypolimnion. Diese Feststellungen bezog THIENEMANN damals auf die harmonischen Typen der gemäßigten Zone, und er betonte, daß die vollkommene Mineralisation der in der trophogenen Schicht erzeugten Substanz den oligotrophen See kennzeichne und daß der Grenzwert Oligotrophie-Eutrophie von allgemeinen Umweltsverhältnissen, in erster Linie vom Klima, abhänge. THIENEMANN war vorsichtig genug - in Unkenntnis der tropischen Verhältnisse -, damals zu betonen, daß diese Regel bei Änderung jener Bedingungen keine Gültigkeit mehr besitze. THIENEMANN fand denn auch in Niederländisch-Indien tiefe, echte Tropenseen, die nach den morphologischen Gesichtspunkten unbedingt als oligotroph zu gelten hätten, die aber auf Grund der chemischen Verhältnisse eindeutig zu den eutrophen Seen zu zählen sind. Mit andern Worten: Der morphometrische Grenzwert als Kriterium für den Seetypus fällt in den Tropen wegen der hohen Bedeutung des Temperaturfaktors dahin, der eine extreme, nie gänzlich reversible Maximalproduktion im See hervorruft. Der «jugendliche» See - in der gemäßigten Zone 
vom oligotrophen Typus, der sich mit zunehmendem Alter in einen eutrophen verwandelt - ist in den Tropen schon eutroph.

Schon früher stellte THIENEMANN fest, daß auch beim Typus des dystrophen Sees (Humussee) der Bau des Seebeckens bedeutungslos ist, das heißt, daß die Bildung der Dystrophie bei flachen wie auch bei tiefen Seen möglich ist, aus dem einfachen Grunde, weil Dystrophie allochthon bedingt sei. Wenn Faktoren, die mit dem See selbst unmittelbar nichts zu tun hätten - weil sie durch die Umgebung bewirkt sind -, ihm das Gepräge aufdrückten, so sei der Bau des Beckens bedeutungslos, denn bei der Bildung der Dystrophie handle es sich um Stoffe, deren Zersetzung nicht in erster Linie durch biologische Vorgänge bewirkt sei. So weit THIENEMANN.

Untersuchen wir nun, ob wir bei den amazonischen Seen zu denselben Schlußfolgerungen gelangen wie ThIENEMANN. Stellen wir uns die Frage, die auch THIENEMANN und RUTTNER in den Vordergrund ihrer Betrachtung stellen: Ist die Bildung des oligotrophen Sees in den Tropen möglich?

Wir müssen uns bei der Behandlung dieser Frage bewußt sein, daß sich unsere Feststellungen und Schlußfolgerungen auf relativ wenige Untersuchungsresultate stïtzen können. Da sie aber die ersten derartigen Bestimmungen aus diesem Gebiet sind, dürften sie, wenn auch nur als bescheidene Grundlage und Anregungen für weitere Forschungen im Amazonasgebiet, einen gewissen Wert beanspruchen.

Was den Sauerstoff haushalt anbelangt, so sind fast alle der untersuchten Amazonasseen eutroph, mit dem charakteristischen Verlauf der Sauerstoffkurve bzw. deren Abfall mit zunehmender Tiefe während einer Stagnationsperiode. Soweit stimmen unsere Erhebungen mit denen von RUTTNER und Thimenemann überein. Doch ändert sich das Bild, wenn wir den allgemeinen Chemismus betrachten, zum Beispiel im Lago Jurucui (der am gründlichsten untersuchte See). Auch er ist, was Gestalt und Sauerstoffhaushalt anbelangt, unbedingt als eutroph zu bezeichnen. Wenn wir jedoch den Nährstoffgehalt, überhaupt die Gesamtkonzentration an gelösten Stoffen berücksichtigen, ist er doch zweifellos als oligotroph zu bezeichnen. Eine gewisse Eutrophie bringt, wie aus den vorangehenden Kapiteln hervorgegangen ist, die Regenzeit. Durch die Überschwemmungen der umliegenden Gebiete werden dem See in geringen Mengen Nährstoffe zugefügt, die aber mit fortschreitender Regenzeit infolge der gesteigerten Planktonproduktion bald aufgebraucht sind. Aber auch diese Erhöhung des Nährstoffgehaltes reicht keineswegs aus, das Wasser des Lago Jurucui etwa als eutroph zu bezeichnen. 
ThIEnEmann schließt die Bildung des oligotrophen Sees - mit Hinblick auf den Nährstoffgehalt und die Gesamtproduktion - in den Tropengebieten mit der Begründung aus, daß infolge der hohen Temperatur und großen Regenmenge die Erschließung des tropischen Bodens, also auch des Untergrundes der Seen, so rasch fortschreite, daß eine genügende Nährstoffmenge aus dem Untergrund immer vorhanden sei. Aber wie steht es denn bei denjenigen tropischen Böden, die bereits so ausgelaugt sind, daß trotz hoher Temperatur und Feuchtigkeit keine bedeutende Nährstoffbildung mehr möglich ist? Diesen Fall haben wir aber bei den Tertiärseen Jurucui, Muretá und Caxambú! Diese Seen liegen zur Hauptsache in unfruchtbarem Quarzsand der Tapajozdüne eingebettet. Auch in diesen Seen beobachten wir zu gewissen Zeiten - trotz der Nährstoffarmut - « eutrophe» Sauerstoffverhältnisse, die durch die temperaturbedingten erhöhten Zersetzungsprozesse verursacht werden. Es scheint uns daher vorsichtiger zu sein, diesen Fragenkomplex, ob Oligotrophie in den Tropen möglich sei, noch nicht definitiv zu verneinen, bevor nicht noch eine genügend große Zahl von Untersuchungsergebnissen aus tropischen Gegenden, namentlich aus Gebieten mit solch ausgelaugten Böden, vorliegen. Warum sollte auch ein tiefer Tropensee, der in altem, gut erschlossenem Boden eingebettet liegt, nicht chemisch oligotrophes Wasser besitzen? Dies alles unter Ausschluß der Sauerstoffverhältnisse. Wir sprechen hier ja nur vom Salz- bzw. Nährstoffgehalt des Wassers. Die Sauerstoffverhältnisse werden - aus den bereits dargelegten Gründen - wohl allgemein in den Tropen eutroph sein.

Wir halten also fest: Was Nährstoffe anbelangt, muß der Lago Jurucui zur Reihe der oligotrophen Seen gestellt werden.

Aber es bleibt uns noch ein wichtiges Kriterium zu diskutieren: die Gesamtentfaltung des Lebens im See! Müssen wir den Lago Jurucui, was die «Biomasse» anbelangt, als oligotroph oder als eutroph bezeichnen, oder müssen wir ihn zur Reihe der disharmonischen Seetypen stellen?

Um diese nicht ganz einfache Frage zu beantworten, stehen uns einerseits die Planktonuntersuchungen, anderseits die quantitativen Untersuchungen der Grundfauna zur Verfügung. Der Grund für die etwas stiefmütterliche Behandlung der biologischen Verhältnisse in dieser Arbeit wurde bereits erwähnt, doch dürften die bisherigen Erhebungen für die nachfolgende Diskussion genügen. Greifen wir zurück auf das vorhergehende Kapitel. Wir haben dort gesehen, daß zu Beginn der Regenzeit das Plankton extrem arm entwickelt war, entsprechend dem niederen Nährstoffgehalt des Wassers. Wir haben also zu diesem Zeitpunkt ausgesprochen oligotrophe Verhältnisse, auch in biologischem Sinne. Doch die 
Mitte der Regenzeit zeichnet sich durch eine reiche Entwicklung des Planktons aus - in erster Linie Desmidiazeen -, entsprechend der geringen Nährstoffzufuhr. Chemiscb ist auch das Wasser des Lago Jurucui während der Regenzeit noch als oligotroph zu bezeichnen, doch biologisch haben wir zu diesem Zeitpunkt unbedingt eutrophe Verhältnisse. Doch sehen wir uns noch kurz die produktionsbiologischen Gegebenheiten des Seegrundes an. In Tabelle I3 sind die quantitativen Grundfaunauntersuchungen dargestellt; allerdings sind die einzelnen Arten noch nicht bestimmt, was für diese Diskussion jedoch nicht stark ins Gewicht fällt. Diese Zahlen zeigen uns, daß wir es im Lago Jurucui immerhin um eine ganz ansehnliche Produktion der Grundfauna zu tun haben - bis I2000 Organismen pro Quadratmeter --, unter denen rote Chironomiden, die ja bekanntlich eutrophe Seen kennzeichnen, eine sehr große Rolle spielen. Wir glauben, die «allgemeine Gesamtentfaltung des Lebens» im Lago Jurucui im Sinne THIENEMANNS als reich bezeichnen zu dürfen.

Chemisch oligotrophes Wasser und eutrophe biologische Verhältnisse wie reimt sich das zusammen?

Es ist seit langem bekannt, daß in Tropengebieten die Lebenszyklen der verschiedenen Organismen sehr stark verkürzt sind, daß pro Zeiteinheit eine größere Generationsfolge vor sich geht als in der gemäßigten Zone. Das Wachstum ist durch die erhöhte Temperatur beschleunigt; demzufolge muß auch die Nährstoffaufnahme rascher und leichter vor sich gehen, als dies in kühleren Klimaten der Fall ist.

Nach all dem Gesagten drängt sich uns folgende Schlußfolgerung auf: Cbemisch oligotrophes $W$ asser kann in tropiscben Gemässern - dank der besseren Ausnützung und Aufnebmbarkeit der Näbrstoffe infolge der erböbten Temperatur trotzdem zu großer Gesamtentfaltung des Lebens, also zu biologisch eutrophen Verbälttnissen fübren.

Diese Schlußfolgerung stützt sich nicht nur auf die Verhältnisse in den besprochenen Seen, sondern auch auf den Rio Tapajoz. Obschon das Wasser dieses «Flußsees» chemisch vollkommen oligotroph ist, beobachteten wir im November 1947 eine Massenentwicklung, ja sogar eine Wasserblüte einer Anabaenaart! Nach Aussagen verschiedener Personen soll diese Wasserblüte fast jedes Jahr im Rio Tapajoz auftreten. Massenentwicklungen einer einzelnen Art - speziell von Zyanophyzeen - sind aber doch ein Indizium für eutrophe Verhältnisse!

Um zum Beispiel des Lago Jurucui zurückzukommen: Zu Beginn der Regenzeit war der Nährstoffgehalt für die Entfaltung des Planktons unter dem absoluten Minimum. Die geringe Nährstoffzufuhr durch die Regen- 
zeit erhöhte dann den Gehalt so weit, daß sich die Organismen schlagartig bis zur Massenentfaltung entwickeln konnten, obschon für unsere Begriffe immer noch oligotrophe Nährstoffverhältnisse vorlagen. Ein Seewasser, dessen Nährstoffgehalt in unserer gemäßigten Zone nur zu oligotropher biologischer Entfaltung genügen würde, wäre also in den Tropen befähigt, eutrophe, reiche Entfaltung des Lebens herbeizuf ühren.

Nach all dem Gesagten geht doch deutlich hervor, daß es nach unseren bisherigen Anschauungen über Oligotrophie und Eutrophie unmöglich ist, zum Beispiel den Lago Jurucui zu klassifizieren, oder dann höchstens auf die folgende, etwas komplizierte Art und Weise: Chemiscb ist der Lago Jurucui oligotroph, trotz der geringen Nährstoffanreicherung in der Regenzeit. Was Sauerstoff haushalt anbelangt, ist er eutroph. Biologisch ist er am Ende der Trockenzeit und zu Beginn der Regenzeit als oligotroph, während der Regenzeit aber als eutroph zu bezeichnen. Er ist also ein oligotropher See mit zeitlich begrenzter Eutropbie!

Prinzipiell dasselbe gilt auch für die anderen Tertiärseen Muretá, Caxambú und Alter do Chão. Auf Grund ihres chemischen Bildes können wir sie mit noch größerer Berechtigung zur Reihe der oligotrophen Seen stellen.

Der Lago Salgado besitzt ebenfalls für europäische Begriffe oligotrophes Wasser, was den Nährstoffgehalt anbelangt, obschon der allgemeine Salzgehalt bedeutend höher ist als in den Tertiärseen. Doch biologisch ist auch er unbedingt als eutroph zu bezeichnen (siehe Grundfauna!).

Leichter wird die Klassifizierung bei den typischen Schwarzwasserseen, wie Lago Pauxis, Lago Maritima und Lago Pindobal, die auf Grund der chemischen Analysen, der Wasserfarbe und der Armut an Plankton wohl zu der Reihe der dystrophen Seen (Humusseen) zu stellen sind.

\section{Zusammenfassung}

An Hand chemisch-physikalischer und biologischer Untersuchungen wurde der Charakter einiger im unteren Amazonasgebiet gelegener Seen geschildert und die Auswirkung der Regenzeit auf Chemismus und Biologie dieser Seen beschrieben, soweit dies auf Grund der bis heute vorliegenden Resultate möglich war. Es wurde ferner versucht, die amazonischen Seen auf Grund ihres chemisch-biologischen Verhaltens in das System der Seetypenlehre einzugliedern. Zu Vergleichszwecken zogen wir die temperierten Seen der gemäßigten Zone sowie die von RUTTNER untersuchten niederländisch-indischen Tropenseen bei und stellten sie den 
Amazonasseen gegenïber, um die grundlegenden Unterschiede in Chemismus und Biologie aufzuzeigen.

Die Seen im unteren Amazonasgebiet sind durchwegs flache, seichte Austiefungs-, Abdämmungs- oder Dünenseen mit einer Tiefe von 6 bis Io $\mathrm{m}$ während der Regenzeit bzw. 2 bis $5 \mathrm{~m}$ während der Trockenzeit; manche von ihnen besitzen jedoch eine sehr große Oberfläche.

Trotz ihrer geringen Tiefe können sich in diesen Seen ausgeprägte physikalisch-chemische und biologische Schichtungen ausbilden, mit den charakteristischen Zonen Epi-, Meta- und Hypolimnion, gemäß denjenigen der temperierten Seen während der Stagnationsperiode, allerdings mit dem Unterschied, daß sich die Schichtungen in den amazonischen Seen auf engstem Raum zusammendrängen. Was sich in den temperierten Scen in einem Raum von vielleicht 20 bis $30 \mathrm{~m}$ abspielt, findet in den seichten Amazonasseen zwischen I bis $3 \mathrm{~m}$ statt. Epilimnion und Sprungschicht zeigen manchmal eine Mächtigkeit von nur I bis $2 \mathrm{~m}$ ! Außerdem besteht noch ein grundlegender Unterschied: Das Temperaturgefälle ist in den amazonischen Seen in einen um etwa $20^{\circ} \mathrm{C}$ höheren Bereich verschoben, was einige grundlegende Folgen auf das gesamte Lebensgeschehen im See nach sich zieht, zum Beispiel erhöhte Stabilität, Steigerung der gesamten Lebenstätigkeit der Organismen, Erhöhung der Zersetzungsgeschwindigkeit auf Grund des van-t'Hoffschen Gesetzes usw.

Typisch für die amazonischen Seen ist die Inkonstanz der Schicbtungsverhältnisse. Die Dauer und Ausbildung der Stagnationsperiode und Zirkulationsperiode werden nicht wie in den temperierten Seen durch die Jahreszeiten gesteuert, sondern sind von den zufällig herrschenden Witterungsverhältnissen abhängig; das bedeutet, daß wir an Hand der Jahrestemperaturkurven kein «Seejahr» herauslesen können, wie wir dies von den temperierten Seen her gewohnt sind.

Die erhöhte Temperatur und die daraus resultierende Erhöhung der Zersetzungsgeschwindigkeit bewirkt, daß in der Tiefe der amazonischen Seen Sauerstoffarmut, manchmal sogar Sauerstofflosigkeit herrscht, denn eine bestimmte Menge organischer Substanz wird dort etwa sechsmal rascher abgebaut und der Sauerstoff verbraucht sein, als dies zum Beispiel im Zürichsee der Fall sein wird. Deshalb verlieren die Sauerstoffkurven der amazonischen Seen ihre Funktion als Indikator organischer Produktion, denn auch Seen mit oligotrophem Wasser - was Salzkonzentration anbelangt - können « eutrophe» Sauerstoff kurven aufweisen.

Gemäß ihrer Lage in geologisch verschiedenen Gebieten können wir die untersuchten Amazonasseen in Tertiär- und Karbonseen einteilen, die sich 
sowohl chemisch als auch biologisch ganz verschieden verhalten. So zeichnen sich die Tertiärseen durch extreme Armut an gelösten Stoffen aus, durch niedere $\mathrm{pH}$-Werte und zum Teil durch hohe Mengen freier Kohlensäure, während die Karbonseen einen deutlich höheren Salzgehalt und höhere pHWerte besitzen. Doch auch die Karbonseen sind für europäische Begriffe noch als außerordentlich arm an gelösten Stoffen zu bezeichnen. Dies hat zur Folge, daß die Pufferungskapazität der Amazonasseen sehr gering ist, was wiederum eine große Unstabilität der bialogischen Verbältnisse nach sich zieht.

Biologisch unterscheiden sich die Seen darin, daß die Tertiärseen ein sehr ausgeprägtes Desmidiazeenplankton, die Karbonseen dagegen ein Chloropbyzeenplankton besitzen, während der Rio Tapajoz und der Amazonas, die wir als Vergleich anführten, in erster Linie ein Diatomeenplankton aufweisen. Das Plankton der untersuchten Gewässer kann ausgeprägte Schichtungsbilder zeigen, worunter wir je nach Anhäufung der Organismen im Raum vier charakteristische Schichtungstypen unterscheiden können. Auch bei dieser biologischen Schichtung stellen wir wie bei der chemischen Schichtung prinzipielle Ähnlichkeit mit denjenigen der temperierten Seen fest, nur daß sich diese Schichtungen in viel engeren Grenzen im Raum ausbilden.

Das besondere Augenmerk schenkten wir dem Einfluß der Regenzeit auf Biologie und Chemismus der Seen. Die Regenzeit wirkt eutrophierend auf die Seen, das heißt, durch die Überschwemmungen der umliegenden Landgebiete während der Regenperiode werden den Seen Bodensalze zugeführt, was eine Steigerung des Salzgehaltes und parallel dazu eine rasche Erhöhung der Planktonquantität und -qualität herbeiführt. Obschon die Erhöhung des Salzgehaltes mit der Regenzeit an und für sich gering ist und in den Seen der gemäßigten Zone mit ihrem ungleich höheren Gehalt an Nährstoffen zu keiner großen Veränderung der biologischen Verhältnisse führen würde, kann sich diese Erhöhung des Salzgehaltes in den chemisch armen amazonischen Seen grundlegend auf das gesamte Lebensgeschehen auswirken, denn sie bedeutet hier hundert und mehr Prozent! Es ergibt sich daraus die Schlußfolgerung, daß chemisch oligotrophes Wasser, das in den Seen der gemäßigten Zone zu einer ebenfalls nur oligotrophen Entwicklung der biologischen Verhältnisse führt, in den amazonischen Seen dank der hohen Temperatur und der dadurch bewirkten leichteren Aufnehmbarkeit und besseren Ausnützbarkeit der Nährstoffe eine biologisch eutrophe Entwicklung der Lebewesen hervorzubringen vermag.

Auf Grund der chemisch-biologischen Untersuchungen müssen wir die Amazonasseen nach den Prinzipien der Seetypenlehre folgendermaßen einteilen: 
a) Oligotrophe Seen mit zeitlich beschränkter, durch die Regenzeit bewirkter Eutropbie: Lago Jurucui, Lago Muretá, Lago Caxambú, Lago Alter do Chão, Lago Salgado (?).

b) Dystrophe Seen: Lago Pauxis, Lago Pindobal, Lago Maritima.

\section{LITER A TUR VERZEICHNIS}

BEAdLE, L. C., The Wraters of some East African Lakes in relation to their flora and fauna, J. Linn. Soc. Zool. 38 (1932).

BERL-LUNGE, Chemisch-techniscbe Untersuchungsmetboden, Band 2, 8. Auflage (1932).

BLuntschli, H., Die Amazonasniederung als barmonischer Organismus, Geogr. Z. 27, Heft 3/4 (I92I).

BoulllenNe, R., Un Voyage Botanique dans le Bas-Amazone (Imprimerie Médicale et Scientifique, Bruxelles 1930).

Brandt, A. voN, Temperaturschwankungen in kleinen Waldgemässern, Arch. Hydrobiol. 30, I32-14I (1936).

CUNNINGTON, Reports on the Tanganjika expedition 1904/05 (Cambridge 1905).

DAMAS, H., Recherches bydrobiologiques dans les Lacs Kivu, Edouard et Ndalaga (Institut des Parcs nationaux, Bruxelles 1937).

- La stratification thermique et cbimique des Lacs Kinu, Edouard et Ndalaga (Congo Belge), Int. Ver. theor. angew. Limnol., Congrès de Paris (1937).

- La Biologie lacustre équatoriale, Ass. franc. Avancement Sci., $63^{\mathrm{e}}$ Session, (Liège 1939).

Downes, A study of the water supplies of the Istbmus of Panama, Proc. med. Ass. Isthmus Panama 3 (I9II).

Einbeitsverfabren der physikaliscben und chemiscben Wasseruntersucbung, Arbeitsgruppe für Wasserchemie des Vereins Deutscher Chemiker (1940).

Elster, H. J., und EINSELE, W., Beiträge zur Hydrographie des Bodensees, Int. Rev. ges. Hydrobiol. Hydrogr. 35, Heft 4/6 (1937).

GRAHAM, M., A Report of the Fishing Survey of Lake Victoria 1927-1928 and Appendices (London I929).

JAAG, O., Die neuere Entwicklung und der beutige Zustand der Schweizer Seen, Verh. int. Ver. theor. angew. Limnol. 10, 192-209 (1949).

JudAy, C., Limnological studies on some lakes in Central-America, Trans. Wisconsin Acad. Sci. 18 (I9I5).

Juday, C., Birge, E. A., Kemmerer, G. J., und Robinson, R., Pbosphorus content of lake waters of Northern Wisconsin, Trans. Wisconsin Acad. Sci. 28 (1928).

Katzer, F., Grundzüge der Geologie des unteren Amazonasgebietes (Verlag Max Weg, Leipzig 1903).

- Geologia do Estado do Pará, Bol. Museu Paraense Emilio Goeldi 9 (1933).

Kleerexoper, H., Estudo limnologico da Respresa de Santo Amaro em São Paulo, Bol. Fac. Philos., Sci. Ietras Univ. S. Paulo 17 (I939). 
KLUT, H., Untersuchung des Wassers und Abriassers an Ort und Stelle, 6. Aufl. (Springer, Berlin I931).

Le CoINTE, P., O Estado do Pará (Comp. Editora Nacional, Rio de Janeiro I945).

LENZ, F., Zur Limnologie der niederschlagsarmen Gebiete Nordost-Brasiliens, Verh. int. Ver. theor. angew. Limnol. 8, 121-137 (1937).

MaERKI, E., Chemische, physikaliscbe und bakteriologiscbe Untersucbungen am Greifensee, Ber. Schwciz. bot. Ges. 54, 75-r40 (I944).

Marquarden, H., Die Seen Tanganjika, Moero, Bangqoelo, Mitt. dtsch. Schutzgebieten 29 (I9I6).

MINDER, L., Über biogene Entkalkung im Zürichsee, Verh. int. Ver. theor. angew. Limnol. 1, (1923).

Moura P. DE, Geologia do Baixa Amazonas, Bol. Nr. 9I, Serv. geol. mineral. (Rio de Janeiro I938).

NaUmann, E., Grundzüge der regionalen Limnologie, in: Die Binnengemässer, Band II (Schweizerbart, Stuttgart 1932).

Ohlmueller-Spitta, Untersuchung und Beurteilung des Wassers und Abpassers, 5. Auflage (Springer, Berlin 1931).

RAwITSCHER, F., Die Erschäpfung tropischer Böden infolge der Entwaldung, Acta Tropica 3, Nr. 3, 2 II (1947).

RUTTNER, F., Hydrograpbische und bydrocbemische Beobachtungen anf Fava, Sumatra und Bali, Arch. Hydrobiol. Suppl. 8 (193 I).

- Die Schichtung im tropischen See, Verh. int. Ver. theor. angew. Limnol. 5, 144-167 (193I a).

- Stabilität und Umscbichtung im tropischen und temperierten See, Arch. Hydrob. Suppl. 15 (1938).

- Grundriß der Limnologie (de Gruyter, Berlin 1940).

Sioli, H., O Rio Cupari, Bol. tecn. Inst. agronom. Norte Nr. I7 (Belém do Pará i949). Das Wasser im Amazonas-Gebiet, Forschung und Fortschritt 26, Heft 21/22 (1950).

Schmid, W., Über den Energiegehalt der Seen, Int. Rev. ges. Hydrobiol. Hydrogr., Suppl.-Bd. zu 6 (I915).

STEINER, M., Zur Kenntnis des Pbosphatkreislaufs in Seen, Naturwissenschaften 26 (I938).

Thienemann, A., Biologische Seetypen und die Gründung einer Hydrobiologiscben Anstalt am Bodensee, Arch. Hydrobiol. 13, 347 (1922).

- Der Sauerstoff im eutropben und oligotrophen See, in: Die Binnengewässer, Band 4 (Schweizerbart, Stuttgart 1928 ).

- Tropiscbe Seen und Seetypenlebre, Arch. Hydrobiol. Suppl. 9, 205 (193I).

ULE, E., II. Bericbt über den Verlauf der zapeiten Expedition in das Gebiet des Amazonenstromes in den Fabren 1908-1912, Notizbl. Königl. bot. Gartens Museums BerlinDahlem 6, Nr. 53 (19r4).

- Die Vegetation des Amazonasgebietes, Verh. botan. Ver. Prov. Brandenburg 57, Heft I (I9I5).

- Biologiscbe Beobacbtungen im Amazonasgebiet, Vortr. Gesamtgebiet Bot. (dtsch. bot. Ges.), Heft 3 (I9isa).

WEIMANN, R., Hydrobiologische und bydrograpbische Untersuchungen an zmei teichartigen Gemässern, Beih. Bot. Cbl. [II], 51, 397 (1933). 
WINkLER, L. W., Über die Bestimmung des im Wasser gelösten Sauerstoffs, Z. anal. Chemie 53,665 (I914).

WORTHINGTON, E. B., Observations on the temperature, etc. of the Victoria and Albert Nyancas, Int. Rev. ges. Hydrobiol. Hydrogr. 24, 328 (1930).

Yoshimura, S., Seasonal variation of silica in Takasuka-Uuma, Saitama, Jap. J. Geol. Geogr. 7 (1930). 